Universidade de São Paulo

Instituto de Astronomia, Geofísica e Ciências Atmosféricas

Departamento de Geofísica

\author{
Victor Sacek
}

\title{
Modelagem numérica conjunta de processos sedimentares e tectônicos em bacias sedimentares
}

São Paulo 

Victor Sacek

\section{Modelagem numérica conjunta de processos sedimentares e tectônicos em bacias sedimentares}

Tese apresentada ao Departamento de Geofísica do Instituto de Astronomia, Geofísica e Ciências Atmosféricas da Universidade de São Paulo como requisito parcial para a obtenção do título de Doutor em Ciências.

Área de Concentração: Geofísica

Orientadora: Prof. ${ }^{\text {a }}$ Dr. ${ }^{\text {a }}$ Naomi Ussami

Co-orientador: Prof. Dr. Jean Braun

São Paulo 



\section{Agradecimentos}

Gostaria de agradecer primeiramente à minha orientadora Profa. Dra. Naomi Ussami que participou da minha formação científica desde o primeiro ano da minha graduação em Geofísica. Agradeço pela amizade e por tudo que aprendi durante esses anos através de diálogos que guiaram todo o desenvolvimento desta tese e a minha carreira.

I thank Professor Jean Braun for his profound contributions on the development of this work and incentive since my visit to Grenoble.

I thank Professor Peter van der Beek for the important geological contributions that significantly improved the work.

Agradeço à Fundação de Amparo à Pesquisa do Estado de São Paulo pela concessão da bolsa de doutorado e pelo apoio financeiro para a realização desta pesquisa. À Petrobras pela oportunidade de interagir com diferentes pesquisadores durante esses últimos anos. Aos professores, funcionários e alunos do IAG pela amizade e pela ajuda em diferentes necessidades durante o doutorado.

Agradeço à minha esposa Caroline pelo carinho, paciência e sacrifício pessoal ao longo do período de elaboração deste trabalho. Ao meu pai Ivica e à minha mãe Eleni pela educação que recebi e pelo apoio desde minha infância para estudar as Obras do Criador. Ao meu irmão Arthur, meu amigo.

Esta tese foi escrita em $\mathrm{LT}_{\mathrm{E}} \mathrm{X}$ com a classe IAGTESE, para teses e dissertações do IAG. 



\section{Resumo}

\section{SACEK, V. Modelagem numérica conjunta de processos sedimentares e}

tectônicos em bacias sedimentares 2011. 184pp. Tese (Doutorado) - Instituto de Astronomia, Geofísica e Ciências Atmosféricas, Universidade de São Paulo, São Paulo, 2011.

O principal objetivo deste trabalho é prever a evolução de margens divergentes desde o início da extensão litosférica, levando-se em consideração a interação entre processos superficiais e tectônicos. Para isto, foi desenvolvido um modelo numérico que acopla isostasia flexural, efeitos térmicos, estiramento litosférico e processos superficiais. A isostasia flexural é simulada através de uma placa elástica fina sobre um fluido invíscido, representando o comportamento flexural da litosfera flutuando sobre a astenosfera. Durante a simulação, a estrutura térmica da litosfera evolui como um resultado da advecção e difusão do calor no interior da Terra. Considera-se que o estiramento da litosfera é acomodado por falhas planas na crosta superior e deformação dúctil na crosta inferior e manto. O modelo de processos superficiais descreve como a paisagem é erodida e como os sedimentos são transportados e depositados nas bacias sedimentares. Através desse modelo numérico, é mostrado que o estiramento litosférico tem uma profunda influência na evolução da migração de escarpas em margens divergentes. Os resultados sugerem que escarpas limitadas por falhas criadas em flancos de rifts por descarregamento mecânico e resposta flexural têm pouca chance de "sobreviver" através de recuo erosivo se a crosta inferior sob o flanco do rift foi substancialmente estirada. Nessa configuração, o divisor de drenagem que persiste através do tempo é criado em direção ao continente em uma posição que depende da rigidez flexural da crosta superior. Esse cenário ocorre quando a topografia pré-rift 
mergulha para o continente, caso contrário a evolução da escarpa é guiada pelo divisor de águas interior pré-existente. Esses conceitos são aplicados no estudo das margens do sudeste da Australia e do sudeste do Brasil, onde o cenário de retração de escarpas através de recuo erosivo mostrou-se improvável. O mesmo modelo numérico foi utilizado para estudar como a passagem de uma anomalia térmica sob a litosfera pode afetar a evolução pós-rift de bacias sedimentares em margens divergentes. Os resultados numéricos mostram que a velocidade da litosfera em relação à anomalia térmica e a rigidez flexural da litosfera oceânica e continental afetam a evolução de bacias sedimentares devido ao soerguimento da superfície relacionado com a expansão térmica da litosfera. Como exemplo, é estudada a possível influência de uma anomalia térmica (Pluma de Trindade?) na evolução das bacias de Campos e Espírito Santo, na margem sudeste brasileira.

Palavras chave: Processos superficiais, processos tectônicos, modelagem numérica, margens divergentes. 


\section{Abstract}

\section{SACEK, V. Joint numerical modeling of sedimentary and tectonic processes}

in sedimentary basins 2011. 184pp. Thesis (Doctorate) - Instituto de Astronomia, Geofísica e Ciências Atmosféricas, Universidade de São Paulo, São Paulo, 2011.

The purpose of this work is to predict the evolution of divergent margins since the onset of lithospheric extension, taking into account the interaction between surface and tectonic processes. For this, a numerical model was developed to study the coupling of flexural isostasy, thermal effects, stretching of the lithosphere and surface processes. The flexural isostasy is simulated through a thin elastic plate overlying an inviscid fluid, representing the flexural behavior of the lithosphere floating on the asthenosphere. During the simulation, the thermal structure of the lithosphere evolves as a result of advection and diffusion of heat in the Earth's interior. The stretching of the lithosphere is assumed to be accommodated by planar faults in the upper crust and ductile flow in the lower crust and mantle. The surface processes model describes how the landscape is eroded and how the sediments are transported and deposited in the sedimentary basins. The results from this numerical model show that the amount of lithospheric stretching has a profound influence on the evolution of escarpment migration in divergent margins. These results suggest that fault-bounded escarpments created at rift flanks by mechanical unloading and flexural rebound have little potential to "survive" as retreating escarpments if the lower crust under the rift flank is substantially stretched. In this configuration, a drainage divide that persists through time is created landward in a position that depends on the flexural rigidity of the upper crust. This scenario occurs when the pre-rift topography dips landward, otherwise the evolution of the escarpment is guided by the pre-existing 
inland drainage divide. These concepts are applied to study the margins of Southeastern Australia and Southeastern Brazil, where the retreating escarpment scenario showed to be unlikely. The same numerical model is used to study how the passage of a thermal anomaly under the lithosphere can affect the post-rift evolution of sedimentary basins in divergent margins. The numerical results show that the velocity of the lithosphere relative to the thermal anomaly and the flexural rigidity of the continental and oceanic lithospheres affect the evolution of sedimentary basins due to surface uplift related to thermal expansion of the lithosphere. As an example, the model is applied to assess the possible influence of a thermal anomaly (Trindade Plume?) on the evolution of the Campos and Espírito Santo Basins, in Southeastern Brazilian margin.

Keywords: Surface processes, tectonic processes, numerical modeling, divergent margins. 


\section{List of Figures}

1.1 Surface and tectonic processes that influence the evolution of the Earth's surface in the context of divergent margins. Extracted from Bishop (2007). Original figure from Beaumont et al. (2000). . . . . . . . . . . . . . . 30

1.2 Schematic crustal section illustrating (a) the effect of erosion along valleys on the topography and (b) the combination of erosion and isostatic response, resulting in uplift of mountain peaks. . . . . . . . . . . . .

1.3 Comparison between the topography predicted by the flexural models and the topographic profile of the Southwestern Africa. Different effective elastic thicknesses $T_{e}$ for the flexural model are presented. The escarpment is created by the flexural response of lithosphere to the unloading of the coastal region (for $x<100 \mathrm{~km}$ ). Extracted from Bishop (2007), based on a modified figure from the original work of Gilchrist and Summerfield (1990).

1.4 The effect of variation of flexural rigidity in the stratigraphy. (a) The increase of rigidity results in widening of the basin, causing stratigraphic onlap. (b) The response of a viscoelastic lithosphere to the filling of a sedimentary basin. The decrease of the rigidity results in gradual narrowing of the basin, causing stratigraphic offlap. . . . . . . . . . . . . . . .

2.1 Geometric representation of the areal coordinates $L_{i}, L_{j}$ and $L_{k}$ of the point $p$ inside the triangle $i j k \ldots \ldots \ldots \ldots \ldots$ 
2.2 Illustration of the construction of the stiffness matrix $\mathbf{K}$ and the load vector f. (a) Finite element mesh composed of 3 elements and 5 nodes. (b) Summation of the stiffness matrices $\overline{\mathbf{K}}^{e}$ to obtain $\mathbf{K}$ for the finite element mesh shown in (a). (c) Summation of the load vector $\overline{\mathbf{f}}^{e}$ to obtain $\mathbf{f}$ for the finite element mesh shown in (a). Italic numbers indicate the nodes and upright ones indicate the elements. . . . . . . . . . . . . . . . . . . . 43

2.3 Uniform load applied over an infinite plate. . . . . . . . . . . . . . . 44

2.4 Scheme representing the plate and the load geometries to study the case of an uniformly distributed load. Three meshes used to discretize the plate are presented. . . . . . . . . . . . . . . . .

2.5 (a) Comparison of the analytical solution with the numerical ones for the problem of an uniformly load applied over an infinite plate. (b) Difference between numerical and analytical solution. All the curves are divided by the modulus of the exact deflection $\left|w_{0}\right|$ under the center of the load. . . .

2.6 A scheme of the problem of an infinite elastic plate with two different rigidities $D_{1}$ and $D_{2}$ under a line load $V_{0} \ldots \ldots \ldots \ldots$

2.7 (a) Comparison of the analytical solution with the numerical ones for the problem of a line load applied over an infinite plate with two different flexural rigidities. The vertical dashed line marks the change of the flexural rigidity. (b) Difference between numerical and analytical solutions. All the curves are divided by the modulus of the exact deflection $\left|w_{0}\right|$ under the line load.

2.8 (a) Comparison of the analytical solution with the numerical ones for the problem of a line load applied over an infinite plate with constant flexural rigidity. (b) Difference between numerical and analytical solution. All the curves are divided by the modulus of the exact deflection $\left|w_{0}\right|$ under the line

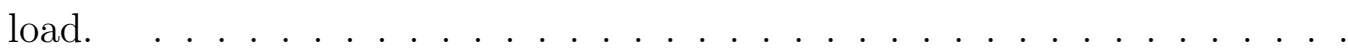

3.1 Scheme of a tetrahedral element with nodes $i, j, k$ and $l$. The gray lines represent the edges of four sub-tetrahedra formed by the internal node $p$ and other three nodes of the original tetrahedron. . . . . . . . . . . . 
3.2 Illustration for the construction of the linear system to numerically solve the three dimension heat transfer problem. (a) Finite element mesh composed of 3 elements and 6 nodes. (b) Representation of each finite element. (c) Summation of the matrices $\overline{\mathbf{K}}^{e}$ to obtain $\mathbf{K}$, where $\mathbf{K}$ can represent $\mathbf{M}, \mathbf{K}_{a}^{*}$ or $\mathbf{K}_{c}$. (d) Summation of the column vector $\overline{\mathbf{F}}^{e}$ to obtain $\mathbf{F}$. . . . . . . 60

3.3 Scheme of the model for the thermal evolution of a stretched lithosphere (McKenzie, 1978). The upper figures show the geometrical configuration of the lithosphere and the graphs show the corresponding temperature profiles. (a) Initial state of the lithosphere previous to stretching. C represents crust and $\mathrm{L}$ represents lithospheric mantle. (b) Stretched lithosphere at $t=0$ showing the passive uplift of the asthenosphere, indicated as A. (c) Final state of the lithosphere, restoring the thermal profile previous to stretching.

3.4 Representation of the finite element mesh composed of tetrahedra to study the thermal evolution of the lithosphere. $a_{L}$ represents the initial thickness of the lithosphere. . . . . . . . . . . . . . . . .

3.5 A systematic way to subdivide a right-rectangular prism into six tetrahedra. The prism is subdivided into two wedges, each one subdivided into three tetrahedra. . . . . . . . . . . . . . . . .

3.6 Comparison between analytical and numerical solutions for McKenzie's model. The upper graphics show the temperature profile at $t=10,30$ and 50 Myr. The dashed lines indicate the temperature profile for $t \rightarrow \infty$. The lower graphics show the difference between numerical and analytical solutions. 64

3.7 Comparison between analytical and numerical solutions for a steadily eroding lithosphere for different Peclet number. The upper graphics show the temperature profile for $P e_{L}=1,5$ and 10. The dashed lines indicate the temperature profile for $P e_{L}=0$. The lower graphics show the difference between numerical and analytical solutions. . . . . . . . . . . . .

3.8 Comparison between analytical and numerical solutions for a steadily eroding lithosphere for $P e_{L}=10,25$ and 100. The dashed line indicates the temperature profile for $P e_{L}=0$. 
4.1 Comparison between different models to represent the stretching of the lithosphere. The left panels show the lithospheric configuration previous to stretching, while the right ones show the final state of the lithosphere after stretching. The dark gray region is the crust and the light gray one is the lithospheric mantle. (a) Pure shear model of McKenzie (1978), where the stretching is uniform. The dashed lines bound the stretched regions. (b) Non-uniform pure shear model of Royden and Keen (1980). (c) Simple shear model of Wernicke (1985). . . . . . . . . . . . . . . . .

4.2 Illustration of lithospheric necking and the regional isostatic response to stretching (Braun and Beaumont, 1989). The left panels show the kinematic model for a shallow (upper figure) and deep (lower figure) necking depth without isostatic compensation. The dashed lines represent the necking depth and the gray region is the lithosphere. The right panels show the combination of stretching and regional isostatic response of the lithosphere.

4.3 Scheme of the streamlines for the upwelling divergent flow. . . . . . . . .

4.4 Velocity field for the upwelling divergent flow, obtained from equation 4.1 with $U_{z} / U_{x}=1$, observed from (a) the axis of the upwelling flow at $x=0$ and (b) from an observer moving with the plate at the surface. Depth is in

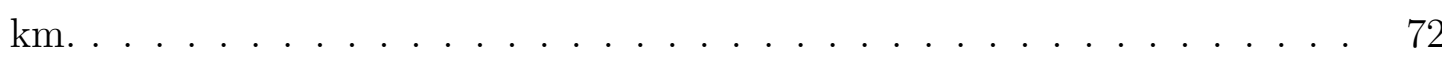

4.5 Diagram describing the flexural cantilever model of Kusznir et al. (1991). . 73

5.1 Example of Delaunay triangulation and Voronoi diagrams. In $\mathrm{c}$ and $\mathrm{d}$ the Voronoi cells at the border of the mesh are truncated. . . . . . . . . . .

5.2 Illustration of the algorithm to create the Delaunay triangulation from a set of $n=30$ points. The point in each figure indicates the next node to be included in the triangular mesh. The light gray triangles show the region that must be re-meshed to include the new point. . . . . . . . . . . .

5.3 Illustration of a Voronoi cell. $S_{i}$ is the area of the Voronoi cell (gray region) related to the point $i . \partial S_{i j}$ is the edge of $S_{i}$ (green line) in contact with $S_{j}$. $L_{i j}$ is the distance between the points $i$ and $j \ldots \ldots \ldots$. . . . . . . . 
5.4 Representation of the landscape in the numerical model. (a) representation of the topography using the Voronoi diagrams. The dots are the nodes of the mesh. (b) representation of the topography using the Delaunay triangulation. (c) Stream channels plus topography using Voronoi cells. (d) Stream channels plus topography using Delaunay triangulation. . . . . . . . . . .

5.5 Example of the surface processes model, illustrating the erosion of a plateau and the deposition of the sediments in the offshore domain, at 0 and 2 Myr. The horizontal dimensions of the model are in kilometers. The gray and yellow regions at the side of the model represent the bedrock and the sediments, respectively. . . . . . . . . . . . . . .

5.6 Continuation of the Figure 5.5, at 4 and 6 Myr. The horizontal dimensions of the model are in kilometers. . . . . . . . . . . . . . . . . . .

6.1 Interaction between the different processes in the numerical model to study the evolution of passive margins. $F_{T}, F_{S}, F_{F}$ and $F_{s p}$ represent, respectively, the vertical loads associated with thermal effects, stretching of the lower crust, faulting in the upper crust and surface processes of erosion and deposition. $w_{t}$ represents the vertical movement of the lithosphere. . . . . . 91

6.2 Diagram showing the coupling of the stretching, thermal and flexural models. 92

6.3 Diagram showing the influence of faulting on the surface processes. . . . . 93

6.4 Illustration of the updating of the surface mesh during faulting. The dots represent the nodes of the surface mesh. The position of the fault line is indicated by a vertical arrow. $\delta_{r}$ is the mean distance between adjacent nodes (see section 5.3). Note that this illustration shows only the kinematic description of the relative movement between the two crustal blocks and does not take into account the flexural response to this tectonism. (a) Initial configuration. (b) Configuration after an extension $E_{f}=0.5 \delta_{r}$. (c) Configuration after an extension $E_{f}=\delta_{r}$, when a new point is added to the mesh and this new point belongs to the footwall. . . . . . . . . . . . 
6.5 : Updating of the triangular mesh during faulting. The orange line shows the position of the fault line. In this figure the nodes to the left of the fault line belong to the footwall and the nodes to the right belong to the hanging wall. After an extension $E_{f} \geq \delta_{r}$ (see section 5.3), new nodes are added to the footwall block, indicated in the figure as orange dots. During the faulting the mesh is continuously updated, following the Delaunay triangulation. . . 95

6.6 Interaction between surface processes and flexural isostasy. . . . . . . . . . 96

6.7 (a) Superposition of the Voronoi cells of the surface processes model on the triangular finite element mesh of the flexural model. (b) Approximation for the load of the surface processes, assuming that loading in one cell is concentrated on the node at the center of the cell. The figure shows the five cells that contribute with the load on the highlighted triangular element. .

7.1 Scheme showing the relative position of the faults I-V in the upper crust and the upwelling-divergent flow. . . . . . . . . . . . . . . . . 111

7.2 Evolution of the rift for Model $1\left(T_{e}=20 \mathrm{~km}, T_{e, u c}=5 \mathrm{~km}, k_{f} v_{R}=0.003\right.$ $\mathrm{m} /$ year and $L_{u d f}=-15 \mathrm{~km}$ ). Topography (bottom scale) is in meters. The light and dark gray regions on the side of the model represent the lower and upper crust, respectively. The black and red arrows indicate the position of the flexural depression and the secondary bulge divide, respectively.

7.3 Continuation of Figure 7.2 - Model 1. Topography (bottom scale) is in meters. The light and dark gray regions on the side of the model represent the lower and upper crust, respectively. The yellow regions on the side of the model represent sediments. The blue curves represent the shoreline. The black dots mark the position of fault $\mathrm{V}$. The green lines mark the zones of mean relief $>300 \mathrm{~m}$ (see Figure 7.6). 
7.4 Graphical representation of the analytical solution of the flexural cantilever model (a) $w_{\max }$ is the half-fault heave; $x_{2}$ is the distance between the fault and the secondary bulge; $h_{2}=0.07 w_{\max }$ is the difference in elevation between the secondary bulge and the flexural depression. (b) Mechanisms that reshape the margin after faulting. Open arrows indicate direction of drainage and the size of the arrows illustrate the magnitude of erosion. The black dot represents an axial river, parallel to the fault, between the coastal escarpment and the secondary bulge. Gray arrows represent the differential subsidence (decreasing landward) due to thinning of the lower crust and thermal cooling of the lithosphere.

7.5 Evolution of the rift margin for Model $2\left(T_{e}=20 \mathrm{~km}, T_{e, u c}=5 \mathrm{~km}, k_{f} v_{R}=\right.$ $0.003 \mathrm{~m} /$ year and $L_{u d f}=-115 \mathrm{~km}$ ). Symbols as in Figure 7.3. Black dots mark the position of fault $\mathrm{V}$. The red lines mark the zones of mean relief $>300 \mathrm{~m}$ (see Figure 7.6).

7.6 Temporal evolution of the zones with high relief (mean relief $>300 \mathrm{~m}$ ) for the models illustrated in Figures 7.2 to 7.5. The black dashed line indicates the position $x_{2}^{\prime}$ of the secondary bulge calculated analytically. . . . . . . .

7.7 Comparison for different numerical simulations of the temporal evolution of the zones with high relief (mean relief $>300 \mathrm{~m}$ ) for the models with low erosional rates. The black dashed line indicates the position $x_{2}^{\prime}$ of the secondary bulge calculated analytically. The arrows indicate the retreat of the escarpment for the models with $L_{u d f}=-15 \mathrm{~km}$. . . . . . . . . .

7.8 Stretching factor of the crust $\beta_{\text {crust }}$ for different initial position $L_{u d f}$ of the upwelling flow.

7.9 Comparison between the numerical model and the southeastern Australia margin (a) Model 3: Numerical simulation with initial topography dipping landward. See Table 7.2 for parameter values used in this experiment; (b) Model 4: Numerical simulation with an initial inland drainage divide; (c) Digital elevation model of southeastern Australia, showing the coastal escarpment and the inland drainage divide, indicated by the arrows. . . . . 126 
7.10 (a) Stratigraphic pattern predicted by Model 1 (Figure 7.2 and 7.3) at the end of the simulation (120 Myr). The lines are in intervals of $10 \mathrm{Myr}$. The green line marks the stratigraphic unit at $50 \mathrm{Myr}$ after the initiation of the rift. The blue box represents the region equivalent to the interpreted seismic section in (b). (b) Seismic section crossing the Santos basin. The arrow indicates the position of the Cretaceous hinge line. Black curves: basement; Yellow curves: top of pre-salt sediments ( $120 \mathrm{Ma})$; Red curves: top of salt $(\sim 112 \mathrm{Ma})$; Green curves: Top of the Cretaceous sediments $(\sim 65.5$ Ma); Blue curves: Post-Cretaceous sediments. Modified from Assine et al. (2008). (c) Topography and bathymetry of Southeastern Brazil. The thick black curve shows the position of the hinge line based on Assine et al. (2008). I and II indicate the Serra do Mar and Serra da Mantiqueira escarpments. The white line represents the geographic position of the seismic section shown in (b).

7.11 Evolution of Model 5 where the margin is affected by late-stage rifting at 70 Myr. (a) Model at $20 \mathrm{Myr}$, showing the escarpment formed on the secondary bulge, like in Model 1. (b) Model at $70 \mathrm{Myr}$, when the margin starts to be affected by the formation of a graben, as indicated in the figure. The faults of the graben are active during 70-71 Myr. (c) Model at 80 Myr, presenting the double escarpment pattern after the creation of the graben. (d) Model at $120 \mathrm{Myr}$, showing that the two escarpments persist through time, resembling the Serra do Mar and Serra da Mantiqueira escarpments in Southeastern Brazil.

7.12 Illustration of the numerical model to study the isostatic effect of a thermal plume hitting the base of the lithosphere. . . . . . . . . . . . . . . . . 134

7.13 Uplift maps for different relative velocities $v_{r e l}$, viewed from a reference frame fixed relative to the thermal anomaly, at the origin of the coordinates. Due to the symmetry of the model, only half of the plate is shown. . . . . 138

7.14 Maps of rate of uplift for different relative velocities $v_{r e l}$. The horizontal axis represents the time since the moment that the plate crossed the plume. Due to the symmetry of the model, only half of the plate is shown. 
7.15 Numerical model to study the influence of the passage of a thermal anomaly at the base of the lithosphere on the evolution of passive margins. (a) Initial configuration of the topography and position of the center of the thermal anomaly at $x=800 \mathrm{~km}$, indicated by the red triangle. (b) Model at 20 Myr, when the thermal anomaly is at $x=600 \mathrm{~km}$. The gray and yellow regions on the sides of the model represent the basement and the sediments, respectively.

7.16 Continuation of Figure 7.15. (c) Model at $40 \mathrm{Myr}$, when the thermal anomaly is at $x=400 \mathrm{~km}$. (d) Model at $60 \mathrm{Myr}$, when the thermal anomaly is at $x=200 \mathrm{~km}$.

7.17 Continuation of Figure 7.15. The red bars show the position of the Sections A (Figure 7.18) and B (Figure 7.19) . . . . . . . . . . . . .

7.18 Stratigraphic evolution of the margin far from the thermal anomaly - Section A. The stratigraphic interval is 10 Myr.

7.19 Stratigraphic evolution of the margin close to the thermal anomaly - Section B. The red triangles represent the position of the thermal anomaly. The stratigraphic interval is 10 Myr.

7.20 Comparison of the stratigraphy between Sections A and B, at 100 Myr. The stratigraphic interval is 10 Myr. . . . . . . . . . . . . . . . .

7.21 Chronostratigraphy of the marginal basin through Sections A and B. NDH - Nondepositional hiatus. TUH - Hiatus related to the thermal uplift. The continuous line indicates the position of the thermal anomaly through time and the dashed line indicates the projection of the thermal anomaly on Section A. $T_{e}=5 \mathrm{~km}$ and $v_{r e l}=1 \mathrm{~cm} / \mathrm{yr} \ldots \ldots \ldots \ldots$

7.22 Chronostratigraphy of the marginal basin through Sections A and B as in Figure 7.21 , but with $v_{r e l}=2 \mathrm{~cm} / \mathrm{yr} \ldots \ldots \ldots \ldots$

7.23 Chronostratigraphy of the marginal basin through Sections A and B as in Figure 7.21, but with $T_{e}=20 \mathrm{~km} \ldots \ldots \ldots \ldots$

7.24 Chronostratigraphy of the marginal basin through Sections A and B as in Figure 7.21 , but with $T_{e}=20 \mathrm{~km}$ for the continent $(x>400 \mathrm{~km}) . \ldots . . .150$ 
7.25 The Vitória - Trindade Chain. TI - Trindade Island; MVI - Martin Vaz Islands; ESB: Espírito Santo Basin; CB - Campos Basin; CFML - Cabo Frio Magmatic Lineament. . . . . . . . . . . . . . . . . . . . . . . . . . . 150

7.26 Stratigraphic charts for Santos, Campos and Espírito Santo Basins during the Cenozoic. Modified from Milani et al. (2007). . . . . . . . . . . . . . . 151

7.27 Backstripped model for the Campos Basin compared with curves of subsidence predicted by the model of McKenzie (1978). Modified from Thomaz Filho et al. (2005). . . . . . . . . . . . . . . . . . . . . . . 151

7.28 Uplift through time related to the emplacement of a vertical cylinder of $\sim 2$ $\mathrm{km}$ wide with $T=1300^{\circ} \mathrm{C}$ crossing the entire lithosphere. Local isostasy is assumed. . . . . . . . . . . . . . . . . . . 152

A.1 (a) Scheme of the problem of an infinite elastic plate with two different rigidities $D_{1}$ and $D_{2}$ under a line load $V_{0}$. (b) Representation of the continuous plate by two semi-infinite plates. The moments $M_{1}$ and $M_{2}$ and the line loads $V_{1}$ and $V_{2}$ represent the coupling of the two halves. . . . . . . . . 175

B.1 Successive loading of the crust by sedimentation. The figures $i$, ii and $i i i$ are in isostatic equilibrium and $i^{\prime}$ and $i i^{\prime}$ are out of isostatic equilibrium. 


\section{List of Tables}

2.1 Parameters for the problem of an elastic plate under a distributed load. . . 45

2.2 Parameters for the problem of variable flexural rigidity. . . . . . . . . . . 47

3.1 Parameters for the model of McKenzie (1978) . . . . . . . . . . . . . 63

5.1 Parameters and their values used in the model of Figures 5.5 and 5.6. . . . 90

7.1 Fixed parameters and their values used in the models. . . . . . . . . . . . . 113

7.2 Variable parameters and their values used in the models. . . . . . . . . . . 114

7.3 Fixed parameters and their values used in the models. . . . . . . . . . . 136

7.4 Maximum uplift $w_{T}$, shift between the axis of the plume and the position of maximum $w_{T}$, and maximum and minimum rates of uplift $\partial w_{T} / \partial t$ for the four models shown in Figures 7.13 and 7.14 . . . . . . . . . . . . . . 137 



\section{List of Symbols}

The main variables and parameters used in the manuscript are listed here. Other temporary symbols used in specific parts of the thesis are not presented in this list.

\begin{tabular}{ll} 
Symbol & Meaning \\
\hline$x, y$ & Horizontal coordinates \\
$z$ & Vertical coordinate \\
$t$ & Time \\
$\mathrm{T}$ & Transpose of a matrix \\
\hline$w$ & Vertical displacement of the plate \\
$q$ & Vertical loads \\
$\mathbf{D}$ & Flexural rigidity matrix \\
$D$ & Flexural rigidity \\
$T_{e}$ & Effective elastic thickness \\
$\nu$ & Poisson's ratio \\
$E$ & Young's modulus \\
$\delta w$ & Arbitrary vertical displacement \\
$\Omega$ & Domain in the plane $x y$ \\
$\delta \Pi_{\text {int }}$ & Internal virtual work \\
$\delta \Pi_{e x t}$ & External virtual work \\
$b . c$. & Boundary conditions \\
$g$ & Gravity \\
$\rho$ & Density \\
$\rho_{m}$ & Mantle density \\
\hline &
\end{tabular}




\begin{tabular}{|c|c|}
\hline Symbol & Meaning \\
\hline$\rho_{c}$ & Crust density \\
\hline$\rho_{w}$ & Water density \\
\hline$\rho_{s}$ & Sediment density \\
\hline $\bar{q}$ & Vertical load not associated with buoyancy \\
\hline $\mathbf{N}$ & Shape functions for the flexural model \\
\hline $\mathbf{a}$ & Unknowns of the finite element model for the flexural problem \\
\hline $\mathbf{K}$ & Stiffness matrix of the finite element flexural model \\
\hline f & Load vector of the finite element flexural model \\
\hline$L_{i}, L_{j}, L_{k}$ & Local coordinates for the triangular element \\
\hline$\triangle$ & Area of the triangular element \\
\hline$T$ & Temperature \\
\hline$c$ & Specific heat capacity \\
\hline $\mathbf{v}$ & Advection velocity \\
\hline$k_{T}$ & Thermal conductivity \\
\hline$A_{r}$ & Radioactive production \\
\hline$\Omega_{V}$ & Domain in $\mathbb{R}^{3}$ \\
\hline$\Gamma_{V}$ & Boundary of $\Omega_{V}$ \\
\hline $\bar{q}_{H}$ & Heat flux \\
\hline $\mathbf{N}_{V}$ & Shape functions for the thermal model \\
\hline $\mathbf{a}_{V}$ & Unknowns of the finite element model for the thermal problem \\
\hline \multicolumn{2}{|l|}{$\mathbf{M}, \mathbf{K}_{c}, \mathbf{K}_{a}$} \\
\hline $\mathbf{K}_{a}^{*}, \mathbf{F}$ & Matrices of the finite element model for the thermal problem \\
\hline$\triangle_{\text {tet }}$ & Volume of the tetrahedral element \\
\hline \multicolumn{2}{|l|}{$L_{V 1}, L_{V 2}$} \\
\hline$L_{V 2}, L_{V 4}$ & Local coordinates for the tetrahedral elements \\
\hline$\kappa$ & Thermal diffusivity \\
\hline$a_{L}$ & Thickness of the lithosphere \\
\hline$U_{x}$ & Half-spreading horizontal velocity in the upwelling divergent flow \\
\hline$U_{z}$ & Vertical velocity at the center of the upwelling divergent flow \\
\hline $\mathbf{D}_{u c}$ & Flexural rigidity matrix for the upper crust \\
\hline
\end{tabular}




\begin{tabular}{|c|c|}
\hline Symbol & Meaning \\
\hline$T_{e, u c}$ & Effective elastic thickness of the upper crust \\
\hline$E_{f}$ & Extension in the upper crust \\
\hline$\theta$ & Fault dip \\
\hline$d_{f}$ & Fault heave \\
\hline$h$ & Topography \\
\hline$k_{d}$ & Coefficient of diffusive transport \\
\hline$q_{f}^{e q b}$ & Maximum sediment transport capacity \\
\hline$q_{f}$ & Sediment flux per unit width \\
\hline$k_{f}$ & Erosional coefficient due to the fluvial process \\
\hline$L_{f}$ & Erosion length scale \\
\hline$q_{r}$ & Water discharge \\
\hline$v_{R}$ & Precipitation rate \\
\hline$k_{m}$ & Non-linear diffusivity for the offshore transport \\
\hline$h_{0}$ & Decay factor for the offshore transport \\
\hline$h_{s . l .}$ & Sea level \\
\hline$\delta_{r}$ & Mean distance between adjacent nodes in the surface model \\
\hline$S_{i}$ & Area of the Voronoi cell $i$ \\
\hline$\partial S_{i j}$ & Edge between the Voronoi cells $i$ and $j$ \\
\hline$L_{i j}$ & Distance between the points $i$ and $j$ \\
\hline$Q_{f i}$ & Sediment volume transported in cell $i$ \\
\hline$Q_{f i}^{e q b}$ & Maximum sediment volume that the cell $i$ can transport \\
\hline$Q_{r i}$ & Cumulative volume of water that flows to the cell $i$ \\
\hline$F_{T}$ & Vertical load associated with any perturbation of temperature \\
\hline$\alpha_{T}$ & Thermal expansion coefficient \\
\hline$\Delta T$ & Temperature perturbation \\
\hline$F_{S}$ & Vertical load arising from thinning of the lower crust \\
\hline$\Delta h_{\text {crust }}$ & Variation of crustal thickeness due to stretching \\
\hline$F_{F}$ & Vertical load due to faulting in the upper crust \\
\hline$F_{s p}$ & Vertical load associated with surface processes \\
\hline
\end{tabular}





\section{Contents}

1. Introduction . . . . . . . . . . . . . . . . . . . . . . . . . 29

1.1 Surface and tectonic processes: a complex system . . . . . . . . . . . . 29

1.2 The purpose of this work . . . . . . . . . . . . . . . 33

2. Flexure and isostasy . . . . . . . . . . . . . . . . . . . . 35

2.1 Introduction . . . . . . . . . . . . . . . . . . . 35

2.2 Flexure of a thin elastic plate and its numerical solution . . . . . . . . . 36

2.3 The choice of the finite element f . . . . . . . . . . . . . 38

2.4 Construction of the stiffness matrix $\mathbf{K}$ and the load vector $\mathbf{f} \ldots \ldots$. . . . 41

2.5 Applying the boundary conditions and solving the linear system . . . . . . 42

2.6 Comparison with analytical solutions . . . . . . . . . . . . . . . 44

3. Thermal model . . . . . . . . . . . . . . . . . . . . . . . . 51

3.1 Introduction . . . . . . . . . . . . . . . . . . 51

3.2 Heat transfer equation and its numerical solution . . . . . . . . . . . . 52

3.3 The choice of the finite element . . . . . . . . . . . . . 56

3.4 Construction of the linear system . . . . . . . . . . . . . . . . 58

3.5 Comparison with analytical solutions . . . . . . . . . . . . . . . . 59

4. Stretching of the lithosphere . . . . . . . . . . . . . . . . . 67

4.1 Introduction . . . . . . . . . . . . . . . . . . . . 67

4.2 The upwelling divergent flow . . . . . . . . . . . . . . . . 71

4.3 The flexural cantilever model . . . . . . . . . . . . . . . . . . . 73 


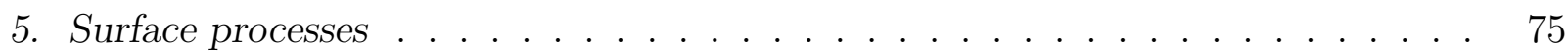

5.1 Introduction . . . . . . . . . . . . . . . . . . . 75

5.2 Mathematical description of the surface processes $\ldots \ldots \ldots \ldots . \ldots 77$

5.3 Generation of the irregular mesh and discretization of the surface . . . . 78

5.3.1 Irregular distribution of the points . . . . . . . . . 78

5.3.2 Delaunay triangulation and Voronoi diagrams . . . . . . . . . 79

5.4 Formulation of the surface processes in the irregular mesh $\ldots \ldots \ldots$

5.4 .1 Onshore and offshore diffusion . . . . . . . . . . . . . . 85

5.4 .2 Fluvial processes . . . . . . . . . . . . . . . . 86

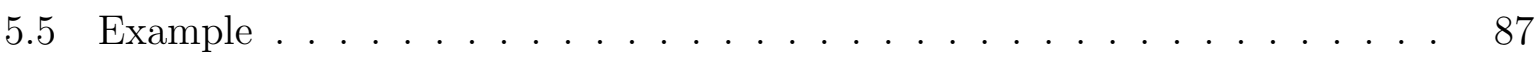

6. Coupling of the processes . . . . . . . . . . . . . . . . . . 91

6.1 The coupling of stretching, thermal and flexural models . . . . . . . . . 92

6.2 Modification of the surface processes due to faulting . . . . . . . . . . 93

6.3 Flexure and isostatic compensation . . . . . . . . . . . . 96

6.4 The "water load delay" algorithm . . . . . . . . . . . . . . . . . . . 98

7. Application of the model to natural examples . . . . . . . . . . . . . . 101

7.1 The influence of rifting on escarpment migration . . . . . . . . . . . 102

7.1 .1 Abstract . . . . . . . . . . . . . . . . . . 102

7.1 .2 Introduction . . . . . . . . . . . . . . . . . . . 102

7.1 .3 The numerical model . . . . . . . . . . . . . . . . . . . . . . . . . . 104

7.1 .4 Model setup . . . . . . . . . . . . . . . . . . . . . . . . . 111

7.1 .5 Results . . . . . . . . . . . . . . . . . . . . . . 112

7.1 .6 Discussion . . . . . . . . . . . . . . . . . . . . . 123

7.1.6.1 Condition for migration of the drainage divide . . . . . . 123

7.1.6.2 Comparison with natural examples . . . . . . . . . . . 124

7.1.6.3 Southeastern Highlands of Australia . . . . . . . . . . 124

7.1.6.4 Serra do Mar, Southeastern Brazil _. . . . . . . . . 128

7.1 .7 Conclusions . . . . . . . . . . . . . . . . . . . . . 132

7.2 Post-rift influence of a thermal plume on passive margins . . . . . . . 133

7.2 .1 Abstract . . . . . . . . . . . . . . . . . . 133 
7.2 .2 Introduction . . . . . . . . . . . . . . . . . . 133

7.2.3 The isostatic effect of a moving plume . . . . . . . . . . . . . 134

7.2.4 The influence of thermal anomalies on the evolution of passive margins 139

7.2.5 Application: The influence of the Trindade Plume on the evolution of the Campos and Espírito Santo Basins . . . . . . . . . . . . 147

7.2 .6 Conclusions . . . . . . . . . . . . . . . . . . . . . . 154

8. Final remarks . . . . . . . . . . . . . . . . . . . . . 155

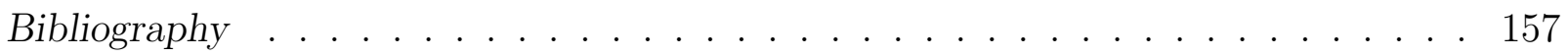

$\begin{array}{ll}\text { Appendix } & 173\end{array}$

A. Flexure of an elastic plate with an abrupt rigidity variation under a line load . . 175

B. Analytical proof of the "water load delay" approximation . . . . . . . . . . . . . 179

B.1 Exact solution for null rigidity . . . . . . . . . . . . . . 179

B.2 "Water load delay" approximation for null rigidity . . . . . . . . . . . . . . 181

B.3 Exact solution for nonzero rigidity . . . . . . . . . . . . . . 182

B.4 "Water load delay" approximation for nonzero rigidity . . . . . . . . . . 183

B.5 Conclusions . . . . . . . . . . . . . . . . . 184 

Chapter 1

\section{Introduction}

Everything is simple, neat, and expressible in terms of everyday mathematics, either partial differential or ordinary differential equations. Everything is simple and neat - except, of course, the world.

(Goldenfeld and Kadanoff, 1999)

\subsection{Surface and tectonic processes: a complex system}

The Earth's surface is shaped by different processes that act in different time and space scales and evolves through the combined effect of tectonic movements and surface processes. While tectonic movements modify the topography as a result of the Earth's interior dynamics, the surface processes sculpt the landscape through erosion and deposition, resulting in horizontal remobilization of material. These surface processes are dependent on, e.g., the climatic conditions, local relief and lithological controls.

On the other hand, the evolution of the Earth's surface also affects the interior of the Earth. For example, the primary direct influence of surface processes on the lithosphere is the isostatic effect due to erosion of continents and deposition of sediments in the sedimentary basins. These processes related to (un)loading at the surface can result in many kilometers of vertical lithospheric displacement (Reiners and Brandon, 2006).

Therefore, the surface and the interior of the Earth must be seen as a coupled system, each one modifying the evolution of the other (Figure 1.1). In this sense, the coupling of surface and tectonic processes represents a complex system (Bar-Yam, 1997). A complex system can be defined as a system composed of interconnected components that interact with each other and, eventually, the combination of these components can manifest pro- 


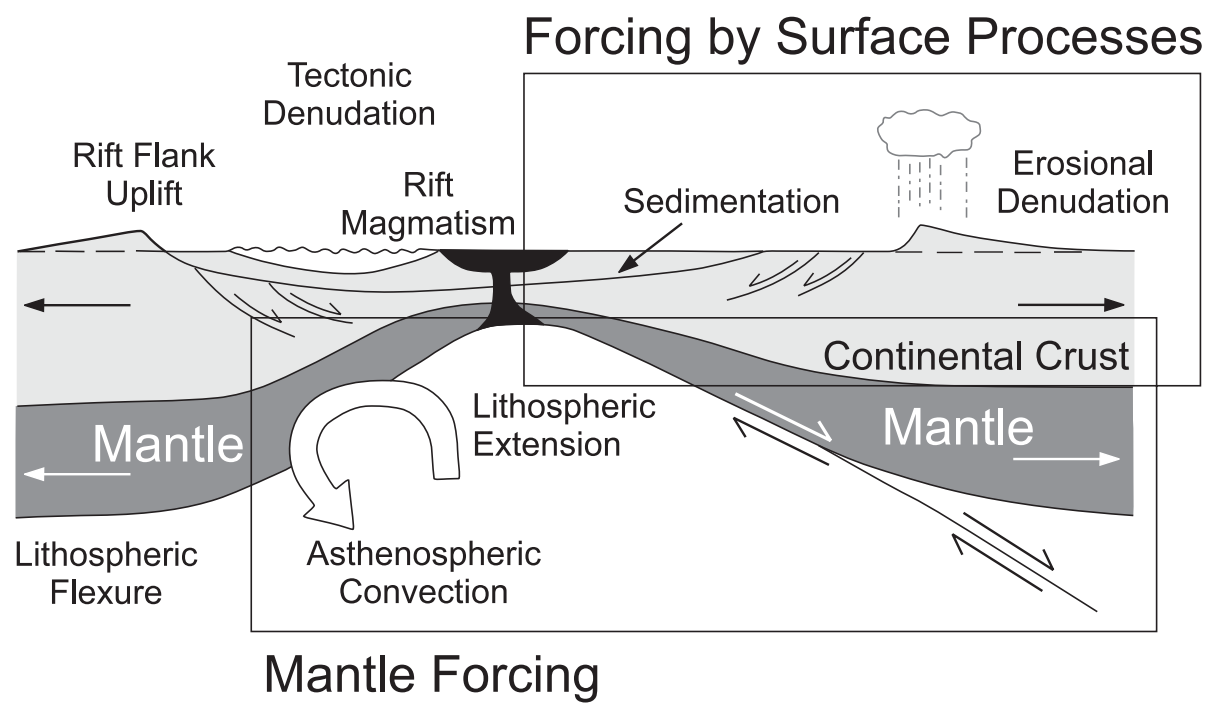

Figure 1.1: Surface and tectonic processes that influence the evolution of the Earth's surface in the context of divergent margins. Extracted from Bishop (2007). Original figure from Beaumont et al. (2000).

perties that are not observed when each component acts isolated.

An example of complex system is the interaction of erosion and isostatic response. The erosion of the continents, when observed isolated, results in the lowering of the topography (Figure 1.2a). On the other hand, when erosion is combined with the regional isostatic response of the lithosphere (Figure 1.2b), the evolving topography can leads to mountain peak uplift (Molnar and England, 1990). In both cases the mean elevation decreases through time, but the regional isostatic compensation causes uplift of portions of the surface less eroded. This example shows how the interaction between surface and tectonic processes can lead to counterintuitive results: erosion can induce local uplift.

In the context of divergent margins, Gilchrist and Summerfield (1990) showed that the combination of erosion and flexural isostatic compensation can explain the formation and permanence of escarpments parallel to the coast, as observed in many rifted margins around the world (Matmon et al., 2002). In this model, the escarpment is maintained by flexural response of the lithosphere to the denudational unloading of the margin, resulting in the formation of the coastal plain (Figure 1.3).

Following the model of Gilchrist and Summerfield (1990), many numerical models were 


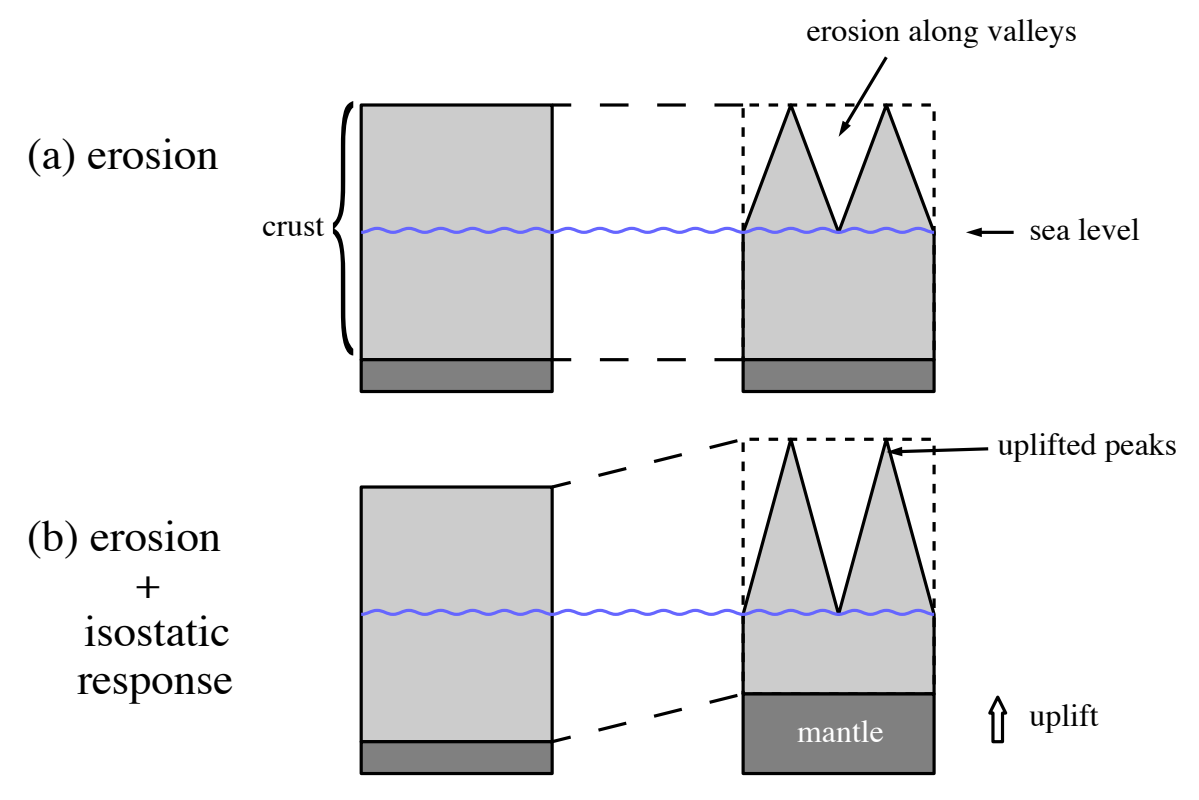

Figure 1.2: Schematic crustal section illustrating (a) the effect of erosion along valleys on the topography and (b) the combination of erosion and isostatic response, resulting in uplift of mountain peaks.

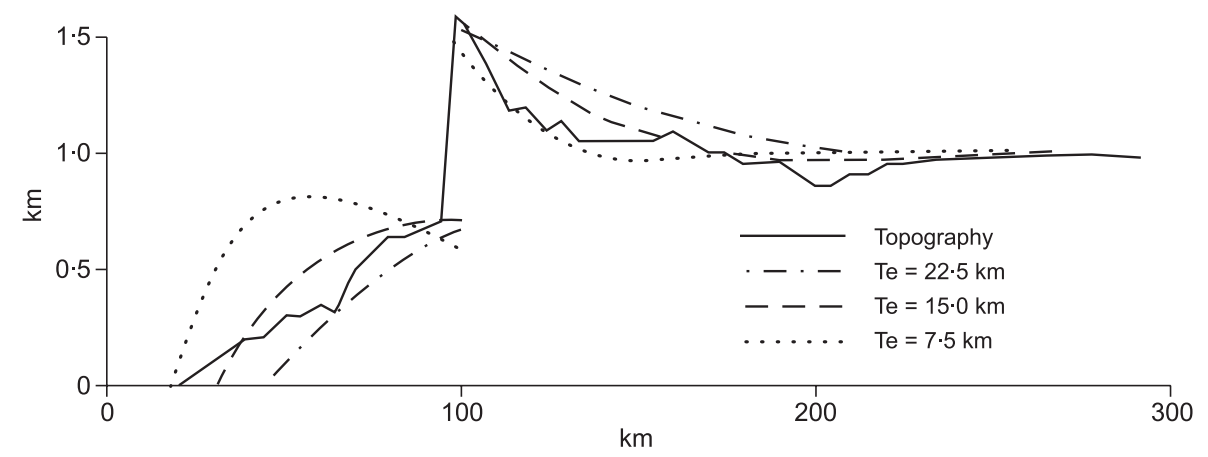

Figure 1.3: Comparison between the topography predicted by the flexural models and the topographic profile of the Southwestern Africa. Different effective elastic thicknesses $T_{e}$ for the flexural model are presented. The escarpment is created by the flexural response of lithosphere to the unloading of the coastal region (for $x<100 \mathrm{~km}$ ). Extracted from Bishop (2007), based on a modified figure from the original work of Gilchrist and Summerfield (1990).

developed to study the interaction of erosion and flexural isostasy in divergent margins, incorporating sophisticated models that dynamically simulate the erosion of the landscape 
(see Merrits and Ellis, 1994, and papers in this volume). These models also explored how preexistent topographic features, climatic conditions, lithological resistance and flexural rigidity of the lithosphere influence the evolution of the escarpment. All these models showed that the evolution of high-elevation escarpments in rifted margins is intimately related to the coupling of surface and tectonic processes.

Likewise the escarpments along divergent margins, the sedimentary basins in rifted margins are the product of the combined action of different processes. A classical example is the elegant model proposed by McKenzie (1978), where the subsidence history of the basin in the rifted margin can be described as the coupling between a pure-shear stretching model, the thermal cooling of the lithosphere and the isostatic compensation. In this model, the total subsidence of the sedimentary basin can be decomposed into three parts: (1) due to the initial stretching and thinning of the lithosphere; $(2)$ due to the following cooling of the lithosphere; and (3) due to the load of the influx of sediments to the basin.

Other advances about the understanding of the evolution of sedimentary basins appeared in the study of two dimensional problems. For example, Watts et al. (1982) developed basin filling models where the flexural rigidity of the lithosphere increases through time as a result of the cooling of the lithosphere. They observed that the increase of the flexural rigidity in the margin during the sedimentary filling results in the widening of the basin, producing stratigraphic onlap (Figure 1.4a). Using a viscoelastic plate to represent the flexural behavior of the lithosphere to loading, Beaumont (1978) simulated the evolution of sedimentary basins on a lithosphere with decreasing rigidity, resulting in stratigraphic offlap (Figure 1.4b). An important result from these numerical models is that the effect of variations of flexural rigidity may be misinterpreted as due to variations in the sea level in the stratigraphic record.

All the models presented in this introduction are a few examples of how the coupling of different surface and tectonic processes can lead to fruitful insights into the evolution of divergent margins. More examples can be seen in recent reviews that show the state-ofthe-art of the coupling of surface and tectonic processes in different tectonic settings (e.g. Beaumont et al., 2000; Braun, 2006; Bishop, 2007). Due to the complexity of the coupling of the many processes acting in the evolution of Earth's surface, the use of computer models is a natural procedure to quantify the relative importance of each of them. 
(a) Increase of rigidity

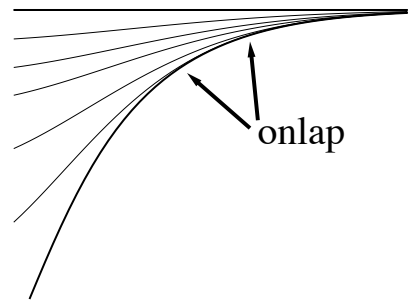

(b) Decrease of rigidity

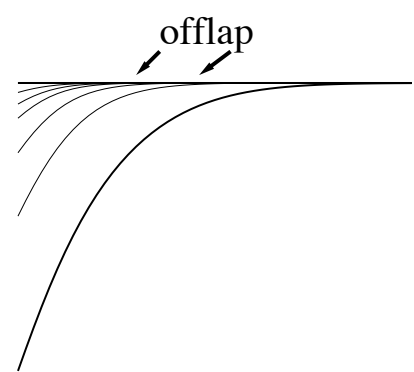

Figure 1.4: The effect of variation of flexural rigidity in the stratigraphy. (a) The increase of rigidity results in widening of the basin, causing stratigraphic onlap. (b) The response of a viscoelastic lithosphere to the filling of a sedimentary basin. The decrease of the rigidity results in gradual narrowing of the basin, causing stratigraphic offlap.

\subsection{The purpose of this work}

In spite of the great number of numerical models created in the last decades to study the coupling between surface and tectonic processes, there is a lack of models that take into account the onshore and offshore parts of rifted margins, with a few exceptions (e.g. van Balen et al., 1995). Furthermore, previous models developed to study the evolution of passive margins and the coupling of surface processes and flexural response do not include the rifting during the simulation and treat the rifting conditions as a "black box".

Aiming to further contribute on the study of divergent margins, this work presents a numerical model that tries to simulate the evolution of divergent margins since the onset of rifting, incorporating onshore and offshore processes of erosion and sedimentation, flexural compensation and thermal processes in the lithosphere.

The aim of this thesis is not to develop new algorithms to investigate a specific geological process. Instead, the purpose of this work is to study how the combination of preexistent models for different geological processes contributes to the emergence of new scenarios, that otherwise could not be predicted through the analysis of isolated processes.

The numerical model proposed here is a means to improve the understanding on the interaction between different processes acting during and after lithospheric stretching. Therefore, the main target was to apply the model to geological problems, instead of the 
development of the code itself. On the other hand, most of the project time was devoted to the development of each part of the code and the coupling of them. Thus the first chapters of this thesis are dedicated to describe in detail the numerical approach for each physical/geological process incorporated in this study (Chapters 2 to 5), culminating in the description of the coupling of all the processes (Chapter 6).

Chapter 2 presents the flexural model used to simulate the regional isostatic behavior of the lithosphere to vertical loading and Chapter 3 describes the model for the thermal evolution of the lithosphere. In both chapters, the finite element formulation is presented in detail, as well as the comparisons with analytical solutions. The kinematic model for the stretching of the lithosphere to simulate rifting during the formation and evolution of divergent margins is presented in Chapter 4. Chapter 5 describes the surface processes model that simulates the erosion, transport and deposition of sediments on the surface.

Chapter 7 shows the applications of the numerical model described in the previous chapters. In Section 7.1 an example of application is discussed on how rifting influences the evolution of the landscape and the position of the drainage divide along rifted margins. The predicted results are compared with the Southeastern margins of Brazil and Australia. Section 7.2 describes how the passage of thermal anomalies under the lithosphere influences the evolution of sedimentary basins in divergent margins. A possible thermal influence of the Trindade Plume on the evolution of the Campos and Espírito Santo Basins in Southeastern Brazil is analysed and discussed.

Finally, Chapter 8 gives the conclusions of the thesis, the advantages and limitations of the numerical models as well as perspectives for future work. 
Chapter 2

\title{
Flexure and isostasy ${ }^{1}$
}

\author{
It appears as though the mountain ranges \\ had been piled too high by tangential forces, \\ and by virtue of the partial rigidity of the crust, \\ had depressed the heighboring ocean bottoms.
}

(Barrell 1914 in Watts 2001)

\subsection{Introduction}

The concept of a strong uppermost layer of the Earth, named lithosphere, floating on a weak layer, the asthenosphere, originated in the beginning of the $20^{\text {th }}$ century, with the work of Barrell (1914). This concept has survived through time and is an important element to the theory of plate tectonics: "Plate tectonics is based on the assumption that the lithosphere is rigid on long timescales and is moving across the surface of the Earth with the plates" (Watts, 2007).

A strong lithosphere floating on a weak substratum implies that geological loads are not locally compensated by the buoyancy forces exerted by the asthenosphere (i.e. pure isostasy), but the load is partly sustained by the rigidity of the lithosphere. This behavior of the lithosphere can be approximated as a thin elastic plate floating on an inviscid substratum.

Since the second half of the $20^{\text {th }}$ century, the thin elastic plate representation of the lithosphere has been successfully used to explain the flexural behavior of the lithosphere,

\footnotetext{
${ }^{1}$ The numerical model described in this chapter was presented in the article of Sacek and Ussami (2009).
} 
both in oceans (e.g. Walcott, 1970; Watts, 1982) and continents (e.g. Karner and Watts, 1983; Lyon-Caen and Molnar, 1983).

The thickness of the elastic plate that represents the flexural behavior of the real lithosphere is named effective elastic thickness or $T_{e}$. The $T_{e}$ does not coincide with the lithospheric thickness and does not represent a real layer of the Earth. Instead, the effective elastic thickness is a measure of the integrated strength of the lithosphere. As part of the lithosphere behaves non-elastically through the geological time, the $T_{e}$ is thinner than the lithospheric thickness. The value of $T_{e}$ can vary in space and time and there are many physical properties of the lithosphere that influence the $T_{e}$ : the thickness of the crust and lithospheric mantle; the crustal composition; the thermal state of the lithosphere; the state of stress and the local curvature of the lithosphere (Burov and Diament, 1995). Therefore the determination of $T_{e}$ can be used to study the thermal and mechanical structure of the lithosphere.

In the present work, the flexure of the lithosphere is simulated using the thin elastic plate approximation. In the following sections, the numerical approach for the flexural isostasy of the lithosphere is described, as well as the comparison with analytical solutions.

\subsection{Flexure of a thin elastic plate and its numerical solution}

The differential equation that describes the flexure $w=w(x, y)$ of a thin elastic plate under the vertical loads $q$ is presented in equation 2.1 .

$$
(\mathbf{L} \nabla)^{\mathrm{T}} \mathbf{D L} \nabla w-q=0
$$

where

$$
\begin{aligned}
& (\mathbf{L} \nabla)=\left[\frac{\partial^{2}}{\partial x^{2}}, \frac{\partial^{2}}{\partial y^{2}}, 2 \frac{\partial^{2}}{\partial x \partial y}\right]^{\mathrm{T}} \\
& \mathbf{D}=D\left[\begin{array}{ccc}
1 & \nu & 0 \\
\nu & 1 & 0 \\
0 & 0 & (1-\nu) / 2
\end{array}\right] .
\end{aligned}
$$

$D=E T_{e}^{3} / 12\left[1-\nu^{2}\right]$ is the flexural rigidity of the plate, that depends on the Young's modulus $E$, the $T_{e}=T_{e}(x, y)$ and the Poisson's ratio $\nu$. T indicates the transpose of a 
matrix. A detailed deduction of equation 2.1 is provided by Timoshenko and WoinowskyKrieger (1959).

The numerical solution of equation 2.1 through the finite element method is presented by Zienkiewicz and Taylor (2000a) and is based on the principle of virtual work: for an arbitrary displacement $\delta w$ of a plate $\Omega$ out of the plane $x y$, the plate will be at equilibrium if the internal virtual work $\delta \Pi_{\text {int }}$ (related to the deformations of the plate) and the external virtual work $\delta \Pi_{e x t}$ (related to the loads applied on the plate) are equal:

$$
\delta \Pi_{i n t}-\delta \Pi_{e x t}=0
$$

The internal and external virtual works for the thin elastic plate problem are given by (see Zienkiewicz and Taylor, 2000a)

$$
\begin{gathered}
\delta \Pi_{i n t}=\int_{\Omega} \delta w(\mathbf{L} \nabla)^{\mathrm{T}} \mathbf{D}(\mathbf{L} \nabla) w d \Omega \\
\delta \Pi_{\text {ext }}=\int_{\Omega} \delta w q d \Omega+\text { b.c. }
\end{gathered}
$$

where the term b.c. represents boundary conditions of $\Omega$, necessary for the solution of the problem and physically represents the link of the plate with adjacent regions.

For the study of lithospheric flexure, the load $q$ can be decomposed into two components:

1. due to the buoyancy force per unit area exerted by the asthenosphere $-\rho_{m} g w$, where $\rho_{m}$ is the density of the asthenosphere and $g$ is the gravity. The negative sign indicates that the buoyancy force has the opposite sense of the deflection $w$;

2. due to other loads $\bar{q}$ related to topographic loads, sedimentary loads and thermal expansion of the lithosphere, for example.

In the geoscience literature (e.g. Turcotte and Schubert, 1982), the buoyancy force term is commonly represented as an effective buoyancy force, dependent on the difference of density between the asthenosphere and the material infilling the depressions at the surface created during the deflection of the plate $\left(\rho_{m}-\rho_{\text {infill }}\right)$. Here the buoyancy term is treated as dependent only on $\rho_{m}$ and all the other external loads are merged in the $\bar{q}$ term. The reason for this procedure will be explained in detail in section 6.4 , where the coupling of the different processes that compose the numerical model is described. 
Therefore, the expression 2.4 can be rewritten as

$$
\delta \Pi_{e x t}=\int_{\Omega} \delta w\left[\bar{q}-\rho_{m} g w\right] d \Omega+b . c .
$$

The function $w$ can be approximated by $w \approx \tilde{w}=\mathbf{N a}$ where $\mathbf{N}=\mathbf{N}(x, y)$ is a row vector containing interpolation functions called shape functions chosen a priori and $\mathbf{a}$ is a column vector containing the unknown parameters. The shape functions used in this work will be described in the next section. The virtual displacement $\delta w$ is replaced by $\delta w=\delta \mathbf{a}^{\mathrm{T}} \mathbf{N}^{\mathrm{T}}$, where $\delta \mathbf{a}^{\mathrm{T}}$ is a row vector containing arbitrary parameters.

Replacing $w$ and $\delta w$ in Eqs. 2.3 and 2.5, the equation 2.2 becomes

$$
\delta \mathbf{a}^{\mathrm{T}}\left(\int_{\Omega} \mathbf{B}^{\mathrm{T}} \mathbf{D B} d \Omega \mathbf{a}-\int_{\Omega} \mathbf{N}^{\mathrm{T}} \bar{q} d \Omega+\int_{\Omega} \mathbf{N}^{\mathrm{T}} \rho_{m} g \mathbf{N} d \Omega \mathbf{a}\right)-\text { b.c. }=0
$$

where $\mathbf{B}=(\mathbf{L} \nabla) \mathbf{N}$.

As described by Zienkiewicz and Taylor (2000a), the boundary conditions b.c. can be approximated by b.c. $\approx \delta \mathbf{a}^{\mathrm{T}} \mathbf{f}_{\mathbf{b}}$. Using this approximation for b.c., the equation 2.6 becomes independent of $\delta \mathbf{a}^{\mathrm{T}}$, resulting in the linear system

$$
\mathbf{K a}=\mathbf{f}
$$

where

$$
\begin{gathered}
\mathbf{K a}=\int_{\Omega}\left(\mathbf{B}^{\mathrm{T}} \mathbf{D B}+\mathbf{N}^{\mathrm{T}} \rho_{m} g \mathbf{N}\right) d \Omega \mathbf{a} \\
\mathbf{f}=\int_{\Omega} \mathbf{N}^{\mathrm{T}} \bar{q} d \Omega+\mathbf{f}_{\mathbf{b}}
\end{gathered}
$$

$\mathbf{K}$ and $\mathbf{f}$ are usually called stiffness matrix and load vector, respectively.

\subsection{The choice of the finite element}

There are dozens of different finite element types used to study the problem of bending of thin elastic plates (see Zienkiewicz and Taylor, 2000a). In the present work, triangular elements and the shape functions developed by Specht (1988) were adopted. This triangular element is composed of 3 nodes, each one with 3 degrees of freedom: the vertical displacement $w$ and the partial derivatives of $w$ with respect to $x$ and $y$. Zienkiewicz and 
Taylor (2000a) pointed out that this type of element is one of the best triangular elements with 9 degrees of freedom currently available.

The domain $\Omega$ is subdivided into triangular elements $\Omega^{e}(e=1, \ldots, m)$, where $m$ is the number of elements. These $m$ elements are interconnected by $n$ nodes that are, in this case, the vertices of the triangles. The function $\tilde{w}=\mathrm{Na}$ is composed of

$$
\begin{array}{r}
\mathbf{a}=\left[\begin{array}{c}
\mathbf{a}_{1} \\
\mathbf{a}_{2} \\
\mathbf{a}_{3} \\
\vdots \\
\mathbf{a}_{n}
\end{array}\right] \\
\mathbf{N}=\left[\mathbf{N}_{1}, \mathbf{N}_{2}, \mathbf{N}_{3}, \cdots, \mathbf{N}_{n}\right] \\
\mathbf{a}_{i}=\left[\tilde{w}_{i}, \theta_{x i}, \theta_{y i}\right]^{\mathrm{T}}, N_{i}=\left[N_{w i}, N_{\theta_{x} i}, N_{\theta_{y} i}\right]
\end{array}
$$

The equation 2.11 shows that each node $i$ has 3 degrees of freedom: (1) displacement $\tilde{w}_{i}$ in the $z$ direction, (2) rotation $\theta_{x i}$ around the $x$ axis and (3) rotation $\theta_{y i}$ around the $y$ axis.

For a certain point $\mathbf{x}_{p}=\left(x_{p}, y_{p}\right)$ inside the element $e$, the functions $\mathbf{N}_{i}$ are

$$
\mathbf{N}_{i}\left(x_{p}, y_{p}\right)=\left\{\begin{array}{cll}
\mathbf{N}_{i}^{e}\left(x_{p}, y_{p}\right) & \text { if } i & \text { is a vertex of } e \\
\mathbf{0} & \text { if } i & \text { is not a vertex of } e
\end{array}\right.
$$

and the shape functions for the element $e$ with node $i, j$ and $k$ developed by Specht (1988) are

$$
\mathbf{N}_{i}^{e \mathrm{~T}}=\left[\begin{array}{c}
N_{w i}^{e} \\
N_{\theta_{x} i}^{e} \\
N_{\theta_{y} i}^{e}
\end{array}\right]=\left[\begin{array}{c}
P_{i}-P_{i+3}+P_{k+3}+2\left(P_{i+6}-P_{k+6}\right) \\
-b_{j}\left(P_{k+6}-P_{k+3}\right)-b_{k} P_{i+6} \\
-c_{j}\left(P_{k+6}-P_{k+3}\right)-c_{k} P_{i+6}
\end{array}\right]
$$

where $\mathbf{N}_{i}^{e}, \mathbf{N}_{j}^{e}$ and $\mathbf{N}_{k}^{e}$ are obtained through ciclic permutation of $i, j$ and $k$ by 1,2 and 3 on the right side of 2.15 . The terms $P$ in 2.15 are the 9 coefficients of the vector $\mathbf{P}$ :

$$
\begin{aligned}
\mathbf{P}= & {\left[L_{i}, \quad L_{j}, \quad L_{k}, \quad L_{i} L_{j}, \quad L_{j} L_{k}, \quad L_{k} L_{i},\right.} \\
& L_{i}^{2} L_{j}+\frac{1}{2} L_{i} L_{j} L_{k}\left\{3\left(1-\mu_{k}\right) L_{i}-\left(1+3 \mu_{k}\right) L_{j}+\left(1+3 \mu_{k}\right) L_{k}\right\}, \\
& L_{j}^{2} L_{k}+\frac{1}{2} L_{i} L_{j} L_{k}\left\{3\left(1-\mu_{i}\right) L_{k}-\left(1+3 \mu_{i}\right) L_{k}+\left(1+3 \mu_{i}\right) L_{i}\right\}, \\
& \left.L_{k}^{2} L_{i}+\frac{1}{2} L_{i} L_{j} L_{k}\left\{3\left(1-\mu_{j}\right) L_{i}-\left(1+3 \mu_{j}\right) L_{i}+\left(1+3 \mu_{j}\right) L_{j}\right\}\right]
\end{aligned}
$$


and

$$
\mu_{i}=\frac{l_{k}^{2}-l_{j}^{2}}{l_{i}^{2}}
$$

where $l_{i}$ is the lenght of the triangle's edge oposite to $i$.

$L_{i}, L_{j}$ and $L_{k}$ are the local coordinates of the element and are defined as

$$
\begin{aligned}
L_{i} & =\frac{a_{i}+b_{i} x_{p}+c_{i} y_{p}}{2 \triangle} \\
L_{j} & =\frac{a_{j}+b_{j} x_{p}+c_{j} y_{p}}{2 \triangle} \\
L_{k} & =\frac{a_{k}+b_{k} x_{p}+c_{k} y_{p}}{2 \triangle}
\end{aligned}
$$

where

$$
\begin{aligned}
& a_{i}=x_{j} y_{k}-x_{k} y_{j} ; \quad b_{i}=y_{j}-y_{k} ; \quad c_{i}=x_{k}-x_{j} ; \\
& a_{j}=x_{k} y_{i}-x_{i} y_{k} ; \quad b_{j}=y_{k}-y_{i} ; \quad c_{j}=x_{i}-x_{k} ; \\
& a_{k}=x_{i} y_{j}-x_{j} y_{i} ; \quad b_{k}=y_{i}-y_{j} ; \quad c_{k}=x_{j}-x_{i}
\end{aligned}
$$

and $\triangle$ is the area of the triangle $i j k$

$$
\triangle=\frac{1}{2} \operatorname{det}\left|\begin{array}{ccc}
1 & x_{i} & y_{i} \\
1 & x_{j} & y_{j} \\
1 & x_{k} & y_{k}
\end{array}\right|=\text { area } i j k
$$

The use of local coordinates for each element, instead of global coordinates, is a common procedure in finite element method to facilitate the computation of the stiffness and load matrices for each element.

The local coordinates $L_{i}, L_{j}$ and $L_{k}$ are also called areal coordinates and are used to represent the position of an internal point relative to the vertices of the triangle. Geometrically, the areal coordinates can be defined as the following ratios (see Figure 2.1)

$$
\begin{aligned}
& L_{i}=\frac{\text { area } p j k}{\text { area } i j k}=\frac{\text { area } p j k}{\triangle} \\
& L_{j}=\frac{\text { area } i p k}{\text { area } i j k}=\frac{\text { area } i p k}{\triangle} \\
& L_{k}=\frac{\text { area } i j p}{\text { area } i j k}=\frac{\text { area } i j p}{\triangle}
\end{aligned}
$$

The areal coordinate is non-dimensional and range from 0 to $1: L_{i}=1$ if $\mathbf{x}_{p}=\mathbf{x}_{i}$ and $L_{i}=0$ if the point $\mathbf{x}_{p}$ lies on the opposite edge $j k$. Another property is $L_{i}+L_{j}+L_{k}=1$. 
The stiffness matrix in 2.8 depends on the shape functions $\mathbf{N}$ and the second derivatives of $\mathbf{N}$ with respect to the horizontal coordinates, represented by $\mathbf{B}=(\mathbf{L} \nabla) \mathbf{N}$. To obtain these derivatives with respect to the areal coordinates, the chain rule is used, as shown below

$$
\begin{gathered}
{\left[\begin{array}{cc}
\frac{\partial^{2}}{\partial x^{2}} & \frac{\partial^{2}}{\partial x \partial y} \\
\frac{\partial^{2}}{\partial x \partial y} & \frac{\partial^{2}}{\partial y^{2}}
\end{array}\right]=\left[\begin{array}{ccc}
\frac{\partial L_{i}}{\partial x} & \frac{\partial L_{j}}{\partial x} & \frac{\partial L_{k}}{\partial x} \\
\frac{\partial L_{i}}{\partial y} & \frac{\partial L_{j}}{\partial y} & \frac{\partial L_{k}}{\partial y}
\end{array}\right]\left[\begin{array}{ccc}
\frac{\partial^{2}}{\partial L_{i}^{2}} & \frac{\partial^{2}}{\partial L_{i} \partial L_{j}} & \frac{\partial^{2}}{\partial L_{i} \partial L_{k}} \\
\frac{\partial^{2}}{\partial L_{j} \partial L_{i}} & \frac{\partial^{2}}{\partial L_{j}^{2}} & \frac{\partial^{2}}{\partial L_{j} \partial L_{k}} \\
\frac{\partial^{2}}{\partial L_{k} \partial L_{i}} & \frac{\partial^{2}}{\partial L_{k} \partial L_{j}} & \frac{\partial^{2}}{\partial L_{k}^{2}}
\end{array}\right]\left[\begin{array}{cc}
\frac{\partial L_{i}}{\partial x} & \frac{\partial L_{i}}{\partial y} \\
\frac{\partial L_{j}}{\partial x} & \frac{\partial L_{j}}{\partial y} \\
\frac{\partial L_{k}}{\partial x} & \frac{\partial L_{k}}{\partial y}
\end{array}\right]} \\
{\left[\begin{array}{cc}
\frac{\partial^{2} \mathbf{N}_{i}}{\partial x^{2}} & \frac{\partial^{2} \mathbf{N}_{i}}{\partial x \partial y} \\
\frac{\partial^{2} \mathbf{N}_{i}}{\partial x \partial y} & \frac{\partial^{2} \mathbf{N}_{i}}{\partial y^{2}}
\end{array}\right]=\frac{1}{4 \triangle^{2}}\left[\begin{array}{ccc}
b_{i} & b_{j} & b_{k} \\
c_{i} & c_{j} & c_{k}
\end{array}\right]\left[\begin{array}{ccc}
\frac{\partial^{2} \mathbf{N}_{i}}{\partial L_{i}^{2}} & \frac{\partial^{2} \mathbf{N}_{i}}{\partial L_{i} \partial L_{j}} & \frac{\partial^{2} \mathbf{N}_{i}}{\partial L_{i} \partial L_{k}} \\
\frac{\partial^{2} \mathbf{N}_{i}}{\partial L_{j} \partial L_{i}} & \frac{\partial^{2} \mathbf{N}_{i}}{\partial L_{j}^{2}} & \frac{\partial^{2} \mathbf{N}_{i}}{\partial L_{j} \partial L_{k}} \\
\frac{\partial^{2} \mathbf{N}_{i}}{\partial L_{k} \partial L_{i}} & \frac{\partial^{2} \mathbf{N}_{i}}{\partial L_{k} \partial L_{j}} & \frac{\partial^{2} \mathbf{N}_{i}}{\partial L_{k}^{2}}
\end{array}\right]\left[\begin{array}{ccc}
b_{i} & c_{i} \\
b_{j} & c_{j} \\
b_{k} & c_{k}
\end{array}\right]}
\end{gathered}
$$

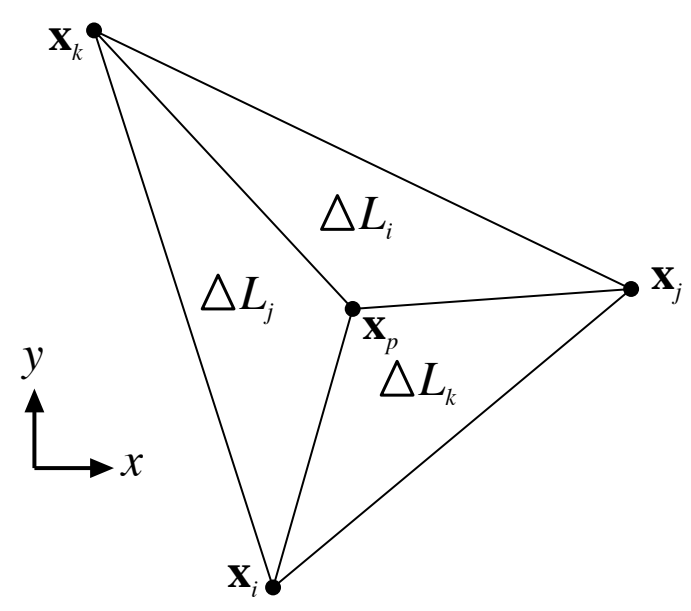

Figure 2.1: Geometric representation of the areal coordinates $L_{i}, L_{j}$ and $L_{k}$ of the point $p$ inside the triangle $i j k$.

\subsection{Construction of the stiffness matrix $\mathbf{K}$ and the load vector $\mathbf{f}$}

The matrix $\mathbf{K}$ can be obtained through the summation of the stiffness matrices $\overline{\mathbf{K}}^{e}$ of each element of the mesh

$$
\mathbf{K}=\sum_{e} \overline{\mathbf{K}}^{e}=\sum_{e} \int_{\Omega^{e}}\left(\mathbf{B}^{T} \mathbf{D B}+\mathbf{N}^{T} \rho_{m} g \mathbf{N}\right) d \Omega
$$

where $\Omega^{e}$ is the domain of the element $e$. 
In the same way, the vector $\mathbf{f}$ can be written as the sum of $\overline{\mathbf{f}}^{e}$ for each element

$$
\mathbf{f}=\sum_{e} \overline{\mathbf{f}}^{e}=\sum_{e}\left[\int_{\Omega^{e}} \mathbf{N}^{\mathrm{T}} \bar{q} d \Omega+\mathbf{f}_{\mathbf{b}}{ }^{e}\right]
$$

For an element $e$ only 9 coefficients of $\mathbf{N}$ are non-zero: 3 nodes $\times 3$ degrees of freedom. Therefore, the load vector $\overline{\mathbf{f}}^{e}$ has 9 non-zero coefficients and the stiffness matrix $\overline{\mathbf{K}}^{e}$ has $9 \times 9=81$ non-zero coefficients.

To illustrate the construction of $\mathbf{K}$ and $\mathbf{f}$, the Figure 2.2a presents a finite element mesh composed of 3 elements and 5 nodes and Figures $2.2 \mathrm{~b}$ and c show the non-zero coefficients of the stiffness matrices and the load vectors, respectively.

The integration over each finite element is made numerically using three points of quadrature: for a certain function $f=f\left(L_{i}, L_{j}, L_{k}\right)$, where $L_{i}, L_{j}$ and $L_{k}$ are the areal coordinates of the triangle $i j k$, the integral $I$ over the triangle $i j k$

$$
I=\int_{0}^{1} \int_{0}^{1-L_{i}} f\left(L_{i}, L_{j}, L_{k}\right) d L_{j} d L_{i} \quad L_{k}=1-L_{i}-L_{j}
$$

can be approximated by

$$
2 I \approx I^{\prime}=\frac{1}{3} f\left(\frac{1}{2}, \frac{1}{2}, 0\right)+\frac{1}{3} f\left(\frac{1}{2}, 0, \frac{1}{2}\right)+\frac{1}{3} f\left(0, \frac{1}{2}, \frac{1}{2}\right)
$$

Applying the transformation of variable $(x, y) \rightarrow\left(L_{i}, L_{j}\right)$

$$
\int_{\Omega^{e}} f(x, y) d x d y=\int_{0}^{1} \int_{0}^{1-L_{i}} f\left(x_{\left(L_{i}, L_{j}\right)}, y_{\left(L_{i}, L_{j}\right)}\right)\left|\begin{array}{cc}
\frac{\partial x}{\partial L_{i}} & \frac{\partial x}{\partial L_{j}} \\
\frac{\partial y}{\partial L_{i}} & \frac{\partial y}{\partial L_{j}}
\end{array}\right| d L_{j} d L_{i}=2 I \triangle \approx I^{\prime} \triangle
$$

Therefore, the numerical integration over each triangular element can be done through the product of $I^{\prime}$ and the area of the element.

\subsection{Applying the boundary conditions and solving the linear system}

After the construction of $\mathbf{K}$ and $\mathbf{f}$, it is imposed restrictions to some degrees of freedom on nodes at the border of finite element mesh. This is done prescribing values to some coefficients of the vector $\mathbf{a}$. Algebraically, this result in the elimination of lines and columns of the matrix $\mathbf{K}$ and coefficients of vector $\mathbf{f}$.

The vector $\mathbf{f}_{\mathbf{b}}$ is not known a priori. This vector represents tractions on the borders of the plate that, in combination with the pre-determined loads of the problem (i.e. the 
(a)

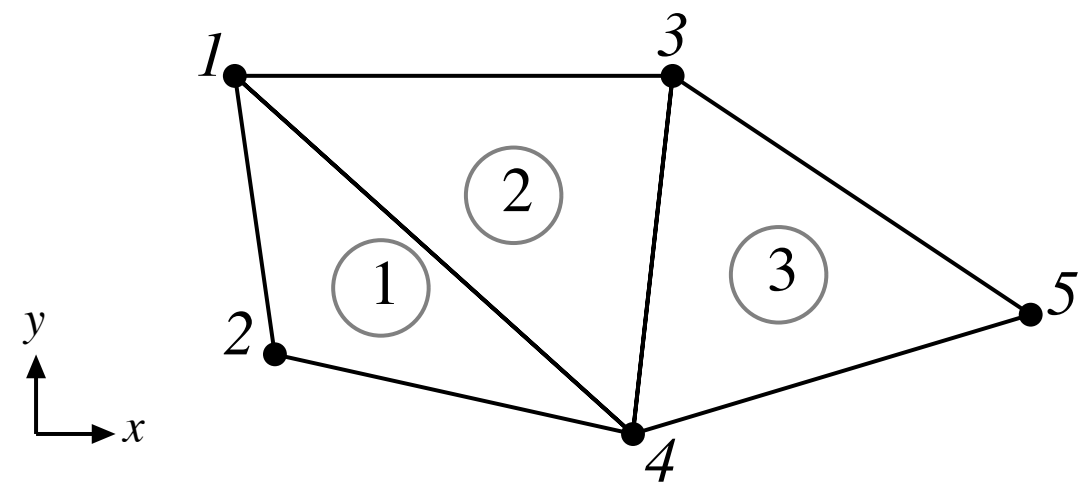

(b)

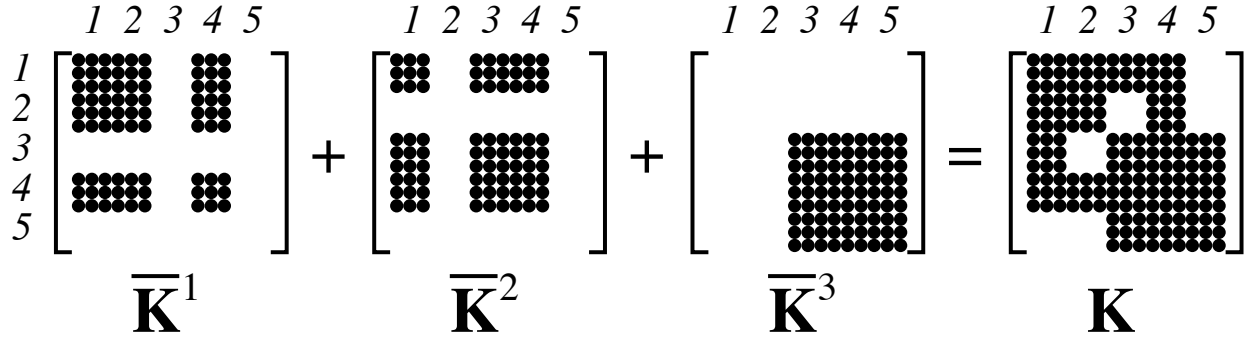

(c)

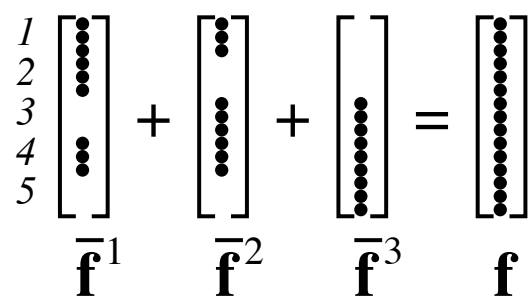

- Nonzero coefficients

Figure 2.2: Illustration of the construction of the stiffness matrix $\mathbf{K}$ and the load vector $\mathbf{f}$.

(a) Finite element mesh composed of 3 elements and 5 nodes. (b) Summation of the stiffness matrices $\overline{\mathbf{K}}^{e}$ to obtain $\mathbf{K}$ for the finite element mesh shown in (a). (c) Summation of the load vector $\overline{\mathbf{f}}^{e}$ to obtain $\mathbf{f}$ for the finite element mesh shown in (a). Italic numbers indicate the nodes and upright ones indicate the elements.

known loads), result in the prescribed displacement of the plate at the nodes of the border. The vector $\mathbf{f}_{b}$ can be determined as a post-process procedure, after the calculation of the vector a.

The resulting linear system is solved iteratively through the biconjugate gradient method (Press et al., 2002). 


\subsection{Comparison with analytical solutions}

In this section, numerical solutions are compared with analytical ones to validate the numerical model to study the flexure of the lithosphere.

Firstly, it is considered the case of an infinite elastic beam of constant rigidity $D$ floating on a substratum of density $\rho_{m}$, under the load $q$ uniformly distributed over the segment $A-B$ of the beam (Figure 2.3). The deflection of the plate at the point $C$, which is a distance $a$ from $A$ and a distance $b$ from $B$, can be classified in three cases (Hetenyi, 1967):

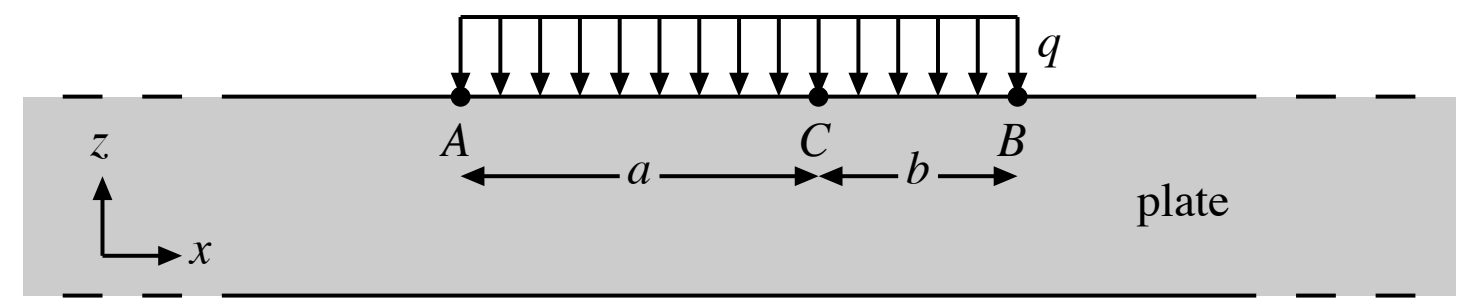

Figure 2.3: Uniform load applied over an infinite plate.

- when point $C$ is to the left of the load

$$
w=\frac{q}{2 k_{W}}\left(e^{-\lambda a} \cos \lambda a-e^{-\lambda b} \cos \lambda b\right)
$$

- when point $C$ is under the load

$$
w=\frac{q}{2 k_{W}}\left(2-e^{-\lambda a} \cos \lambda a-e^{-\lambda b} \cos \lambda b\right)
$$

- when point $C$ is to the right of the load

$$
w=\frac{-q}{2 k_{W}}\left(e^{-\lambda a} \cos \lambda a-e^{-\lambda b} \cos \lambda b\right)
$$

where $k_{W}=\rho_{m} g$ and $\lambda=\sqrt[4]{k_{W} / 4 D}$.

To compare this analytical solution with the numerical approach, it is considered a plate under a distributed load as shown in Figure 2.4. The physical parameters of the problem are presented in Table 2.1. The Figure 2.4 also shows three finite element meshes 


\begin{tabular}{llr} 
Parameter & Definition & Value \\
\hline$T_{e}$ & Effective elastic thickness & $10 \mathrm{~km}$ \\
$A B$ & Width of the load & $100 \mathrm{~km}$ \\
$q$ & Distributed load & $-1.0 \times 10^{8} \mathrm{~N} / \mathrm{m}^{2}$
\end{tabular}

Table 2.1 - Parameters for the problem of an elastic plate under a distributed load.

with different element size $L_{e}$, defined here as the length of the legs of an isosceles right triangle. The boundary condition in all the edges of the plate is

$$
\frac{\partial w}{\partial \mathbf{n}_{\text {out }}}=0
$$

where $\mathbf{n}_{\text {out }}$ is the normal direction pointing out the plate.

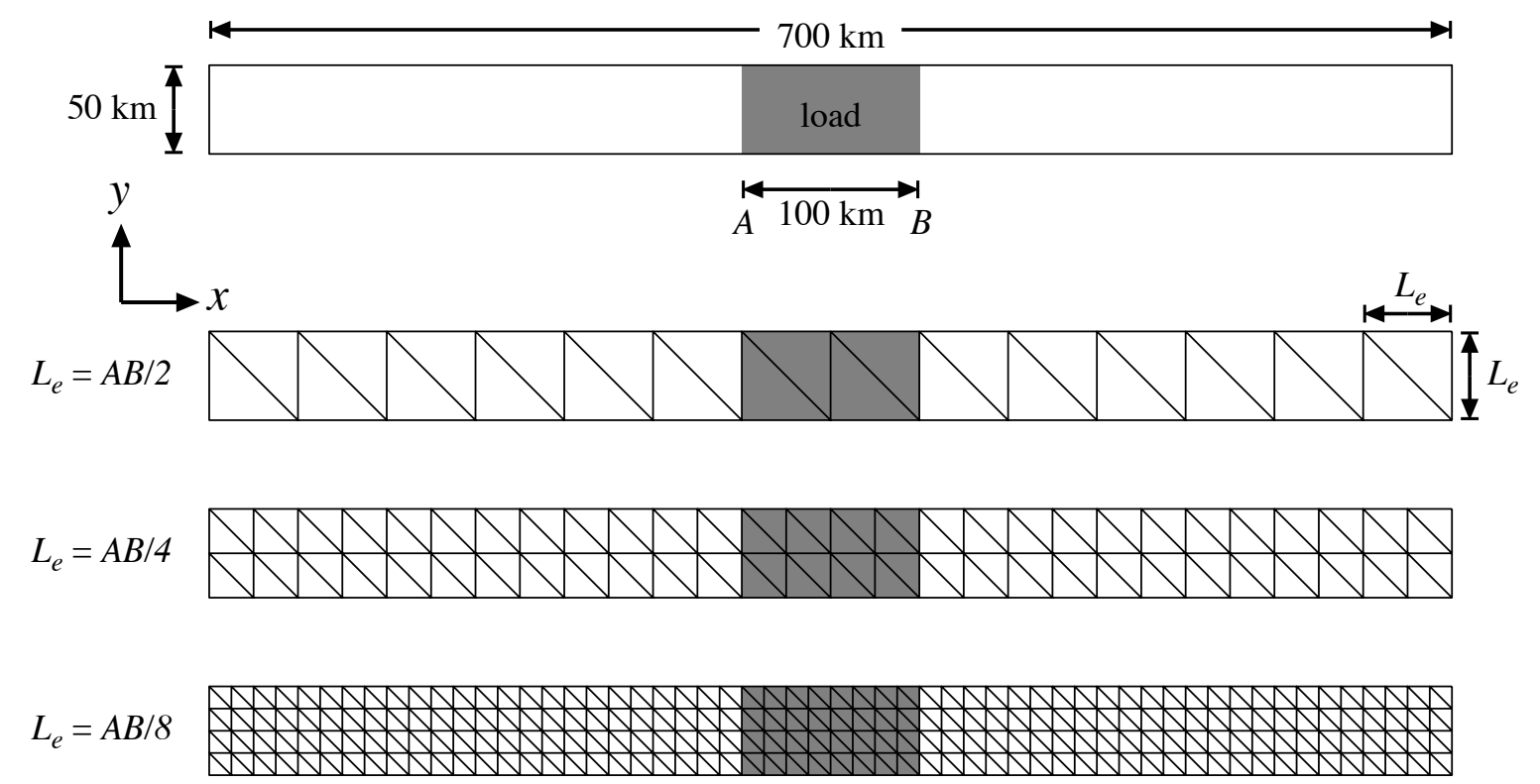

Figure 2.4: Scheme representing the plate and the load geometries to study the case of an uniformly distributed load. Three meshes used to discretize the plate are presented.

Figure 2.5a presents the comparison between the analytical and numerical solutions. Independent of the element size $L_{e}$, all the meshes presented a good agreement with the analytical solution. To visualize the convergence to the exact solution with the decreasing of $L_{e}$, Figure 2.5b shows the difference between the analytical and numerical solutions. 
It can be observed that the maximum difference is smaller than $2.5 \%$ of the deflection at the center of the load $w_{0}$. For the mesh with the smallest elements $\left(L_{e}=A B / 8\right)$ the maximum difference was less than $0.2 \%$ of $w_{0}$.
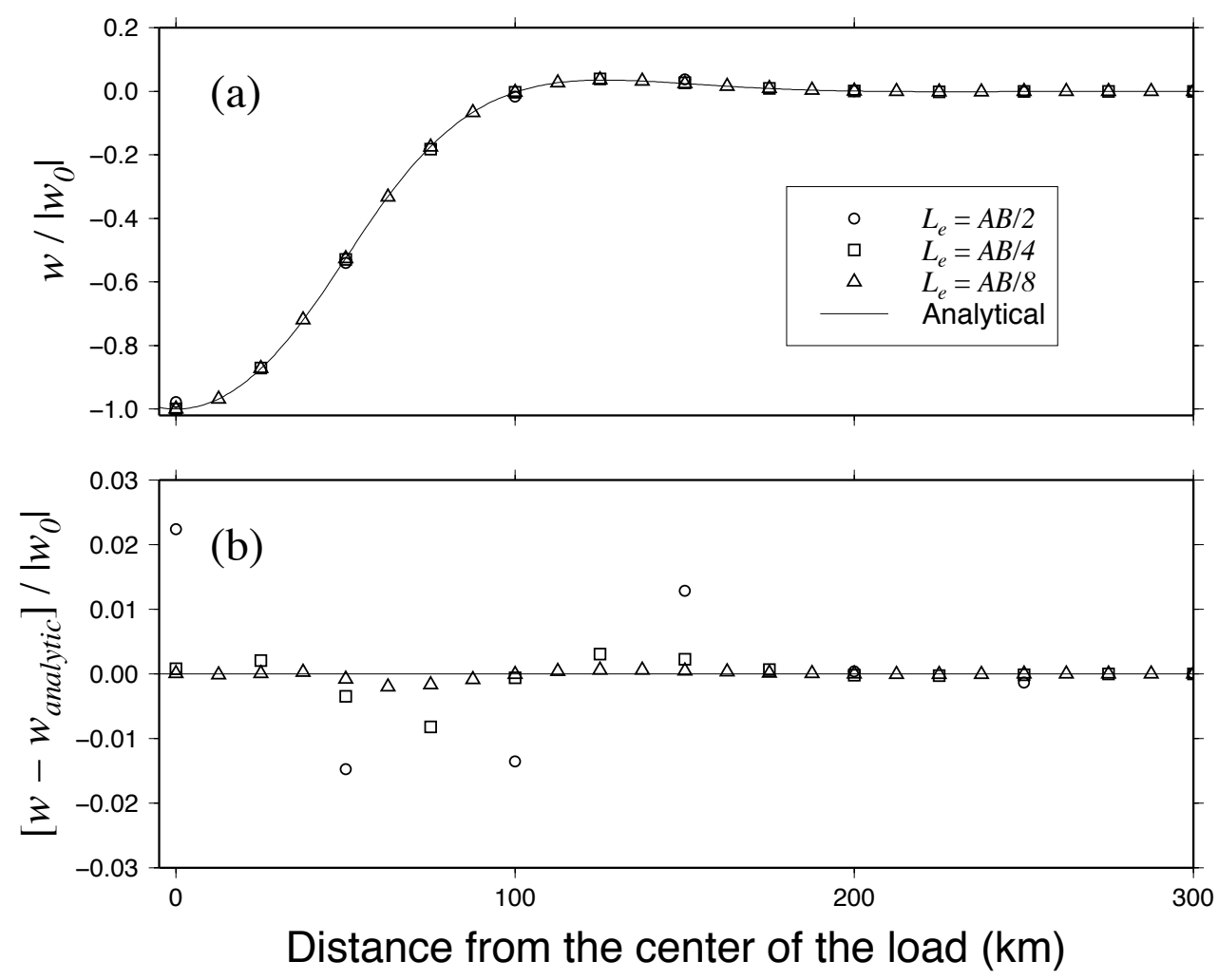

Figure 2.5: (a) Comparison of the analytical solution with the numerical ones for the problem of an uniformly load applied over an infinite plate. (b) Difference between numerical and analytical solution. All the curves are divided by the modulus of the exact deflection $\left|w_{0}\right|$ under the center of the load.

As a second example it is considered the case of horizontal variation of flexural rigidity. van Wees and Cloetingh (1994) and Stewart and Watts (1997) presented numerical solutions using the finite difference method for the problem of flexure of elastic plates with spatial variation of flexural rigidity. They showed the importance of considering the lateral variation of rigidity to appropriately describe the flexure of the lithosphere. However, these authors did not validate their codes comparing the results with analytical solutions that take into account variable flexural rigidity.

To validate the finite element code used in this thesis, the case of an infinite plate 


\begin{tabular}{llr} 
Parameter & Definition & Value \\
\hline$T_{e 1}$ & Effective elastic thickness for $x \geq 0$ & $10 \mathrm{~km}$ \\
$T_{e 2}$ & Effective elastic thickness for $x<0$ & $3 \mathrm{~km}$ \\
$V_{0}$ & Line load & $1.0 \times 10^{13} \mathrm{~N} / \mathrm{m}$
\end{tabular}

Table 2.2 - Parameters for the problem of variable flexural rigidity.

composed of two flexural rigidities is tested:

$$
\begin{aligned}
& \text { for } x \geq 0, D=D_{1} \\
& \text { for } x<0, D=D_{2}
\end{aligned}
$$

floating on a substratum of density $\rho_{m}$. At $x=0$ the plate is under a line load $V_{0}$ (Figure 2.6). The analytical solution for this problem is presented in the Appendix A and the physical parameters of the problem are presented in Table 2.2.

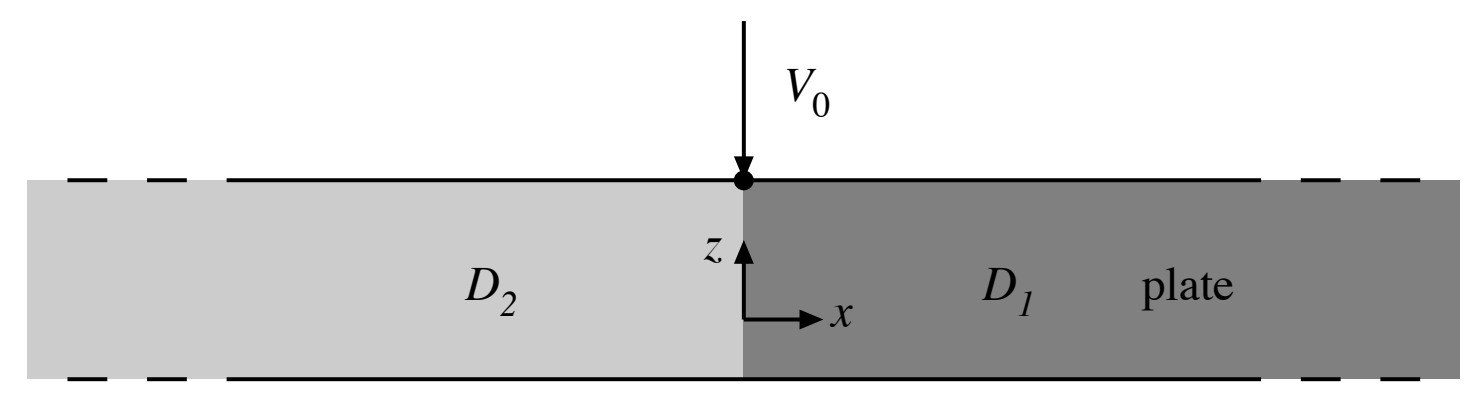

Figure 2.6: A scheme of the problem of an infinite elastic plate with two different rigidities $D_{1}$ and $D_{2}$ under a line load $V_{0}$.

The comparison between the analytical and numerical solutions for the problem of variable flexural rigidity is presented in Figure 2.7. As in the previous example, the numerical solutions for the flexure of a plate with lateral variation of $D$ converge to the exact solution (Figure 2.7b). But in the second example the magnitude of the errors is larger than in the previous one. For the coarsest mesh $\left(L_{e}=25 \mathrm{~km}\right)$, the difference between the numerical and analytical solutions reaches up to $16.8 \%$ of $w_{0}$, the exact deflection under the line load. For the finest mesh $\left(L_{e}=6.25 \mathrm{~km}\right)$ the maximum error is smaller than $1.1 \%$ of $w_{0}$. 

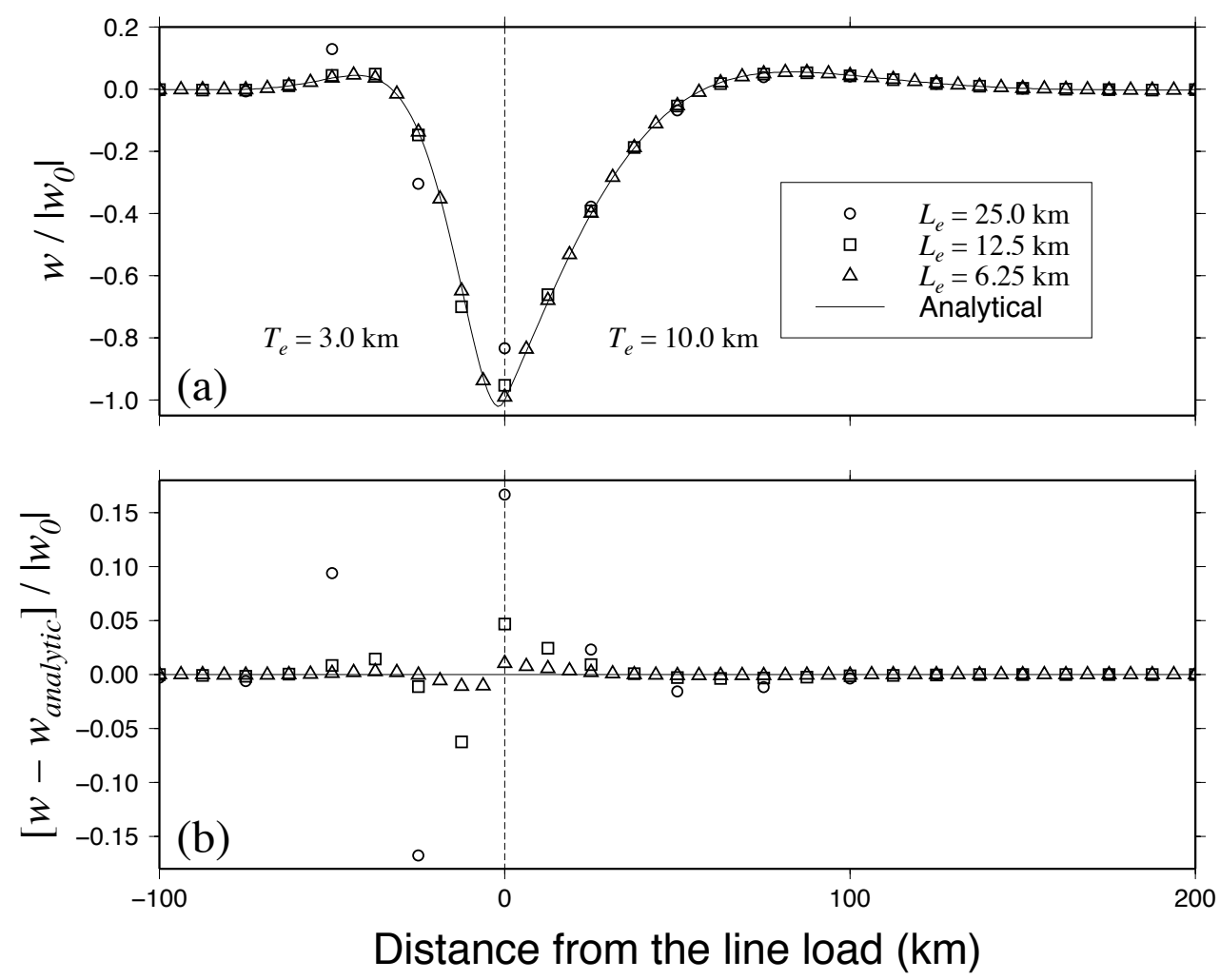

Figure 2.7: (a) Comparison of the analytical solution with the numerical ones for the problem of a line load applied over an infinite plate with two different flexural rigidities. The vertical dashed line marks the change of the flexural rigidity. (b) Difference between numerical and analytical solutions. All the curves are divided by the modulus of the exact deflection $\left|w_{0}\right|$ under the line load.

There are two reasons for the increase of the error in this second example: Firstly, it is known that for the same finite element mesh and using the shape functions derived by Specht (1988), the convergence to the analytical solution occurs faster for distributed loads than concentrated ones (see Zienkiewicz and Taylor, 2000a, section 4.8). Secondly, observe that the largest discrepancy occurs to the left of the line load, where the flexural rigidity is low. For a finite element mesh with constant element size $L_{e}$, it would be expected that the error must be larger in the portions of the plate where it is less rigid, because the wavelength of the deflection in these regions is shorter than in other ones. The characteristic wavelength of the plate can be calculated through the flexural parameter $\alpha$ 
defined as

$$
\alpha=\left[\frac{4 D}{\rho_{m} g}\right] .
$$

For $T_{e}=3 \mathrm{~km}$, the flexural parameter is $\alpha \approx 13.1 \mathrm{~km}$, which is nearly half of $L_{e}$ of the coarsest mesh of the second example. Therefore, if $L_{e}$ is much larger than the characteristic wavelength of the plate, the numerical solution cannot appropriately describe the real deflection.
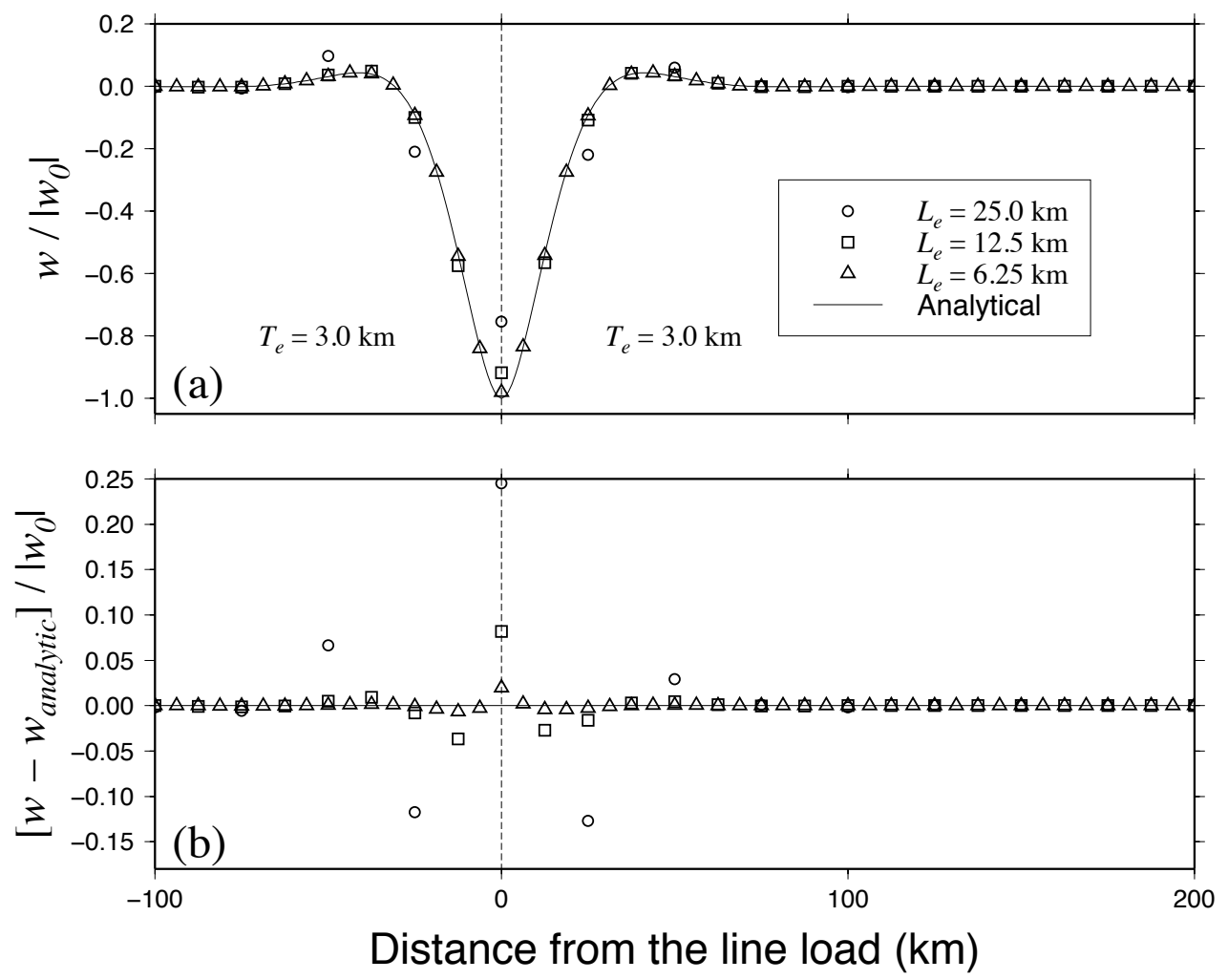

Figure 2.8: (a) Comparison of the analytical solution with the numerical ones for the problem of a line load applied over an infinite plate with constant flexural rigidity. (b) Difference between numerical and analytical solution. All the curves are divided by the modulus of the exact deflection $\left|w_{0}\right|$ under the line load.

To prove that an increase of the error in the second example is due to the two reasons previously explained and not due to an abrupt transition of rigidity, the same problem of the line load but with constant $T_{e}=3 \mathrm{~km}$ (Figure 2.8) is presented.

By comparing Figures 2.7b and 2.8b, it can be observed that the errors are of the same order, implying that the abrupt variation of flexural rigidity did not introduce expressive 
errors in the numerical solution. This shows that the proposed finite element model to study the flexure of lithospheric plates is robust to incorporate lateral variation of rigidity. With the appropriate choice of the finite element size $L_{e}$, depending on the flexural rigidity of the plate, provides accurate solutions for the problem of bending of thin elastic plates. 


\title{
Chapter 3
}

\section{Thermal model}

\author{
Earth's heat engine works in ways which \\ still elude us after many years of research, \\ both on the fundamental physical aspects of convection \\ in the mantle and on securing new and precise observations.
} (Jaupart et al., 2007)

\subsection{Introduction}

The thermal structure of the crust and mantle is a key aspect to understand the mechanical behavior of the Earth in different tectonic settings. As pointed out in the beginning of the previous chapter, the temperature is one of the physical parameters that controls the rheology of the lithosphere. Actually, laboratorial experiments and theoretical studies show that the temperature is one of the most important physical parameter controlling the rheology of solids (Turcotte and Schubert, 1982).

Besides the rheological aspect, the variation in the thermal structure of the lithosphere leads to vertical movements of the surface due to thermal contraction or expansion of the lithosphere (e.g. Parsons and Sclater, 1977; McKenzie, 1978). Therefore the evolution of the thermal structure of the lithosphere influences the topography and bathymetry and, consequently, the surface processes through the geological time.

The variation in the thermal structure of the lithosphere occurs by heat transfer and there are three mechanisms for the transport of heat: thermal diffusion, advection and radiation. Thermal diffusion occurs by transfer of kinetic energy through collision of adjacent particles that compose the material, without mass transport. This kind of heat transport 
is only possible when there is a spatial variation of the temperature in the medium. Unlike the thermal diffusion, the advection is related to the transport of mass, i.e. the movement of the particles carries the heat to another place. The third way to transport heat, the electromagnetic radiation, is important only in small scale due to the absorption of this energy by the adjacent rocks and therefore can be treated as part of the thermal diffusion. This radiative transport probably contributes as a minor component of the thermal diffusion because the mean free path of photons in the crust and mantle is very small (Ricard, 2007). Therefore the transport of heat in the interior of the Earth can be described through the advection and the thermal diffusion.

In the following sections, the heat transfer equation is presented as well as its numerical treatment through the finite element method.

\subsection{Heat transfer equation and its numerical solution}

To study the evolution of the temperature in the interior of the crust and mantle during and after tectonism, the transient, three dimensional heat transfer equation is considered (Carslaw and Jaeger, 1959)

$$
\rho c\left(\frac{\partial T}{\partial t}+\mathbf{v} \cdot \nabla T\right)=\nabla^{\mathrm{T}}\left(k_{T} \nabla T\right)+\rho A_{r}
$$

where $T$ is temperature, $t$ is the time dimension, $\rho$ is density, $c$ is the specific heat capacity, $k_{T}$ is conductivity, $\mathbf{v}=\left(u_{a d v}, v_{a d v}, w_{a d v}\right)$ is the advection velocity, $A_{r}$ is the radioactive production and $\nabla=\left[\frac{\partial}{\partial x}, \frac{\partial}{\partial y}, \frac{\partial}{\partial z}\right]^{\mathrm{T}}$. Note that $\mathrm{T}$ indicates the transpose of a matrix while $T$ is the temperature. In this equation, the advection velocity $\mathbf{v}$ describes the velocity of rock particles in the interior of crust and mantle.

In equation 3.1, the first term represents the local variation of the temperature and the second is the advective term. The two terms on the right side of the equation are the diffusive term and the source term, respectively.

Assume that equation 3.1 is valid in the domain $\Omega_{V}$ with the boundary $\Gamma_{V}$. The boundary conditions are

$$
\left(k_{T} \nabla T\right)^{\mathrm{T}} \mathbf{n}_{V}+\bar{q}_{H}=0 \quad \text { on } \Gamma_{V q}
$$

and

$$
T=\bar{T} \quad \text { on } \Gamma_{V T}
$$


where

$$
\Gamma_{V}=\overline{\Gamma_{V T} \cup \Gamma_{V q}}
$$

and

$$
\emptyset=\Gamma_{V T} \cap \Gamma_{V q}
$$

The superposed bar in equation 3.4 represents the set closure and $\emptyset$ in equation 3.5 is the empty set.

The equation 3.2 is the boundary condition that represents the prescribed heat flow $\bar{q}_{H}$ on $\Gamma_{V q}$, where $\mathbf{n}_{V}$ is the unit vector normal to $\Gamma_{V}$ and pointing outward of $\Omega_{V}$. The equation 3.3 is the boundary condition imposing the temperature $\bar{T}$ on $\Gamma_{V T}$.

The variational formulation for equation 3.1 with the boundary condition 3.2 is (see Zienkiewicz and Taylor, 2000b, chapter 3)

$$
\begin{array}{r}
\int_{\Omega_{V}} v_{w}\left[\rho c\left(\frac{\partial T}{\partial t}+\mathbf{v} \cdot \nabla T\right)-\nabla^{\mathrm{T}}\left(k_{T} \nabla T\right)-\rho A_{r}\right] d \Omega_{V}+ \\
+\int_{\Gamma_{V q}} v_{w}\left[\left(k_{T} \nabla T\right)^{\mathrm{T}} \mathbf{n}_{V}+\bar{q}_{H}\right] d \Gamma_{V}=0
\end{array}
$$

where $v_{w}$ is a scalar function. The boundary condition of equation 3.3 is automatically satisfied by the choice of $T$ on $\Gamma_{V T}$.

The diffusive term in equation 3.6 is integrated by parts

$$
-\int_{\Omega_{V}} v_{w}\left[\nabla^{\mathrm{T}}\left(k_{T} \nabla T\right)\right] d \Omega_{V}=\int_{\Omega_{V}} \nabla^{\mathrm{T}} v_{w} k_{T} \nabla T d \Omega_{V}-\int_{\Gamma_{V}} v_{w}\left(k_{T} \nabla T\right)^{\mathrm{T}} \mathbf{n}_{V} d \Gamma_{V}
$$

and equation 3.6 becomes

$$
\begin{aligned}
\int_{\Omega_{V}} v_{w} \rho c & \left(\frac{\partial T}{\partial t}+\mathbf{v} \cdot \nabla T\right)+\nabla^{\mathrm{T}} v_{w} k_{T} \nabla T-v_{w} \rho A_{r} d \Omega_{V}+ \\
& +\int_{\Gamma_{V q}} v_{w} \bar{q}_{H} d \Gamma_{V}-\int_{\Gamma_{V T}} v_{w}\left(k_{T} \nabla T\right)^{\mathrm{T}} \mathbf{n}_{V} d \Gamma_{V}=0 .
\end{aligned}
$$

As the temperature is specified on $\Gamma_{V T}$ (equation 3.3), the last term in equation 3.7 is omitted by restricting the choice of $v_{w}$ to functions which give $v_{w}=0$ on $\Gamma_{V T}$. If $\bar{q}_{H}=0$ on $\Gamma_{V q}$, this means that the normal gradient of temperature is zero

$$
\frac{\partial T}{\partial n_{V}}=(\nabla T)^{\mathrm{T}} \mathbf{n}_{V}=0 \quad \text { on } \Gamma_{V q}
$$

and the integration on $\Gamma_{V q}$ in equation 3.7 is zero. Therefore, under these conditions, the equation 3.7 can be simplified as

$$
\int_{\Omega_{V}} v_{w} \rho c\left(\frac{\partial T}{\partial t}+\mathbf{v} \cdot \nabla T\right)+\nabla^{\mathrm{T}} v_{w} k_{T} \nabla T-v_{w} \rho A_{r} d \Omega_{V}=0
$$


The domain $\Omega_{V}$ is subdivided into elements $\Omega_{V}^{e}(e=1, \ldots, m)$, where $m$ is the number of elements. These $m$ elements are interconnected by $n$ nodes. If $T$ and $\frac{\partial T}{\partial t}$ are approximated by

$$
T \approx \tilde{T}=\sum_{i=1}^{n} N_{V i} a_{T i}=\mathbf{N}_{V} \mathbf{a}_{T}
$$

and

$$
\frac{\partial T}{\partial t} \equiv \dot{T} \approx \mathbf{N}_{V} \dot{\mathbf{a}}_{T}
$$

where $\mathbf{N}_{V}=\mathbf{N}_{V}(x, y, z)$ is a row vector containing the shape functions and $\mathbf{a}_{T}=\mathbf{a}_{T}(t)$ is a column vector with unknown parameters, the equation 3.8 becomes

$$
\int_{\Omega_{V}} v_{w} \rho c\left(\mathbf{N}_{V} \dot{\mathbf{a}}_{T}+\mathbf{v} \cdot \mathbf{B}_{V} \mathbf{a}_{T}\right)+\nabla^{\mathrm{T}} v_{w} k_{T} \mathbf{B}_{V} \mathbf{a}_{T}-v_{w} \rho A_{r} d \Omega_{V}=0,
$$

where $\mathbf{B}_{V} \equiv \nabla \mathbf{N}_{V}$

Replacing the function $v_{w}$ by $\delta \mathbf{a}_{T}^{\mathrm{T}} \mathbf{N}_{V}^{\mathrm{T}}$ in equation 3.9 , where $\delta \mathbf{a}_{T}$ is a column vector with arbitrary parameters, results in the following equation:

$$
\delta \mathbf{a}_{T}^{\mathrm{T}} \int_{\Omega_{V}} \mathbf{N}_{V}^{\mathrm{T}} \rho c\left(\mathbf{N}_{V} \dot{\mathbf{a}}_{T}+\mathbf{v} \cdot \mathbf{B}_{V} \mathbf{a}_{T}\right)+\mathbf{B}_{V}^{\mathrm{T}} k_{T} \mathbf{B}_{V} \mathbf{a}_{T}-\mathbf{N}_{V}^{\mathrm{T}} \rho A_{r} d \Omega_{V}=0 .
$$

Since $\delta \mathbf{a}_{T}$ is arbitrary, the equation 3.10 leads to a set of equations for the parameters $\mathbf{a}_{T}$ and $\dot{\mathbf{a}}_{T}$

$$
\begin{gathered}
\int_{\Omega_{V}} \mathbf{N}_{V}^{\mathrm{T}} \rho c\left(\mathbf{N}_{V} \dot{\mathbf{a}}_{T}+\mathbf{v} \cdot \mathbf{B}_{V} \mathbf{a}_{T}\right)+\mathbf{B}_{V}^{\mathrm{T}} k_{T} \mathbf{B}_{V} \mathbf{a}_{T}-\mathbf{N}_{V}^{\mathrm{T}} \rho A_{r} d \Omega_{V}=0 \\
\int_{\Omega_{V}} \mathbf{N}_{V}^{\mathrm{T}} \rho c \mathbf{N}_{V} d \Omega_{V} \dot{\mathbf{a}}_{T}+\int_{\Omega_{V}}\left(\mathbf{N}_{V}^{\mathrm{T}} \rho c \mathbf{v} \cdot \mathbf{B}_{V}+\mathbf{B}_{V}^{\mathrm{T}} k_{T} \mathbf{B}_{V}\right) d \Omega_{V} \mathbf{a}_{T}=\int_{\Omega_{V}} \mathbf{N}_{V}^{\mathrm{T}} \rho A_{r} d \Omega_{V} \\
\mathbf{M} \dot{\mathbf{a}}_{T}+\left(\mathbf{K}_{a}+\mathbf{K}_{c}\right) \mathbf{a}_{T}=\mathbf{F}
\end{gathered}
$$

where

$$
\begin{aligned}
\mathbf{M} & =\int_{\Omega_{V}} \mathbf{N}_{V}^{\mathrm{T}} \rho c \mathbf{N}_{V} d \Omega_{V} \\
\mathbf{K}_{a} & =\int_{\Omega_{V}} \mathbf{N}_{V}^{\mathrm{T}} \rho c \mathbf{v} \cdot \mathbf{B}_{V} d \Omega_{V} \\
\mathbf{K}_{c} & =\int_{\Omega_{V}} \mathbf{B}_{V}^{\mathrm{T}} k_{T} \mathbf{B}_{V} d \Omega_{V} \\
\mathbf{F} & =\int_{\Omega_{V}} \mathbf{N}_{V}^{\mathrm{T}} \rho A_{r} d \Omega_{V}
\end{aligned}
$$


Unlike $\mathbf{M}$ and $\mathbf{K}_{d}$, the matrix $\mathbf{K}_{a}$, related to the advection velocity $\mathbf{v}$, is non-symmetric. Due to this asymmetry, when the advection is the dominant process to transport heat, the accuracy of the numerical solution of equation 3.11 deteriorates and, in some cases, becomes unstable (see Zienkiewicz and Taylor, 2000c, chapter 2).

To improve the accuracy and stability of the solution, the streamline upwind PetrovGalerkin process is applied (Hughes and Brooks, 1979, 1982; Zienkiewicz and Taylor, 2000c) and the equation 3.11 is replaced by

$$
\begin{gathered}
\mathbf{M} \dot{\mathbf{a}}_{T}+\left(\mathbf{K}_{a}^{*}+\mathbf{K}_{c}\right) \mathbf{a}_{T}=\mathbf{F} \\
\mathbf{M} \dot{\mathbf{a}}_{T}+\mathbf{K}_{T} \mathbf{a}_{T}=\mathbf{F}
\end{gathered}
$$

where

$$
\begin{gathered}
\mathbf{K}_{a}^{*}=\int_{\Omega_{V}} \mathbf{N}_{V}^{* \mathrm{~T}} \rho c \mathbf{v} \cdot \mathbf{B}_{V} d \Omega_{V} \\
N_{V i}^{*}=N_{V i}+\frac{\alpha_{\mathrm{opt}} h^{e} \mathbf{v} \cdot \nabla N_{V i}}{2|\mathbf{v}|} \\
\alpha_{\mathrm{opt}}=\operatorname{coth} P e-\frac{1}{P e} \\
P e=\frac{|\mathbf{v}| h^{e}}{2 k_{T}} .
\end{gathered}
$$

$h^{e}$ is the characteristic element size in the direction of the advection velocity $\mathbf{v}$ and will be defined in the next section.

The discretization in time is done following the implicit scheme adopted by Braun (2003):

$$
\frac{\mathbf{a}_{T}(t+\Delta t)-\mathbf{a}_{T}(t)}{\Delta t}=\theta \dot{\mathbf{a}}_{T}(t+\Delta t)+(1-\theta) \dot{\mathbf{a}}_{T}(t)
$$

where $\theta$ is a weighting parameter adopted here equal to 0.5 . Multiplying both sides by $\mathbf{M}(t+\Delta t)$, the equation 3.18 becomes

$$
\mathbf{M}(t+\Delta t) \frac{\mathbf{a}_{T}(t+\Delta t)-\mathbf{a}_{T}(t)}{\Delta t}=\theta \mathbf{M}(t+\Delta t) \dot{\mathbf{a}}_{T}(t+\Delta t)+(1-\theta) \mathbf{M}(t+\Delta t) \dot{\mathbf{a}}_{T}(t) .
$$

Assuming that $\mathbf{M}(t+\Delta t) \approx \mathbf{M}(t)$ and using the equation 3.16, results in

$$
\begin{array}{r}
\mathbf{M}(t+\Delta t) \frac{\mathbf{a}_{T}(t+\Delta t)-\mathbf{a}_{T}(t)}{\Delta t}=\theta[\mathbf{F}(t+\Delta t) \\
\left.-\mathbf{K}_{T}(t+\Delta t) \mathbf{a}_{T}(t+\Delta t)\right]+ \\
+(1-\theta)\left[\mathbf{F}(t)-\mathbf{K}_{T}(t) \mathbf{a}_{T}(t)\right] .
\end{array}
$$


Rearranging the terms, the following equation is obtained

$$
\begin{aligned}
& {\left[\mathbf{M}(t+\Delta t)+\Delta t \theta \mathbf{K}_{T}(t+\Delta t)\right] \mathbf{a}_{T}(t+\Delta t)=} \\
& \quad=\left[\mathbf{M}(t+\Delta t)-\Delta t(1-\theta) \mathbf{K}_{T}(t)\right] \mathbf{a}_{T}(t)+\Delta t[\theta \mathbf{F}(t+\Delta t)+(1-\theta) \mathbf{F}(t)]
\end{aligned}
$$

\subsection{The choice of the finite element}

The linear tetrahedron is the finite element used in the three dimensional heat transfer problem. Therefore, the domain $\Omega_{V}$ is subdivided into $m$ tetrahedral elements, interconnected by $n$ nodes. As previously presented, the function $\tilde{T}=\mathbf{N}_{V} \mathbf{a}_{T}$ is composed of

$$
\begin{gathered}
\mathbf{a}_{T}=\left[\begin{array}{lll}
a_{T 1}, & a_{T 2}, & a_{T 3}, \cdots, \\
\mathbf{N}_{V} & =\left[\begin{array}{lll}
N_{V 1}, & N_{V 2}, & N_{V 3}, \cdots,
\end{array}\right]^{\mathrm{T}}
\end{array}\right] .
\end{gathered}
$$

Unlike the flexural model, in the thermal model each node has only one degree of freedom: the temperature.

For a certain point $\mathbf{x}_{p}=\left(x_{p}, y_{p}, z_{p}\right)$ inside the element $e$, the function $N_{V i}$ is

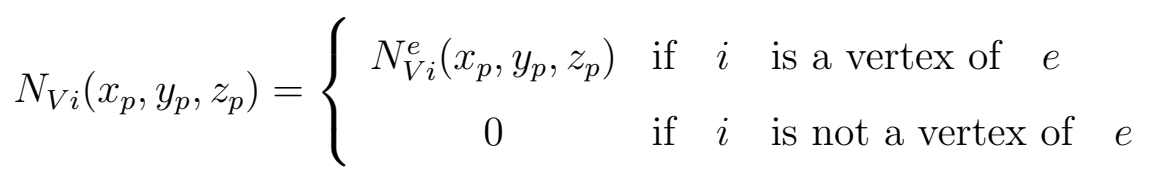

and the shape functions for the element $e$ with nodes $i, j, k$ and $l$ are

$$
\begin{array}{ll}
N_{V i}^{e}=L_{V 1}\left(\mathbf{x}_{p}\right)=\frac{\text { Volume } p j k l}{\text { Volume } i j k l}, & N_{V j}^{e}=L_{V 2}\left(\mathbf{x}_{p}\right)=\frac{\text { Volume } i p k l}{\text { Volume } i j k l}, \\
N_{V k}^{e}=L_{V 3}\left(\mathbf{x}_{p}\right)=\frac{\text { Volume } i j p l}{\text { Volume } i j k l}, & N_{V l}^{e}=L_{V 4}\left(\mathbf{x}_{p}\right)=\frac{\text { Volume } i j k p}{\text { Volume } i j k l}
\end{array}
$$

where $L_{V}$ 's are the local coordinates for the tetrahedral element and Volume $i j k l$ represents the volume of the tetrahedron formed by the nodes $i, j, k$ and $l$, and so on. The denominator represents the volume of the tetrahedral element and the numerator represents the volume of the sub-tetrahedra composed of three nodes of the tetrahedral element plus the internal node $p$ (Figure 3.1). Since the sum of the volumes of the four sub-tetrahedra is equal to the total volume of the tetrahedral element, the sum of the shape functions for an element $e$ is:

$$
L_{V 1}\left(\mathbf{x}_{p}\right)+L_{V 2}\left(\mathbf{x}_{p}\right)+L_{V 3}\left(\mathbf{x}_{p}\right)+L_{V 4}\left(\mathbf{x}_{p}\right)=1
$$




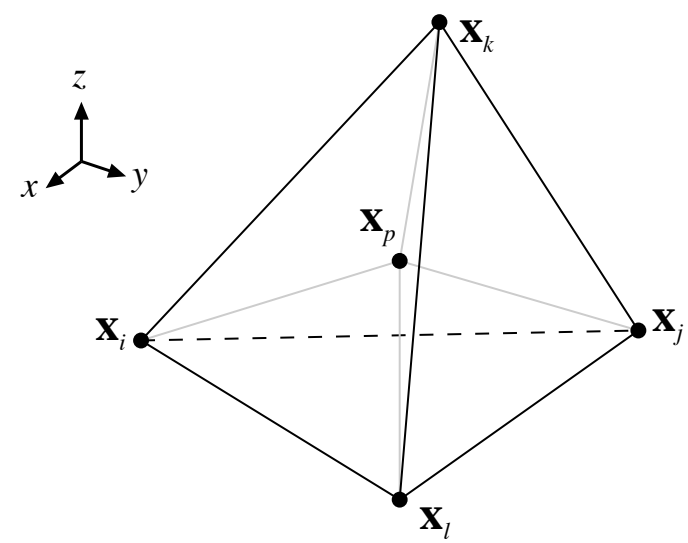

Figure 3.1: Scheme of a tetrahedral element with nodes $i, j, k$ and $l$. The gray lines represent the edges of four sub-tetrahedra formed by the internal node $p$ and other three nodes of the original tetrahedron.

The volume of the tetrahedral element can be calculated from the following equation:

$$
\text { Volume } i j k l=\triangle_{\text {tet }}^{e}=\frac{1}{6} \operatorname{det}\left[\begin{array}{cccc}
1 & x_{i} & y_{i} & z_{i} \\
1 & x_{j} & y_{j} & z_{j} \\
1 & x_{k} & y_{k} & z_{k} \\
1 & x_{l} & y_{l} & z_{l}
\end{array}\right]
$$

To obtain a positive value for the volume using the previous expression, the ordering of the nodes $i, j, k$ and $l$ must follow the right-hand rule as in Figure 3.1. In this rule the nodes $i, j$ and $k$ are numbered in an anti-clockwise manner when viewed from node $l$.

The local coordinates are written directly as functions of the coordinates of the element nodes and the position of the internal point of interest $p$ as

$$
\begin{aligned}
L_{V 1}\left(\mathbf{x}_{p}\right) & =\frac{a_{V i}+b_{V i} x_{p}+c_{V i} y_{p}+d_{V i} z_{p}}{6 \triangle_{t e t}^{e}} \\
L_{V 2}\left(\mathbf{x}_{p}\right) & =\frac{a_{V j}+b_{V j} x_{p}+c_{V j} y_{p}+d_{V j} z_{p}}{6 \triangle_{t e t}^{e}} \\
L_{V 3}\left(\mathbf{x}_{p}\right) & =\frac{a_{V k}+b_{V k} x_{p}+c_{V k} y_{p}+d_{V k} z_{p}}{6 \triangle_{t e t}^{e}} \\
L_{V 4}\left(\mathbf{x}_{p}\right) & =1-L_{V 1}\left(\mathbf{x}_{p}\right)-L_{V 2}\left(\mathbf{x}_{p}\right)-L_{V 3}\left(\mathbf{x}_{p}\right)
\end{aligned}
$$


where

$$
\begin{gathered}
a_{V i}=\operatorname{det}\left[\begin{array}{lll}
x_{j} & y_{j} & z_{j} \\
x_{k} & y_{k} & z_{k} \\
x_{l} & y_{l} & z_{l}
\end{array}\right], \quad b_{V i}=-\operatorname{det}\left[\begin{array}{ccc}
1 & y_{j} & z_{j} \\
1 & y_{k} & z_{k} \\
1 & y_{l} & z_{l}
\end{array}\right] \\
c_{V i}=-\operatorname{det}\left[\begin{array}{lll}
x_{j} & 1 & z_{j} \\
x_{k} & 1 & z_{k} \\
x_{l} & 1 & z_{l}
\end{array}\right], \quad d_{V i}=-\operatorname{det}\left[\begin{array}{lll}
x_{j} & y_{j} & 1 \\
x_{k} & y_{k} & 1 \\
x_{l} & y_{l} & 1
\end{array}\right]
\end{gathered}
$$

and the other parameters are defined by cyclic interchange of the subscript in the order $i$, $j, k$ and $l$.

To determine the matrices 3.14 and 3.17, the calculation of $\mathbf{B}_{V}=\nabla \mathbf{N}_{V}$ is necessary. This calculation can be done directly from the expressions for the local coordinates of equation 3.24:

$$
\begin{gathered}
{\left[\begin{array}{c}
\frac{\partial N_{V i}^{e}}{\partial x} \\
\frac{\partial N_{V i}^{e}}{\partial y} \\
\frac{\partial N_{V i}^{e}}{\partial z}
\end{array}\right]=\frac{1}{6 \triangle_{t e t}^{e}}\left[\begin{array}{l}
b_{V i} \\
c_{V i} \\
d_{V i}
\end{array}\right],\left[\begin{array}{c}
\frac{\partial N_{V j}^{e}}{\partial x} \\
\frac{\partial N_{V j}^{e}}{\partial y} \\
\frac{\partial N_{V j}^{e}}{\partial z}
\end{array}\right]=\frac{1}{6 \triangle_{t e t}^{e}}\left[\begin{array}{l}
b_{V j} \\
c_{V j} \\
d_{V j}
\end{array}\right],\left[\begin{array}{c}
\frac{\partial N_{V k}^{e}}{\partial x} \\
\frac{\partial N_{V k}^{e}}{\partial y} \\
\frac{\partial N_{V k}^{e}}{\partial z}
\end{array}\right]=\frac{1}{6 \triangle_{t e t}^{e}}\left[\begin{array}{l}
b_{V k} \\
c_{V k} \\
d_{V k}
\end{array}\right],} \\
{\left[\begin{array}{l}
\frac{\partial N_{V l}^{e}}{\partial x} \\
\frac{\partial N_{V l}^{e}}{\partial y} \\
\frac{\partial N_{V l}^{e}}{\partial z}
\end{array}\right]=\frac{1}{6 \triangle_{t e t}^{e}}\left[\begin{array}{l}
-b_{V i}-b_{V j}-b_{V k} \\
-c_{V i}-c_{V j}-c_{V k} \\
-d_{V i}-d_{V j}-d_{V k}
\end{array}\right]}
\end{gathered}
$$

Finally, the characteristic element size $h^{e}$ used in equation 3.16 to determine $\mathbf{K}_{a}^{*}$ is defined here as

$$
h^{e}=\max _{i^{\prime}=j, k, l}\left[\left(\mathbf{x}_{i}^{e}-\mathbf{x}_{i^{\prime}}^{e}\right) \cdot \frac{\mathbf{v}}{|\mathbf{v}|}\right] \frac{1}{2}-\min _{i^{\prime}=j, k, l}\left[\left(\mathbf{x}_{i}^{e}-\mathbf{x}_{i^{\prime}}^{e}\right) \cdot \frac{\mathbf{v}}{|\mathbf{v}|}\right] \frac{1}{2}
$$

where $\mathbf{x}_{i^{\prime}}^{e}=\left(x_{i^{\prime}}^{e}, y_{i^{\prime}}^{e}, z_{i^{\prime}}^{e}\right)$ for $i^{\prime}=i, j, k, l$ are the nodes of the tetrahedral element $e$.

\subsection{Construction of the linear system}

As in the flexural problem, the matrices $\mathbf{M}, \mathbf{K}_{a}^{*}, \mathbf{K}_{c}$ and $\mathbf{F}$ of equation 3.16 are constructed as the summation of $\overline{\mathbf{M}}^{e}, \overline{\mathbf{K}}_{a}^{* e}, \overline{\mathbf{K}}_{c}^{e}$ and $\overline{\mathbf{F}}^{e}$ over each element $e$ :

$$
\mathbf{M}=\sum_{e} \overline{\mathbf{M}}^{e}=\sum_{e} \int_{\Omega_{V}^{e}} \mathbf{N}_{V}^{\mathrm{T}} \rho c \mathbf{N}_{V} d \Omega_{V}
$$




$$
\begin{gathered}
\mathbf{K}_{a}^{*}=\sum_{e} \overline{\mathbf{K}}_{a}^{* e}=\sum_{e} \int_{\Omega_{V}^{e}} \mathbf{N}_{V}^{* \mathrm{~T}} \rho c \mathbf{v} \cdot \mathbf{B}_{V} d \Omega_{V} \\
\mathbf{K}_{c}=\sum_{e} \overline{\mathbf{K}}_{c}^{e}=\sum_{e} \int_{\Omega_{V}^{e}} \mathbf{B}_{V}^{\mathrm{T}} k_{T} \mathbf{B}_{V} d \Omega_{V} \\
\mathbf{F}=\sum_{e} \overline{\mathbf{F}}^{e}=\sum_{e} \int_{\Omega_{V}^{e}} \mathbf{N}_{V}^{\mathrm{T}} \rho A_{r} d \Omega_{V} .
\end{gathered}
$$

From equation 3.22 , it is possible to see that, for an element $e$, only 4 coefficients of $\mathbf{N}_{V}$ are non-zero, that are the 4 coefficients related to the 4 nodes of the element $e$. Thus, the column vector $\overline{\mathbf{F}}^{e}$ has 4 non-zero coefficients and the matrices $\overline{\mathbf{M}}^{e}, \overline{\mathbf{K}}_{a}^{* e}$ and $\overline{\mathbf{K}}_{c}^{e}$ have $4 \times 4=16$ non-zero coefficients.

To exemplify the construction of the linear system from the summation of the matrices in equations 3.27, Figure 3.2a illustrates the assemblage of 3 tetrahedral elements and 6 nodes. Figures 3.2c and d show the matrices and the column vector for each element and the resulting summation, indicating the non-zero coefficients, where $\mathbf{K}$ can represent $\mathbf{M}$, $\mathbf{K}_{a}^{*}$ or $\mathbf{K}_{c}$.

To calculate the integrals from equations 3.27 over each element, an useful formula is presented by Zienkiewicz and Taylor (2000b):

$$
\int_{\Omega_{V}^{e}} L_{V 1}^{a} L_{V 2}^{b} L_{V 3}^{c} L_{V 4}^{d} d \Omega_{V}^{e}=\frac{a ! b ! c ! d !}{(a+b+c+d+3) !} 6 \triangle_{t e t}^{e}
$$

\subsection{Comparison with analytical solutions}

To validate the numerical model to study the heat transport in the crust and mantle, the numerical solutions were compared with analytical ones. The first case is the McKenzie's model (McKenzie, 1978).

In this model, a portion of the lithosphere of length $a_{L}$ (Figure 3.3a) is suddenly stretched to a length $a_{L} \beta$, resulting in the upward movement of hot asthenosphere (Figure 3.3b). After this, the thermal perturbation is gradually dissipated by thermal diffusion, restoring the temperature profile previous to stretching (Figure 3.3c).

In this model, the advection and the radioactive production are neglected $(\mathbf{v}=\mathbf{0}$ and $\left.A_{r}=0\right)$. Moreover the temperature is dependent only on depth and time $(T=T(t, z))$. Assuming a constant thermal conductivity $k_{T}$, the equation 3.1 becomes

$$
\rho c \frac{\partial T}{\partial t}=k_{T} \frac{\partial^{2} T}{\partial z^{2}}
$$


(a)

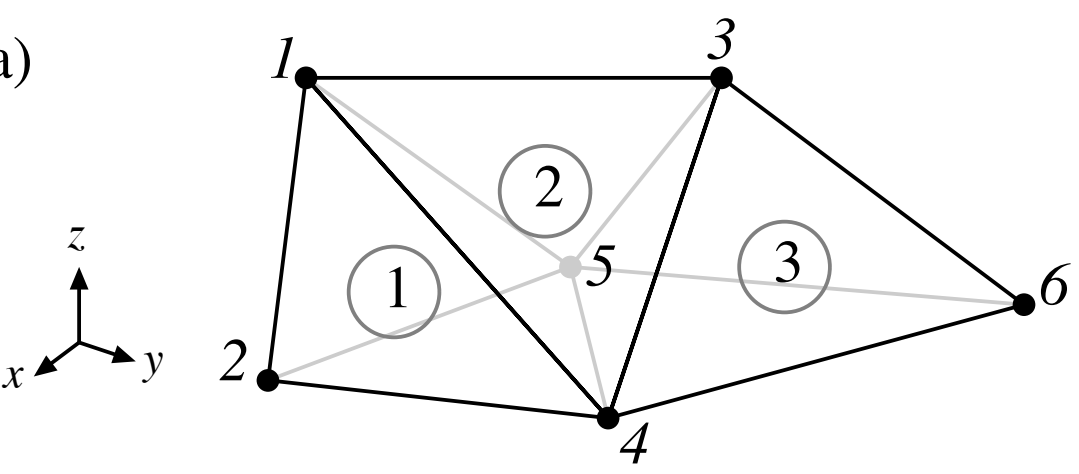

(b)

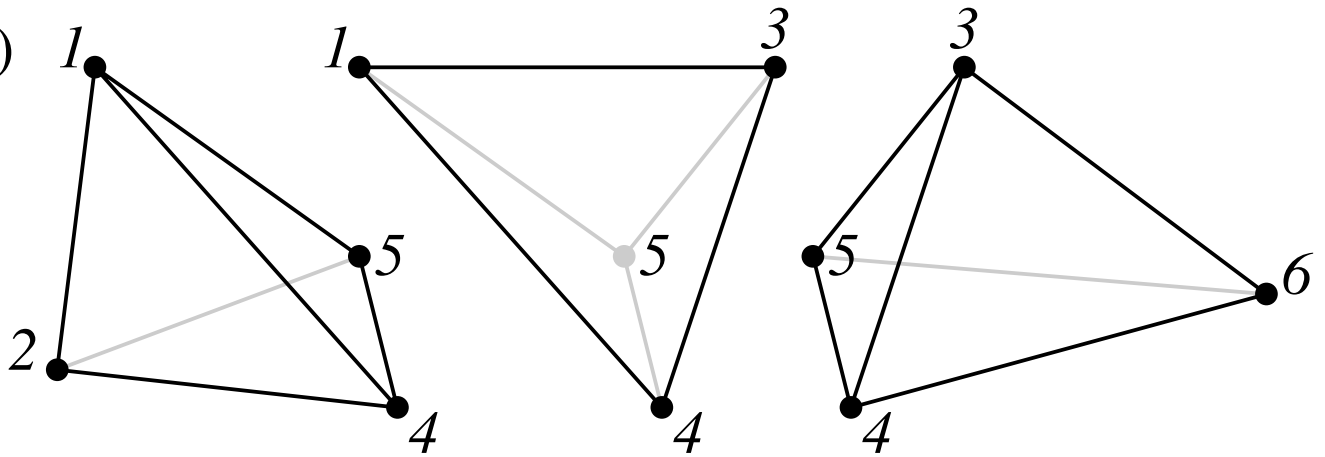

(c) 123456

123456

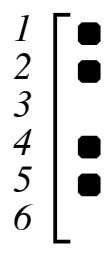

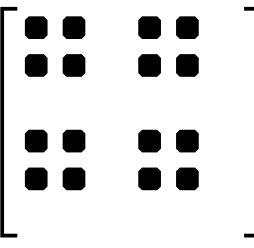

$\overline{\mathbf{K}}^{1}$ $+\left[\begin{array}{lll}0 & 000 \\ 0 & 000 \\ 0 & 000 \\ 0 & 000\end{array}\right]+[$

$\overline{\mathbf{K}}^{2}$

123456

$\begin{array}{llllll}1 & 2 & 3 & 4 & 6\end{array}$

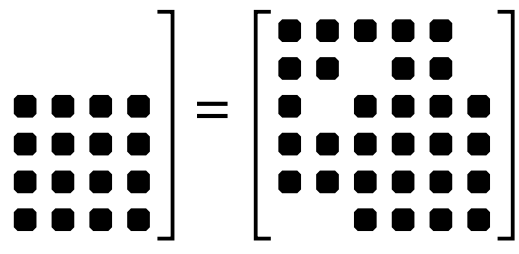

$\overline{\mathbf{K}}^{3}$

K

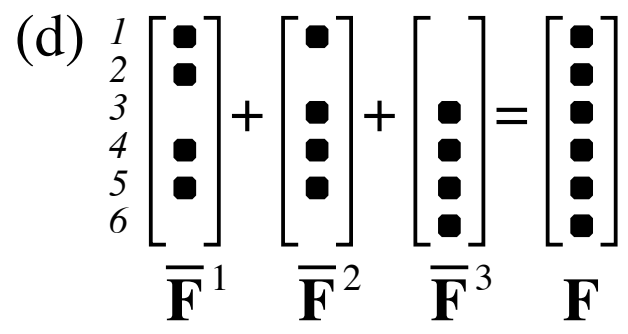

Nonzero coefficients

Figure 3.2: Illustration for the construction of the linear system to numerically solve the three dimension heat transfer problem. (a) Finite element mesh composed of 3 elements and 6 nodes. (b) Representation of each finite element. (c) Summation of the matrices $\overline{\mathbf{K}}^{e}$ to obtain $\mathbf{K}$, where $\mathbf{K}$ can represent $\mathbf{M}, \mathbf{K}_{a}^{*}$ or $\mathbf{K}_{c}$. (d) Summation of the column vector $\overline{\mathbf{F}}^{e}$ to obtain $\mathbf{F}$. 
(a) $t<0$
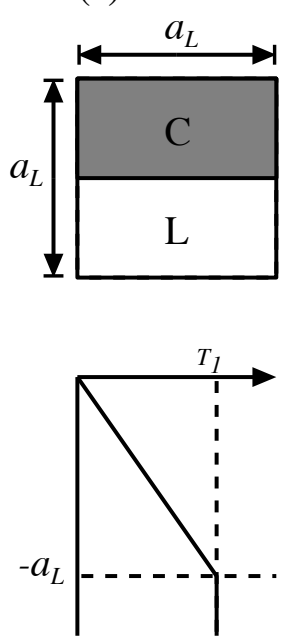

(b) $t=0$
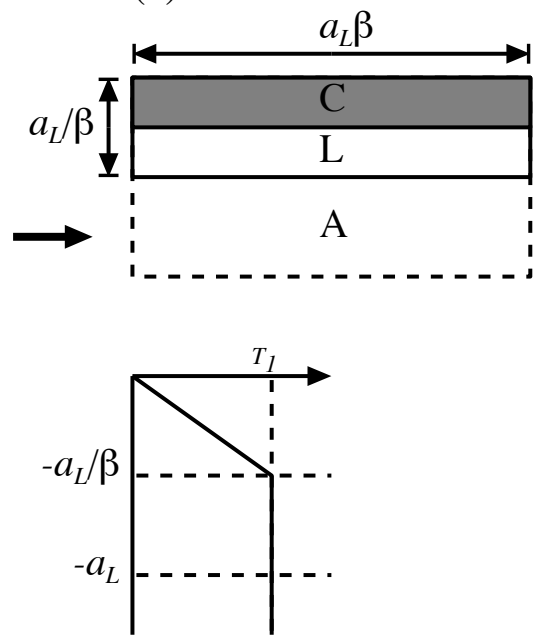

(c) $t \rightarrow \infty$
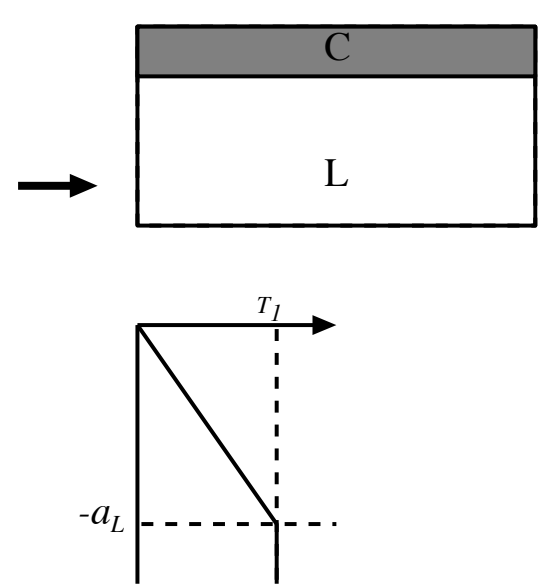

Figure 3.3: Scheme of the model for the thermal evolution of a stretched lithosphere (McKenzie, 1978). The upper figures show the geometrical configuration of the lithosphere and the graphs show the corresponding temperature profiles. (a) Initial state of the lithosphere previous to stretching. C represents crust and L represents lithospheric mantle. (b) Stretched lithosphere at $t=0$ showing the passive uplift of the asthenosphere, indicated as A. (c) Final state of the lithosphere, restoring the thermal profile previous to stretching.

Previous to extension, the temperature profile is in equilibrium, varying linearly from $T=T_{1}$ at the base of the lithosphere $\left(z=-a_{L}\right)$ to $T=0$ at the surface $(z=0)$ (Figure 3.3a). After the extension of the lithosphere, at $t=0$, the temperature profile is (see Figure 3.3b)

$$
\begin{gathered}
T=T_{1} \frac{-z}{a_{L} / \beta} \quad \text { for } \quad-a_{L} / \beta<z \leq 0 \\
T=T_{1} \text { for } \quad-a_{L}<z \leq-a_{L} / \beta
\end{gathered}
$$

The thermal evolution of the lithosphere since $t=0$ considers the temperature at $z=0$ and $z=-a_{L}$ constant at $T=0$ and $T=T_{1}$, respectively. The evolution of the temperature profile for $t>0$ is described by the following equation (see McKenzie, 1978).

$$
\frac{T}{T_{1}}=-\frac{z}{a_{L}}+\frac{2}{\pi} \sum_{n=0}^{\infty} \frac{-1}{n}\left[\frac{\beta}{n \pi} \sin \frac{n \pi}{\beta}\right] \times \exp \left(\frac{-n^{2} t}{\tau}\right) \sin \frac{n \pi z}{a_{L}}
$$

where

$$
\tau=\frac{a_{L}^{2}}{\pi^{2} \kappa}
$$


and $\kappa$ is the thermal diffusivity

$$
\kappa=\frac{k_{T}}{\rho c} .
$$

This expression for $T$ is slightly different from the equation presented by McKenzie (1978), because in the present work $z$ varies from $-a_{L}$ to 0 , instead of 0 to $a_{L}$ of the original paper.

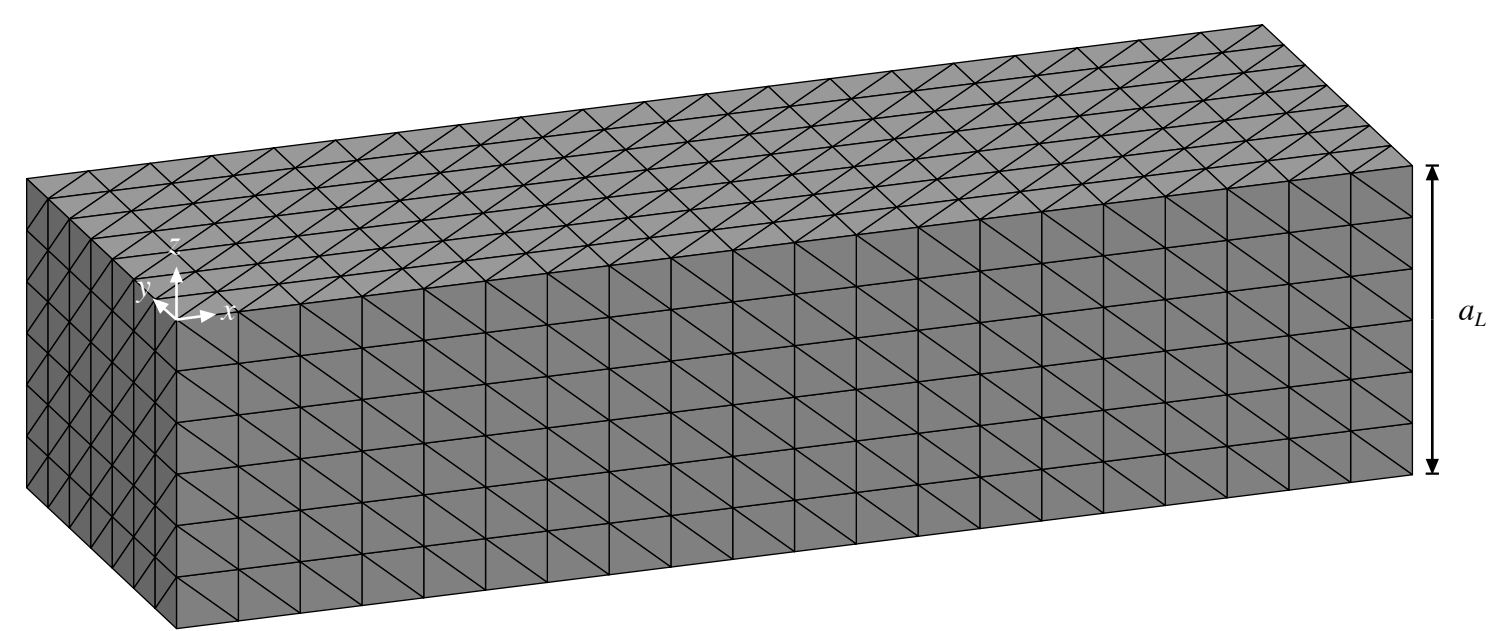

Figure 3.4: Representation of the finite element mesh composed of tetrahedra to study the thermal evolution of the lithosphere. $a_{L}$ represents the initial thickness of the lithosphere.

To numerically simulate McKenzie's model, a finite element mesh with tetrahedra was constructed, as shown in Figure 3.4. The domain $\Omega_{V}$ is a right-rectangular prism and the discretization in tetrahedra is done subdividing the domain into smaller prisms, then subdividing each prism into two wedges and each wedge into three tetrahedra (see Figure $3.5)$.

The temperature at the top and the bottom faces of the domain $\Omega_{V}$ are maintained constant throughout the simulation

$$
T=0 \quad \text { at } z=0, \quad T=T_{1} \quad \text { at } z=-a_{L}
$$

and the heat flux through the side faces are zero

$$
\frac{\partial T}{\partial n_{v}}=0 .
$$

The other physical parameters of the model are shown in Table 3.1. 


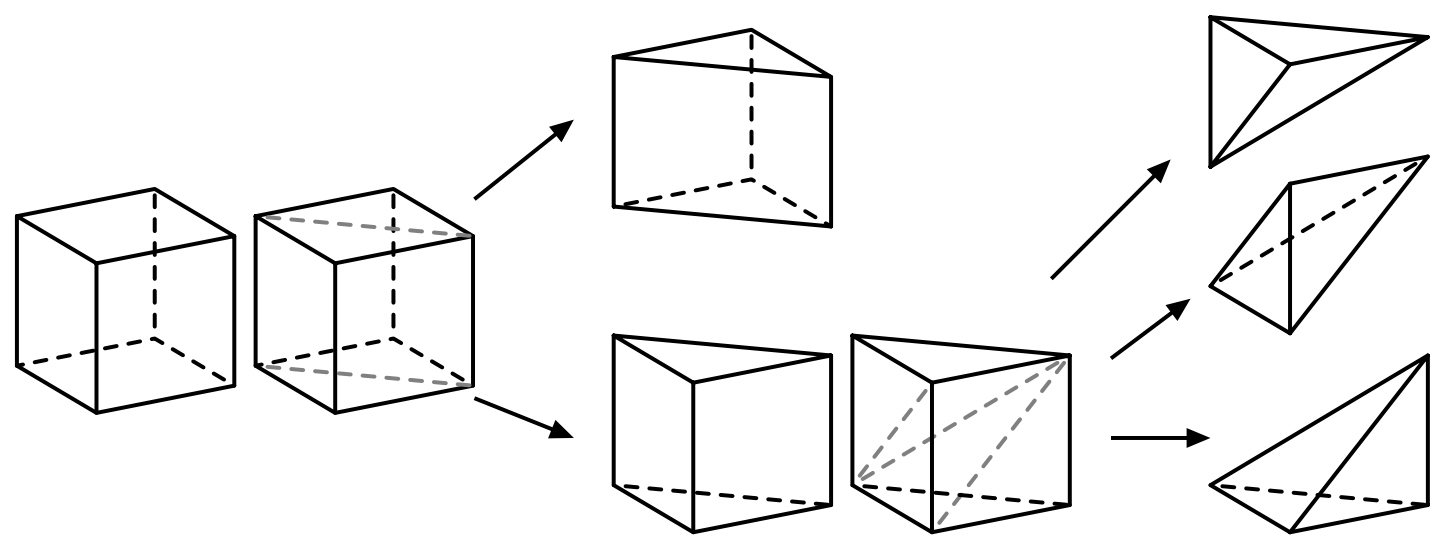

Figure 3.5: A systematic way to subdivide a right-rectangular prism into six tetrahedra. The prism is subdivided into two wedges, each one subdivided into three tetrahedra.

\begin{tabular}{llr} 
Parameter & Definition & Value \\
\hline$\kappa$ & Thermal diffusivity & $1 \times 10^{-6} \mathrm{~m}^{2} / \mathrm{s}$ \\
$\beta$ & Stretching factor & 2 \\
$a_{L}$ & Initial lithospheric thickness & $150 \mathrm{~km}$ \\
$T_{1}$ & Temperature at $z=-a_{L}$ & $1300^{\circ} \mathrm{C}$ \\
$\Delta t$ & Time step & $5 \times 10^{3}$ years
\end{tabular}

Table 3.1 - Parameters for the model of McKenzie (1978).

To check the convergence of the numerical solution toward the correct one with the refinement of the mesh, different models were tested with different number of element layers $n_{e l}$ in the $z$ direction. For example, the mesh of Figure 3.4 has 6 layers $\left(n_{e l}=6\right)$.

Figure 3.6 shows the numerical solutions and the analytical one at $t=10,30$ and 50 My. In this figure, the dashed lines show the steady-state configuration $(t \rightarrow \infty)$. All the numerical solutions compare well with the analytical one. Moreover, the increase in the number of layers $n_{e l}$ results in the convergence toward the analytical solution. The greatest differences between analytical and numerical solutions occur during the first stages of the simulation, when the rate of temperature variation is high.

The second example is the case of a steadily eroding lithosphere. The free surface at $z=0$ is eroded at a constant rate $w_{a d v}$. As a consequence the lithosphere moves upward 

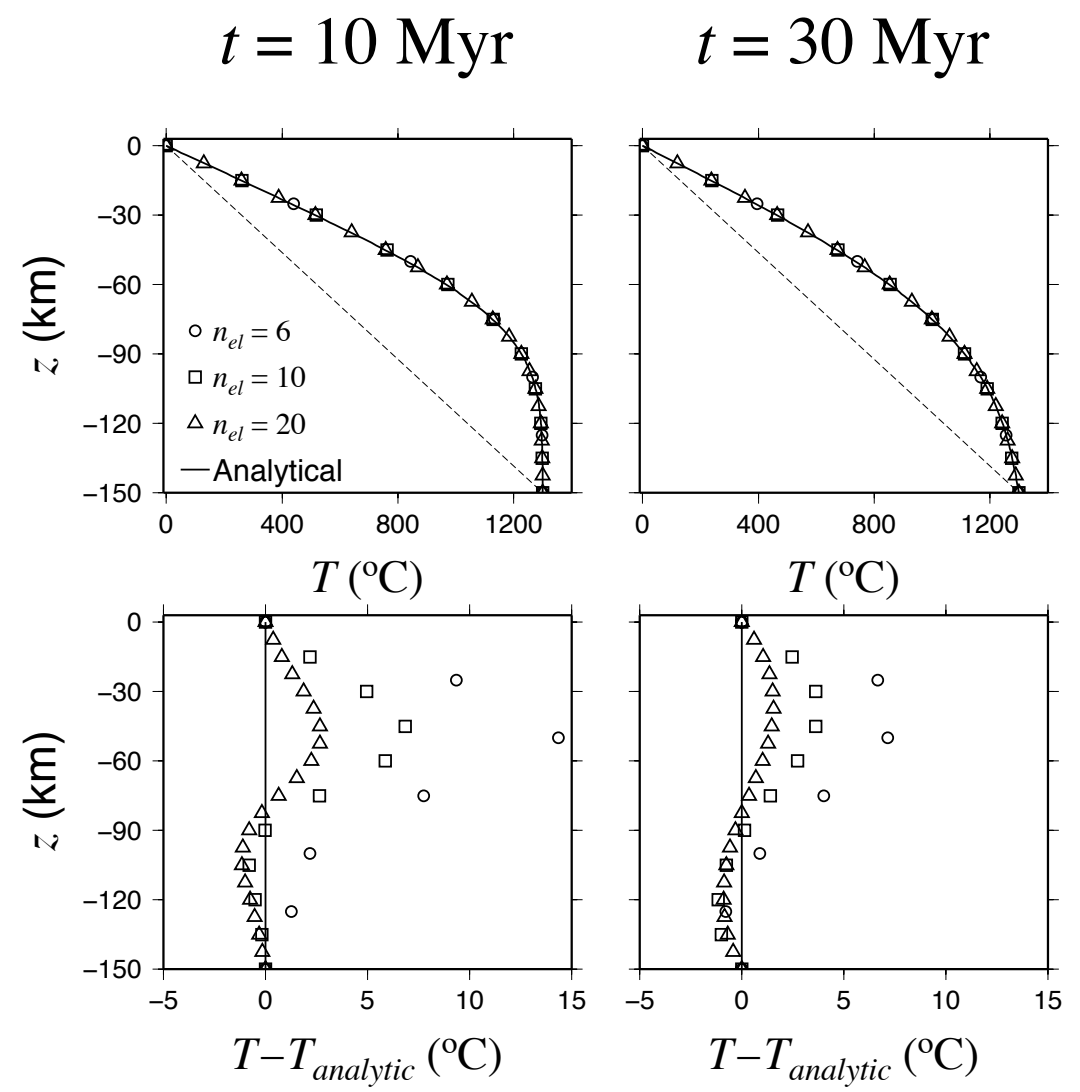

\section{$t=50 \mathrm{Myr}$}
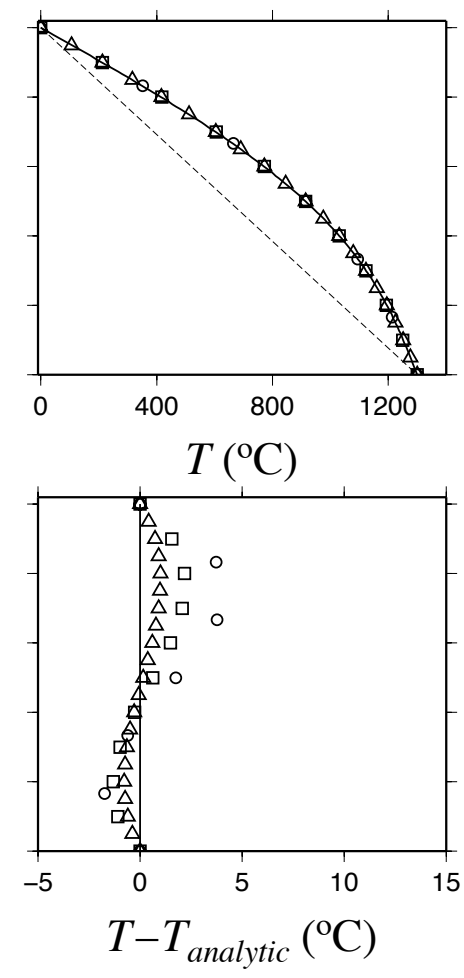

Figure 3.6: Comparison between analytical and numerical solutions for McKenzie's model. The upper graphics show the temperature profile at $t=10,30$ and $50 \mathrm{Myr}$. The dashed lines indicate the temperature profile for $t \rightarrow \infty$. The lower graphics show the difference between numerical and analytical solutions.

with a constant velocity $w_{a d v}$ relative to the free surface. As in the previous example, the temperature at the surface $(z=0)$ and at the bottom of the lithosphere $\left(z=-a_{L}\right)$ are maintained constant at $T=0$ and $T=T_{1}$, respectively.

The steady-state equation $(\partial T / \partial t=0)$ for this diffusion-advection problem is derived from equation 3.1, assuming a constant conductivity $k_{T}$

$$
\begin{gathered}
\rho c w_{a d v} \frac{\partial T}{\partial z}=k_{T} \frac{\partial^{2} T}{\partial z^{2}} \\
w_{a d v} \frac{\partial T}{\partial z}=\kappa \frac{\partial^{2} T}{\partial z^{2}} .
\end{gathered}
$$

Imposing the temperature at the top and bottom of the lithosphere, the analytical solution for equation 3.28 is

$$
T=\frac{T_{1}}{e^{-P e_{L}}-1}\left(e^{z w_{a d v} / \kappa}-1\right)
$$


where $P e_{L}$ is the Peclet number for the lithosphere, defined as

$$
P e_{L}=\frac{a_{L} w_{a d v}}{\kappa}
$$

This dimensionless number compares the heat transport by advection with the heat transport by diffusion. When $P e_{L} \rightarrow 0$, the heat is mainly transported by diffusion and when $P e_{L} \gg 1$ the advection is the dominant process to transfer heat.

Three values of the Peclet number were studied: $P e_{L}=1,5$ and 10 . The values for $k_{T}, a_{L}$ and $T_{1}$ are the same for the previous example (Table 3.1) and the upward velocity $w_{a d v}$ is determined from the expression 3.29 for $P e_{L}$. The results are shown in Figure 3.7.
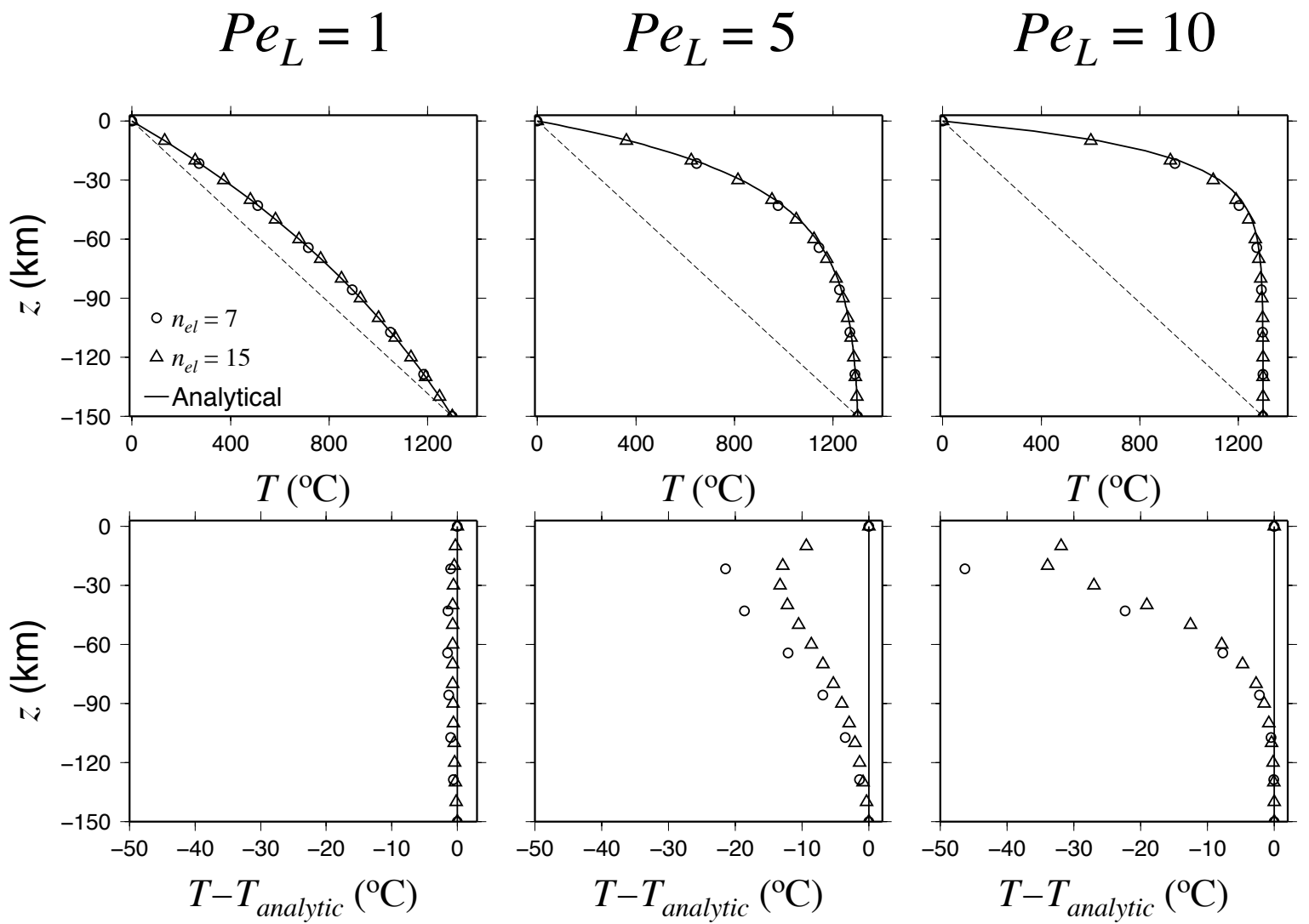

Figure 3.7: Comparison between analytical and numerical solutions for a steadily eroding lithosphere for different Peclet number. The upper graphics show the temperature profile for $P e_{L}=1,5$ and 10. The dashed lines indicate the temperature profile for $P e_{L}=0$. The lower graphics show the difference between numerical and analytical solutions.

In the three cases the numerical solutions compare well with the analytical ones and the convergence to the exact solution occurs as the number of element layers $n_{e l}$ increases. One 
can observe in the lower graphics in Figure 3.7 that the magnitude of the error increases for high $P e_{L}$ numbers, and the errors are concentrated in the upper portion of the plate. This is because for higher Peclet number the vertical gradient of temperature $\partial T / \partial z$ also increases, mainly in the upper portion of the plate, close to the free surface.

For advection dominated heat transport, the numerical model remains stable and the solution is very close to the analytical one (Figure 3.8). Therefore, the proposed numerical model is robust to study the thermal evolution of the lithosphere even when the advection is the dominant process to transport heat.

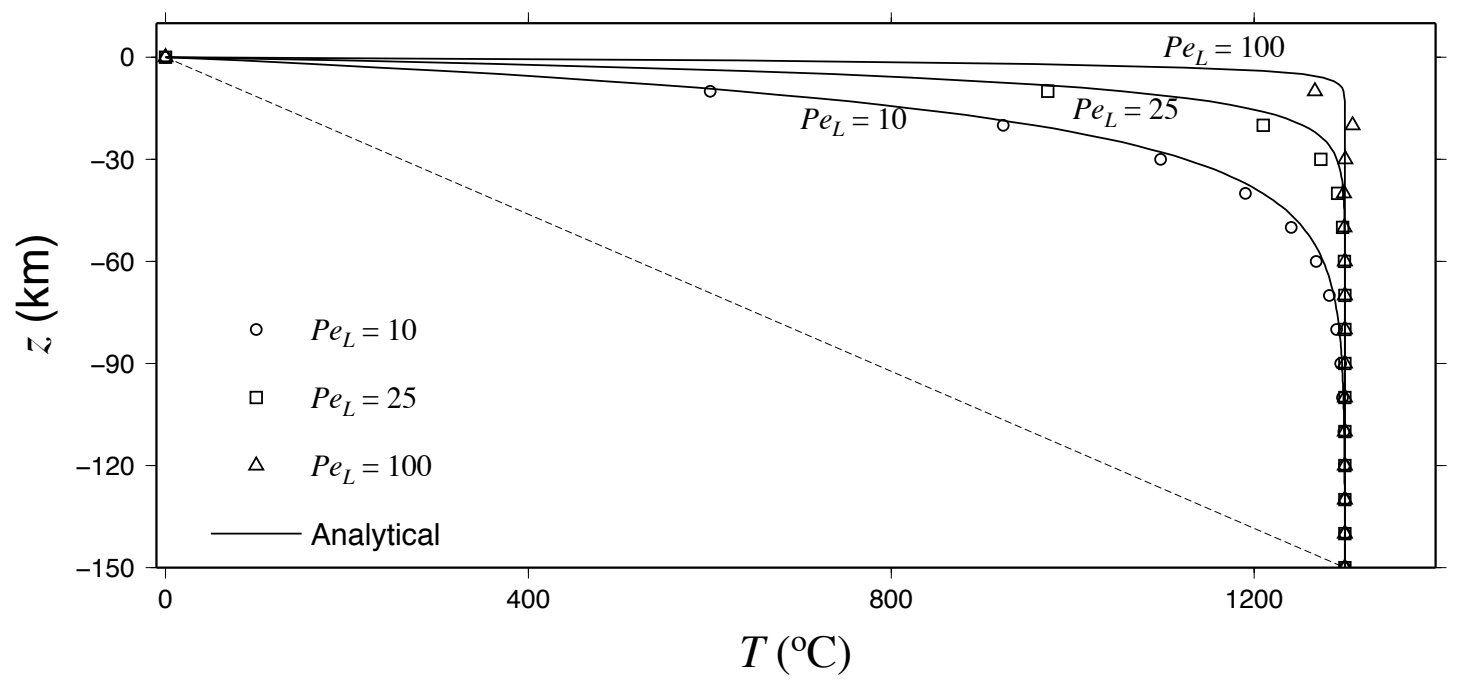

Figure 3.8: Comparison between analytical and numerical solutions for a steadily eroding lithosphere for $P e_{L}=10,25$ and 100. The dashed line indicates the temperature profile for $P e_{L}=0$. 
Chapter 4

\section{Stretching of the lithosphere}

The more closely we look at areas of continental extension the more we see that all rifts are not created equal.

(Buck et al., 1999)

\subsection{Introduction}

Since the acceptance of plate tectonics by the scientific community, many geoscientists have attempted to understand how the lithosphere breaks and evolves to divergent margins (Buck, 2004, and references therein). One challenging aspect is to understand the diversity of rift styles observed on Earth. Rifts can be narrow or wide (England, 1983) and present different "degrees" of asymmetry between the conjugate margins. Furthermore, the influence of magmatism during rifting varies widely and many rifts fail and do not evolve to passive margins. In spite of this variety of rift styles, rifted regions are generally characterized by crustal thinning, high heat flow, negative Bouguer anomalies and uplifted margins (Allen and Allen, 2005) and these similarities were the starting point for the geodynamic study of rifts.

A strategy to study the rift of the lithosphere is through kinematic models to describe the strain field during stretching. This kind of model was successfully applied by McKenzie (1978), where he presented an elegant analytical formulation that quantifies the gross pattern of subsidence for basins in divergent margins, identifying two stages of subsidence: the first one related to stretching and thinning of the lithosphere; and a second one caused by the thermal cooling of the lithosphere.

In the model of McKenzie (1978), the lithosphere is stretched instantaneously and the 
stretch is uniform with depth, by pure-shear (Figure 4.1a). There is no lateral heat transfer and local isostasy is assumed, i.e. the rigidity of the lithosphere is null.

(a) McKenzie [1978]
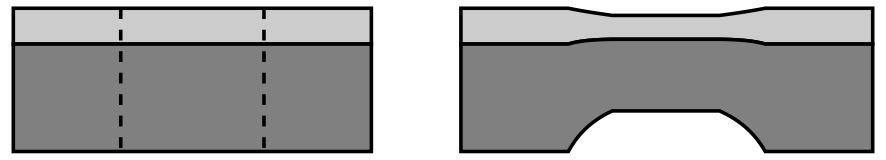

(b) Royden and Keen [1980]
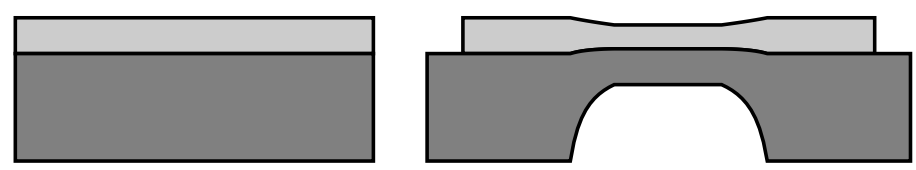

(c) Wernicke [1985]
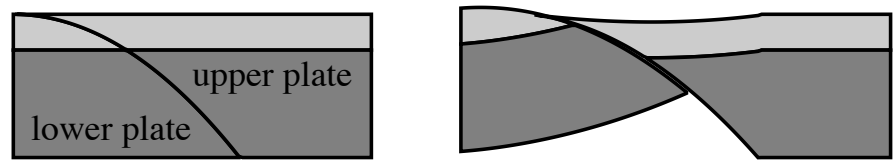

Figure 4.1: Comparison between different models to represent the stretching of the lithosphere. The left panels show the lithospheric configuration previous to stretching, while the right ones show the final state of the lithosphere after stretching. The dark gray region is the crust and the light gray one is the lithospheric mantle. (a) Pure shear model of McKenzie (1978), where the stretching is uniform. The dashed lines bound the stretched regions. (b) Non-uniform pure shear model of Royden and Keen (1980). (c) Simple shear model of Wernicke (1985).

In the following years, this simple model was improved. Jarvis and McKenzie (1980) considered finite rates of extension and therefore the rift is not instantaneous as in the model of McKenzie (1978). Studying the subsidence history of the Labrador shelf, Royden and Keen (1980) observed that the Mckenzie's model cannot describe the evolution of this margin. They concluded that the mantle under the Labrador margin was considerably more extended than the crust to fit the subsidence curve. Later, this variation of extension with depth was observed in other margins (e.g. Roberts et al., 1997; Driscoll and Karner, 1998). Royden and Keen (1980) proposed a model that consider the effect of non-uniform stretch with depth, assuming that the extension of the crust and lithospheric mantle are independent (Figure 4.1b). Although the model of Royden and Keen (1980) reasonably 
describes the subsidence of margins with non-uniform stretch with depth, their model presents problems of mass conservation during stretching (Figure 4.1b).

Wernicke (1985) proposed a simple shear model to describe the stretching of the lithosphere, where a low-angle detachment fault divides the lithosphere into two portions: an upper plate or hangingwall, and a lower plate or footwall (Figure 4.1c). Unlike the model of Royden and Keen (1980), in the simple shear model the mass is conserved during stretching. This model implies asymmetric conjugate margins, where the lithospheric mantle is more extended than the crust in the upper plate margin, while in the lower plate margin the crust is more extended than the mantle. On the other hand, Driscoll and Karner (1998) observed that many rifted margins, including conjugate ones, are characterized by lithospheric mantle much more stretched than the crust. They coined this as the upper plate paradox.

Combination of the pure shear and simple shear was presented by Kusznir et al. (1991), where the upper-crust is stretched following a simple shear deformation pattern, while the lower crust and lithospheric mantle are stretched following the pure shear style. Kusznir et al. (1991) included in their model the flexural cantilever effect to describe the flexural behavior of the upper crust during stretching, producing uplift of footwall. This model also simulates the formation of small wavelength features of few kilometers, describing the geometry of grabens and crustal block rotation. Previous to Kusznir et al. (1991), Weissel and Karner (1989) applied the flexural cantilever model for the entire lithosphere to describe the flexural response of the plate to extension.

Braun and Beaumont (1989) showed the importance of consider the finite strength of the lithosphere during stretching and introduced the concept of necking depth, which is defined as the depth in the lithosphere that remains horizontal during stretching if no isostatic compensation is applied. Physically the necking depth is close to the layer of maximum strength in the lithosphere. If the necking depth is shallow (Figure 4.2), e.g. representing a strong crust, the addition of isostatic forces produces a down warping of the rift zone. On the other hand, a deep necking depth, associated with the isostatic forces, produces an upward movement of the rift zone, creating flank uplifts.

In spite of the different formalisms, the flexural cantilever and the necking depth models agree that the lithosphere retains flexural rigidity during extension, and the regional 
isostatic compensation produces permanent flank uplifts as observed in many divergent margins around the world.

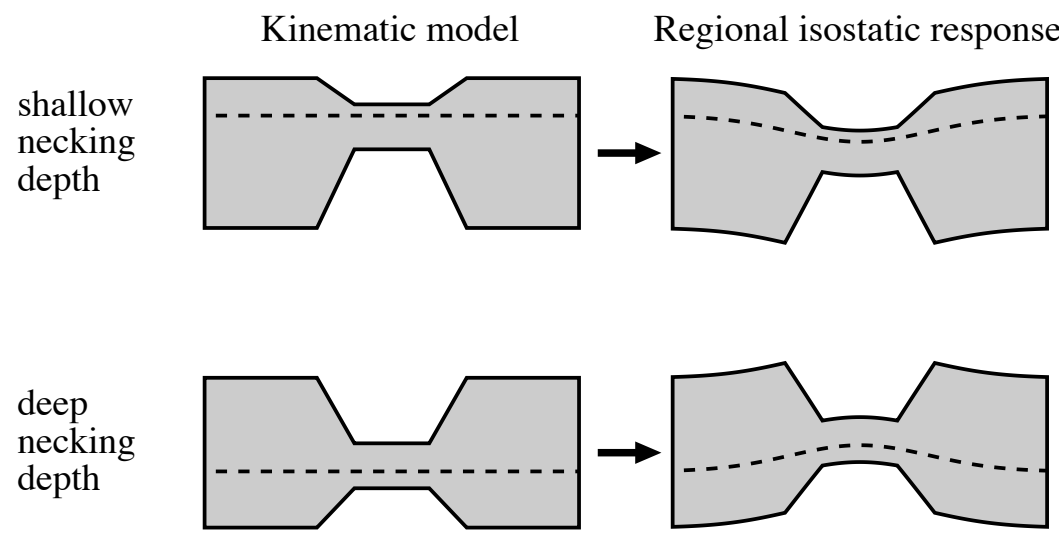

Figure 4.2: Illustration of lithospheric necking and the regional isostatic response to stretching (Braun and Beaumont, 1989). The left panels show the kinematic model for a shallow (upper figure) and deep (lower figure) necking depth without isostatic compensation. The dashed lines represent the necking depth and the gray region is the lithosphere. The right panels show the combination of stretching and regional isostatic response of the lithosphere.

Kusznir and Karner (2007) and Fletcher et al. (2009) proposed that the deformation of the lithosphere during stretching is similar to previous models for the evolution of oceanic crust and mid ocean ridges (Reid and Jackson, 1981). In this model (Figure 4.3), the upward movement of the mantle is maximum under the zone of stretching. Close to the surface, the upward movement diverges laterally and reaches the highest horizontal velocity at the surface.

Kusznir and Karner (2007) proposed that the deformation and thinning of the continental lithosphere guided by the upwelling divergent flow field naturally leads to breakup and formation of sea-floor spreading. This model successfully predicted depth-dependent stretching, resulting in "upper plate" behavior on both conjugate margins.

In the present work, different aspects of these previous models were used to study the stretching of the lithosphere. The upwelling divergent flow was used to describe the stretching pattern of the lithospheric mantle and lower crust during rifting. To simulate the creation of faults and the flexural response to faulting of the upper crust, the flexural cantilever model of Kusznir et al. (1991) was used. Furthermore, the horizontal movement 


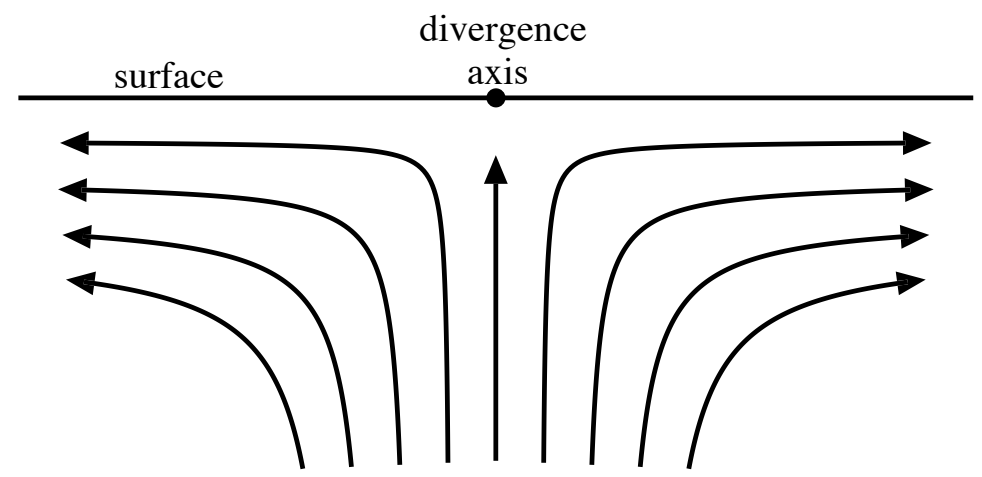

Figure 4.3: Scheme of the streamlines for the upwelling divergent flow.

of density interfaces during stretching results in vertical loads on the lithosphere that are regionally compensated, as described in Chapter 6.

The details about the stretching model used in the present work are described in the following sections.

\subsection{The upwelling divergent flow}

To simulate the upwelling divergent flow associated with the divergence of conjugate margins and stretching of the lower part of the lithosphere near the center of the rift, the solution to the classical corner flow problem (Fletcher et al., 2009) is used to describe $\mathbf{v}$, which is given by:

$$
\begin{aligned}
& u_{a d v}=\operatorname{sign}(x)\left[-A_{2}-A_{4}\left(\arctan \frac{z}{|x|}\right)+\left(A_{3}|x|+A_{4} z\right)\left(\frac{-|x|}{x^{2}+z^{2}}\right)\right] \\
& w_{a d v}=-\left[A_{1}+A_{3}\left(\arctan \frac{z}{|x|}\right)+\left(A_{3}|x|+A_{4} z\right)\left(\frac{-z}{x^{2}+z^{2}}\right)\right]
\end{aligned}
$$

where, for the geometry and boundary conditions of our problem,

$$
A_{1}=0, A_{2}=\frac{2 \pi U_{z}-\pi^{2} U_{x}}{\pi^{2}-4}, A_{3}=\frac{4 U_{x}-2 \pi U_{z}}{\pi^{2}-4}, A_{4}=\frac{2 \pi U_{x}-4 U_{z}}{\pi^{2}-4} .
$$

$U_{x}$ is the half-spreading horizontal velocity at the surface and $U_{z}$ is the axial vertical velocity at $x=0$, the center of the rift.

The advection velocity $\mathbf{v}=\left(u_{a d v}, v_{a d v}, w_{a d v}\right)$ is the same used in equation 3.1 to describe the velocity of rock particles during stretching of the lithosphere. 
(a) From an observer at axis of the upwelling flow

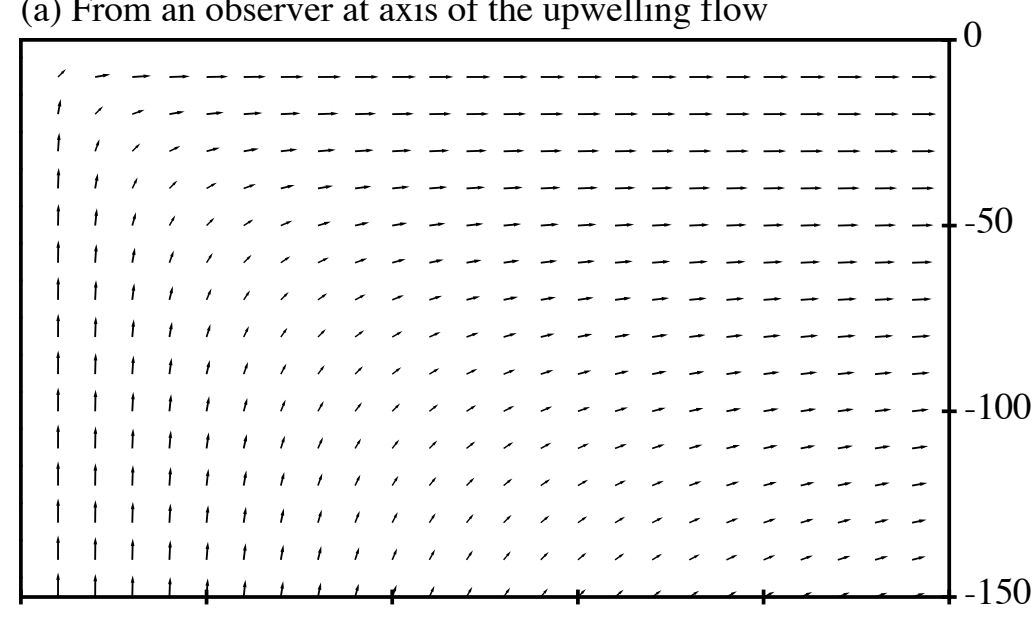

(b) From an observer moving with the plate at the surface

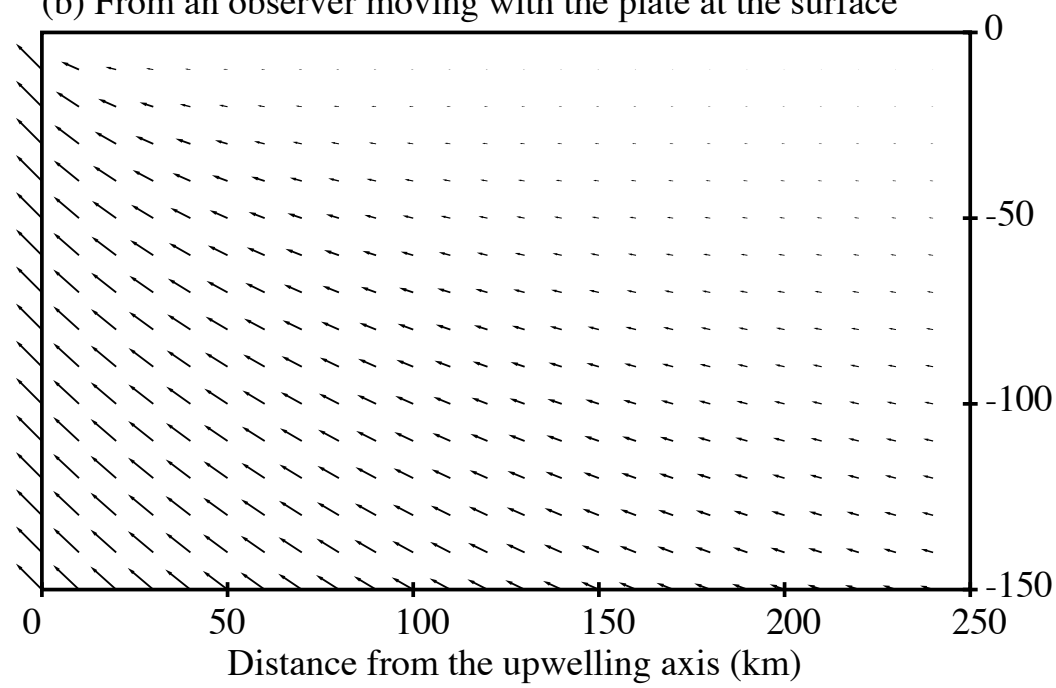

Figure 4.4: Velocity field for the upwelling divergent flow, obtained from equation 4.1 with $U_{z} / U_{x}=1$, observed from (a) the axis of the upwelling flow at $x=0$ and (b) from an observer moving with the plate at the surface. Depth is in $\mathrm{km}$.

In this model there are two parameters to be adjusted: the horizontal velocity $U_{x}$ and the vertical velocity $U_{z} . U_{x}$ can be derived from the relative movement between divergent lithospheric plates. On the other hand, $U_{z}$ cannot be directly measured. For a passive divergent flow with constant viscosity, the ratio $U_{z} / U_{x}=2 / \pi$ (Morgan, 1987), thus $U_{z}<U_{x}$ in this situation. But considering that the viscosity is dependent on stress and temperature, Fletcher et al. (2009) proposed that the ratio $U_{z} / U_{x}$ must be higher than expected by the passive isoviscous flow. 
In Figure $4.4 \mathrm{a}$ is presented the velocity field for the upwelling divergent flow with $U_{z} / U_{x}=1$. Due to symmetry, only half of the velocity field is plotted. Observe that the vectorial field shown in Figure 4.4a is independent of the absolute value of $U_{x}$ or $U_{z}$, depending only on the ratio $U_{z} / U_{x}$. From an observer moving with the surface with velocity $U_{x}$ relative to the axis of the upwelling flow (Figure 4.4b) it is easy to verify that the lower portion of the lithosphere flows oceanward. This shows the depth-dependent stretching of the lithosphere in this model.

\subsection{The flexural cantilever model}

The Figure 4.5 exemplifies the flexural cantilever model. In this model, the footwall and hanging wall (Figure 4.5a) interact as flexural cantilevers during planar faulting of the upper crust. Under the upper crust, the lower crust flows to accommodate the faulting and the density of the upper and lower crust are the same.

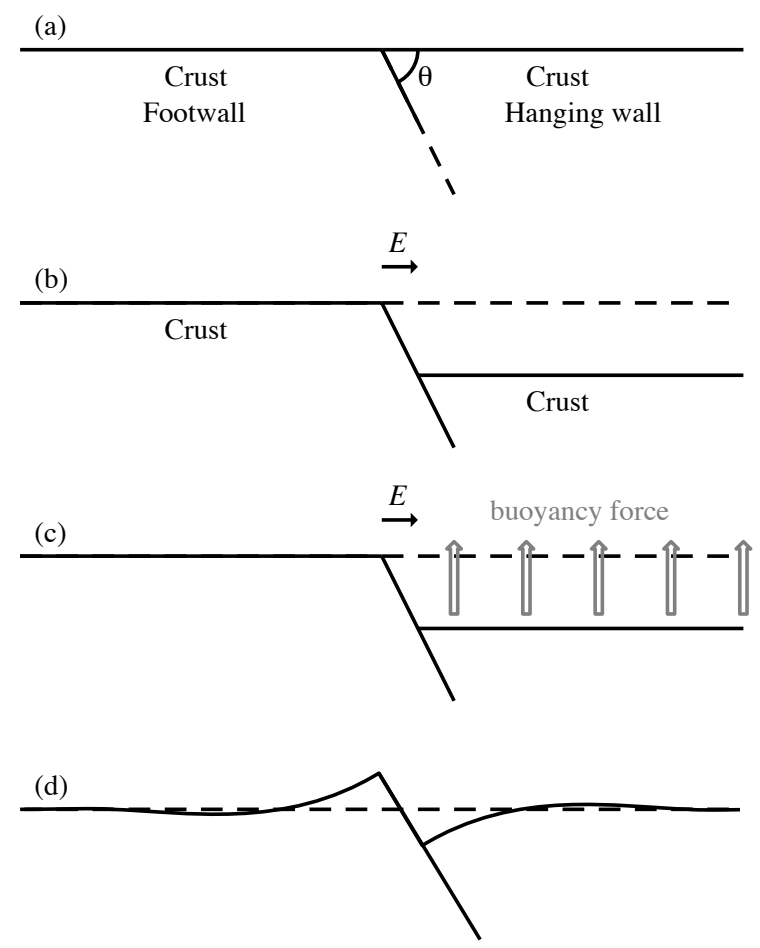

Figure 4.5: Diagram describing the flexural cantilever model of Kusznir et al. (1991).

Considering an extension $E_{f}$ of the upper crust accommodated by a planar fault dipping at an angle $\theta$ (Figure $4.5 \mathrm{a}$ ), the vertical displacement $d_{f}$ of the surface relative to the 
footwall, in the absence of gravity, is (Figure 4.5b)

$$
d_{f}=\left\{\begin{aligned}
0 & \text { if the point is on the footwall } \\
-E_{f} \cdot \tan \theta & \text { if the point is on the hangingwall }
\end{aligned}\right.
$$

After faulting, the two blocks are welded together, behaving as a single plate.

To restore isostatic equilibrium, the lower crust imposes a buoyancy force per unit area under the hanging wall (Figure 4.5) given by

$$
F_{F}=-\rho_{c} g d_{f}
$$

where $\rho_{c}$ is the density of the lower crust and $g$ is the gravity.

The flexural response $w_{F}$ of the upper plate to the upward load $F_{F}$ is given by

$$
(\mathbf{L} \nabla)^{\mathrm{T}} \mathbf{D}_{u c} \mathbf{L} \nabla w_{F}+\rho_{c} g w_{F}=F_{F}
$$

where $\mathbf{D}_{u c}$ is the flexural rigidity of the upper crust, i.e. dependent of $T_{e, u c}$. The final configuration is shown in Figure 4.5d and the resulting topographic variation is

$$
w_{F}^{\prime}=w_{F}+d_{f}
$$

Observe that in this case the fluid that produces the isostatic compensation is the lower crust, and not the mantle. This is the reason for the appearance of $\rho_{c}$ in the second term of equation 4.3 . 


\section{Chapter 5}

\section{Surface processes}

Overall, we have learned two things:

1 It is not hard to invent plausible stratigraphic models.

2 It is very hard to test them.

(Paola, 2000)

\subsection{Introduction}

In the present work, the meaning of surface processes encompasses subaerial and submarine processes of erosion, transport and deposition of sediments.

In spite of the clear relationship between erosion of emerged regions and deposition in the sedimentary basins, quantitative models tend to treat them independently, with few exceptions (e.g. Johnson and Beaumont, 1995; van Balen et al., 1995; Garcia-Castellanos, 2002). Therefore, through the last decades, the parallel development of quantitative models of sedimentary basin filling and landscape evolution models has occurred almost isolated from each other.

The first quantitative basin filling models to simulate clastic sequence stratigraphy were based on two-dimensional geometric models (e.g. Pitman, 1978), where the geometry of the sediment surface is previously prescribed and the evolution of the basin filling depends on the imposed sediment supply and variations in the sea-level. These models were followed by dynamic models based on equations of conservation of mass and "rules" guiding the transport of sediments. For example Jordan and Flemings (1991), Rivenæs (1992) and Rivenæs (1997) used linear diffusion to simulate the sediment transport on continental shelves. Kaufman et al. (1991) proposed a depth-dependent diffusivity to simulate the 
decrease in energy available for sediment transport with increasing water depth. One of the limitations of diffusion based stratigraphic models is that the diffusion tends to spread the sediments and flatten the bathymetry, does not producing the characteristic feature of prograding clinoforms as observed in seismic sections. Considering the depth-dependent diffusivity, the flattening process is diminished. To reproduce the clinoform geometry, Pirmez et al. (1998), followed by Driscoll and Karner (1999), proposed a advective-diffusive model of sediment transport. The advective term in this model represents the residual river current carrying sediments into deep water. On the other hand, both diffusional and advective-diffusional models are empirical equations and they try to represent the combination of different physical and chemical processes acting in the depositional setting. Until now, it is not clear what is the best first-order dynamic equation to describe the evolution of clastic shelves (Paola, 2000). Despite of the lack of a clear dynamic equation, the reviewed models predict useful stratigraphic evolution of basin filling.

The development of numerical models to study landscape evolution started in the 1970s [Ahnert 1976 in Coulthard 2001]. In the following years, new numerical models were developed showing improved descriptions of the different processes involved in the evolution of the landscape, as well as its geometric discretization (Kirkby, 1986; Willgoose et al., 1991; Beaumont et al., 1992; Tucker and Slingerland, 1994; Braun and Sambridge, 1997; Tucker and Bras, 2000). A detailed revision of the different models is presented by Coulthard (2001). Basically, the processes that sculpt the landscape in these numerical models are described as short- and long-range processes. Short-range processes describe the transport of sediments and the erosion along hillslopes, such as soil creep, earth flows, slides and rockfall (Kooi and Beaumont, 1994). These processes depend on the local slope, the soil type, vegetation and climate. In the numerical models, the short range processes are simulated through linear diffusion (e.g. Kooi and Beaumont, 1994), non-linear diffusion (Martin, 2000) or dependent on critical slope angle for soil movement by sliding (Densmore et al., 1998). The long-range processes describe the cumulative effect of fluvial transport either as bedload or in suspension (Beaumont et al., 1992). Besides the local slope, lithology and vegetation, the long-range processes are dependent on water discharge, that is dependent on precipitation and drainage area. If the effective precipitation is assumed uniform over the surface, the water discharge is proportional to the drainage area. There are other 
models that take into account glacial erosion (Braun et al., 1999), chemical weathering (Kaufmann and Braun, 2001) and aeolian systems (conceptual model of Kocurek and Havholm, 1993), but they are not discussed in the present work.

All these models try to study the large-scale long-term evolution of the surface processes. They represent a simple description of the complex processes that occur in different time and space scales in the real world. About this aspect, Kooi and Beaumont (1994) wrote: "As demonstrated in other sciences, a fruitful approach to such problems of scale is to set aside (for the time being) the small-scale, short-timescale picture and to explore simple relationships cast in terms of large-scale, long-timescale quantities. In thermodynamics, for example, the behavior of gases was first formulated in terms of properties associated with the collective behavior of molecules (pressure, temperature, and entropy) and not the interactions between individual molecules".

The following sections present the mathematical description of the surface processes used in the present work, showing the discretization of the surface and the numerical treatment of each process.

\subsection{Mathematical description of the surface processes}

In this work, the landscape evolution is guided by two types of processes (Beaumont et al., 1992): short-range hillslope processes, like weathering and soil creep; and long-range fluvial process.

Hillslope processes are modeled through a linear diffusion equation applied to topography $h$, assuming that transport is linearly proportional to the slope (see Dietrich et al. (2003) and references therein):

$$
\frac{\partial h}{\partial t}=\nabla \cdot\left(k_{d} \nabla h\right)
$$

where $k_{d}$ is the coefficient of diffusive transport.

Fluvial processes of erosion, transport and sedimentation are modeled following the formulation of Beaumont et al. (1992) where local variations in topography are described through a first-order reaction equation given by:

$$
\frac{\partial h}{\partial t}=-\frac{q_{f}^{e q b}-q_{f}}{L_{f}}
$$


where $q_{f}^{e q b}$ is the maximum sediment transport capacity, $q_{f}$ is the sediment flux per unit width $\left[\mathrm{L}^{2} \mathrm{~T}^{-1}\right]$ and $L_{f}$ is a parameter of erosion/deposition with dimension of $[\mathrm{L}] . q_{f}^{e q b}$ in a channel takes the following form:

$$
q_{f}^{e q b}=k_{f} q_{r}|\nabla h|
$$

where $k_{f}$ is the erosional coefficient due to the fluvial process, $q_{r}$ is water discharge and $|\nabla h|$ is the modulus of topographic gradient. The water discharge is calculated by spatially integrating the net precipitation rate $v_{R}$, which is assumed uniform in space and time for simplicity. There are different expressions for $q_{f}^{e q b}$ in the literature, where the exponents of $q_{r}$ and $|\nabla h|$ are not equal to one (see Braun (2006)). These variations in the value of the exponents of $q_{r}$ and $|\nabla h|$ are of secondary importance for the present work, since the general drainage pattern and the position of the drainage divides will not be significantly modified with the variation of the exponents (see Figure 9 in Tucker and Whipple, 2002).

The methodology of van Balen et al. (1995) is used for the offshore transport of sediments, based on the same principle as for diffusion processes on land, but with a non-linear diffusion coefficient, $k_{m}$. Thus,

$$
\frac{\partial h}{\partial t}=\nabla \cdot\left(k_{m} \nabla h\right)
$$

In this simple model, the diffusivity $k_{m}$ decreases exponentially with water depth, simulating the decrease in energy available for sediment transport with increasing water depth:

$$
k_{m}=k_{m}^{*} \exp \left(\frac{h-h_{s . l .}}{h_{0}}\right)
$$

$k_{m}^{*}$ is a constant $\left[\mathrm{L}^{2} \mathrm{~T}^{-1}\right], h_{s . l}$ is sea level and $h_{0}$ is another constant that has dimension of [L].

\subsection{Generation of the irregular mesh and discretization of the surface}

\subsubsection{Irregular distribution of the points}

To represent the surface of the numerical model, an irregular mesh was adopted (Braun and Sambridge, 1997). The main reason to use irregular meshes is the possibility to adapt the mesh to appropriately deal with the landscape evolution during faulting of the upper crust and simulate continuos horizontal movement between crutal blocks without 
loss of short-wavelength features (Braun and Sambridge, 1997). Besides the facility to deal with relative movement of blocks, irregular meshes eliminate the artificial symmetry effect observed in regular grids.

A fast way to produce an irregular mesh with uniform point density is to perturb the position of the points of a regular mesh in a random manner

$$
\begin{aligned}
& x_{i} \leftarrow x_{r i}+\delta_{r} \text { rand } \\
& y_{i} \leftarrow y_{r i}+\delta_{r} \text { rand }
\end{aligned}
$$

where $\mathbf{x}_{r i}=\left(x_{r i}, y_{r i}\right)$ is the point of the grid, $\mathbf{x}_{i}=\left(x_{i}, y_{i}\right)$ is the new point of the irregular mesh, $\delta_{r}$ is the distance between two adjacent points in the grid and rand is a random number centered in zero controlling the magnitude of the perturbation. Only the nodes on the edge of the grid are maintained on the edge to preserve the rectangular geometry of the mesh.

\subsubsection{Delaunay triangulation and Voronoi diagrams}

After the creation of the points of the mesh, the connectivity between them is determined. The first step is to discover the adjacent points for each point, named here as neighbor points. Due to the initial perturbation of the grid, the neighbor points in the irregular mesh do not necessarily coincide with the adjacent points in the previous grid, and the task of identifying them is not trivial and requires a special way to interconnect the points.

In the present work, the interconnection between the points of the irregular mesh (Figure 5.1a) is done through the Delaunay triangulation (Delaunay, 1934). An example is shown in Figure 5.1b. This triangulation has the property of maximize the minimum inner angle of all created triangle. This means that from all the possible ways to create the triangular mesh over $n$ points, the Delaunay triangulation results in triangles "closer" to equilateral triangles. Another property of this triangulation is that a circle circumscribed on any Delaunay triangle does not contain any other point of the mesh.

The algorithm used to generate the triangular mesh is based on the works of Sloan (1987) and Fortune (1992). Initially the mesh is constructed with a minimum number of points of the border that encompasses all the other points of the mesh. For an example, 
for a rectangular mesh, only four points and two triangles are needed to initiate the triangulation, as in the example of Figure 5.2, first picture. After this, a new point is added to the mesh, verifying which circles circumscribed on the preexisting triangles contain the new point. In this case, the respective triangles (indicated as light gray triangles in Figure 5.2) are erased, and only the points of these triangles, together with the new point, are used to locally remake the mesh. Successively, all the other points are added and the mesh is locally updated in each step (Figure 5.2).

To determine whether a point $\mathbf{x}_{p}=\left(x_{p}, y_{p}\right)$ is inside a circle circumscribing a triangle composed of the points $\mathbf{x}_{1}, \mathbf{x}_{2}$ and $\mathbf{x}_{3}$, ordered in the anti-clockwise sense, the following determinant is calculated

$$
D_{\text {inside }}=\left|\begin{array}{llll}
x_{1} & y_{1} & x_{1}^{2}+y_{1}^{2} & 1 \\
x_{2} & y_{2} & x_{2}^{2}+y_{2}^{2} & 1 \\
x_{3} & y_{3} & x_{3}^{2}+y_{3}^{2} & 1 \\
x_{p} & y_{p} & x_{p}^{2}+y_{p}^{2} & 1
\end{array}\right| .
$$

If $D_{\text {inside }}>0$, the point $\mathbf{x}_{p}$ is inside the circle.

After the determination of the triangular mesh, the next step is determine the area associated with each point of the mesh. For this, the Voronoi diagram is used (Voronoi, 1908). An example of this diagram is presented in Figure 5.1c. This diagram divides the plane in polygons named Voronoi cells. The Voronoi cell associated with the point $\mathbf{x}_{P}$ represents the region in the plane that is closest to this point than any other point of the mesh.

The Voronoi diagram is a dual graph of the Delaunay triangulation. This means that it is possible to associate each vertex of the Delaunay triangulation with a Voronoi cell, and each edge of the triangles with one edge of the cells (Figure 5.1d). This implies that the Voronoi cells are obtained from the Delaunay triangulation.

In this work, the algorithm of Lasserre (1983) was used to determine the area of each Voronoi cell from the triangular mesh. The area $S_{i}$ of a Voronoi cell (Figure 5.3), related to the point $i$ is given by

$$
S_{i}=\frac{1}{2} \sum_{j}^{n_{i}}\left|\partial S_{i j}\right|\left[\frac{b_{i j}}{\sqrt{a_{x i j}^{2}+a_{y i j}^{2}}}\right]
$$


(a) Points

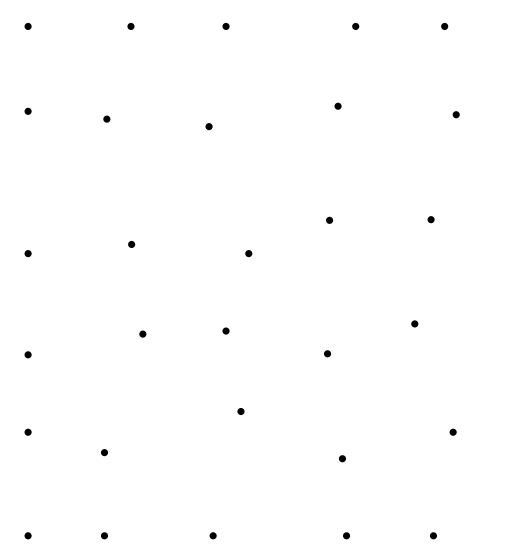

(c) Voronoi cells

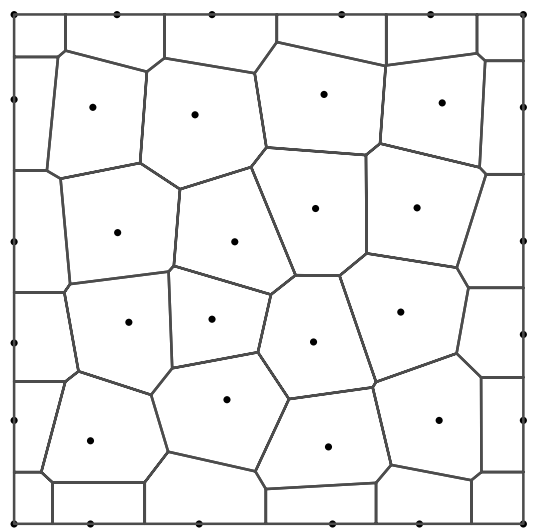

(b) Delaunay triangles

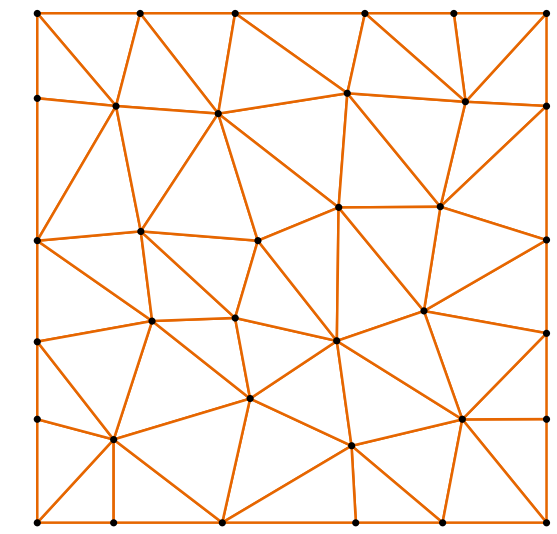

(d) Delaunay + Voronoi

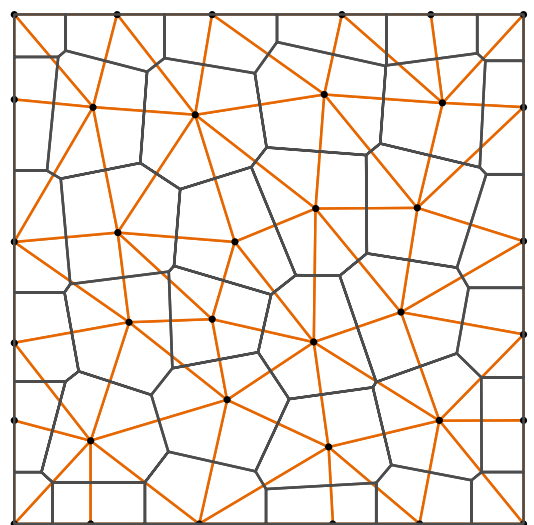

Figure 5.1: Example of Delaunay triangulation and Voronoi diagrams. In c and d the Voronoi cells at the border of the mesh are truncated.

where $n_{i}$ is the number of edges of the polygon, $j$ is the index of each neighbor point of $i$, $\left|\partial S_{i j}\right|$ is the length of the edge $\partial S_{i j}$ between $i$ and $j$ and

$$
a_{x i j} x+a_{y i j} y=b_{i j}
$$

is the line equation that contains $\partial S_{i j}$.

The coefficients $a_{x i j}, a_{y i j}$ and $b_{i j}$ are determined from the following expressions: if $a_{x i j} x_{i}+a_{y i j} y_{i}<b_{i j}$ then

$$
\begin{aligned}
& a_{x i j}=\left(x_{j}-x_{i}\right) \\
& a_{y i j}=\left(y_{j}-y_{i}\right)
\end{aligned}
$$



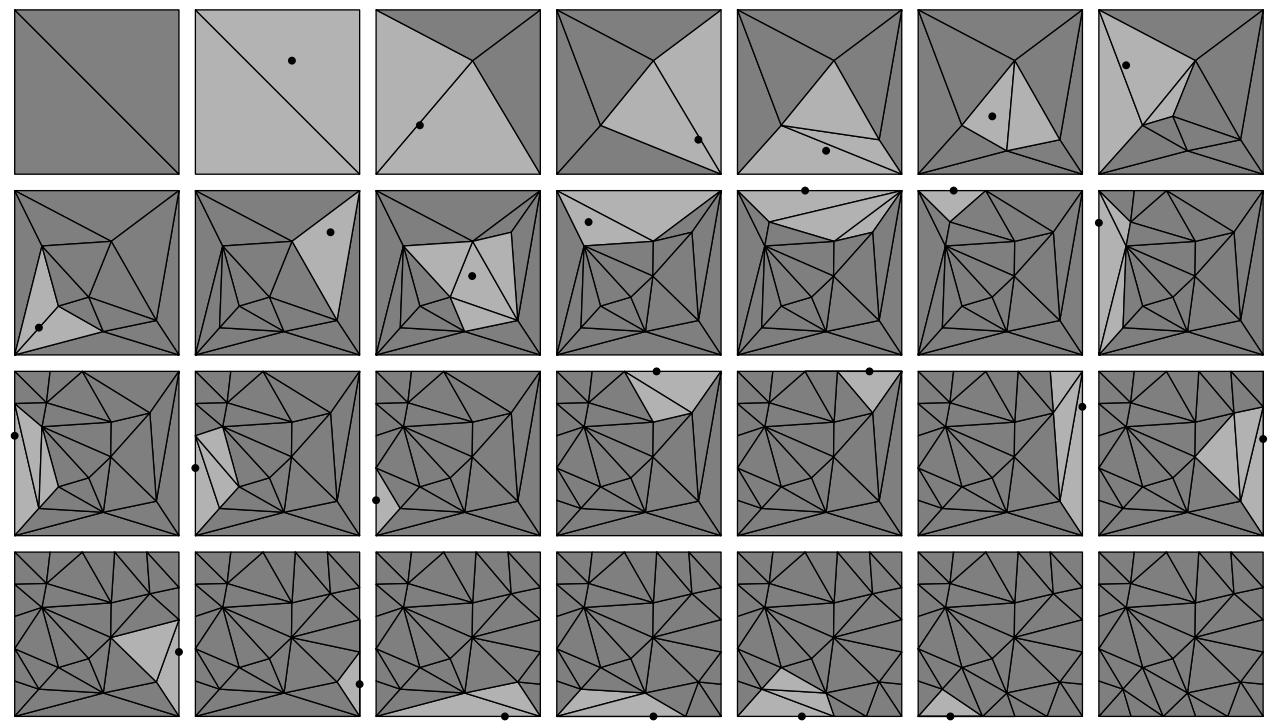

Figure 5.2: Illustration of the algorithm to create the Delaunay triangulation from a set of $n=30$ points. The point in each figure indicates the next node to be included in the triangular mesh. The light gray triangles show the region that must be re-meshed to include the new point.

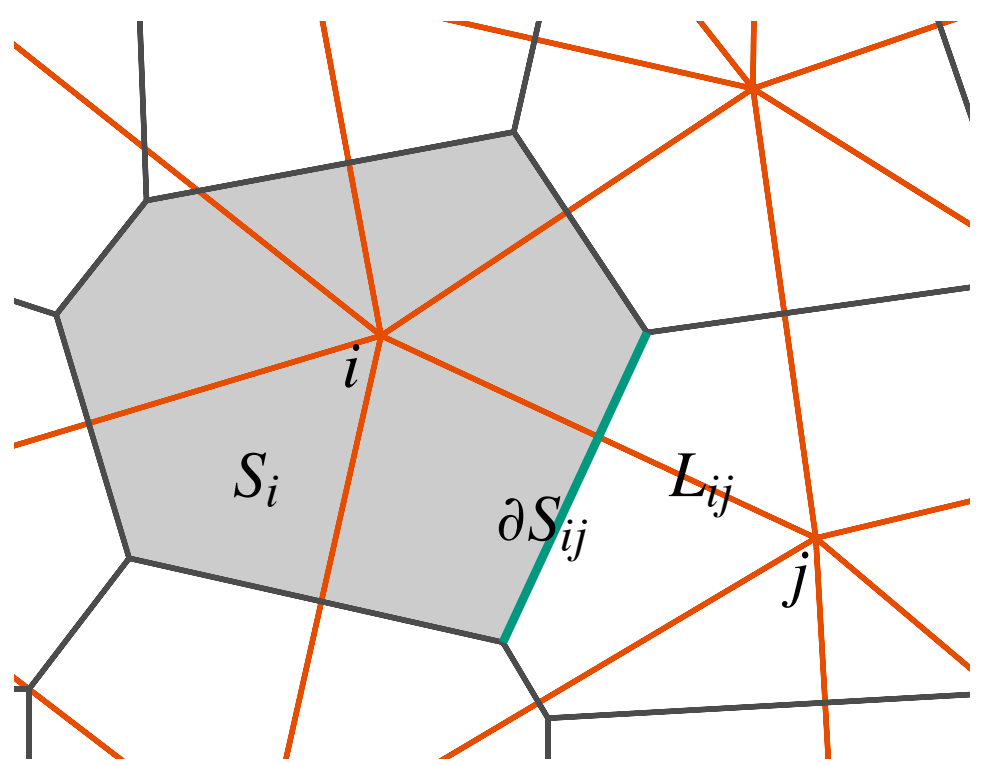

Figure 5.3: Illustration of a Voronoi cell. $S_{i}$ is the area of the Voronoi cell (gray region) related to the point $i . \partial S_{i j}$ is the edge of $S_{i}$ (green line) in contact with $S_{j} . L_{i j}$ is the distance between the points $i$ and $j$.

$$
b_{i j}=\frac{1}{2}\left(x_{j}^{2}+y_{j}^{2}-x_{i}^{2}-y_{i}^{2}\right)
$$


otherwise

$$
\begin{gathered}
a_{x i j}=-\left(x_{j}-x_{i}\right) \\
a_{y i j}=-\left(y_{j}-y_{i}\right) \\
b_{i j}=-\frac{1}{2}\left(x_{j}^{2}+y_{j}^{2}-x_{i}^{2}-y_{i}^{2}\right)
\end{gathered}
$$

The length of the edge $\partial S_{i j}$ is given by

$$
\begin{gathered}
\left|\partial S_{i j}\right|=\frac{\sqrt{a_{x i j}^{2}+a_{y i j}^{2}}}{\left|a_{x i j}\right|} \max \left\{0,\left[\min _{\alpha_{i l}>0}\left(\beta_{i l} / \alpha_{i l}\right)-\max _{\alpha_{i l}<0}\left(\beta_{i l} / \alpha_{i l}\right)\right]\right\} \text { for } l \neq j \\
\beta_{i l}=b_{i l}-b_{i j} \frac{a_{x i l}}{a_{x i j}} \\
\alpha_{i l}=a_{y i l}-a_{y i j} \frac{a_{x i l}}{a_{x i j}}
\end{gathered}
$$

for $a_{x i j} \neq 0$, or

$$
\begin{gathered}
\left|\partial S_{i j}\right|=\frac{\sqrt{a_{x i j}^{2}+a_{y i j}^{2}}}{\left|a_{y i j}\right|} \max \left\{0,\left[\min _{\alpha_{i l}>0}\left(\beta_{i l} / \alpha_{i l}\right)-\max _{\alpha_{i l}<0}\left(\beta_{i l} / \alpha_{i l}\right)\right]\right\} \text { for } l \neq j \\
\beta_{i l}=b_{i l}-b_{i j} \frac{a_{y i l}}{a_{y i j}} \\
\alpha_{i l}=a_{x i l}-a_{x i j} \frac{a_{y i l}}{a_{y i j}}
\end{gathered}
$$

for $a_{x i j}=0$.

The Voronoi cells associated with the points on the edge of the triangular mesh have area $S_{i} \rightarrow+\infty$, because they are not bounded by all the sides. To turn them finite, new lines are added on the edge of the mesh. In the case of a rectangular domain, with edges parallel to the axis $0 x$ and $0 y$, the coefficients of the new lines are:

$$
\begin{array}{cccc}
a_{x i b}=-1 & a_{y i b}=0 & b_{i b}=-x_{\min } \text { for } x_{i}=x_{\min } \\
a_{x i b}=1 & a_{y i b}=0 & b_{i b}=x_{\max } \text { for } x_{i}=x_{\max } \\
a_{x i b}=0 & a_{y i b}=-1 & b_{i b}=-y_{\min } \text { for } y_{i}=y_{\min } \\
a_{x i b}=0 & a_{y i b}=1 & b_{i b}=y_{\max } \text { for } y_{i}=y_{\max }
\end{array}
$$



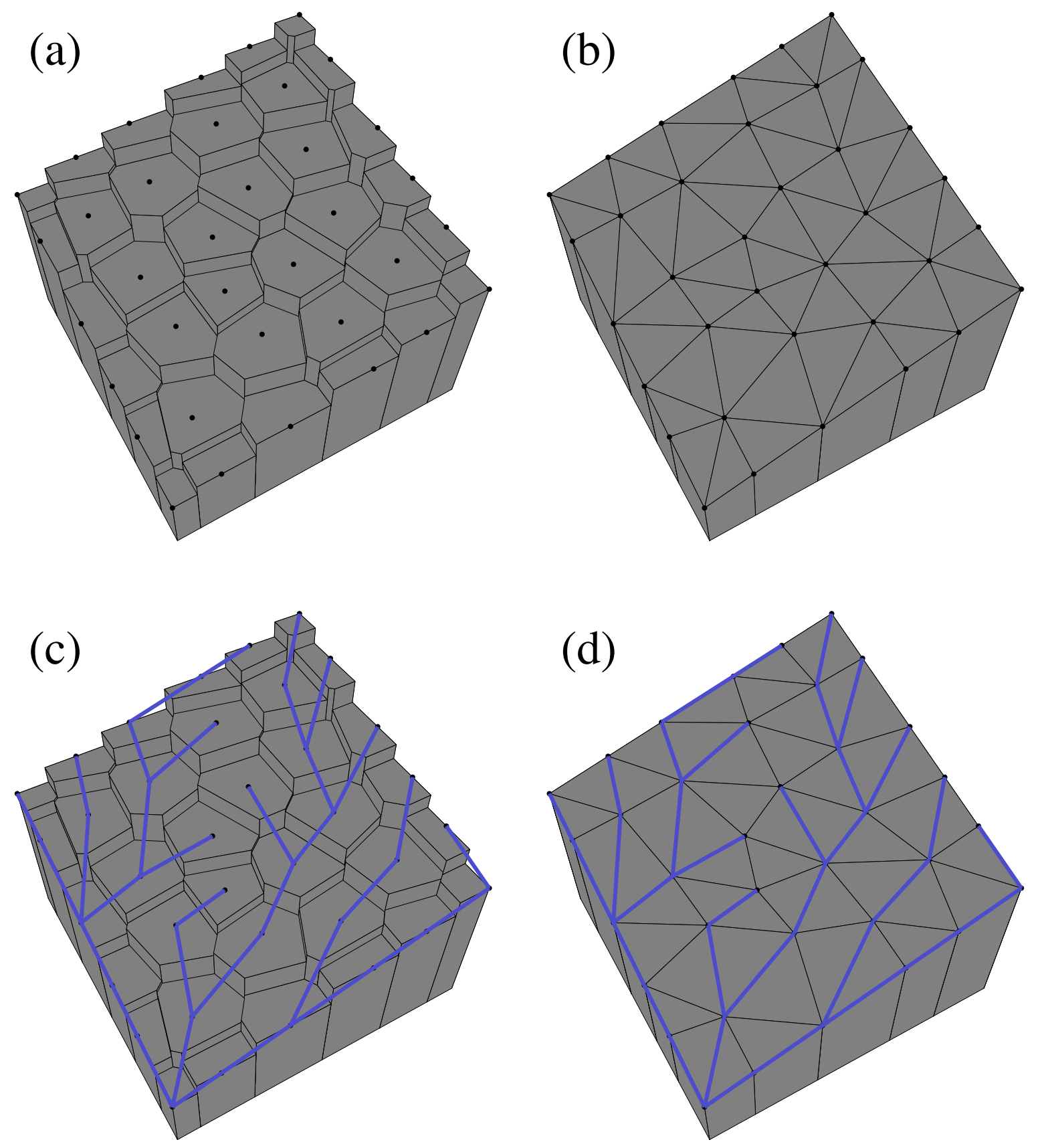

Figure 5.4: Representation of the landscape in the numerical model. (a) representation of the topography using the Voronoi diagrams. The dots are the nodes of the mesh. (b) representation of the topography using the Delaunay triangulation. (c) Stream channels plus topography using Voronoi cells. (d) Stream channels plus topography using Delaunay triangulation. 


\subsection{Formulation of the surface processes in the irregular mesh}

After the creation of the irregular mesh, each cell $i$ of the Voronoi diagram is associated with an elevation $h_{i}$. In this model, the elevation in each cell is assumed to be constant, resulting in a topography resembling "columnar jointing in basalts" (Figure 5.4a). On the other hand, although the calculations of the surface processes are based on the flat top of the Voronoi cells, it is more convenient to render the topography using Delaunay triangulation, reducing the number of polygons to be displayed (Figure 5.4b).

The geometric parameters needed to numerically calculate the surface processes are (for a specific cell $i$ ): the elevation $h_{i}$; the cell area $S_{i}$; the edge length $\partial S_{i j}$ between the cell $i$ and the neighbor cell $j$ and the distance $L_{i j}$ between $i$ and $j$ (see Figure 5.3).

\subsubsection{Onshore and offshore diffusion}

The diffusion, both in equation 5.1 for hillslope transport and in equation 5.4 for offshore transport, is numerically calculated through an explicit finite volume approximation.

Therefore, the variation in elevation $\Delta h_{i}$ due to diffusion for the cell $i$ during the time step $\Delta t$ is

$$
\frac{\Delta h_{i}}{\Delta t}=\nabla \cdot\left(k_{d i f f} \nabla h_{i}\right)
$$

where $k_{\text {diff }}$ can be either $k_{d}$ or $k_{m}$.

Integrating both sides in the cell area $S_{i}$ (observing that $\Delta h_{i}$ is constant in $S_{i}$ ):

$$
S_{i} \frac{\Delta h_{i}}{\Delta t}=\int_{S_{i}} \nabla \cdot\left(k_{d i f f} \nabla h_{i}\right) d S
$$

Applying the divergence theorem to the right side:

$$
S_{i} \frac{\Delta h_{i}}{\Delta t}=\oint_{\partial S_{i}} k_{d i f f} \nabla h_{i} \cdot \vec{n} d l
$$

The line integral can be calculated as the sum of the integrals in each of the edges $\partial S_{i j}$

$$
S_{i} \frac{\Delta h_{i}}{\Delta t}=\sum_{j} \int_{\partial S_{i j}} k_{d i f f} \nabla h_{i} \cdot \vec{n} d l .
$$

In each segment $\partial S_{i j}$, the integrand is constant, and can be approximated as

$$
k_{d i f f} \nabla h_{i} \cdot \vec{n} \approx-k_{d i f f} \frac{h_{i}-h_{j}}{L_{i j}} \quad \text { in } \quad \partial S_{i j}
$$


Finally the expression for $\Delta h_{i}$ is

$$
\Delta h_{i}=-\frac{\Delta t}{S_{i}} \sum_{j} k_{d i f f} \frac{h_{i}-h_{j}}{L_{i j}} \partial S_{i j} .
$$

\subsubsection{Fluvial processes}

The maximum sediment volume $Q_{f i}^{e q b}$ that the cell $i$ can transport to the downstream cell $j$ in the time step $\Delta t$ is

$$
Q_{f i}^{e q b}=k_{f} Q_{r i} \frac{h_{i}-h_{j}}{L_{i j}} .
$$

This expression is the space-time integrated form of equation 5.3, where $Q_{f i}^{e q b}=q_{f}^{e q b} \Delta t S_{i} / L_{i j}$, $Q_{r i}=q_{r} \Delta t S_{i} / L_{i j}$ and $|\nabla h| \approx \frac{h_{i}-h_{j}}{L_{i j}}$. $Q_{r i}$ represents the cumulative volume of water that flows to the cell $i$ from upstream cells $u$ plus the local precipitation $v_{R i}$ during the time step $\Delta t$ :

$$
Q_{r i}=\sum_{u} Q_{r u}+v_{R i} S_{i} \Delta t
$$

If the sediment volume $Q_{f i}$ transported is greater than $Q_{f i}^{e q b}$, deposition takes place in cell $i$ as follows

$$
\Delta h_{i}=\frac{Q_{f i}-Q_{f i}^{e q b}}{S_{i}}
$$

and the sediment volume transported in cell $j$ is updated

$$
Q_{f j} \leftarrow Q_{f j}+Q_{f i}^{e q b}
$$

If $Q_{f i}<Q_{f i}^{e q b}$, then erosion takes place

$$
\Delta h_{i}=\frac{Q_{f i}-Q_{f i}^{e q b}}{S_{i}} \frac{L_{i j}}{L_{f, e}}
$$

and the sediment volume transported in cell $j$ is updated

$$
Q_{f j} \leftarrow Q_{f j}+Q_{f i}+\left(Q_{f i}^{e q b}-Q_{f i}\right) \frac{L_{i j}}{L_{f, e}} .
$$

To calculate the cumulative volume of water $Q_{r}$ in each cell, the first step is to sort the nodes from the upstream cells to the downstream ones. For this, it is assumed that water flows from one cell to the other through the steepest direction, as shown in Figure 5.4c, following the edges of the Delaunay triangulation (Figure 5.4d).

The cascade algorithm developed by Braun and Sambridge (1997) is used to calculate the discharge. This algorithm is as follows, with few modifications here: 
- (1) determine the steepest direction for each node, not taking into account offshore nodes, i.e. nodes below the sea level $\left(h_{i}<h_{s . l .}\right)$, and "sink" nodes, i.e. previously specified nodes that behave as local base levels.

- (2) Each cell receives a flag $=1$

- (3) If a cell receives water from an upstream cell with flag $\neq 2$, flag changes to 0

- (4) If flag $=1$ in cell $i$, calculate $Q_{r i}$ (equation 5.6), $Q_{f i}^{e q b}$ (equation 5.5) and the local topography variation $\Delta h_{i}$ (equation 5.7 or 5.9 ). Update the sediment volume transported in the downstream cell $j$ (equation 5.8 or 5.10) and add the parcel of water $Q_{r i}$ to the cell $j$. Flag of cell $i$ changes to 2 .

- (5) If flag $=0$, change to 1.

- (6) If all flags $=2$, exit, otherwise go to (3).

This algorithm has the advantage that it is not necessary to sort all the nodes from the highest to the lowest, and the sorting of the nodes can be done directly at the catchment level.

To avoid loss of water in local minima in the landscape, the water that flows toward a local minimum is redirected to the lowest cell of a neighbor drainage basin that flows to the base level (see Braun and Sambridge, 1997).

\subsection{Example}

To illustrate the numerical model for the surface processes, in Figures 5.5 and 5.6 is presented the simulation of the erosion of a plateau and the deposition of the eroded material in the offshore domain. The parameters of the model are shown in Table 5.1. At the beggining of the simulation (Figure 5.5), the plateau is at $h=2000 \mathrm{~m}$ and the ocean bottom is at $h=-2000 \mathrm{~m}$. The area of the model is $200 \times 200 \mathrm{~km}^{2}$, and the model configuration is presented at 0,2, 4 and 6 Myr in the Figures 5.5 and 5.6.

During the process of erosion and the formation of incisions throughout the continent, the sediments are transported to the coast. In each river mouth is observed the formation of deltas that widen laterally and oceanward. The gradual deposition of the sediments 

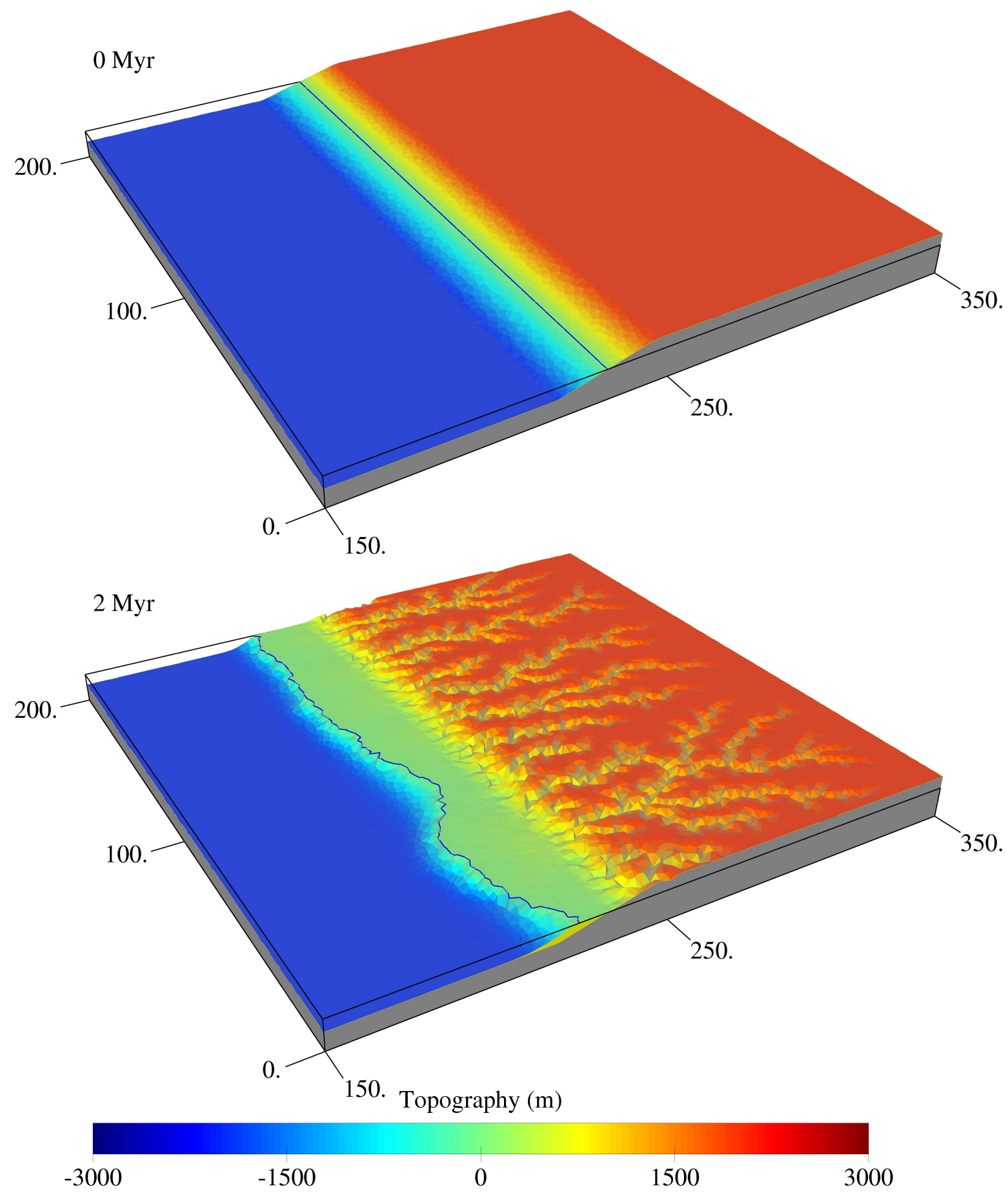

Figure 5.5: Example of the surface processes model, illustrating the erosion of a plateau and the deposition of the sediments in the offshore domain, at 0 and 2 Myr. The horizontal dimensions of the model are in kilometers. The gray and yellow regions at the side of the model represent the bedrock and the sediments, respectively. 

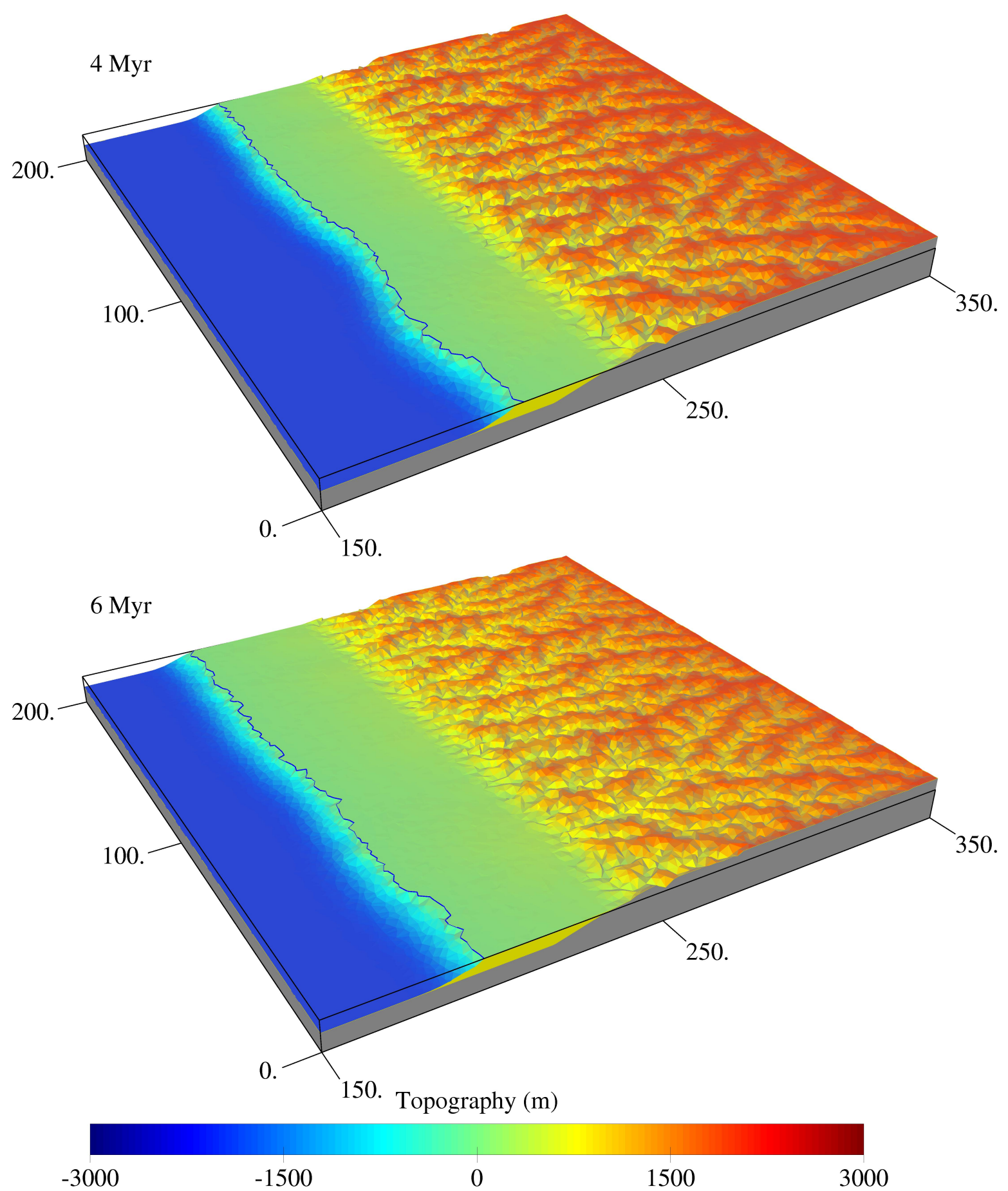

Figure 5.6: Continuation of the Figure 5.5, at 4 and 6 Myr. The horizontal dimensions of the model are in kilometers.

results in the formation of a prograding sedimentary wedge, resulting in the development of a continental shelf. 
As the sea level is constant through time and there is no isostatic compensation or thermal effect in this example, the continuos influx of sediments to the ocean results in progradation, shown by the blue curve in the Figures 5.5 and 5.6, that represents the shoreline.

\begin{tabular}{l|ccl}
\hline & Parameters & Description & Value \\
\hline \multirow{5}{*}{ Surface } & $h_{s . l .}$ & Sea level & $0 \mathrm{~m}$ \\
processes & $k_{m}^{*}$ & Diffusivity for the offshore transport & $80 \mathrm{~m}^{2} /$ year \\
& $h_{0}$ & Decay factor for the offshore transport & $1000 \mathrm{~m}$ \\
& $L_{f s}$ & Alluvial erosion lenght scale & $10 \mathrm{~km}$ \\
& $L_{f b}$ & Bedrock erosion lenght scale & $100 \mathrm{~km}$ \\
& $k_{s} / k_{f} v_{R}$ & & $10 \mathrm{~m}$ \\
& $\delta_{r}$ & Mean distance between adjacent nodes & $2 \mathrm{~km}$ \\
\hline
\end{tabular}

Table 5.1 - Parameters and their values used in the model of Figures 5.5 and 5.6. 


\section{Chapter 6}

\section{Coupling of the processes}

Perhaps the most significant achievement to date is the recognition that the problem is a dynamic one, with a hierarchy of couplings and feedback mechanisms.

(Beaumont et al., 2000)

The coupling of the different processes presented in the previous four chapters is described in the following lines.

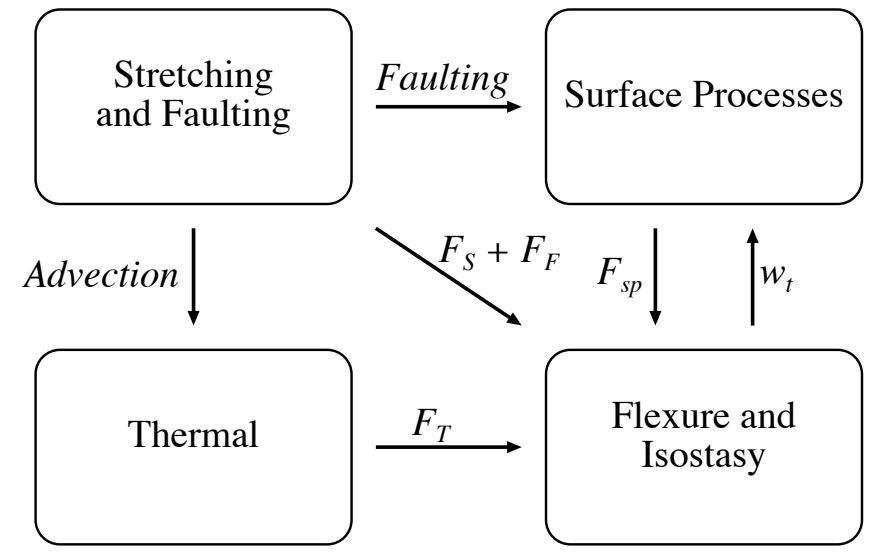

Figure 6.1: Interaction between the different processes in the numerical model to study the evolution of passive margins. $F_{T}, F_{S}, F_{F}$ and $F_{s p}$ represent, respectively, the vertical loads associated with thermal effects, stretching of the lower crust, faulting in the upper crust and surface processes of erosion and deposition. $w_{t}$ represents the vertical movement of the lithosphere.

In the present model (Figure 6.1), the stretching of the lithosphere reshapes the surface by faulting and alters the flexural isostatic state of the lithosphere due to horizontal 
movement of density interfaces, creating a vertical stress related to faulting of the upper crust $\left(F_{F}\right)$ and thinning of the lower crust during stretching $\left(F_{S}\right)$. Stretching also results in advection of material that perturbs the thermal state of the lithosphere, which, in turn, changes its density, resulting in additional vertical stress $\left(F_{T}\right)$. Surface processes also induce vertical stresses in the lithosphere $\left(F_{s p}\right)$ by redistribution of mass associated with erosion, transport and deposition of sediments. The flexural response of the lithosphere to these loads results in vertical movement of the surface $w_{t}$, perturbing the topography and consequently the evolution of surface processes.

\subsection{The coupling of stretching, thermal and flexural models}

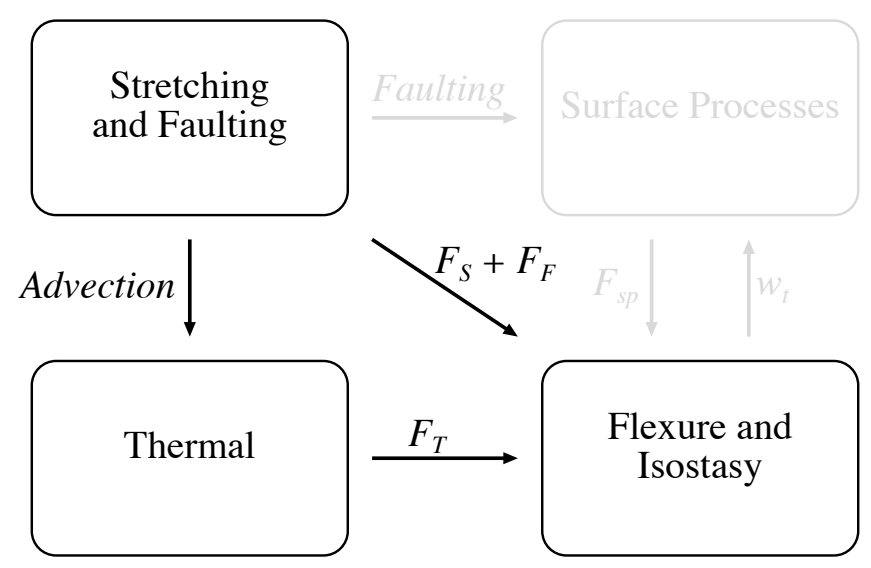

Figure 6.2: Diagram showing the coupling of the stretching, thermal and flexural models.

In the numerical model, stretching of the lithosphere perturbs the thermal state of the lithosphere through advection, guided by the upwelling divergent flow, as described in equation 4.1. This velocity field is used in the expression for the stiffness matrix $\mathbf{K}_{a}^{*}$ in equation 3.17 .

The vertical load $F_{T}$ associated with any perturbation of temperature $\Delta T$, from the initial geothermal gradient and the associated density variation is given by:

$$
F_{T}=\int_{-a_{L}}^{0} \rho_{m}\left[\alpha_{T} \Delta T\right] g d z
$$

where $\alpha_{T}$ is the thermal expansion coefficient and $-a_{L}$ is the base of the lithosphere. 
Thinning of the lower crust and consequent Moho uplift is governed by the same advection velocity as used for the thermal model (equation 4.1). The vertical load $F_{S}$ arising from stretching and thinning of the lower crust is given by:

$$
F_{S}=\left(\rho_{m}-\rho_{c}\right) g \Delta h_{\text {crust }}
$$

where $\Delta h_{\text {crust }}$ is the variation of crustal thickness resulting from the stretching of the lower crust and $\rho_{c}$ is the density of the crust.

The flexural effect due to faulting of the upper crust is treated following the flexural cantilever model, as explained in section 4.3.

\subsection{Modification of the surface processes due to faulting}

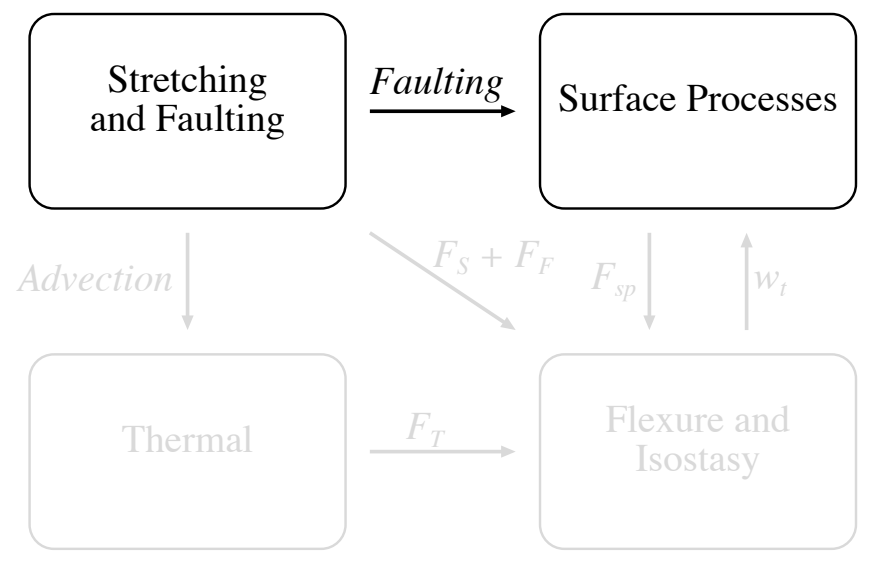

Figure 6.3: Diagram showing the influence of faulting on the surface processes.

To simulate the relative movement between crustal blocks, the irregular surface mesh must be updated and at specific times new points must be introduced.

Firstly, the mesh is divided into two regions $\left(\mathbf{R}_{1}, \mathbf{R}_{2}\right)$ separated by a curve that represents the fault line, i.e. the intersection of the fault with the surface. The position of the curve that represents the fault line in the $x$ axis is function of $y\left(x_{\text {fault }}=x_{\text {fault }}(y)\right)$ and the direction of relative movement of blocks is in the $x$ direction. A point $\mathbf{x}_{i}$ belongs to $\mathbf{R}_{1}$ if $x_{i}<x_{\text {fault }}\left(y_{i}\right)$, and to $\mathbf{R}_{2}$ if $x_{i}>x_{\text {fault }}\left(y_{i}\right)$. 
If the fault dips to the right, $\mathbf{R}_{1}$ represents the footwall and $\mathbf{R}_{2}$ the hanging wall, as shown in Figure 6.4. If the fault dips to the left, $\mathbf{R}_{1}$ is the hanging wall and $\mathbf{R}_{2}$ is the footwall.

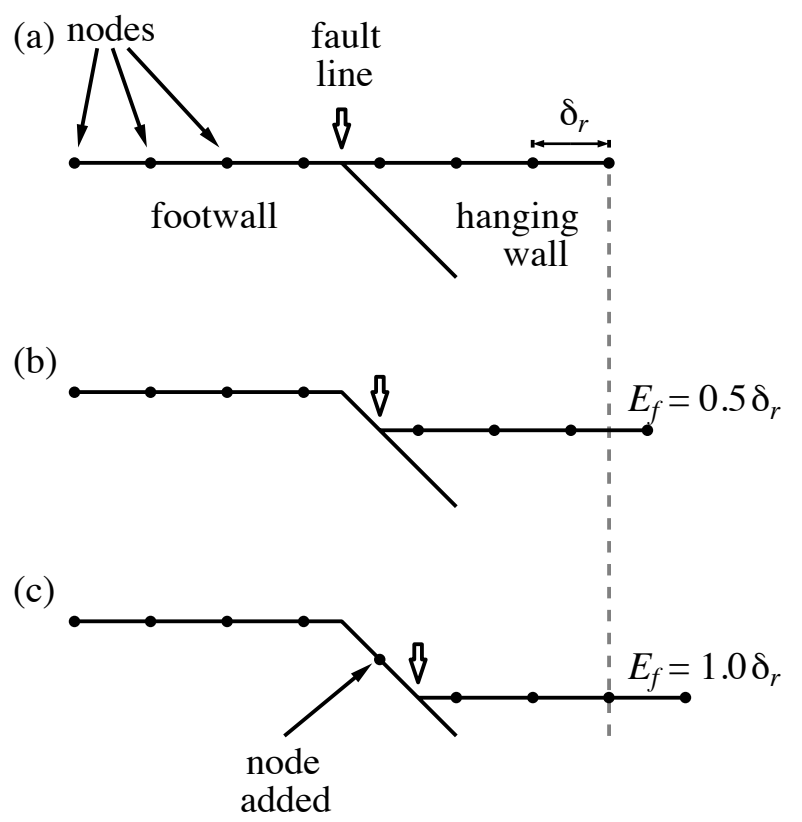

Figure 6.4: Illustration of the updating of the surface mesh during faulting. The dots represent the nodes of the surface mesh. The position of the fault line is indicated by a vertical arrow. $\delta_{r}$ is the mean distance between adjacent nodes (see section 5.3). Note that this illustration shows only the kinematic description of the relative movement between the two crustal blocks and does not take into account the flexural response to this tectonism. (a) Initial configuration. (b) Configuration after an extension $E_{f}=0.5 \delta_{r}$. (c) Configuration after an extension $E_{f}=\delta_{r}$, when a new point is added to the mesh and this new point belongs to the footwall.

Assuming that the fault dips at an angle $\theta$, the extension $E_{f}$ results in the following displacement of the nodes on the hanging wall:

$$
\begin{aligned}
& h_{i} \leftarrow h_{i}-E_{f} \tan \theta \\
& x_{i} \leftarrow x_{i}+E_{f} \operatorname{dip}_{s}
\end{aligned}
$$

where $\operatorname{dip}_{s}$ is related to the dip sense of the fault and is defined as

$$
\operatorname{dip}_{s}=\left\{\begin{aligned}
1 & \text { if } \mathbf{R}_{1} \text { is the footwall } \\
-1 & \text { if } \mathbf{R}_{2} \text { is the footwall }
\end{aligned}\right.
$$



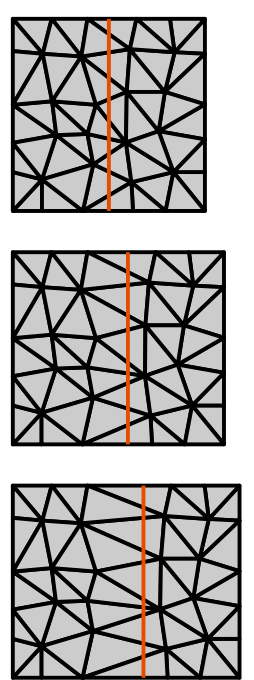

$E_{f}=0.9 \delta_{r}$

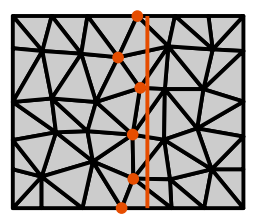

$$
E_{f}=0.0 \delta_{r}
$$
$E_{f}=0.5 \delta_{r}$
Figura 6.5: Updating of the triangular mesh during faulting. The orange line shows the position of the fault line. In this figure the nodes to the left of the fault line belong to the footwall and the nodes to the right belong to the hanging wall. After an extension $E_{f} \geq \delta_{r}$ (see section 5.3), new nodes are added to the footwall block, indicated in the figure as orange dots.

$E_{f}=1.0 \delta_{r} \quad$ During the faulting the mesh is continuously updated, following the Delaunay triangulation.

Likewise the position of the fault line is updated relative to the footwall:

$$
x_{\text {fault }} \leftarrow x_{\text {fault }}+E_{f} \operatorname{dip}_{s}
$$

After the relative movement between the two crustal blocks, the mesh is updated (Figure 6.5), verifying if the triangular mesh preserves the properties of a Delaunay triangulation (see section 5.3.2).

During faulting and extension, the area $S_{i}$ of the Voronoi cells associated with the nodes close the fault line increases. To ensure conservation of sediment volume in the cells during faulting, the sediment thickness $\Delta h_{\text {sed }}$ is updated:

$$
\Delta h_{\text {sed }} \leftarrow \Delta h_{\text {sed }} \frac{S_{i, \text { previous }}}{S_{i, \text { actual }}}
$$

where $S_{i, \text { previous }}$ and $S_{i, \text { actual }}$ are the previous and actual area of the Voronoi cell $i$, respectively.

When the extension $E_{f}$ is equal to or exceeds the distance $\delta_{r}$ (see section 5.3), new nodes are added to preserve the node density of the mesh. The new nodes belong to the footwall block, as shown in Figure 6.4c and the triangular mesh is updated with the inclusion of the new nodes (Figure 6.5).

The elevation of the basement $h_{\text {bed }}$ for the new nodes is equal to the height of the fault at this point (Figure 6.4c). On the other hand, the sediment thickness $\Delta h_{\text {sed }}$ is obtained 
through linear interpolation of the sediment thickness of the neighbor cells. Finally the elevation of the cell $h$ is obtained by:

$$
h=h_{\text {bed }}+\Delta h_{\text {sed }}
$$

\subsection{Flexure and isostatic compensation}

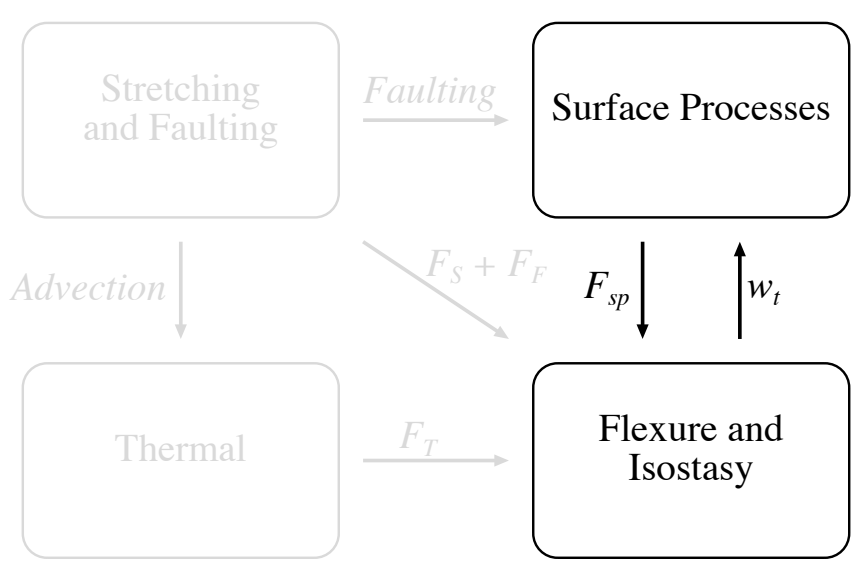

Figure 6.6: Interaction between surface processes and flexural isostasy.

To compute the vertical load $F_{s p}$ resulting from a variation in topography $\Delta h$ associated with surface processes, sediment density $\rho_{s}$ is assumed to be equal to the crustal rock density, for the sake of simplicity. With this approximation, the vertical load $F_{s p}$ is

$$
F_{s p}= \begin{cases}-\rho_{c} g \Delta h+\rho_{w} g \Delta h & \text { if } h+\Delta h<h_{s . l .} \text { and } h<h_{\text {s.l. }} \\ -\rho_{c} g \Delta h+\rho_{w} g\left(h_{s . l .}-h\right) & \text { if } h+\Delta h>h_{s . l .} \text { and } h<h_{\text {s.l. }} \\ -\rho_{c} g \Delta h+\rho_{w} g\left(h+\Delta h-h_{\text {s.l. }}\right) & \text { if } h+\Delta h<h_{\text {s.l. }} \text { and } h>h_{\text {s.l. }} \\ -\rho_{c} g \Delta h & \text { if } h+\Delta h>h_{\text {s.l. }} \text { and } h>h_{\text {s.l. }}\end{cases}
$$

where $\rho_{w}$ is water density and $h_{s . l .}$ is the sea level.

Surface topography is updated by adding the total vertical displacement $w_{t}$ of the surface to the initial topography. This displacement is the sum of the components related to faulting $d_{f}$ (see section 4.3) and the flexural response of the upper crust and lithosphere, respectively $w_{F}$ and $w$ :

$$
w_{t}=w+w_{F}+d_{f} .
$$


Observe that $\Delta h$ is the variation of topography related only to the surface processes of erosion $(\Delta h<0)$ and deposition $(\Delta h>0)$. Therefore $\Delta h$ is independent of the flexural response of the lithosphere. On the other hand, the variation in topography $\Delta h$ induces vertical loads $F_{s p}$ in the lithosphere which are regionally compensated by the lithosphere resulting in a vertical displacement $w_{t}$ of the surface.

To calculate the vector load $\mathbf{f}$ for the flexural model (equation 2.20), the load $F_{s p}$ from the irregular mesh must be interpolated to the finite element mesh of the flexural model (Figure 6.7a).

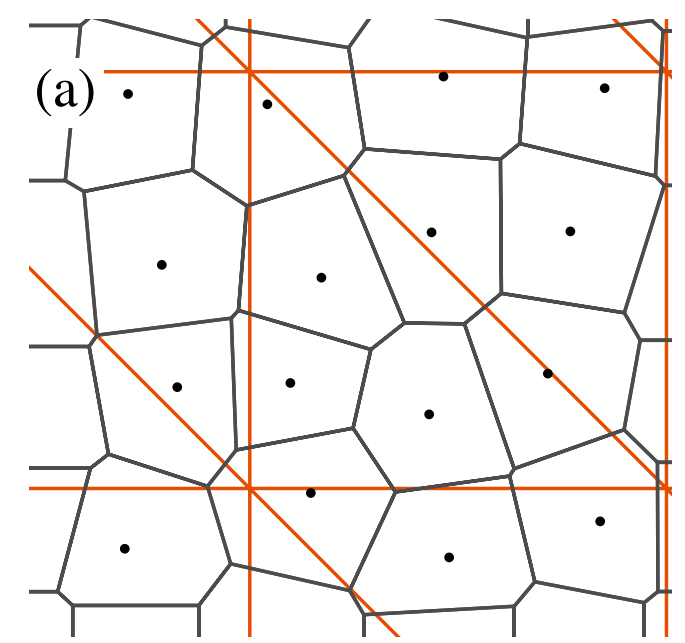

(b)

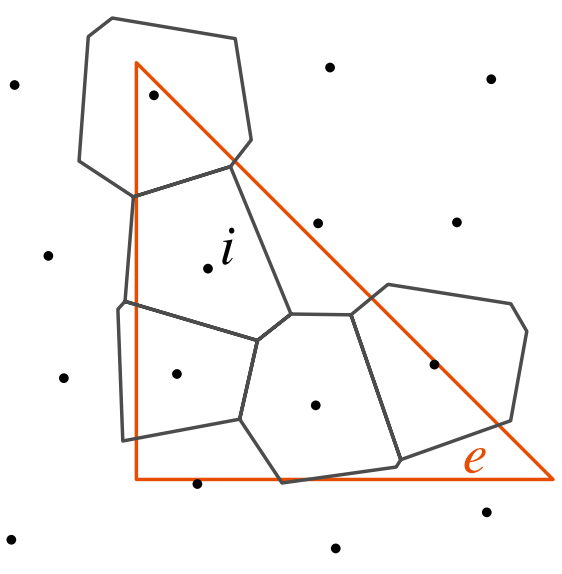

Figure 6.7: (a) Superposition of the Voronoi cells of the surface processes model on the triangular finite element mesh of the flexural model. (b) Approximation for the load of the surface processes, assuming that loading in one cell is concentrated on the node at the center of the cell. The figure shows the five cells that contribute with the load on the highlighted triangular element.

One strategy to rapidly calculate the load from the irregular mesh to the finite element model is to assume that the load in each cell is concentrated on the node at the center of the cell. This approximation avoids the calculation of all partial areas of the cells superposed on the triangular elements.

Therefore, for a node $i$ of the surface mesh inside the triangular element $e$ (Figure 6.7b), the contribution of the load of the cell $i$ on the element $e$ is (see equation 2.20)

$$
\mathbf{f}_{\text {Cell } i}=\overline{\mathbf{f}}_{\text {Cell } i}^{e}=\int_{\Omega^{e}} \mathbf{N}^{\mathrm{T}} \bar{q}_{\text {Cell } i} d \Omega=\mathbf{N}_{\left(x_{i}, y_{i}\right)}^{\mathrm{T}} F_{s p} S_{i}
$$

where $\mathbf{N}$ is the row vector containing the shape functions (see section 2.3) and $S_{i}$ is the 
area of the Voronoi cell $i$. For illustration, the element $e$ in the Figure 6.7b is loaded by five cells.

This approximation is reasonable for two reasons: Firstly the area of the finite elements is relatively larger than the cell area. In the illustration of Figure $6.7 \mathrm{~b}$ the ratio between element area and the cell area is nearly 4.5 , but in the numerical models presented in this work, this ratio is around 20. Secondly the flexural rigidity of the plate tends to smooth the effect of local variation of the load.

After the solution of the flexural equation, the deflection of the plate is interpolated to the irregular mesh:

$$
w_{i}=w_{t 1} L_{1}+w_{t 2} L_{2}+w_{t 3} L_{3}
$$

where $w_{i}$ is the interpolated deflection in the node $i, w_{t 1}, w_{t 2}$ and $w_{t 3}$ are the deflections at the nodes of the finite element $e$, and $L_{1}, L_{2}$ and $L_{3}$ are the areal coordinates (see section 2.3) for the element $e$ at the point $\left(x_{i}, y_{i}\right)$.

\subsection{The "water load delay" algorithm}

The isostatic term in the equation for the flexural isostasy is usually described as dependent on the difference of density $\Delta \rho$ between the asthenosphere and the fluid at the surface displaced during the isostatic adjustment of the plate.

For example, during erosion of the continents, the isostatic response of the lithosphere displaces the air. As the density of the air is negligible, the difference of density $\Delta \rho$ is equal to the density of the asthenosphere $\left(\Delta \rho=\rho_{m}-\rho_{\text {air }}=\rho_{m}\right)$. But the isostatic response of the lithosphere to sedimentation in the offshore basins results in subsidence that is filled with water, amplifying the subsidence. In this case the density of the water is not negligible and $\Delta \rho=\rho_{m}-\rho_{w}$. Therefore, the value of $\Delta \rho$ depends whether the isostatic compensation is subaerial or submarine. Since the position of the shoreline changes through time during the simulation of the surface processes, $\Delta \rho$ is dependent on time and space.

The stiffness matrix $\mathbf{K}$ in equation 2.8 for the flexural problem is dependent on the isostatic term, implying that the stiffness matrix must be rewritten every time $\Delta \rho$ is modified, which is time consuming.

To avoid the modification of $\mathbf{K}$ due to variations in $\Delta \rho$, in the present work the bu- 
oyancy term is treated as dependent only on the density of the asthenosphere $\rho_{m}$ and the additional load associated with variations of the water layer during isostatic compensation is incorporated in the load $\bar{q}$ in equation 2.9 .

To illustrate this procedure, consider equation 2.1 with the isostatic term shown explicitly:

$$
(\mathbf{L} \nabla)^{\mathrm{T}} \mathbf{D L} \nabla w+\Delta \rho g w=\bar{q}
$$

In the submarine domain $\Delta \rho=\rho_{m}-\rho_{w}$. Therefore:

$$
(\mathbf{L} \nabla)^{\mathrm{T}} \mathbf{D L} \nabla w+\rho_{m} g w=\bar{q}+\rho_{w} g w
$$

In equation 6.6 the last term is the additional water load related to the isostatic compensation of the plate to the load $\bar{q}$. Clearly the water load cannot be treated explicitly as the load for the equation, because it depends on the solution $w$ of the equation. One approximation is to use the known water load of the previous time step $\rho_{w} g w_{t-\Delta t}$ to calculate the new deflection $w_{t}$ :

$$
(\mathbf{L} \nabla)^{\mathrm{T}} \mathbf{D L} \nabla w_{t}+\rho_{m} g w_{t}=\bar{q}+\rho_{w} g w_{t-\Delta t}
$$

In this expression, the isostatic term is dependent only on the density of the asthenosphere $\rho_{m}$ and the stiffness matrix $\mathbf{K}$ does not need to be rewritten every time step. This approximation is named here as the "water load delay" approximation.

Observe that the equation 6.7 is applicable to the onshore domain if the last term is omitted.

To show that this new approximation for the isostatic compensation presented in equation 6.7 converges to the exact solution, an analytical proof is given in Appendix B. 
Chapter 7

\title{
Application of the model to natural examples
}

\author{
Models can be confirmed by the demonstration of \\ agreement between observation and prediction, \\ but confirmation is inherently partial.
}

(Oreskes et al., 1994)

The following sections present the application of the numerical models described in the previous chapters to natural examples. In the first section, the model is applied to study how different rift styles influence the evolution of escarpments in divergent margins. The main result from this work is that the position of the drainage divide is strongly dependent on the amount of extension in the rifted margin. Moreover, the models show that the retreating escarpment scenario is unlikely when the lower crust under the rift flank is substantially stretched. These results are applied to study the evolution of the margins in Southeastern Australia and Southeastern Brazil. In the second section, the model is used to study the influence of post-rift thermal anomalies at the base of the lithosphere and how the stratigraphic sequence is affected by isostatic response of the lithosphere to the transient thermal anomaly. As an example, a possible influence of the passage of the Trindade Plume on the marginal basins of Campos and Espirito Santo is discussed.

It is important to highlight that the conclusions of the present work are based on the results of numerical models that represent a simplification of the real world. Certainly, many other processes may affect the evolution of the margin. However, the proposed integrated numerical models quantify the relative influence of flexure, thermal effects, stretching styles and surface processes on the evolution of different tectonic scenarios, keeping in mind that the "primary value of models is heuristic" (Oreskes et al., 1994). 


\subsection{The influence of rifting on escarpment migration ${ }^{1}$}

\subsubsection{Abstract}

Using numerical models that couple surface processes, flexural isostasy, faulting and the thermal effects of rifting, we show that fault-bounded escarpments created at rift flanks by mechanical unloading and flexural rebound have little potential to "survive" as retreating escarpments if the lower crust under the rift flank is substantially stretched. In this configuration, a drainage divide that persists through time appears landward of the initial escarpment in a position close to a secondary bulge that is created during the rifting event at a distance that depends on the flexural rigidity of the upper crust. Moreover, the migration of the escarpment to the secondary bulge occurs when the pre-rift topography dips landward, otherwise the evolution of the escarpment is guided by the pre-existing inland drainage divide. To illustrate this new mechanism for the evolution of passive margins, we study the examples of Southeastern Australia and Southeastern Brazil. We propose that a pre-existing inland drainage divide with rift related flank uplift can produce the double drainage divide observed in Southeastern Australia. On the other hand, we conclude that it is possible that the Serra do Mar escarpments on the Southeastern Brazilian margin originated as a secondary flexural bulge during rifting that persisted through time. In both cases, the retreating escarpment scenario is unlikely and the presentday margin morphology can be explained as resulting from rift-related vertical motions alone, without requiring significant post-rift "rejuvenation".

\subsubsection{Introduction}

Many rifted margins around the world are flanked by great escarpments, i.e. up to 1500m high topographic steps subparallel to the coast that separate high-elevation continental interior plateaux from low-elevation coastal regions. These escarpments are observed along both young and old rifted margins (e.g. the Red Sea escarpment bordering a 30-25 Ma continental margin; the Serra do Mar escarpment along the 140-130 Ma Southeastern

\footnotetext{
${ }^{1}$ This section is part of the submitted article of Sacek, Braun, and van der Beek (2011). The manuscript of this section was maintained in the active voice, as in the original paper. The numerical model described in the Chapters 2 to 6 is briefly reintroduced in this section to maintain the logical structure of the original manuscript.
} 
Brazilian margin; and the Great Escarpment of Southeastern Australia escarpment where rifting occurred at 100-80 Ma).

Many authors have demonstrated that the evolution and persistence of these escarpments through geological time is the result of the combined effect of erosion and the flexural isostatic response of the lithosphere to stretching and rifting (Braun and Beaumont, 1989; Gilchrist and Summerfield, 1990; Kooi and Beaumont, 1994; Tucker and Slingerland, 1994). Although these mechanisms successfully explain the persistence of escarpments, their postrift evolution remains controversial (Braun and van der Beek, 2004), as different initial conditions for the margin may result in very different denudation histories, while leading to similar present-day morphologies (Gilchrist et al., 1994; Gallagher and Brown, 1999; Braun and van der Beek, 2004). Moreover, many geomorphologists remain convinced that high-elevation rifted margins require some form of post-rift reactivation (e.g. Partridge and Maud, 1987; Ollier and Pain, 1994; Japsen et al., 2006; Burke and Gunnell, 2008). Finally, topographic patterns may be complexified by local structural and/or lithological controls (e.g. van der Beek et al., 2001; Gunnell and Harbor, 2010).

Gilchrist et al. (1994), Kooi and Beaumont (1994) and van der Beek et al. (2002) demonstrated the importance of the position of a preexisting drainage divide on the evolution of the escarpment, highlighting two possible denudation scenarios: the escarpment-retreat scenario, where the original escarpment is the main drainage divide after rifting and remains the divide during post-breakup escarpment evolution; and the plateau-degradation scenario, where the initial drainage divide is located landward of the margin. In the first scenario, the escarpment migrates continuously landward as the headwaters of the seaward-draining rivers cut back into the plateau at the escarpment top, whereas in the second scenario the inland drainage divide remains stationary and the original escarpment, near the coast, is eroded away and is progressively replaced by an escarpment pinned at the preexisting inland divide.

In the above models, it was assumed that the existence and location of a preexisting inland divide are set by external factors; i.e. the initial topography is a relict from previous tectonic, magmatic or geomorphic events, unrelated to the rifting process. These results were based on landscape evolution models that do not take the development of offshore basins and the kinematics associated with rifting and breakup into account. Other models 
(e.g. Pazzaglia and Gardner, 1994; van Balen et al., 1995) simulated the post-rift evolution of margins to study the interaction of onshore and offshore processes, considering the flexural response of the lithosphere to erosion and deposition. On the other hand, qualitative models have been proposed to explain the formation of an inland drainage divide in response to underplating during rifting, resulting in crustal thickening and uplift of the topography (e.g Lister et al., 1986; Lister and Etheridge, 1989). More recent thermo-dynamic modelling has shown that this style of rifting is feasible (Huismans and Beaumont, 2003).

In this work we present the results of a new numerical model for the evolution of rifted margins that combines surface processes, flexural isostasy and the kinematic effects of both faulting of the upper crust and stretching of the lithosphere. The novelty of our approach is that it combines the effects of these processes to predict the evolution of the margin's morphology since the onset of extension. We show that even when the initial drainage divide is close to the margin, the effect of crustal thinning and the subsequent thermal subsidence of the margin naturally creates a secondary drainage divide in an inland position, the location of which essentially depends on the flexural rigidity of the crust and lithosphere. Under some circumstances, the system may evolve in such a way that the final escarpment position coincides with the secondary divide, similar to the plateau degradation scenario mentioned above. We apply our model to two case studies on the Southeastern Brazilian and Southeastern Australian margins, to assess how much of the overall margin topography can be explained by our model, without recourse to postrifting tectonic "rejuvenation" of the margins or local structural or lithologic control. Our approach is therefore to explore in how much rifted margin topography can be explained in a systemic manner and what aspects would require conjectural explanations.

\subsubsection{The numerical model}

The processes acting during and after rifting are numerous, complex and often interconnected. They include stretching and faulting in the lithosphere, which will induce a strong perturbation to its thermal structure. The rift and the post-rift stages of the margin evolution are affected by thermal effects, flexure and isostatic compensation that determine the amplitude and rate of change of surface subsidence and uplift. Concomitantly, surface processes act to transport mass at the surface of the Earth to create landforms and also 
affect the isostatic balance of the lithosphere.

These processes result in a set of competing forces as shown in Figure 6.1. Stretching of the lithosphere reshapes the surface by faulting and alters the flexural isostatic state of the lithosphere due to horizontal movement of density interfaces, creating vertical forces related to faulting of the upper crust $\left(F_{F}\right)$ and thinning of the lower crust during stretching $\left(F_{S}\right)$. Stretching also results in advection of material that perturbs the thermal state of the lithosphere, which, in turn, changes its density, resulting in vertical forces, which we name $F_{T}$. Surface processes also induce vertical forces in the lithosphere $\left(F_{s p}\right)$ by redistribution of mass associated with erosion, transport and deposition of sediments. The flexural response of the lithosphere to these loads results in vertical movement of the surface $w_{t}$, perturbing the topography and consequently the evolution of surface processes.

To quantify the complex interactions between there various processes we have developed a numerical model. In the following lines, we describe each process in detail together with its numerical implementation.

\section{Flexure and isostasy}

To simulate the response of the lithosphere to vertical loading, we consider regional isostatic compensation using the thin elastic plate approximation

$$
(\mathbf{L} \nabla)^{\mathrm{T}} \mathbf{D L} \nabla w+\left(\rho_{m}-\rho_{i n}\right) g w=F
$$

where $w$ is the vertical displacement of the plate, $g$ is the acceleration of gravity (Table 7.1), $\rho_{m}$ is mantle density, $\rho_{i n}$ is the density of the material infilling the depressions, $F$ is the vertical load,

$$
\begin{aligned}
& (\mathbf{L} \nabla)=\left[\frac{\partial^{2}}{\partial x^{2}}, \frac{\partial^{2}}{\partial y^{2}}, 2 \frac{\partial^{2}}{\partial x \partial y}\right]^{\mathrm{T}} \\
& \mathbf{D}=D\left[\begin{array}{ccc}
1 & \nu & 0 \\
\nu & 1 & 0 \\
0 & 0 & (1-\nu) / 2
\end{array}\right]
\end{aligned}
$$

$D=E T_{e}^{3} / 12\left[1-\nu^{2}\right]$ is the flexural rigidity of the plate and depends on Young's modulus $E$, the effective elastic thickness $T_{e}$ and Poisson's ratio $\nu$.

The vertical load $F$ is obtained by the summation of the forces related to thermal 
effects $F_{T}$ (equation 7.4), surface processes $F_{s p}$ (equation 7.8) and thinning of the lower crust $F_{S}$ (equation 7.5), as described below.

Equation 7.1 is solved numerically using the finite-element method; a complete description of this implementation is given in Sacek and Ussami (2009). Note that this finiteelement formulation can include effects arising from spatial variations in flexural rigidity.

\section{Thermal model}

The thermal evolution of the lithosphere is obtained by solving the three-dimensional heat-transfer equation

$$
\rho c\left(\frac{\partial T}{\partial t}+\mathbf{v} \cdot \nabla T\right)=\nabla \cdot(k \nabla T)
$$

where $T$ is temperature, $\rho$ is density, $c$ is heat capacity, $k$ is conductivity and $\mathbf{v}=$ $\left(u_{a d v}, v_{a d v}, w_{a d v}\right)$ is the advection velocity.

The advection velocity $\mathbf{v}$ describes the velocity of rock particles during stretching of the lithosphere. To simulate the upwelling divergent flow associated with the divergence of conjugate rift margins and stretching of the lower part of the lithosphere near the center of the rift, we assume that $\mathbf{v}$ is the solution to the classical corner-flow problem, which is given by (Fletcher et al., 2009):

$$
\begin{aligned}
& u_{a d v}=\operatorname{sign}(x)\left[-A_{2}-A_{4}\left(\arctan \frac{z}{|x|}\right)+\left(A_{3}|x|+A_{4} z\right)\left(\frac{-|x|}{x^{2}+z^{2}}\right)\right] \\
& w_{a d v}=-\left[A_{1}+A_{3}\left(\arctan \frac{z}{|x|}\right)+\left(A_{3}|x|+A_{4} z\right)\left(\frac{-z}{x^{2}+z^{2}}\right)\right]
\end{aligned}
$$

where, for the geometry and boundary conditions of our problem,

$$
A_{1}=0, A_{2}=\frac{2 \pi U_{z}-\pi^{2} U_{x}}{\pi^{2}-4}, A_{3}=\frac{4 U_{x}-2 \pi U_{z}}{\pi^{2}-4}, A_{4}=\frac{2 \pi U_{x}-4 U_{z}}{\pi^{2}-4} .
$$

$U_{x}$ is the half-spreading horizontal velocity at the surface and $U_{z}$ is the axial vertical velocity at $x=0$, the center of the rift.

Equation 7.2 is solved using the finite element method following the formulation of Braun (2003). The temperatures of the top and bottom of the thermal model are maintained at constant values (Table 7.1).

The vertical load $F_{T}$ associated with any perturbation of temperature $\Delta T$ from the 
initial geothermal gradient and the associated density variation is given by:

$$
F_{T}=\int_{-a_{L}}^{0} \rho_{m}\left[\alpha_{T} \Delta T\right] g d z
$$

where $\alpha_{T}$ is the thermal expansion coefficient and $a_{L}$ is the initial thickness of the lithosphere (see Table 7.1).

\section{Stretching of the lithosphere}

Stretching of the lithosphere is assumed to be accommodated by planar faults in the upper crust and ductile flow in the lower crust and mantle.

Thinning of the lower crust and consequent Moho uplift is governed by the same advection velocity as used for the thermal model (equation 7.3 ). The vertical force $F_{S}$ arising from stretching and thinning of the lower crust is given by:

$$
F_{S}=\left(\rho_{m}-\rho_{c}\right) g \Delta h_{\text {crust }}
$$

where $\Delta h_{\text {crust }}$ is the variation of crustal thickness resulting from the stretching of the lower crust and $\rho_{c}$ is the density of the crust.

To simulate movement along faults in the upper crust, we use the flexural cantilever model of Kusznir et al. (1991). Although we adopted the flexural cantilever model to reproduce the flexural response of the upper crust during the rift, there is no consensus about the predominant rheological behavior of the upper crust during rifting. Studying the mechanisms responsible for the development of rift flanks in the Baikal rift, SE Siberia, van der Beek (1997), for instance, concluded that plastic behavior of the upper crust is more important than assumed by the flexural cantilever model. On the other hand, the flexural cantilever model was successfully used to describe the geometry of grabens and crustal block rotation with wavelengths of a few kilometers, as observed in many rifted regions (e.g Kusznir and Ziegler, 1992; van Wees and Cloetingh, 1994; Nadin and Kusznir, 1995; Kusznir et al., 2004).

We therefore introduce an effective elastic thickness for the upper crust, $T_{e, u c}$, which does not necessarily coincide with $T_{e}$, the elastic thickness of the entire lithosphere. By using two different values for $T_{e}$, we introduce the possibility to reproduce the superposition of different flexural responses to deformation and/or loading, as observed for example in the East African rift system, where van Wees and Cloetingh (1994) obtained a value of 
$T_{e}=3-5 \mathrm{~km}$ in trying to reproduce basement geometry with a $3-\mathrm{D}$ flexural model whilst Ebinger et al. (1991) obtained $T_{e}=21 \mathrm{~km}$ in the same area fitting gravity data. It is commonly assumed (Burov and Diament, 1995) that low $T_{e}$ values account for the flexural behavior of the upper crust, whereas high $T_{e}$ values reflect the regional response of the subcrustal lithosphere. The use of two different flexural rigidities for the same region implies that the upper crust is partly decoupled from the subcrustal lithosphere by a ductile lower crust. This condition can be satisfied when the crust is thick and/or has a high geothermal gradient (Burov and Diament, 1995; Brown and Phillips, 2000). From the analysis of yield-strength envelopes for different thermal ages and crustal thickness, Burov and Diament (1995) showed that the lithosphere is practically always decoupled for crustal thickness $>35 \mathrm{~km}$, independent of the thermal age of the lithosphere (see Figure 4b in Burov and Diament, 1995). The two margins studied in this work in Section 5.2 are developed on relatively thick crust. Receiver function analysis for Southeastern Brazil showed crustal thicknesses between 35 and $43 \mathrm{~km}$ close to the coast (Assumpção et al., 2002). Likewise, Southeastern Australia presents thick crust from receiver function analysis, between 34 and $52 \mathrm{~km}$ (Clitheroe et al., 2000).

In the formulation of Kusznir et al. (1991), extension of the upper crust is accommodated by planar faults. Considering an amount of extension $E_{f}$ of the upper crust accommodated by a planar fault dipping at an angle $\theta$ (Figure 4.5), the vertical displacement $d_{f}$ of the surface relative to the footwall, in the absence of gravity, is

$$
d_{f}=\left\{\begin{aligned}
0 & \text { if the point is on the footwall } \\
-E_{f} \cdot \tan \theta & \text { if the point is on the hangingwall }
\end{aligned}\right.
$$

To restore isostatic equilibrium (Figure $4.5 \mathrm{c}$ ), a buoyancy force $F_{F}$ given by

$$
F_{F}=-\rho_{c} g d_{f}
$$

has to be added to the isostatic balance. Assuming that the upper crust has finite rigidity during faulting, the flexural response $w_{F}$ of the upper crust to the force $F_{F}$ is given by:

$$
(\mathbf{L} \nabla)^{\mathrm{T}} \mathbf{D}_{u c} \mathbf{L} \nabla w_{F}+\rho_{c} g w_{F}=F_{F}
$$

where $\mathbf{D}_{u c}$ is the flexural rigidity of the upper crust, i.e. dependent of $T_{e, u c}$. The final configuration is shown in Figure 4.5d. 


\section{Surface processes}

Surface processes are taken into account following the methodology of Braun and Sambridge (1997). The main advantage of this approach, based on an irregular discretization of surface topography, is that it is possible to accurately simulate the relative horizontal movement of crustal blocks at finite rates, i.e. without the loss of short-wavelength features that is inherent to other approaches based on interpolation of the topography.

Onshore processes are divided into fluvial and hillslope processes. Fluvial processes of erosion, transport and sedimentation are modeled following the formulation of Beaumont et al. (1992) where local variations in topography $h$ are described through a first-order reaction equation:

$$
\frac{\partial h}{\partial t}=-\frac{q_{f}^{e q b}-q_{f}}{L_{f}}
$$

where $q_{f}^{e q b}$ is the maximum sediment transport capacity, $q_{f}$ is the sediment flux per unit width $\left[\mathrm{L}^{2} \mathrm{~T}^{-1}\right]$ and $L_{f}$ is a parameter with dimension of $[\mathrm{L}] . q_{f}^{e q b}$ in a channel takes the following form:

$$
q_{f}^{e q b}=k_{f} q_{r}|\nabla h|
$$

where $k_{f}$ is the erosional coefficient due to the fluvial process, $q_{r}$ is water discharge and $|\nabla h|$ is the modulus of topographic gradient. The water discharge is calculated by spatially integrating net precipitation rate $v_{R}$, which is assumed uniform in space and time for simplicity. There are different expressions for $q_{f}^{e q b}$ in the literature, where the exponents of $q_{r}$ and $|\nabla h|$ are not equal to one (see Braun, 2006). We assume that these variations in the value of the exponents of $q_{r}$ and $|\nabla h|$ are of secondary importance for the present work, since the general drainage pattern and the position of the drainage divides will not be significantly modified by varying the exponents (see Figure 9 in Tucker and Whipple, 2002).

Hillslope processes are modeled through a linear diffusion equation, assuming that transport is linearly proportional to slope (see Dietrich et al., 2003, and references therein):

$$
\frac{\partial h}{\partial t}=\nabla \cdot\left(k_{d} \nabla h\right)
$$

where $k_{d}$ is the coefficient of diffusive transport. van der Beek and Braun (1998) showed that there is no theoretical basis for including hillslope diffusion in large spatial-scale models. In effect the dominant process in the onshore domain in our numerical simulations 
is fluvial transport and the evolution of the landscape is not significantly modified if we do not include hillslope diffusion. On the other hand, the incorporation of hillslope diffusion can improve the stability of the surface-process simulation for different time steps and grid size, by avoiding exceedingly steep links between grid cells.

For the offshore transport of sediments we used the methodology of van Balen et al. (1995), based on the same principle as for diffusion processes on land, but with a non-linear diffusion coefficient, $k_{m}$ :

$$
\frac{\partial h}{\partial t}=\nabla \cdot\left(k_{m} \nabla h\right)
$$

In this simple model, the diffusivity $k_{m}$ decreases exponentially with water depth, simulating the decrease in energy available for sediment transport with increasing water depth:

$$
k_{m}=k_{m}^{*} \exp \left(\frac{h-h_{s . l .}}{h_{0}}\right)
$$

$k_{m}^{*}$ is a constant $\left[\mathrm{L}^{2} \mathrm{~T}^{-1}\right], h_{\text {s.l. }}$ is sea level and $h_{0}$ is a characteristic length (Table 7.1).

To compute the vertical load $F_{s p}$ resulting from a variation in topography $\Delta h$ associated with surface processes we assume that sediment density, $\rho_{s}$, is equal to crustal rock density, for the sake of simplicity. With this approximation, we obtain the following relationship:

$$
F_{s p}= \begin{cases}-\rho_{c} g \Delta h+\rho_{w} g \Delta h & \text { if } h+\Delta h<h_{s . l .} \text { and } h<h_{s . l .} . \\ -\rho_{c} g \Delta h+\rho_{w} g\left(h_{s . l .}-h\right) & \text { if } h+\Delta h>h_{s . l .} \text { and } h<h_{s . l .} \\ -\rho_{c} g \Delta h+\rho_{w} g\left(h+\Delta h-h_{s . l .}\right) & \text { if } h+\Delta h<h_{s . l .} \text { and } h>h_{s . l .} \\ -\rho_{c} g \Delta h & \text { if } h+\Delta h>h_{\text {s.l. }} \text { and } h>h_{s . l .} .\end{cases}
$$

where $\rho_{w}$ is water density.

Surface topography is updated by adding the total vertical displacement $w_{t}$ of the surface to the initial topography. This displacement is the sum of the components related to faulting $d_{f}$ and the flexural response of the upper crust and lithosphere, respectively $w_{F}$ and $w$ :

$$
w_{t}=w+w_{F}+d_{f}
$$

Note that $\Delta h$ is the variation of topography related only to the surface processes of erosion $(\Delta h<0)$ and deposition $(\Delta h>0)$. Therefore $\Delta h$ is independent of the flexural response of the lithosphere. On the other hand, the variation in topography $\Delta h$ induces vertical loads $F_{s p}$, which are regionally compensated by the lithosphere resulting in a vertical displacement $w$ of the surface. 


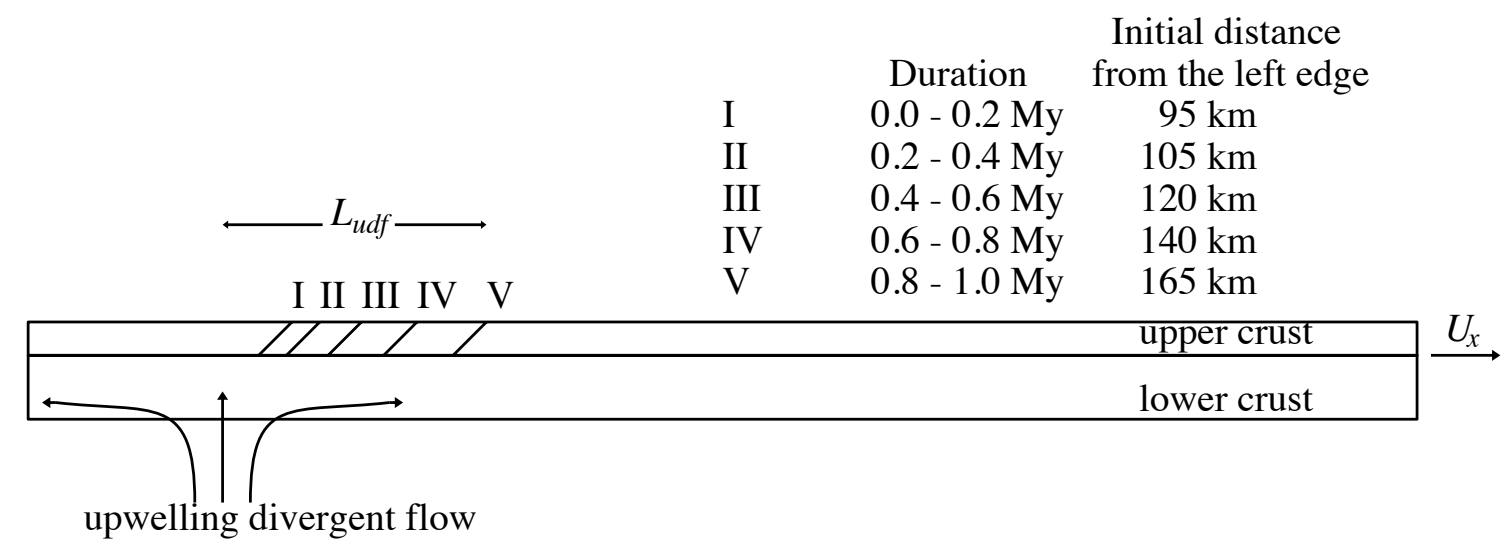

Figure 7.1: Scheme showing the relative position of the faults I-V in the upper crust and the upwellingdivergent flow.

\subsubsection{Model setup}

In our model setup, we introduce a series of faults (Figure 7.1) dipping towards the center (axis) of the rift, as observed in most natural settings (Salveson, 1978). The number of faults (five in our model) is of little importance; they are meant to represent distributed brittle deformation. The faults are activated progressively from I to V, simulating a widening of the rift zone in the early stages of development of the rift; they all dip at an angle equal to $\theta=45^{\circ}$ and the extension per fault is $E_{f}=4 \mathrm{~km}$, resulting in a fault heave $\left|d_{f}\right|=E_{f} \cdot \tan \theta=4 \mathrm{~km}$. The especific value of $\theta$ and $E_{f}$ is not very important and different combinations of $\theta$ and $E_{f}$ can result in the same fault heave $\left|d_{f}\right|$, which is the parameter that principally controls the flexural response of the upper crust during faulting in the flexural cantilever model (see equation 7.6). In the lower part of the model, we impose the velocity field described in equation 7.3 , to accommodate the relative movement of the lithosphere at a velocity $U_{x}$ relative to the axis of the upwelling-divergent flow.

The initial dimensions of the model are $200 \mathrm{~km}$ (width) $\times 600 \mathrm{~km}$ (length), and the mean distance between the nodes in the surface-processes model is $5 \mathrm{~km}$.

Previous works that did not take into account the influence of rifting on the evolution of the landscape (e.g Kooi and Beaumont, 1994) concluded that an initial coastal escarpment adjoining a horizontal or landward-dipping plateau evolves as a retreating escarpment. To assess if this conclusion is valid when stretching and thinning of the lithosphere is considered during the simulation, we use an initial topography that is similar to that used 
in other modeling studies of passive margin escarpments, and that consists of a gently landward dipping surface described here by the following expression:

$$
h(t=0)=500.0 \times \cos \left(\frac{\pi x}{8.0 \times 10^{5}}\right)+1500.0
$$

where $x$ is in meters. In short, the topography decreases monotonically from $2500 \mathrm{~m}$ on the left-hand side of the model to just below $1150 \mathrm{~m}$ on the right-hand side, over a distance of $600 \mathrm{~km}$.

The values of the model parameters are given in Table 7.1. They correspond to commonly accepted values for most parameters. We will vary the value of four model parameters; the effective elastic thickness of the lithosphere $T_{e}$ and of the upper crust $T_{e, u c}$, the erosional parameter $k_{f}$, and the initial position $L_{u d f}$ of the axis of the upwelling-divergent flow relative to the position of fault V (Figure 7.1). Note that the distance $L_{u d f}$ also defines the position of the region of significant crustal thinning. Thus, moving the initial position of the axis of the upwelling-divergent flow will in fact control the offset between the final position of the zone of lower crustal thinning and the position of the faults. We also assume that the region where $x<L_{u d f}$, which, over the duration of the model, evolves to become significantly stretched, is characterized by a low effective elastic thickness $\left(T_{e}=T_{e, u c}\right)$, simulating a decrease in rigidity due to rifting. All other parameters have constant values in all model runs, which are shown in Table 7.1.

\subsubsection{Results}

We first present the results of a model experiment in which the initial position of the upwelling flow is close to the faults $\left(L_{u d f}=-15 \mathrm{~km}\right)$, resulting in thinning of the lower crust just under the faulted region. The solution is shown in Figures 7.2 and 7.3 as a set of snap shots at 12 time intervals in the evolution of the model. The other parameters of Model 1 are shown in Table 7.2.

During the first 1 Myr of the simulation (Figure 7.2), the faults I-V are progressively activated and the lithosphere experiences a total extension of $20 \mathrm{~km}$. After this, the faults are locked, but the lithosphere on the left-hand side of the model continues its movement relative to the axis of the upwelling-divergent flow and, consequently, the lower crust is thinned as a consequence of stretching. In this simulation, we assume that continued 


\begin{tabular}{|c|c|c|c|}
\hline & Parameters & Description & Value \\
\hline \multirow{6}{*}{$\begin{array}{l}\text { Surface } \\
\text { processes }\end{array}$} & $h_{s . l}$ & Sea level & $0 \mathrm{~m}$ \\
\hline & $k_{m}^{*}$ & Diffusivity for the offshore transport & $20 \mathrm{~m}^{2} /$ year \\
\hline & $h_{0}$ & Decay factor for the offshore transport & $1000 \mathrm{~m}$ \\
\hline & $L_{f s}$ & Alluvial erosion lenght scale & $10 \mathrm{~km}$ \\
\hline & $L_{f b}$ & Bedrock erosion lenght scale & $100 \mathrm{~km}$ \\
\hline & $k_{s} / k_{f} v_{R}$ & & $10 \mathrm{~m}$ \\
\hline \multirow{7}{*}{$\begin{array}{l}\text { Flexure } \\
\text { and } \\
\text { Isostasy }\end{array}$} & $E$ & Young's modulus & $1.0 \times 10^{11} \mathrm{~N} / \mathrm{m}^{2}$ \\
\hline & $g$ & acceleration of gravity & $9.8 \mathrm{~m} / \mathrm{s}^{2}$ \\
\hline & $\nu$ & Poisson's ratio & 0.25 \\
\hline & $\rho_{m}$ & Mantle density & $3300 \mathrm{~kg} / \mathrm{m}^{3}$ \\
\hline & $\rho_{c}$ & Crust density & $2700 \mathrm{~kg} / \mathrm{m}^{3}$ \\
\hline & $\rho_{s}$ & Sediment density & $2700 \mathrm{~kg} / \mathrm{m}^{3}$ \\
\hline & $\rho_{w}$ & Water density & $1030 \mathrm{~kg} / \mathrm{m}^{3}$ \\
\hline \multirow{5}{*}{ Thermal } & $a_{L}$ & Initial thickness of the lithosphere & $125 \mathrm{~km}$ \\
\hline & & Top temperature & $0^{\circ} \mathrm{C}$ \\
\hline & & Bottom temperature & $1300^{\circ} \mathrm{C}$ \\
\hline & $\kappa$ & Thermal diffusivity $=k / \rho c$ & $10^{-6} \mathrm{~m}^{2} / \mathrm{s}$ \\
\hline & $\alpha_{T}$ & Thermal expansion coefficient & $3.28 \times 10^{-5}{ }^{\circ} \mathrm{C}^{-1}$ \\
\hline \multirow{4}{*}{$\begin{array}{l}\text { Kinematic } \\
\text { and } \\
\text { Geometry }\end{array}$} & $U_{x}$ & half-spreading velocity & $1 \mathrm{~cm} /$ year \\
\hline & $U_{z}$ & axial velocity & $0.5 \mathrm{~cm} /$ year \\
\hline & & Initial crustal thickness & $35 \mathrm{~km}$ \\
\hline & & Initial upper crustal thickness & $12 \mathrm{~km}$ \\
\hline
\end{tabular}

Table 7.1 - Fixed parameters and their values used in the models. 


\begin{tabular}{lcccc}
\hline & $\begin{array}{c}T_{e} \\
(\mathrm{~km})\end{array}$ & $\begin{array}{c}T_{e, u c} \\
(\mathrm{~km})\end{array}$ & $\begin{array}{c}L_{u d f} \\
(\mathrm{~km})\end{array}$ & $\begin{array}{c}k_{f} v_{R} \\
(\mathrm{~mm} / \text { year })\end{array}$ \\
\hline Model 1 & 20 & 5 & -15 & 3 \\
Model 2 & 20 & 5 & -115 & 3 \\
Sensitivity models & 20,30 & 5,10 & $-15,-65,-115$ & 1 \\
Model 3 (dipping landward) & 10 & 5 & -65 & 1.5 \\
Model 4 (inland drainage divide) & 10 & 10 & -65 & 3 \\
Model 5 (late continental rifting) & 20 & 5 & -15 & 3
\end{tabular}

Table 7.2 - Variable parameters and their values used in the models.

stretching of the upper crust and final breakup occur in a position outside the model, to simulate continued margin formation.

We observe that during stretching of the upper crust (i.e. active faulting), the region just inland of the active fault-escarpment experiences subsidence as indicated by the black arrows in Figure 7.2. This subsidence separates the escarpment from a secondary drainage divide that has formed landward of the initial escarpment (red arrows in Figure 7.2). This evolution of the topography is a result of the flexural response to normal faulting and corresponds to the development of a secondary depression and bulge landward of the rift axis. The position of this secondary bulge relative to the escarpment depends on the effective elastic thickness of the crust. An analytical solution of the flexural cantilever model (Vening-Meinesz, 1950) exists for a single fault:

$$
w=w_{\max } e^{-0.701 \frac{x}{\alpha}} \cos \left(0.701 \frac{x}{\alpha}\right)
$$

where $x$ is the relative position to the fault, $w_{\max }$ is the half-fault heave and

$$
\alpha=\left[\frac{D}{\left(\rho_{c}-\rho_{i n}\right) g}\right]^{\frac{1}{4}},
$$

from which the position of the secondary bulge relative to the fault can be derived (Figure $7.4 \mathrm{a})$

$$
x_{2}=\frac{\alpha}{0.701} \cdot \frac{7 \pi}{4}
$$

On land, $\rho_{i n}=\rho_{\text {air }}$ and the expression for $\alpha$ becomes

$$
\alpha=\left[\frac{D}{\rho_{c} g}\right]^{\frac{1}{4}} .
$$



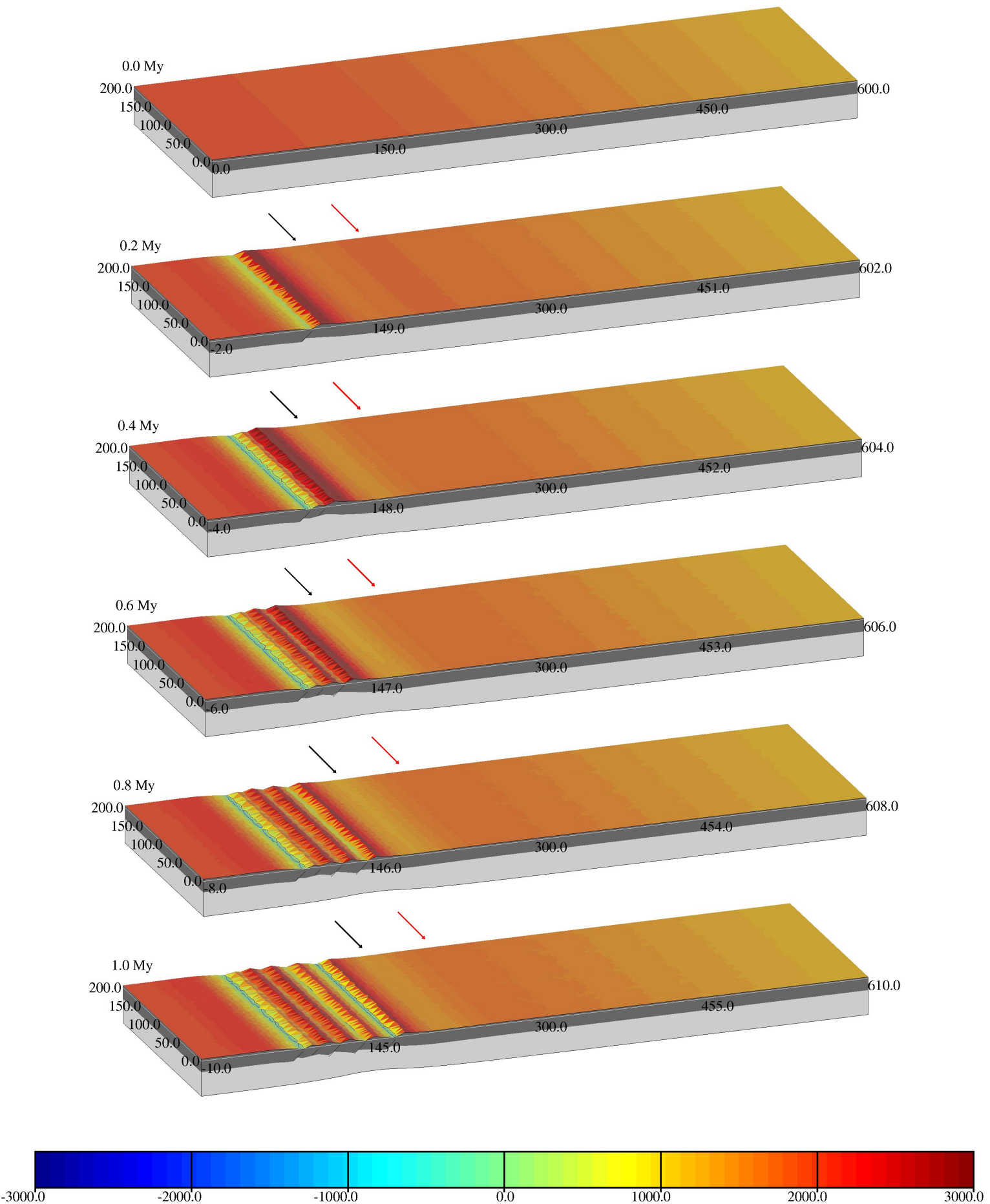

Figure 7.2: Evolution of the rift for Model $1\left(T_{e}=20 \mathrm{~km}, T_{e, u c}=5 \mathrm{~km}, k_{f} v_{R}=0.003 \mathrm{~m} /\right.$ year and $L_{u d f}=-15 \mathrm{~km}$ ). Topography (bottom scale) is in meters. The light and dark gray regions on the side of the model represent the lower and upper crust, respectively. The black and red arrows indicate the position of the flexural depression and the secondary bulge divide, respectively. 

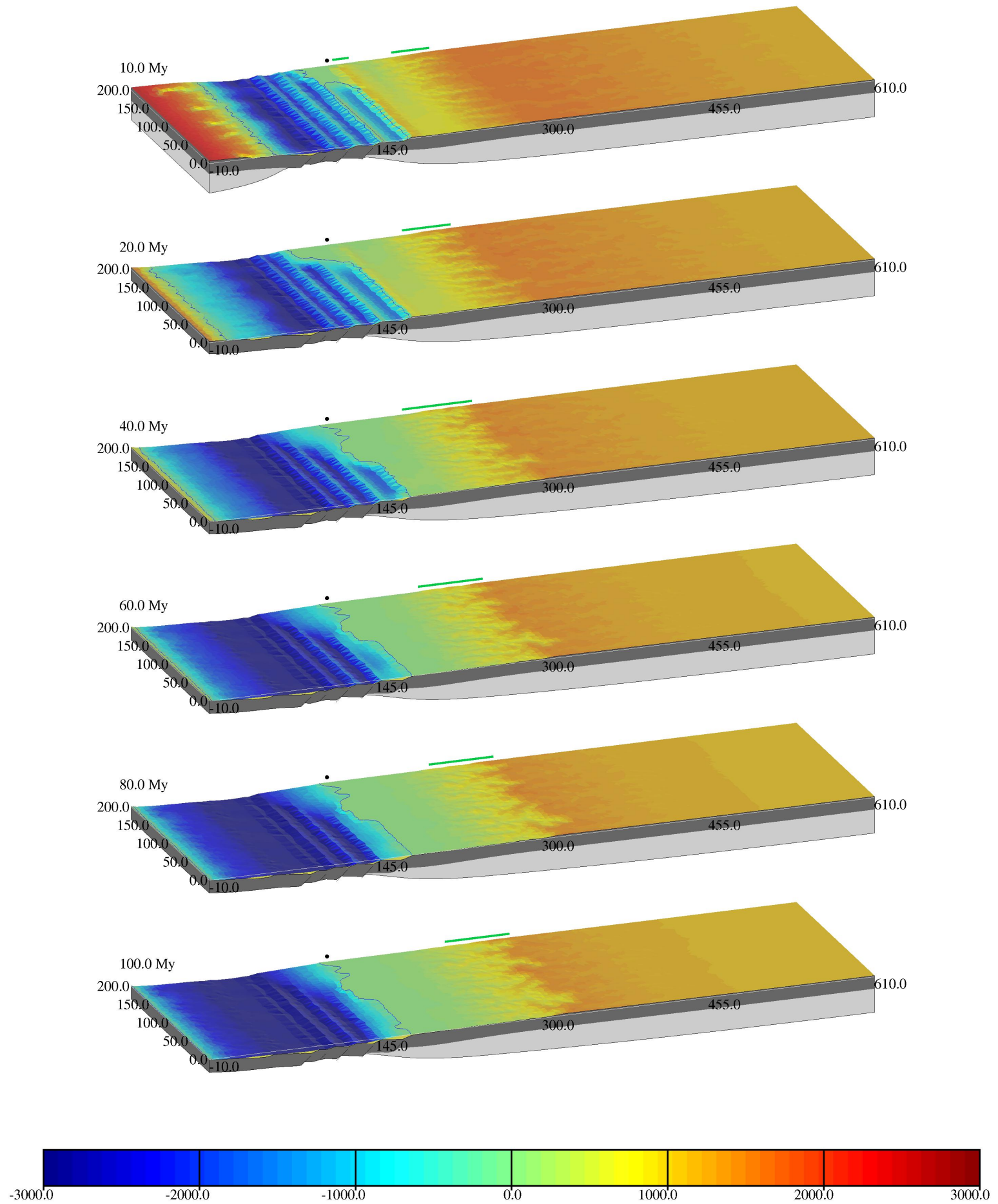

Figure 7.3: Continuation of Figure 7.2 - Model 1. Topography (bottom scale) is in meters. The light and dark gray regions on the side of the model represent the lower and upper crust, respectively. The yellow regions on the side of the model represent sediments. The blue curves represent the shoreline. The black dots mark the position of fault V. The green lines mark the zones of mean relief $>300 \mathrm{~m}$ (see Figure 7.6). 
The analytical solution also gives the difference in elevation $h_{2}$ (Figure $7.4 \mathrm{a}$ ) between the secondary bulge and the adjacent secondary depression; its value is $\sim 7 \%$ of $w_{\max }$, the maximum elevation of the primary rift flank. Thus the secondary depression and adjacent bulge are a logical consequence of the flexural response to rift faulting. Its amplitude is small because of the exponential decrease of the amplitude of the deflection but the difference in height between the secondary high and low is certainly not negligible. Note that the formation of an inland drainage divide occurs when the initial topography is sloping landward or is flat. If the initial topography slopes seaward from a preexisting inland drainage divide, the formation of the depression during faulting will not contribute to the formation of a new inland drainage divide.

For the value of upper-crustal elastic thickness that we have chosen $\left(T_{e, u c}=5 \mathrm{~km}\right)$, the position of the secondary drainage divide should, theoretically, be at $x_{2} \approx 111 \mathrm{~km}$. However, this analytical solution assumes that the preexisting topography is horizontal. For a sloping initial topography, the position of the secondary drainage divide can move by several tens of kilometers, depending on the assumed initial slope. In our example, with the geometric distribution of the faults as shown in Figure 7.1 and the initial topography described by equation 7.9 , the analytical position of the second drainage divide is $x_{2}^{\prime} \approx 85$ $\mathrm{km}$.

With continued stretching and thinning of the lower crust, the region seaward of the secondary bulge subsides. Through the combined effect of erosion and thermal subsidence, the initial escarpment adjacent to the faults rapidly vanishes (i.e., within $20 \mathrm{Myr}$ after rifting) and the main topographic relief that persists through time is the drainage divide created landward by the formation of the secondary bulge (Figure 7.3). Further in the development of the model run, the region that was occupied by the initial escarpment continues to be eroded and progressively subsides, finally crossing the base level and becoming inundated near the end of the model run.

These processes are summarized in Figure 7.4b. Because of its high relief, the coastal escarpment is rapidly eroded. Incision of the adjacent axial river, located between the coastal escarpment and the secondary bulge, tends to isolate the coastal escarpment. Moreover, thinning of the lower crust and cooling of the lithosphere result in subsidence of the margin (vertical arrows in Figure 7.4b), but with decreasing amplitude landwards. The 


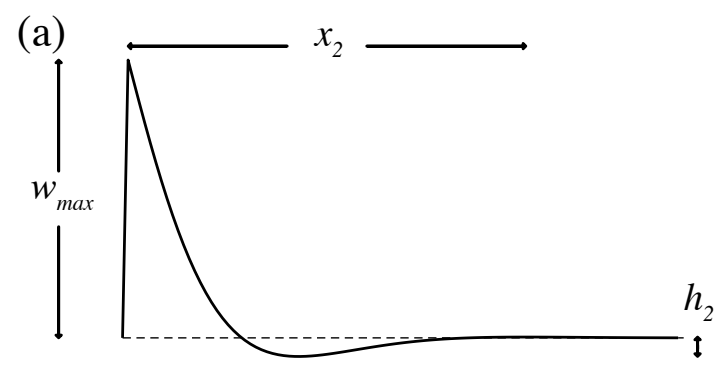

(b)

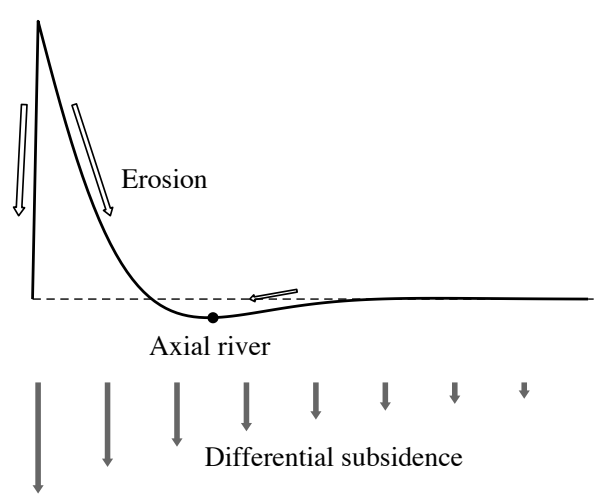

Figure 7.4: Graphical representation of the analytical solution of the flexural cantilever model (a) $w_{\max }$ is the half-fault heave; $x_{2}$ is the distance between the fault and the secondary bulge; $h_{2}=0.07 w_{\max }$ is the difference in elevation between the secondary bulge and the flexural depression. (b) Mechanisms that reshape the margin after faulting. Open arrows indicate direction of drainage and the size of the arrows illustrate the magnitude of erosion. The black dot represents an axial river, parallel to the fault, between the coastal escarpment and the secondary bulge. Gray arrows represent the differential subsidence (decreasing landward) due to thinning of the lower crust and thermal cooling of the lithosphere.

combination of rapid erosion of the coastal escarpment and differential subsidence of the margin favors the emergence of the secondary bulge and its establishment as the main, "permanent" drainage-divide escarpment, while the coastal escarpment progressively disappears. Note that a necessary condition for the formation of the secondary divide is that there is preexisting topography and rifting thus leads to a base-level drop. If the preexisting elevation was at sea level, just the initial fault-controlled escarpment will be eroded. Therefore, the persistence of escarpments requires a preexisting high-standing topography, in accord with previous findings (Tucker and Slingerland, 1994; Kooi and Beaumont, 1994).

If we displace the initial position of the axis of the upwelling flow far from the zone of imposed faulting at $L_{u d f}=-115 \mathrm{~km}(100 \mathrm{~km}$ seaward relative to the first model $)$, the evolution of the margin is dramatically different (Figure 7.5, Model 2). In this situation, 
thinning is almost insignificant under the faulted region and, consequently, the ensuing thermal subsidence of the lithosphere in this zone is negligible. As a result, the initial escarpment created close to fault $\mathrm{V}$ remains the main drainage divide throughout the numerical experiment. This result clearly demonstrates that, together with the slope of the pre-rift topography dipping toward the interior of the continent, the combination of uplift of the secondary bulge and differential thermal subsidence is responsible for the migration of the main drainage divide towards the secondary bulge in the previous experiment.

If we consider the evolution of Model 2 in more detail, we notice that the high topography related to the intermediate faults II-IV is progressively eroded away and the morphological signature of the half-graben structures disappears. Most of the sedimentation occurs just seaward of fault I, because it is only in this region of the model that the lower crust has been sufficiently stretched to produce subsidence and the ensuing accommodation space.

To compare the evolution of relief in both model experiments, we divided the margin in strips of $5 \mathrm{~km}$, parallel to the rift axis, and calculated the mean topographic relief in each of these. Relief is defined here as the maximum elevation difference between adjacent nodes. Results are shown in Figures 7.3 and 7.5, where green lines correspond to strips where mean relief is $>300 \mathrm{~m}$ for the first model experiment (Figure 7.3) and red lines for the second model experiment (Figure 7.5). The regions of high relief are plotted together in Figure 7.6, which also shows the analytical position of the secondary bulge $x_{2}^{\prime}$ for $T_{e, u c}=5$ $\mathrm{km}$. This figure summarizes the relief evolution of both models. We observe that in Model $1\left(L_{u d f}=-15 \mathrm{~km}\right.$, green lines) the high relief of the primary rift flank rapidly vanishes and another region of high relief (a new escarpment) appears close to the secondary bulge at $x_{2}^{\prime}$, and progressively retreats toward the interior of the continent. It is interesting to observe that the region between the primary and secondary escarpments does not present substantial relief during the evolution of the margin. The coastal escarpment has not migrated continuously landward, but has reappeared in its new position. For Model 2, with little thinning of the lower crust below the initial escarpment $\left(L_{u d f}=-115 \mathrm{~km}\right.$, red lines in Figure 7.6) the rift shoulder remains the main escarpment during the entire simulation and significantly less escarpment migration takes place than in the previous model. 

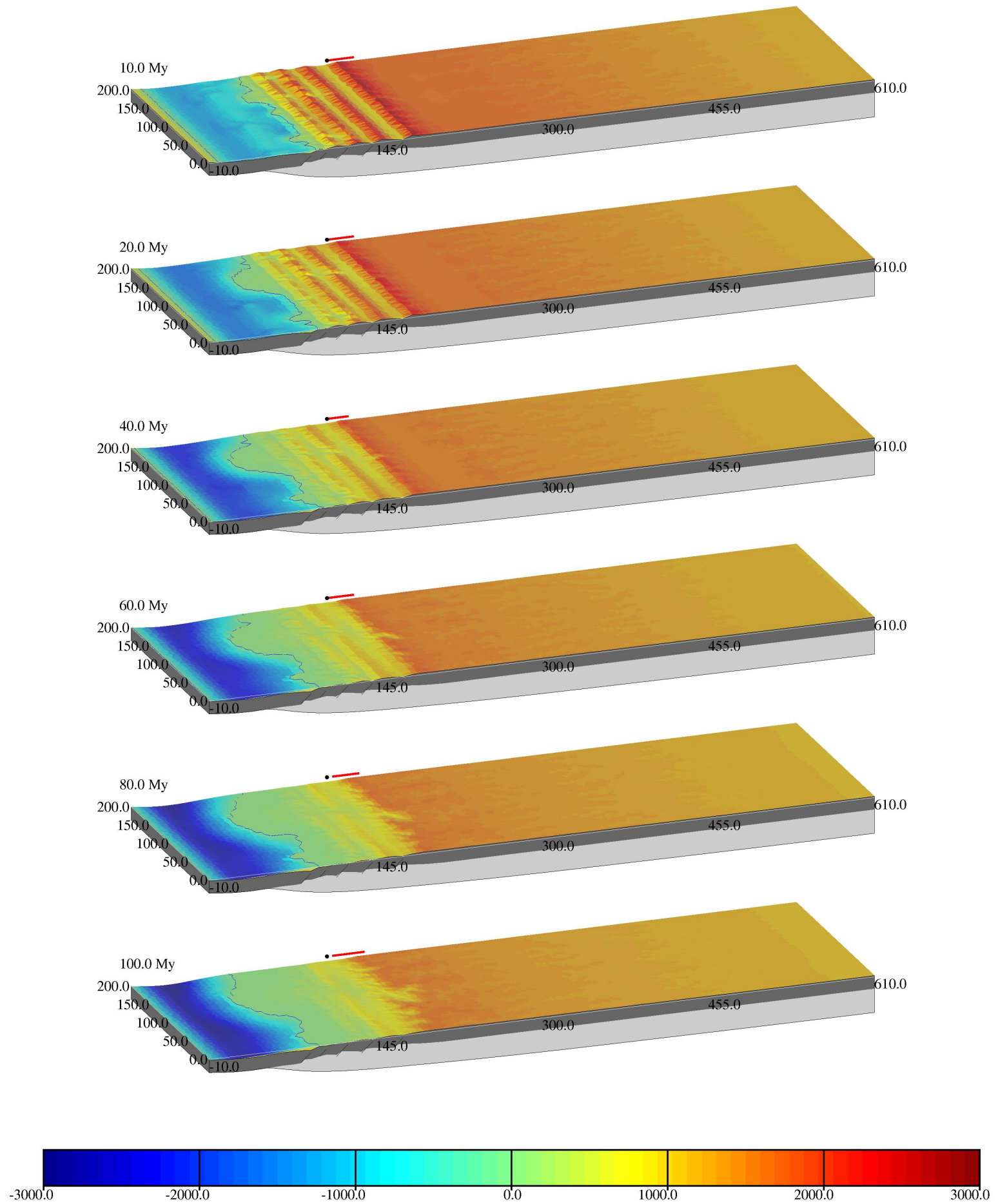

Figure 7.5: Evolution of the rift margin for Model $2\left(T_{e}=20 \mathrm{~km}, T_{e, u c}=5 \mathrm{~km}, k_{f} v_{R}=0.003 \mathrm{~m} /\right.$ year and $\left.L_{u d f}=-115 \mathrm{~km}\right)$. Symbols as in Figure 7.3. Black dots mark the position of fault V. The red lines mark the zones of mean relief $>300 \mathrm{~m}$ (see Figure 7.6). 


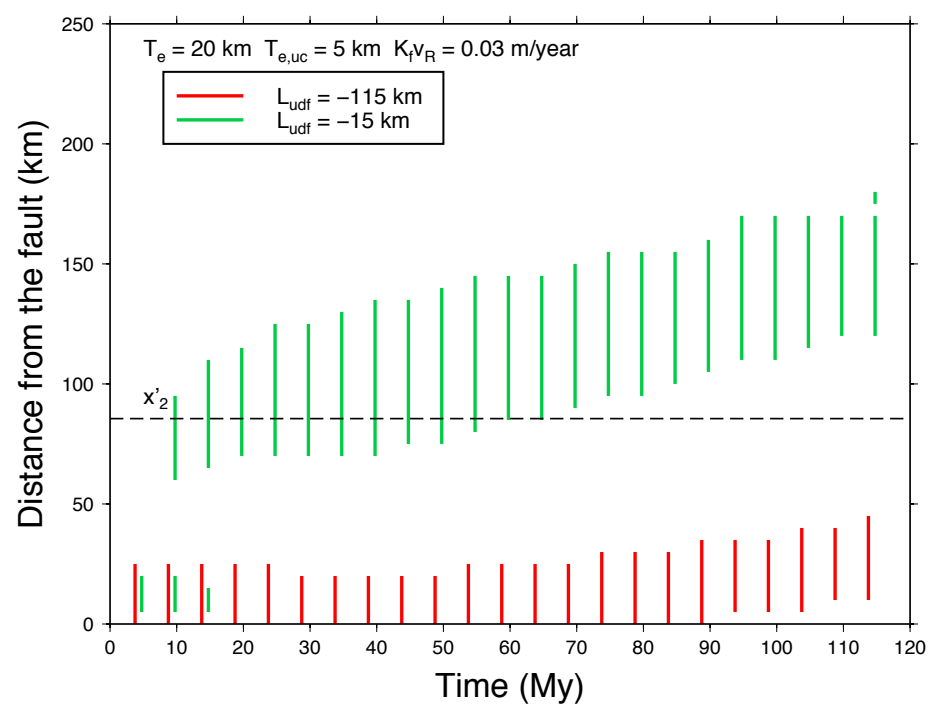

Figure 7.6: Temporal evolution of the zones with high relief (mean relief $>300 \mathrm{~m}$ ) for the models illustrated in Figures 7.2 to 7.5. The black dashed line indicates the position $x_{2}^{\prime}$ of the secondary bulge calculated analytically.

To demonstrate further that the position of the secondary, inland escarpment is controlled by that of the secondary flexural bulge, we have run a series of experiments in which the erosion rate was artificially reduced (by decreasing $k_{f} v_{R}$ to $0.001 \mathrm{~m} /$ year). In this way, the positions of the various drainage divides are less perturbed by erosion. In Figure 7.7 we present different simulations with reduced erosion. A similar pattern of escarpment evolution is nonetheless observed, as shown in the relief-evolution diagrams. In every diagram of Figure 7.7 the model experiments with $L_{u d f}=-15 \mathrm{~km}$ (green lines) are characterized by a secondary escarpment originating very close to the secondary flexural bulge at $x_{2}^{\prime}$, while in the model experiments with $L_{u d f}=-115 \mathrm{~km}$ (red lines) the escarpment remains close to the rift-bounding fault.

The effective elastic thickness of the upper crust $T_{e, u c}$ clearly controls the initial position of the new escarpment at the secondary bulge, which is, on the other hand, relatively insensitive to the effective elastic thickness of the lithosphere $T_{e} . T_{e}$ plays a secondary role by controlling the retreat rate of the escarpment, as indicated by the arrows in Figure 7.7: for the same values of $T_{e, u c}$ and $L_{u d f}$, the retreat rate is positively correlated with $T_{e}$. This behavior was also observed by Kooi and Beaumont (1994) and is related to the wavelength 

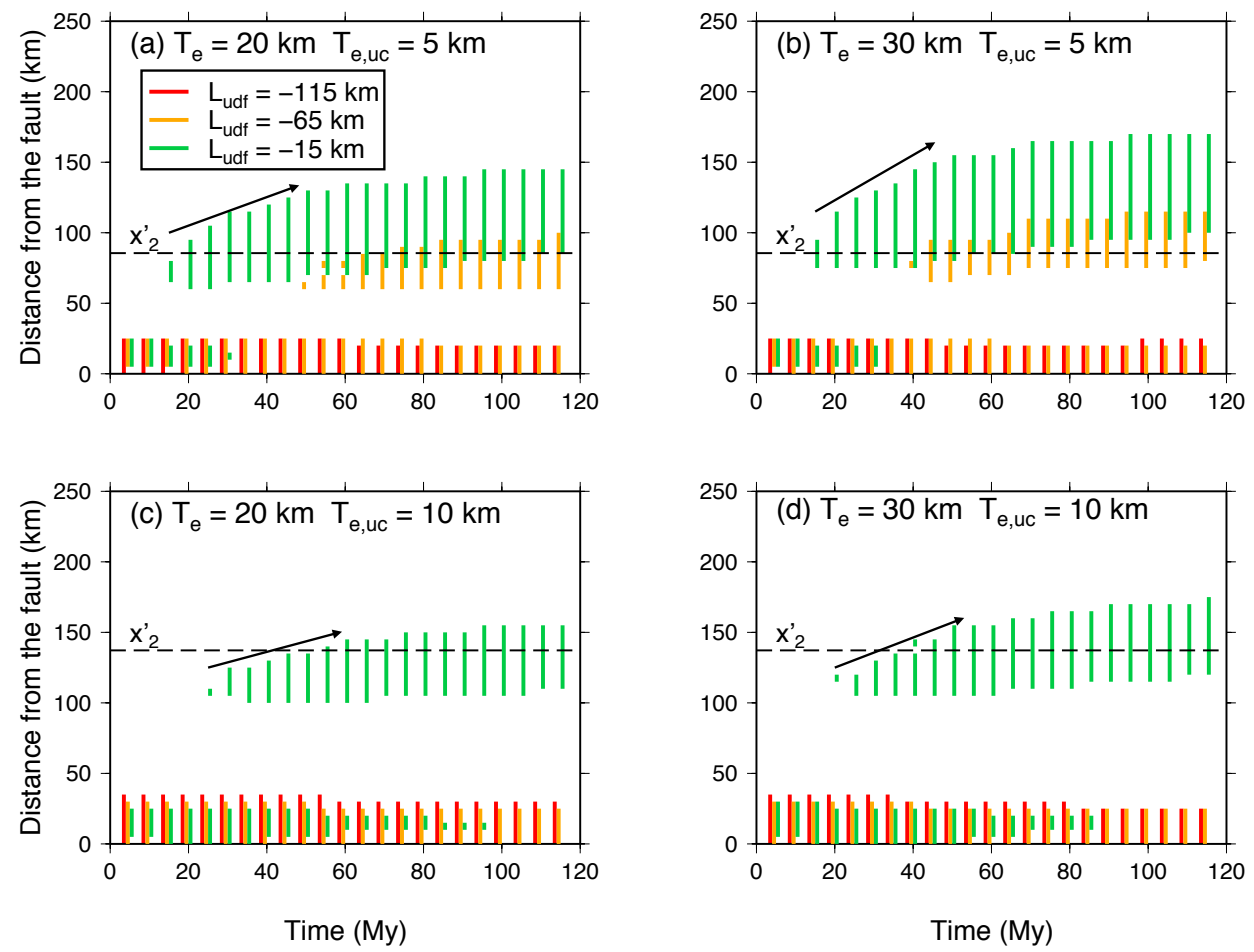

Figure 7.7: Comparison for different numerical simulations of the temporal evolution of the zones with high relief (mean relief $>300 \mathrm{~m}$ ) for the models with low erosional rates. The black dashed line indicates the position $x_{2}^{\prime}$ of the secondary bulge calculated analytically. The arrows indicate the retreat of the escarpment for the models with $L_{u d f}=-15 \mathrm{~km}$. 
and amplitude of the flexural isostatic response of the lithosphere to unloading; escarpment retreat is hindered by efficient isostatic uplift in response to erosional unloading (i.e. low $T_{e}$ ) because this leads to stronger landward tilting of the region adjacent to the escarpment.

In Figure 7.7 we also show an intermediate model experiment where $L_{u d f}=-65 \mathrm{~km}$ (orange lines). In the model runs with $T_{e, u c}=5 \mathrm{~km}$ (Figure $7.7 \mathrm{a}$ and $\mathrm{b}$ ), the intermediate model also generates an inland escarpment, but it develops at a later time relative to the model runs with $L_{u d f}=-15 \mathrm{~km}$. Moreover, in this intermediate model run, high relief close to the fault is preserved for a longer time than for the model runs with $L_{u d f}=-15$ $\mathrm{km}$. On the other hand, the intermediate models with $T_{e, u c}=10 \mathrm{~km}$ (Figure $7.7 \mathrm{c}$ and $\mathrm{d}$ ) do not generate an inland escarpment. This is because the primary flank uplift, next to the faults, is broader due to the higher rigidity of the upper crust, and therefore erodes less efficiently and survives for a longer time as the main drainage divide.

\subsubsection{Discussion}

\subsubsection{Condition for migration of the drainage divide}

As highlighted in the previous section, the primary condition for long-term preservation of an escarpment is the pre-existence of topography. This condition is necessary both in the retreating escarpment scenario and in the pinned divide one. Taking into account this condition, the present model provides a new mechanism for the development of an inland escarpment that retreats only slowly.

The migration of the escarpment from the flank uplift to the inland position depends on the amount of thinning of the crust during lithospheric stretching. In Figure 7.8 we present crustal stretching factor profiles for the models with $L_{u d f}=-15,-65$ and $-115 \mathrm{~km}$. In the numerical models, the formation of the inland escarpment occurred for $L_{u d f}=-15$ and $-65 \mathrm{~km}$ (see Figure 7.7), which are related to maximum $\beta_{\text {crust }}$ values of 1.58 and 1.19 near the flank uplift, respectively (Figure 7.8). Therefore, migration of the escarpment can be produced even for small values of $\beta_{\text {crust }}$ and is also promoted by low crustal rigidity (Figure 7.7). Note that although the effect seems to be controlled by the magnitude of crustal stretching near the fault, it is in fact the lateral variation in the lower crustal thinning parameter, with $\beta_{\text {crust }}$ decreasing landwards and producing differential subsidence of the margin, that plays the fundamental role in producing lateral displacement of the 


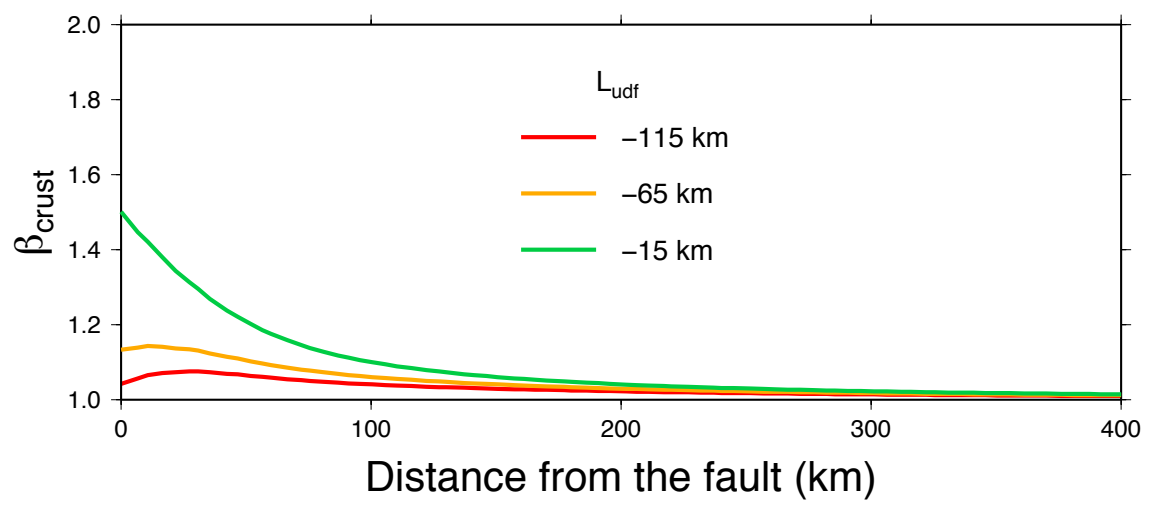

Figure 7.8: Stretching factor of the crust $\beta_{\text {crust }}$ for different initial position $L_{u d f}$ of the upwelling flow.

drainage divide, and thus of the escarpment, to the secondary bulge position.

\subsubsection{Comparison with natural examples}

In the following sections we compare our theoretical results with natural escarpments. We consider two examples, one from the southeastern Australian Great Escarpment, the other from the Serra do Mar in southeastern Brazil.

\subsubsection{Southeastern Highlands of Australia}

In Southeastern Australia, the coastal escarpment is located some 20-50 km from the present-day coastline and the offshore structure is composed of a narrow sediment-starved oblique margin (Shaw, 1990). The coastal escarpment separates the low lying coastal strip from a 600-m high plateau and forms a local drainage divide. The main drainage divide of the Southeastern Highlands is located 50-100 km landward of the coastal escarpment (Figure 7.9c). Between the escarpment and the inland drainage divide, several rivers flow subparallel to the escarpment (e.g. van der Beek and Braun, 1998, 1999). van der Beek and Braun (1999) proposed that this morphology is best explained by the existence of an inland drainage divide predating the rifting episode, which took place 90-100 Ma, at the presentday location of the drainage divide and that the escarpment did not evolve by retreat from the coast to its present-day position, but formed in-place by erosion of the coastal areas 
soon after rifting. These conclusions are consistent with low-temperature thermochronology data (Moore et al., 1986; Dumitru et al., 1991; O'Sullivan et al., 1996; Persano et al., 2002), although, due to the relatively small amounts of exhumation experienced along the escarpment, the interpretation of this data remains somewhat equivocal (Braun and van der Beek, 2004). A large body of geomorphologic work has consistently shown that denudation rates are low and drainage networks of the Southeastern Highlands have been stable throughout the Cenozoic, excluding significant post-breakup tectonic modification of the margin (cf. Bishop and Goldrick, 2000, for a review).

There are two ways in which the modeling work presented here could explain the present-day topography of southeastern Australia. The first, most obvious interpretation is to consider that the present-day escarpment formed as the primary rift flank during rifting and that the inland drainage divide formed as the secondary bulge, later amplified by erosion of the coastal areas and the regions between the two divides, where the rivers run parallel to the escarpment.

As shown in the models with $L_{u d f}=-65 \mathrm{~km}$ in Figure $7.7 \mathrm{a}$ and $\mathrm{b}$, the inland and the coastal regions of high relief can coexist for a long time ( $>100 \mathrm{Myr}$ ), with the main rivers between them running parallel to the escarpment, producing a morphology that resembles the eastern highlands in Australia. Moreover, the distance between the coastal escarpment and the inland drainage divide of southeastern Australia is of the same order as the distance between the initial escarpment and the secondary bulge in the numerical models.

To better illustrate this point, we ran another model experiment (Figure 7.9a, Model 3 ) for which we used low effective elastic thickness values for the lithosphere $\left(T_{e}=10\right.$ $\mathrm{km}$ ), which is likely to be applicable for the southeastern Australian margin, as discussed in Braun and van der Beek (2004). After $90 \mathrm{Myr}$, the numerical model results present an inland drainage divide that has formed at the location of the secondary bulge, and an initial escarpment that has persisted near the coast, similar to the southeastern Australia escarpment.

However, this scenario is inconsistent with the observations on two points: first, the present-day escarpment is clearly erosional rather than tectonic in origin (e.g. Bishop and Goldrick (2000) and references therein), but in our numerical model the escarpment is 

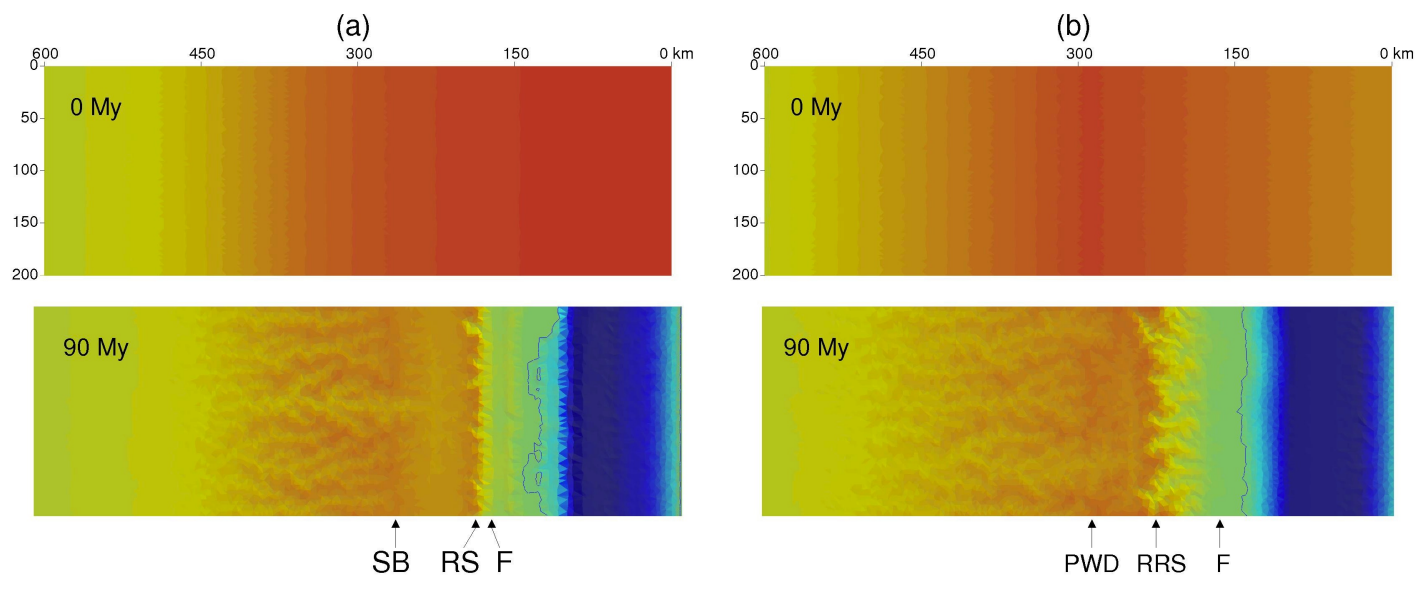

SB: Secondary bulge

RS: $\quad$ Rift shoulder

F: $\quad$ Main fault

PWD: Pre-rift water divide

RRS: Retreated rift shoulder

(c)

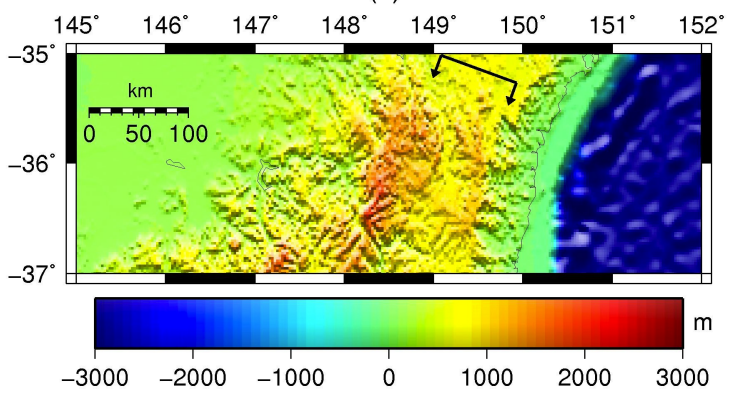

Figure 7.9: Comparison between the numerical model and the southeastern Australia margin (a) Model 3: Numerical simulation with initial topography dipping landward. See Table 7.2 for parameter values used in this experiment; (b) Model 4: Numerical simulation with an initial inland drainage divide; (c) Digital elevation model of southeastern Australia, showing the coastal escarpment and the inland drainage divide, indicated by the arrows. 
associated with the rift flank adjacent to the main basin-bounding fault and has retreated only a short distance. Second, the main drainage divide appears to be an old feature that has been in place at least since the onset of rifting. The SE Australian drainage divide is associated with a strongly negative Bouguer anomaly (Young, 1989), implying a thick crust under this region that isostatically sustains the high topography. Although the timing of crustal thickening is not known, it is possibly related to Paleozoic active-margin tectonics (Lambeck and Stephenson, 1986; van der Beek et al., 1999) or crustal thickening due to underplating during rifting (Lister et al., 1986).

The second, more likely interpretation is to follow the suggestion made by van der Beek and Braun (1999), who consider the main inland divide to be a pre-existing feature. We thus propose that a pre-existing inland drainage divide combined with rift-related flank uplift can produce the double drainage divide observed in Southeastern Australia. Furthermore, the peripheral subsidence created during rift-flank uplift (Figure 7.4) can enhance the double drainage divide pattern, separating the inland drainage divide and the rift flank. To illustrate this idea, we designed a new model that considers an initial inland divide; the evolution of this model is shown in Figure 7.9b. In this model, after the faulting stage, the rift flank retreats $\sim 60 \mathrm{~km}$ landward, approaching the inland divide. Note that in this case the permanence of the landward-retreating rift flank through time results from the low stretching factor of the crust under the rift flank during and after rifting. While the rift flank retreats landward, the inland divide remains at roughly the same position through time. The uplift of the rift flank and the peripheral subsidence locally changes the drainage pattern and promotes rivers flowing parallel to the inland divide and the retreating rift flank in the region between the two (Figure 7.9b, at $90 \mathrm{Myr}$ ). The model of Figure 7.9b combines two models studied by van der Beek and Braun (1999): the flankuplift and the inclined-plateau model. In their work, they analyzed separately the effect of rift-flank uplift and a pre-existing seaward-sloping plateau on landscape evolution. They concluded that only the inclined plateau model can produce the double drainage divide configuration as observed in Southeastern Australia, but only for very small values of the dip of the plateau $(<0.1 \%)$. Combining both models it is possible to explain the double drainage divide pattern in Southeastern Australia without requiring a very specific initial topographic configuration. 
It is important to note that in the model of Figure 7.9a, the formation of the post-rift inland divide at the secondary bulge occurs because the pre-rift topography dips landward. We observed that in the case of pre-existing inland divide (Figure 7.9b, Model 4) with the topography dipping seaward, the secondary bulge does not evolve to a new drainage divide but is gradually eroded.

\subsubsection{Serra do Mar, Southeastern Brazil}

The Serra do Mar consists of a set of escarpments that run parallel to the coast of southeastern Brazil for nearly $1000 \mathrm{~km}$ and locally reach up to $2 \mathrm{~km}$ elevation (Mohriak et al., 2008). Located offshore of the Serra do Mar, the Santos and Campos basins are predominantly developed on thinned continental crust. An important feature of the basement under the Santos and Campos basins is the Cretaceous hinge zone (Figure 7.10b-c) that marks a strong variation in basement dip and represents the western limit of Cretaceous sedimentation in the offshore basins (Karner, 2000). Furthermore, this hinge zone appears to coincide with the western limit of significant crustal thinning (Karner, 2000). Mohriak et al. (2008) proposed that the present-day Serra do Mar is the result of the retreat of an escarpment that formed initially at the Cretaceous hinge zone, resulting in a retreat distance of $172-247 \mathrm{~km}$.

According to the predictions of our models, the thinning of the crust under the offshore portion of southeastern Brazil makes retreat of the present-day escarpment from its original position at the hinge line quite unlikely. It appears much more plausible that the presentday main drainage divide was created as a secondary flexural bulge that persisted through time (see Figure 7.3). These results agree with the conclusions of Hiruma et al. (2010), who suggest that the Bocaina Plateau, the highest part of the Serra do Mar, corresponds to a preserved inland drainage divide. The distance between the escarpment and the initial rift shoulder in the numerical model of Figure 7.3 is nearly $170 \mathrm{~km}$, of the same order as the distance from the present-day Serra do Mar to the Cretaceous hinge zone (Figure 7.10c).

Furthermore, the final configuration of the basement predicted by our model beneath the original rift shoulder is similar to that of the hinge zone in the offshore region of the Santos basin. In Figure 7.10a we show the stratigraphic pattern predicted by our numerical model (Figure 7.3). In this model the rift shoulder is eroded and subsides due to post-rift 
(a) Numerical model

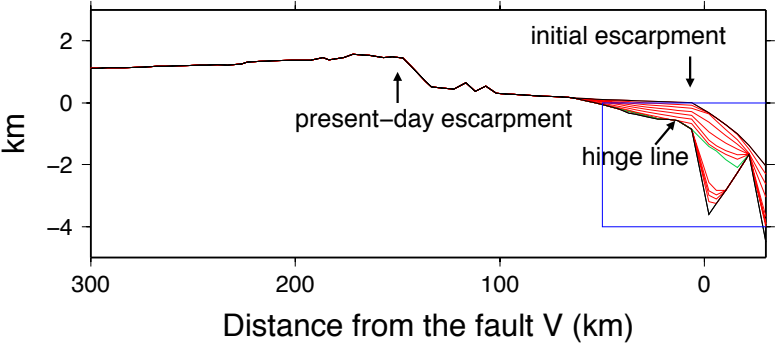

(b) Interpreted seismic section - Santos Basin

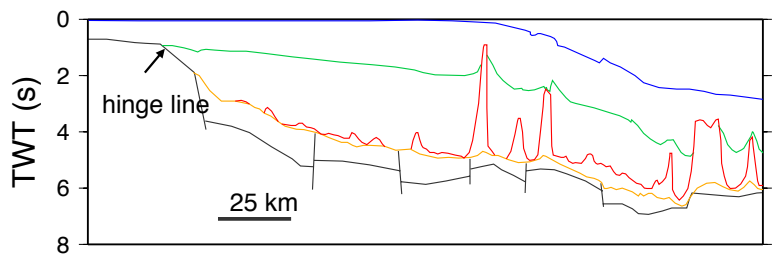

(c) Topography/Bathymetry of SE Brazil

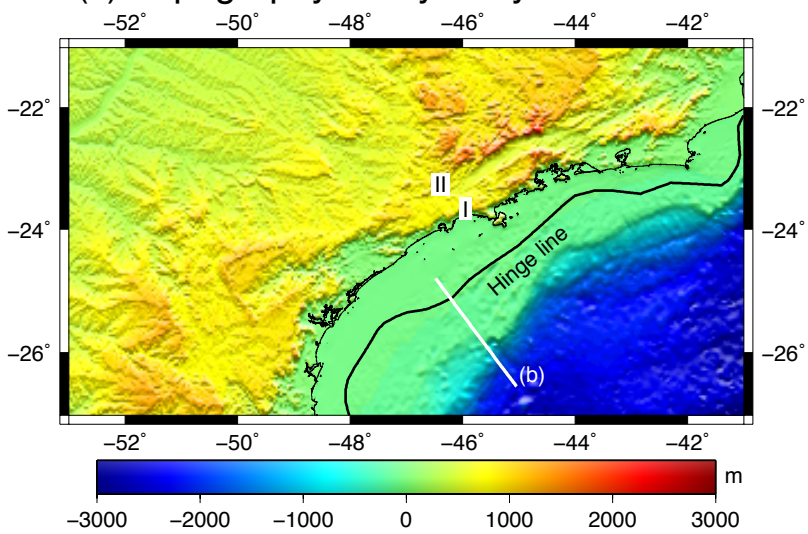

Figura 7.10(a) Stratigraphic pattern predicted by Model 1 (Figure 7.2 and 7.3) at the end of the simulation (120 Myr). The lines are in intervals of $10 \mathrm{Myr}$. The green line marks the stratigraphic unit at $50 \mathrm{Myr}$ after the initiation of the rift. The blue box represents the region equivalent to the interpreted seismic section in (b). (b) Seismic section crossing the Santos basin. The arrow indicates the position of the Cretaceous hinge line. Black curves: basement; Yellow curves: top of pre-salt sediments ( $120 \mathrm{Ma})$; Red curves: top of salt $(\sim 112$ Ma); Green curves: Top of the Cretaceous sediments ( 65.5 Ma); Blue curves: Post-Cretaceous sediments. Modified from Assine et al. (2008). (c) Topography and bathymetry of Southeastern Brazil. The thick black curve shows the position of the hinge line based on Assine et al. (2008). I and II indicate the Serra do Mar and Serra da Mantiqueira escarpments. The white line represents the geographic position of the seismic section shown in (b). 
thermal cooling of the lithosphere and the sedimentary load of the margin. The subsidence of the coastal area creates accommodation space filled by sediments at a later time. After $50 \mathrm{Myr}$ of evolution in our model (the green line in Figure 7.10a) the region landward of the hinge line subsides and preserves a substantial sedimentary package, similar to the post-Cretaceous sedimentation in the Santos basin (Figure 7.10b).

The load of the margin also favors the migration of the drainage divide to the secondary bulge, since it imposes a seaward tilt, similar to the differential subsidence due to thinning of the lower crust.

During the Cenozoic, the Southeastern Brazilian margin was affected by renewed continental rifting (Riccomini et al., 2004) that produced a series of basins parallel to the coast. Rifting also resulted in the isolation of the Serra do Mar escarpments and the formation of the inland escarpment of the Serra da Mantiqueira (Figure 7.10c).

To verify the potential effect of late continental rifting on the evolution of the escarpment system, we developed a new simulation (Model 5) presented in Figure 7.11 (see Table 7.2). Like in Model 1, stretching of the lithosphere and thinning of the lower crust under the rift flank result in the development of an inland drainage divide on the secondary bulge that evolves into the new escarpment, while the rift flank escarpment disappears due to the combined effects of erosion and subsidence (Figure 7.11a).

At $70 \mathrm{Myr}$, we introduce the gradual formation of a 40-km-wide graben, in a position landward of the escarpment as indicated in Figure 7.11b. The development of the graben occurs during $1 \mathrm{Myr}$, and the rate of uplift close to the flanks of the faults is $\partial w_{\max } / \partial t=$ $1 \mathrm{~km} /$ Myr. These faults isolate the oceanward escarpment and create a new one in a landward position (Figure 7.11c).

After formation of the graben, the erosion and flexural response of the lithosphere continue to modify the landscape. $50 \mathrm{Myr}$ after the graben formation (Figure 7.11d), both escarpments persist as prominent topographic features with more than $1500 \mathrm{~m}$ relief, representing local drainage divides and resembling the Serra do Mar and Serra da Mantiqueira escarpments.

This result shows that Cenozoic rifting does not affect the conclusions of the present work about the evolution of the Serra do Mar. The physical explanation for the persistence of the Serra do Mar after the Cenozoic rifting is that this tectonism did not result in 

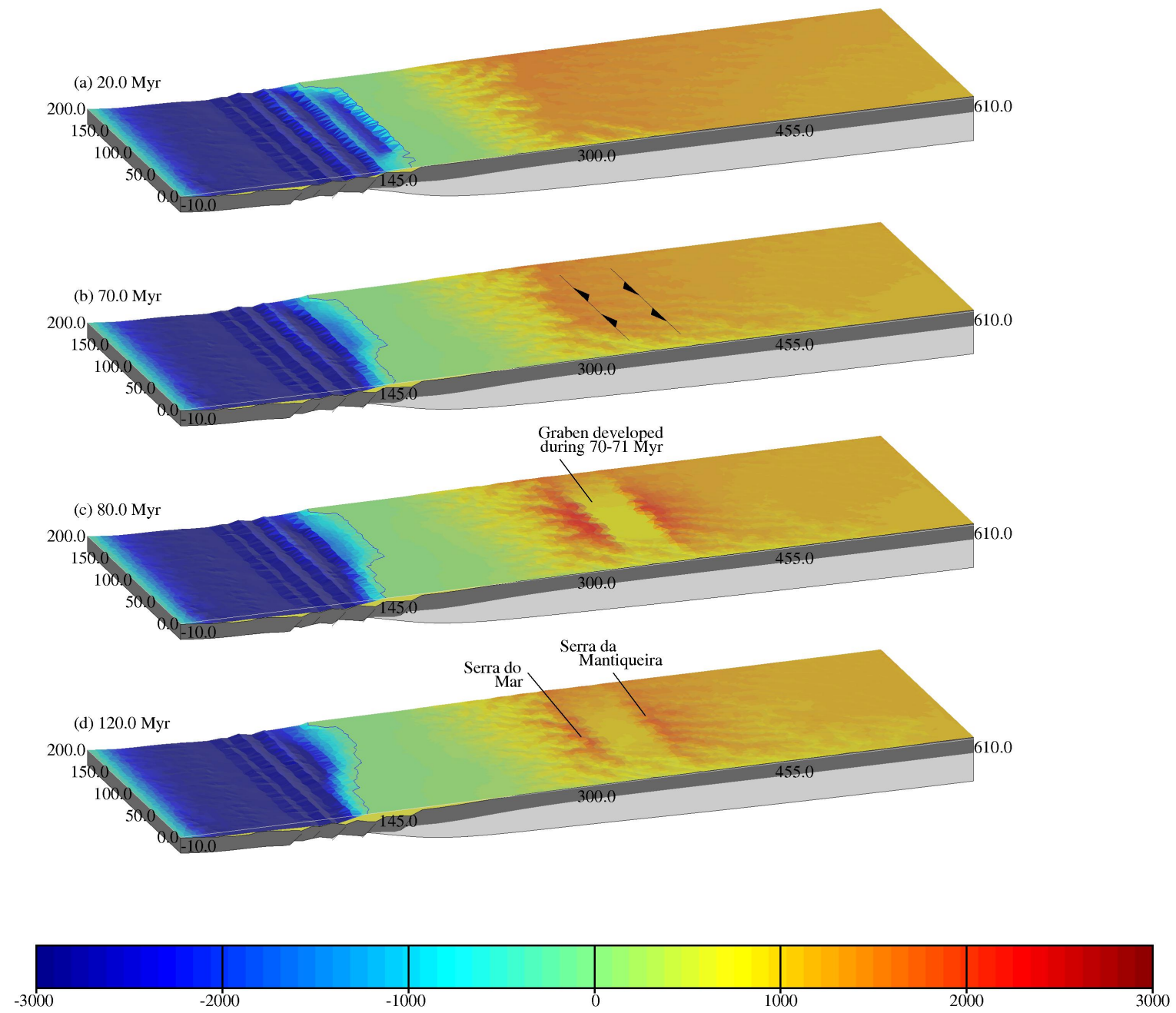

Figure 7.11: Evolution of Model 5 where the margin is affected by late-stage rifting at 70 Myr. (a) Model at $20 \mathrm{Myr}$, showing the escarpment formed on the secondary bulge, like in Model 1. (b) Model at $70 \mathrm{Myr}$, when the margin starts to be affected by the formation of a graben, as indicated in the figure. The faults of the graben are active during 70-71 Myr. (c) Model at $80 \mathrm{Myr}$, presenting the double escarpment pattern after the creation of the graben. (d) Model at 120 Myr, showing that the two escarpments persist through time, resembling the Serra do Mar and Serra da Mantiqueira escarpments in Southeastern Brazil. 
expressive thinning of the lower crust, and the Serra do Mar did not undergo mechanical subsidence, unlike the flank uplift at the hinge zone.

\subsubsection{Conclusions}

The main contribution of this work is the development of a numerical model for rifted margin evolution that takes both onshore and offshore dynamics into account, thereby providing a self-consistent explanation for pinned-divide formation. This work confirms earlier suggestions that long-term preservation of an escarpment requires a high pre-existing plateau to have been present. Our model shows how the combination of flexural response of the crust to faulting during rifting and differential subsidence of the margin can produce an inland drainage divide that persists through time since the onset of rifting and does not evolve from the rift shoulder as a retreating escarpment.

We have observed that the formation of an inland drainage divide is directly controlled by the thinning pattern of the crust during rifting. The position of the drainage divide developed on the secondary bulge is controlled by the rigidity of the crust during rifting, while the rigidity of the entire lithosphere plays a secondary role, controlling the retreat rate of the new escarpment.

These concepts can potentially clarify the understanding of the formation of the double drainage divide pattern observed in Southeastern Australia and can explain the presentday position of the Serra do Mar escarpment in Brazil relative to the Cretaceous hinge zone in the offshore basins. They provide, in both cases, a systemic explanation for the particular topographic patterns observed, without requiring recourse to conjectural postrift reactivation of the margins.

The ideas proposed here can be further tested by studying in greater details the distribution of extension ( $\beta$ maps) in passive margins and how it relates to escarpment geometry and position. They can also be confronted with thermochronological data, which provide constraints on the timing of erosion in the coastal regions. However, as demonstrated by Braun and van der Beek (2004), this approach might be hindered by the relatively low amounts of exhumation experienced by many passive margins. 


\subsection{Post-rift influence of a thermal plume on passive margins ${ }^{2}$}

\subsubsection{Abstract}

This work presents how the passage of a thermal anomaly under the lithosphere can affect the sedimentary evolution of passive margins. We assumed that the uplift related to the thermal anomaly is due to the thermal expansion of the lithosphere, and other effects associated with the dynamics of the asthenosphere are neglected. We studied different scenarios in the numerical models, taking into account the interaction of the thermal evolution of the lithosphere, the flexural isostasy and the surface processes of erosion and deposition. The numerical results show that the velocity of the lithosphere relative to the thermal anomaly and the flexural rigidity of the continental and oceanic lithospheres significantly affect the evolution of the sedimentary shelf. Finally, the concepts from the numerical models are used to study the influence of a thermal anomaly (the Trindade Plume?) on the evolution of the Campos and Espírito Santo Basins, in Southeastern Brazil.

\subsubsection{Introduction}

It is known that many oceanic volcanoes show shallower-than-normal bathymetry that extends for several hundred kilometers beyond the region of volcanism, whereas very old oceanic volcanoes are not associated with swells (Ito and van Keken, 2007). Therefore, a transient mechanism is responsible to produce these swells.

During the last decades, different models have been proposed to explain the formation of these swells. One explanation is that the introduction of buoyant asthenosphere at the base of the lithospheric plate produces these swells (Sleep, 1987). Other models describe the swell as a dynamic topography due to the upwelling movement of material in the sub-lithospheric mantle (Ribe and Christensen, 1994). Also, simple isostatic models based on thermal diffusion explains the evolving bathymetry along seamount chains (Ito and Clift, 1998). In fact, these different mechanisms may be acting concomitantly, each one contributing partially to the total uplift.

In the present work, we simulate the uplift of the lithosphere as a result of the thermal

\footnotetext{
${ }^{2}$ Since this section is part of an article to be submitted, this section was written in the active voice.
} 
heating of the lithosphere due to the passage of a plume head, exemplified here as a thermal anomaly at the base of the lithosphere. The uplift produced by the thermal anomaly is only due to the diffusional heating and thermal expansion of the lithosphere, and does not take into account other effects like dynamic topography created by the upwelling movement of the plume. Certainly, the dynamic topography associated with the plume must amplify the uplift of the surface and, therefore, the uplift predicted in the present work must be taken as an underestimated uplift.

Incorporating surface processes of erosion and deposition and regional isostatic compensation in the numerical models, we discuss how the transient uplift of the lithosphere influences the evolution of passive margins. In spite of the assumption of the thermal expansion of the lithosphere as the mechanism for the formation of swells, the conclusions about the evolution of the passive margins are independent of the transient mechanism to create the swells.

\subsubsection{The isostatic effect of a moving plume}

The model to study the isostatic effect of a plume moving relatively to the lithosphere with velocity $-\mathbf{v}_{r e l}$ under the lithosphere is illustrated in Figure 7.12. The model is constructed considering that the reference frame is fixed relative to the plume and the lithosphere is steadily moving over the plume with velocity $\mathbf{v}_{r e l}=\left(v_{r e l}, 0\right)$.

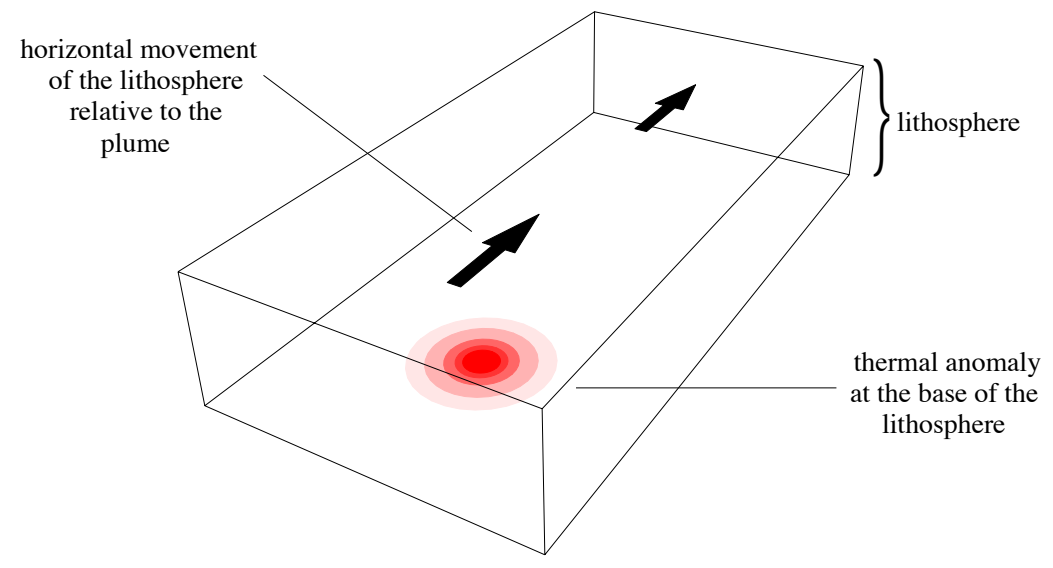

Figure 7.12: Illustration of the numerical model to study the isostatic effect of a thermal plume hitting the base of the lithosphere. 
The temperature at the top surface of the model is maintained fixed at $T_{z=0}=0^{\circ} \mathrm{C}$ and the bottom surface, i.e. the base of the lithosphere, at

$$
T_{z=-a_{L}}=\left[1300+T_{\text {anomaly }} \exp \left(-r^{2} / r_{0}^{2}\right)\right]^{\circ} \mathrm{C}
$$

where $T_{\text {anomaly }}$ is the maximum temperature at the center of the thermal anomaly at the base of the lithosphere, $r$ is the horizontal distance to the center of the plume and $r_{0}$ is a parameter that controls the radius of the thermal anomaly. This problem is solved numerically through the finite element method as described in Chapter 3.

The temperature $T_{\text {anomaly }}$ is based on estimates of excess mantle temperature associated with plumes (e.g. White et al., 1995; Herzberg and O'Hara, 2002) ranging between $100-300^{\circ} \mathrm{C}$. In the present work it is assumed that $T_{\text {anomaly }}=175^{\circ} \mathrm{C}$. The radius $r_{0}$ is estimated from the width of the swells associated with oceanic volcanoes. Ito and van Keken (2007) showed that the width of the swells range from hundreds to thousands kilometers (e.g. Galápagos - 300 km; Trindade-Martin Vaz - 1330 km; Azores - 2300 km). In the present work $r_{0}$ is assumed to be equal to $r_{0}=300 \mathrm{~km}$, resulting in a width of $600 \mathrm{~km}$.

Assuming local isostatic compensation and vertical loading due to thermal expansion of the lithosphere related to temperature variation $\Delta T$, the vertical uplift $w_{T}$ of the lithosphere is

$$
\begin{aligned}
\rho_{m} g w_{T} & =\int_{-a_{L}}^{0} \rho_{m} \alpha_{T} \Delta T g d z \\
w_{T} & =\int_{-a_{L}}^{0} \alpha_{T} \Delta T d z .
\end{aligned}
$$

The uplift of the lithosphere $w_{T}$ due to the passage of a thermal anomaly depends on the relative velocity $v_{r e l}$. If the relative velocity is too high, there is not enough time to heat the lithosphere and the thermal expansion is not expressive. Therefore, the maximum uplift of the lithosphere decreases with the increase of $v_{r e l}$. To illustrate this effect, in the Figure 7.13 we present maps of the thermal uplift of the lithosphere due to a thermal anomaly at the base of the plate, for different relative velocities $\left(v_{r e l}=0,1,2\right.$ and 3 $\mathrm{cm} / \mathrm{yr})$. In these numerical models, the maximum uplift varies from $401 \mathrm{~m}$ for $v_{r e l}=0$ to $122 \mathrm{~m}$ for $v_{r e l}=3 \mathrm{~m} / \mathrm{yr}$ (see Table 7.4). It is possible to observe that the amplitude and shape of the uplift depends on the thickness of the lithosphere, the relative velocity $v_{r e l}$ and the magnitude and extent of the thermal anomaly. 


\begin{tabular}{|c|c|c|c|}
\hline & Parameters & Description & Value \\
\hline \multirow{7}{*}{$\begin{array}{l}\text { Surface } \\
\text { processes }\end{array}$} & $h_{s . l .}$ & Sea level & $0 \mathrm{~m}$ \\
\hline & $k_{m}^{*}$ & Diffusivity for the offshore transport & $80 \mathrm{~m}^{2} /$ year \\
\hline & $h_{0}$ & Decay factor for the offshore transport & $1000 \mathrm{~m}$ \\
\hline & $L_{f s}$ & Alluvial erosion lenght scale & $10 \mathrm{~km}$ \\
\hline & $L_{f b}$ & Bedrock erosion lenght scale & $100 \mathrm{~km}$ \\
\hline & $k_{s} / k_{f} v_{R}$ & & $10 \mathrm{~m}$ \\
\hline & $\delta_{r}$ & Mean distance between adjacent nodes & $8 \mathrm{~km}$ \\
\hline \multirow{8}{*}{$\begin{array}{l}\text { Flexure } \\
\text { and } \\
\text { Isostasy }\end{array}$} & $E$ & Young's modulus & $1.0 \times 10^{11} \mathrm{~N} / \mathrm{m}^{2}$ \\
\hline & $T_{e}$ & Effective elastic thickness & $5 \mathrm{~km}$ (first model) \\
\hline & $g$ & acceleration of gravity & $9.8 \mathrm{~m} / \mathrm{s}^{2}$ \\
\hline & $\nu$ & Poisson's ratio & 0.25 \\
\hline & $\rho_{m}$ & Mantle density & $3300 \mathrm{~kg} / \mathrm{m}^{3}$ \\
\hline & $\rho_{c}$ & Crust density & $2700 \mathrm{~kg} / \mathrm{m}^{3}$ \\
\hline & $\rho_{s}$ & Sediment density & $2700 \mathrm{~kg} / \mathrm{m}^{3}$ \\
\hline & $\rho_{w}$ & Water density & $1030 \mathrm{~kg} / \mathrm{m}^{3}$ \\
\hline \multirow{7}{*}{ Thermal } & $a_{L}$ & Initial thickness of the lithosphere & $150 \mathrm{~km}$ \\
\hline & & Top temperature & $0^{\circ} \mathrm{C}$ \\
\hline & & Bottom temperature & $\begin{array}{l}1300+T_{\text {anomaly }} \\
\exp \left(-r^{2} / r_{0}^{2}\right)^{\circ} \mathrm{C}\end{array}$ \\
\hline & $T_{\text {anomaly }}$ & & $175^{\circ} \mathrm{C}$ \\
\hline & $r_{0}$ & & $300 \mathrm{~km}$ \\
\hline & $\kappa$ & Thermal diffusivity $=k / \rho c$ & $10^{-6} \mathrm{~m}^{2} / \mathrm{s}$ \\
\hline & $\alpha_{T}$ & Thermal expansion coefficient & $3.28 \times 10^{-5}{ }^{\circ} \mathrm{C}^{-1}$ \\
\hline
\end{tabular}

Table 7.3 - Fixed parameters and their values used in the models.

On the other hand, if the relative velocity is too low, the rate of uplift $\partial w_{T} / \partial t$ is also low. The rate of uplift is calculated from the maps of $w_{T}$ of Figure 7.13 as follows:

$$
\frac{\partial w_{T}}{\partial t}=\frac{\partial w_{T}}{\partial x} \frac{\partial x}{\partial t}=\frac{\partial w_{T}}{\partial x} v_{r e l}
$$

Figure 7.14 shows the maps of rate of uplift for $v_{r e l}=1,2$ and $3 \mathrm{~cm} / \mathrm{yr}$, where the horizontal 
axis is the time since the instant the plate crossed the plume. In our numerical models, the maximum uplift rate occurs for the fastest plate (Table 7.4), although in this case the period of uplift is the shortest (Figure 7.14). The rate of uplift maps also show that the regions close to the thermal anomaly initially undergoes uplift, followed by a protracted subsidence.

Another aspect observed in Figure 7.13 is that the maximum uplift does not occur in the center of the thermal anomaly, but is shifted toward the direction of movement of the lithosphere relative to the thermal anomaly. The shift increases with $v_{r e l}$, apparently faster for low $v_{\text {rel }}$ (Table 7.4), reaching up to $172 \mathrm{~km}$ for the model with $v_{r e l}=3 \mathrm{~cm} / \mathrm{yr}$..

\begin{tabular}{lcccc}
\hline $\begin{array}{l}v_{\text {rel }} \\
(\mathrm{cm} / \mathrm{yr})\end{array}$ & $\begin{array}{c}\text { maximum } w_{T} \\
(\mathrm{~m})\end{array}$ & $\begin{array}{c}\text { shift } \\
(\mathrm{km})\end{array}$ & $\begin{array}{c}\text { maximum } \partial w_{T} / \partial t \\
(\mathrm{~m} / \mathrm{Myr})\end{array}$ & $\begin{array}{c}\text { minimum } \partial w_{T} / \partial t \\
(\mathrm{~m} / \mathrm{Myr})\end{array}$ \\
\hline 0 & 401. & 0. & - & - \\
1 & 215. & 162. & 5.4 & -2.8 \\
2 & 151. & 172. & 7.5 & -3.4 \\
3 & 122. & 172. & 9.1 & -4.1
\end{tabular}

Table 7.4 - Maximum uplift $w_{T}$, shift between the axis of the plume and the position of maximum $w_{T}$, and maximum and minimum rates of uplift $\partial w_{T} / \partial t$ for the four models shown in Figures 7.13 and 7.14.

The uplift $w_{T}$ shown in Figure 7.13 could be amplified considering that $w_{T}$ modifies the surface and can lead to a load redistribution at the top of the lithosphere. In submarine swells, the thermal uplift of the lithosphere displaces water on the top of the plate, which results in unloading of the lithosphere. In this case, the expression for the uplift of the lithosphere becomes:

$$
w_{T+w}=\frac{\rho_{m}}{\rho_{m}-\rho_{w}} \int_{-a_{L}}^{0} \alpha_{T} \Delta T d z .
$$

Taking into account the water unloading of the lithosphere, the total uplift $w_{T+w}$ is $\sim 45 \%$ higher than $w_{T}$. In sedimentary basins, the thermal uplift can result in erosion of part of the uplifted sedimentary layers, leading to a total uplift

$$
w_{T+s e d}=\frac{\rho_{m}}{\rho_{m}-\rho_{s}} \int_{-a_{L}}^{0} \alpha_{T} \Delta T d z
$$

where $\rho_{s}$ is the density of the eroded material. If $\rho_{s}=2400 \mathrm{~kg} / \mathrm{m}^{3}$, for example, the maximum uplift $w_{T+s e d}$ is $w_{T+s e d}=3.67 w_{T}$. Therefore, the heating of the lithosphere due 

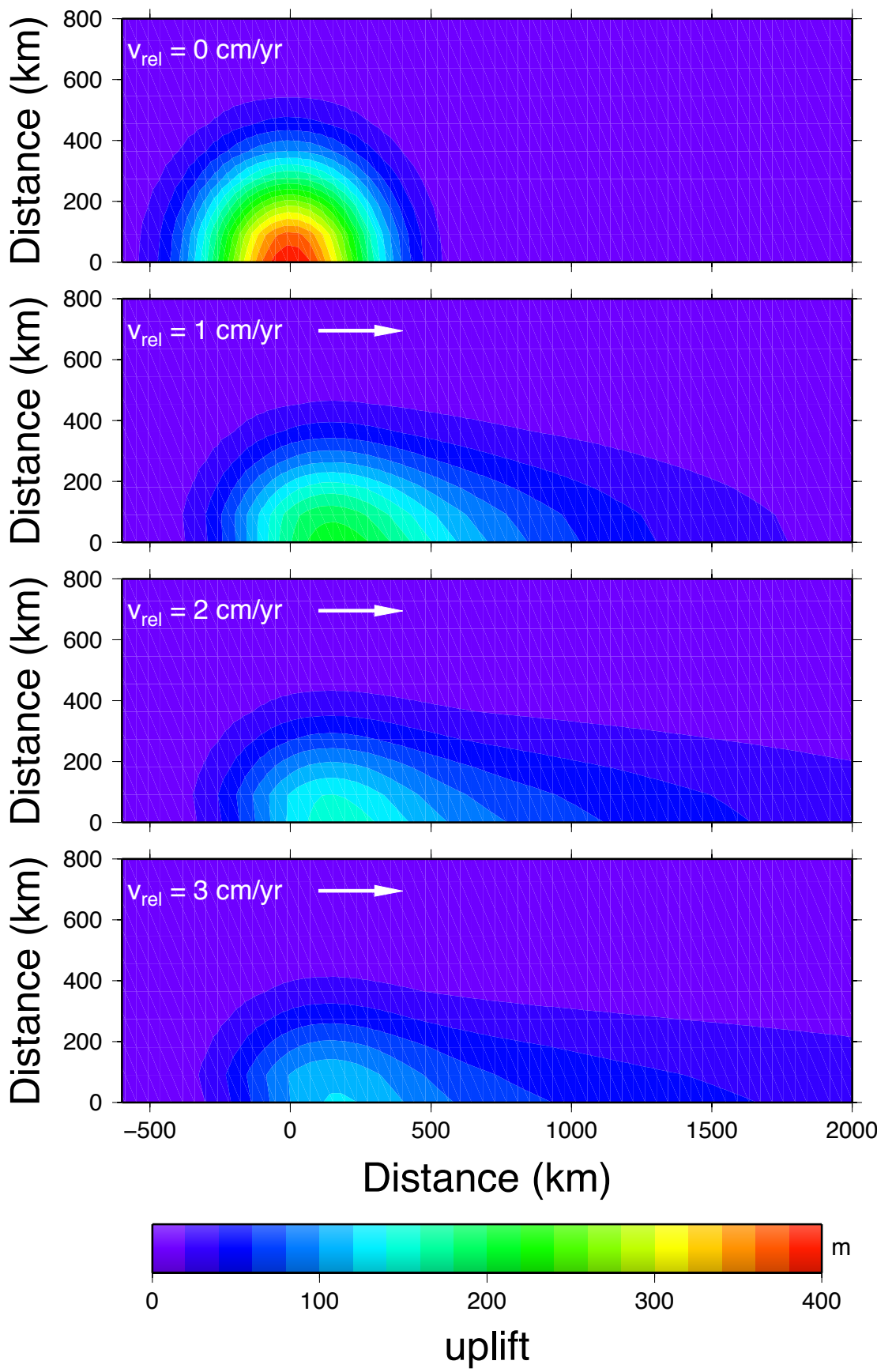

Figure 7.13: Uplift maps for different relative velocities $v_{r e l}$, viewed from a reference frame fixed relative to the thermal anomaly, at the origin of the coordinates. Due to the symmetry of the model, only half of the plate is shown.

to the passage of thermal anomalies combined with its effects on the surface results in hundreds of meters of transient lithospheric uplift. 

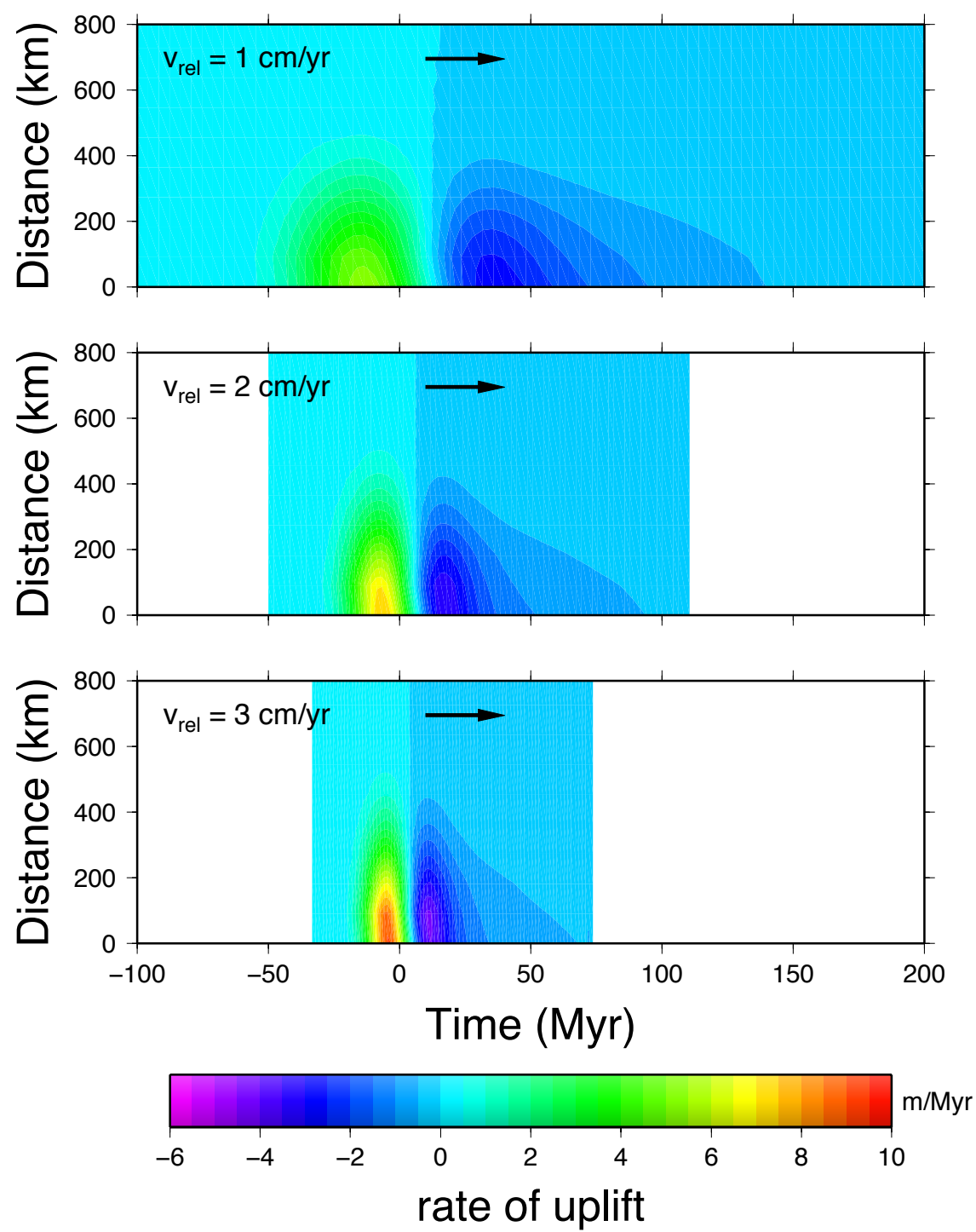

Figure 7.14: Maps of rate of uplift for different relative velocities $v_{r e l}$. The horizontal axis represents the time since the moment that the plate crossed the plume. Due to the symmetry of the model, only half of the plate is shown.

\subsubsection{The influence of thermal anomalies on the evolution of passive margins}

To illustrate the influence of a thermal anomaly at the base of the lithosphere on the evolution of passive margins, we incorporate in the thermal model the surface processes and the flexural isostatic models (Chapters 5 and 2, respectively).

It is assumed a passive margin with the initial topography as shown in Figure 7.15a, and the area of the model is $500 \times 500 \mathrm{~km}^{2}$. Other parameters of the model are shown in 

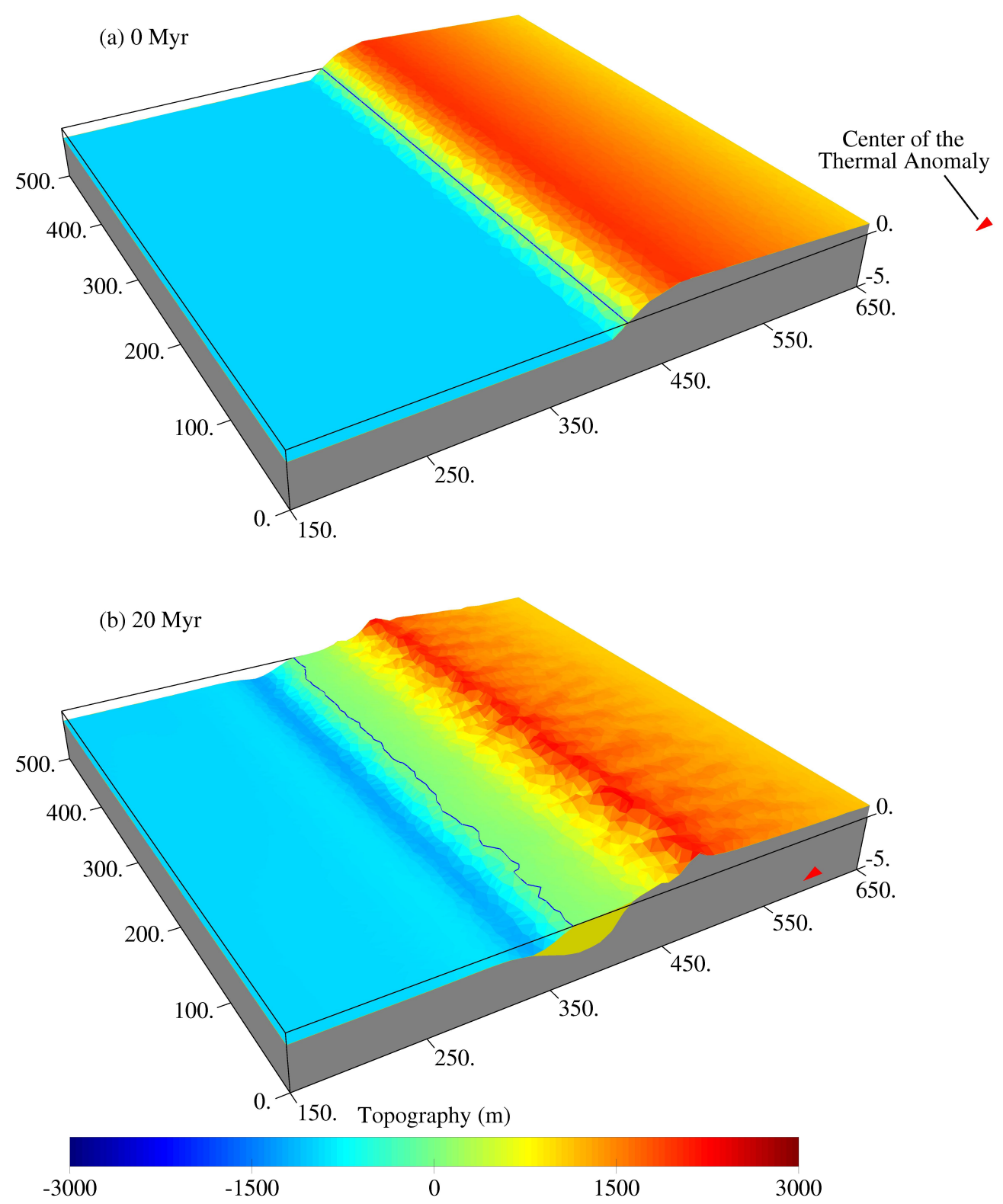

Figure 7.15: Numerical model to study the influence of the passage of a thermal anomaly at the base of the lithosphere on the evolution of passive margins. (a) Initial configuration of the topography and position of the center of the thermal anomaly at $x=800 \mathrm{~km}$, indicated by the red triangle. (b) Model at $20 \mathrm{Myr}$, when the thermal anomaly is at $x=600 \mathrm{~km}$. The gray and yellow regions on the sides of the model represent the basement and the sediments, respectively.

Table 7.3. Initially, it is imposed a thermal anomaly outside the model at $(x, y)=(800,0)$ $\mathrm{km}$, indicated as a red triangle in Figure 7.15a. This thermal anomaly moves toward the 

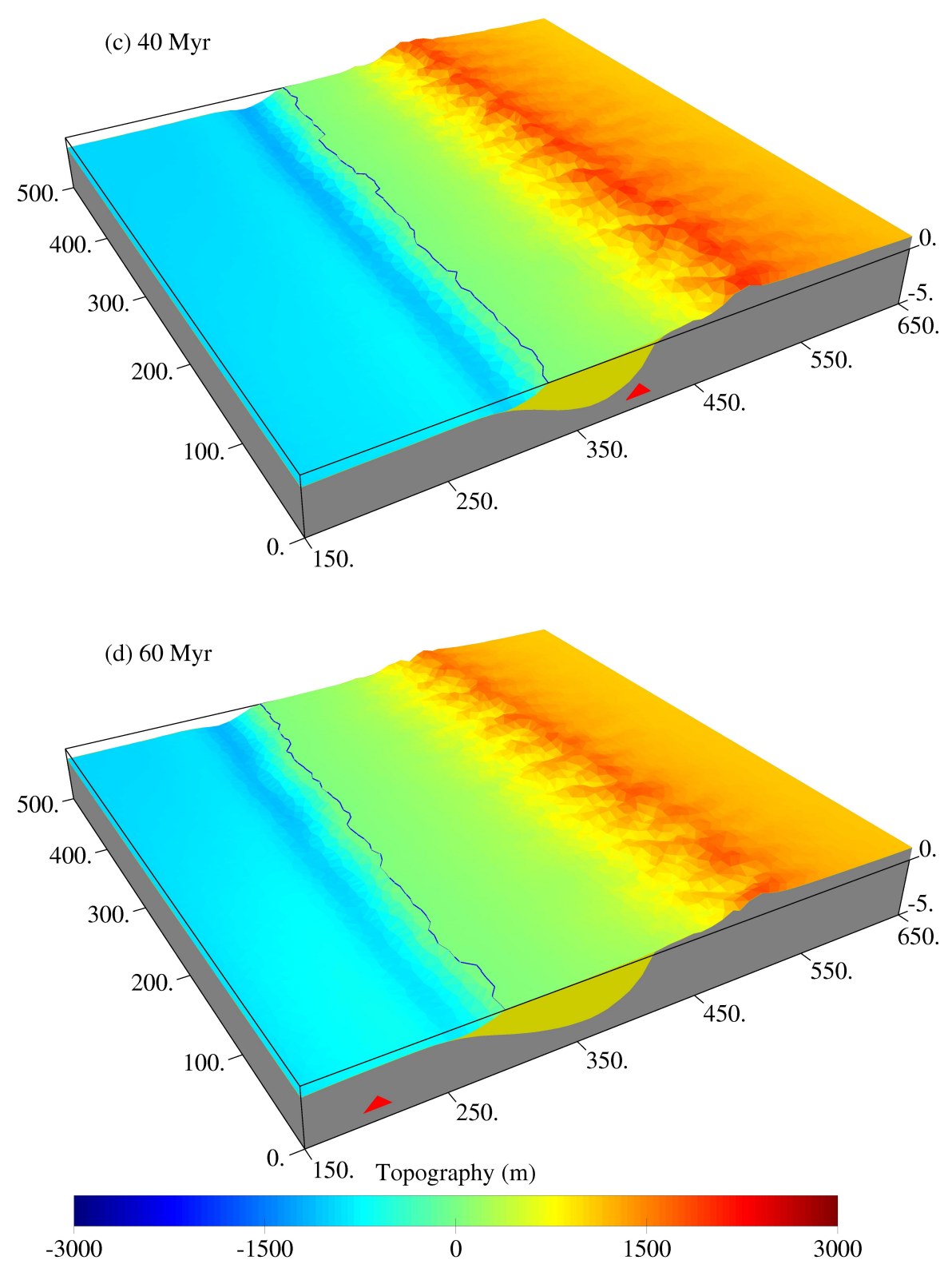

Figure 7.16: Continuation of Figure 7.15. (c) Model at $40 \mathrm{Myr}$, when the thermal anomaly is at $x=400 \mathrm{~km}$. (d) Model at $60 \mathrm{Myr}$, when the thermal anomaly is at $x=200 \mathrm{~km}$.

model with a relative velocity of $\left|v_{r e l}\right|=1 \mathrm{~cm} / \mathrm{yr}$ along the axis $y=0$. Concomitantly with the movement of the thermal anomaly, the topography is eroded and the sediments are deposited on the margin. Due to the parallelism of the topographic feature with the coast, the supply of sediments to the coast is relatively uniform along the margin. Both surface and thermal loading are regionally compensated. During all the numerical simulation, the sea level is maintained at $z=0$. The simulation occurs during $100 \mathrm{Myr}$ (Figures 7.15, 7.16 


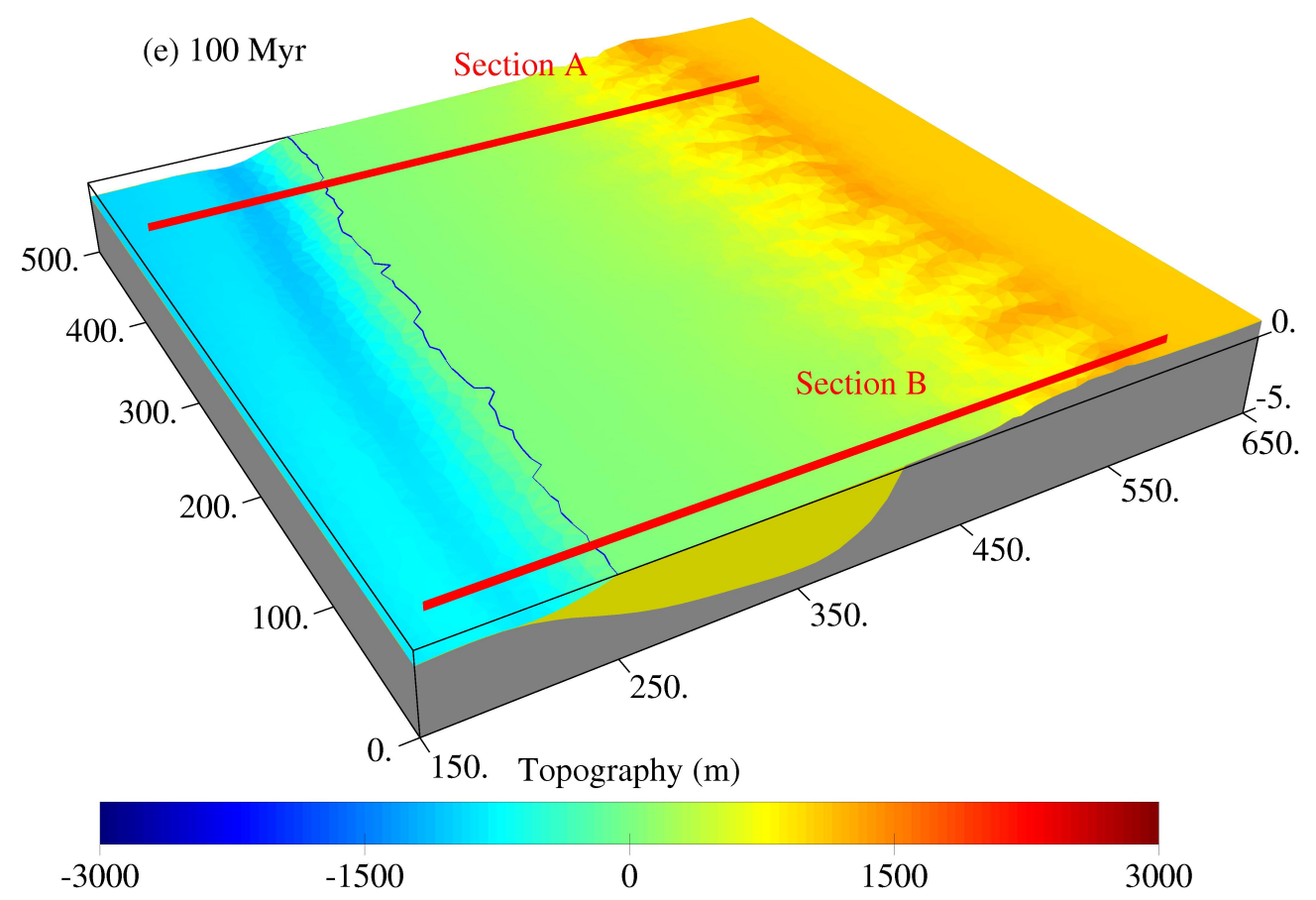

Figure 7.17: Continuation of Figure 7.15. The red bars show the position of the Sections A (Figure 7.18) and B (Figure 7.19).

and 7.17), and, during this period, the thermal anomaly crosses the entire model.

To analyze in detail the effect of the thermal anomaly on the passive margin, two sections are extracted from the model (Figure 7.17): Section A at $y=400 \mathrm{~km}$ (far from the thermal anomaly); and Section B at $y=10 \mathrm{~km}$ (close to the thermal anomaly track). The stratigraphic evolution of the margin in Sections A and B is shown in Figures 7.18 and 7.19 , respectively.

In Section A, where the influence of the thermal anomaly is less expressive, during the first stage of the model, erosion and unloading of the continent result in regional uplift of the margin, producing stratal offlapping of the basin margin (Figures 7.18, 20-60 Myr). When the erosion of the continent occurs mainly far from the coast, the basin undergoes predominantly subsidence due to the sedimentary loading, causing a tenuous stratigraphic onlap of younger sediments onto older ones, as shown in Figures 7.18, 40-100 Myr. This offlapping and subsequent onlapping strata related to the flexural effects of the erosion of rift shoulders was previously observed by van Balen et al. (1995).

In Section B, the initial stratigraphic evolution is very similar to the one in Section 


\section{Section A - far from the plume}

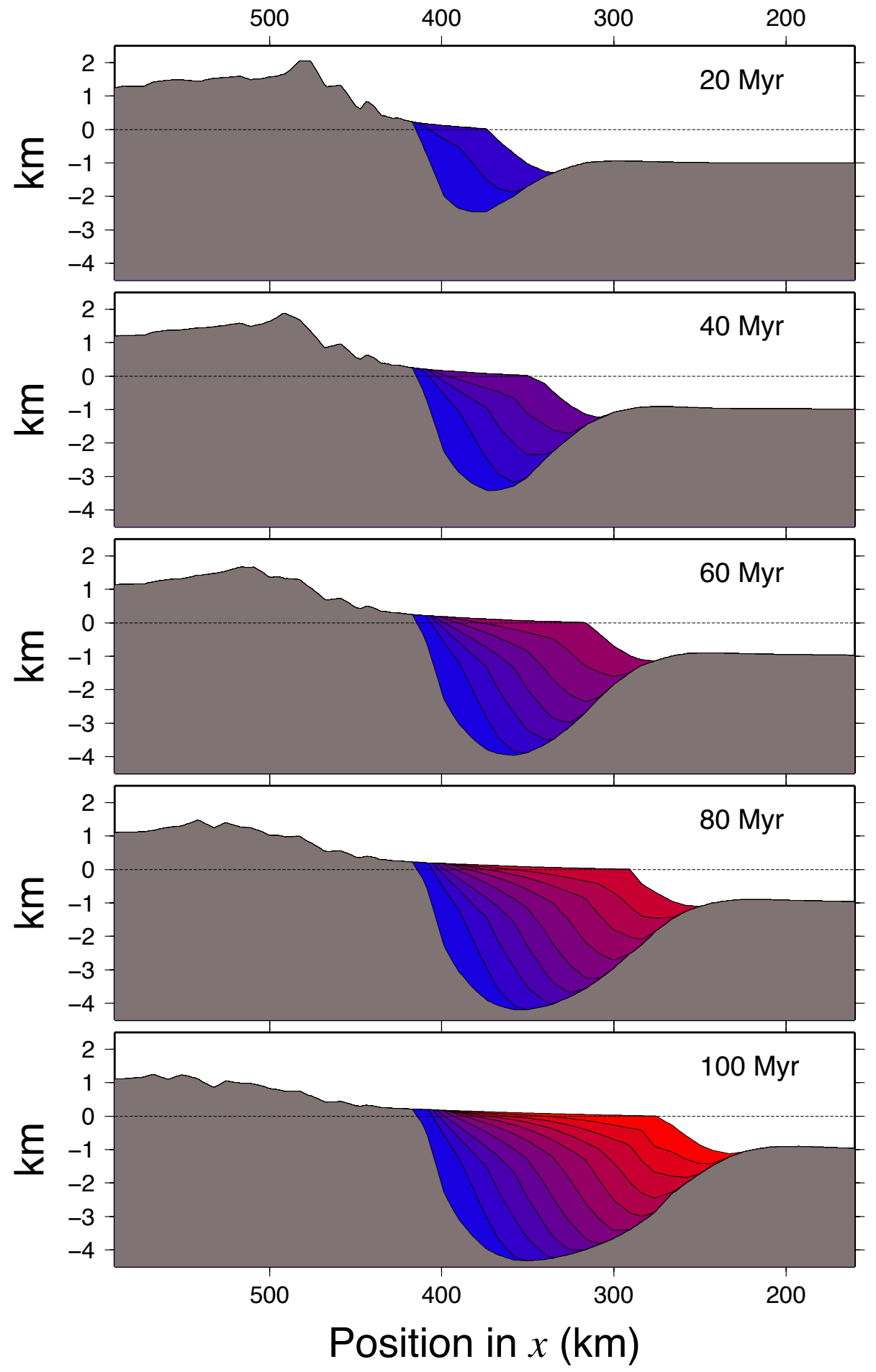

Figure 7.18: Stratigraphic evolution of the margin far from the thermal anomaly - Section A. The stratigraphic interval is $10 \mathrm{Myr}$. 


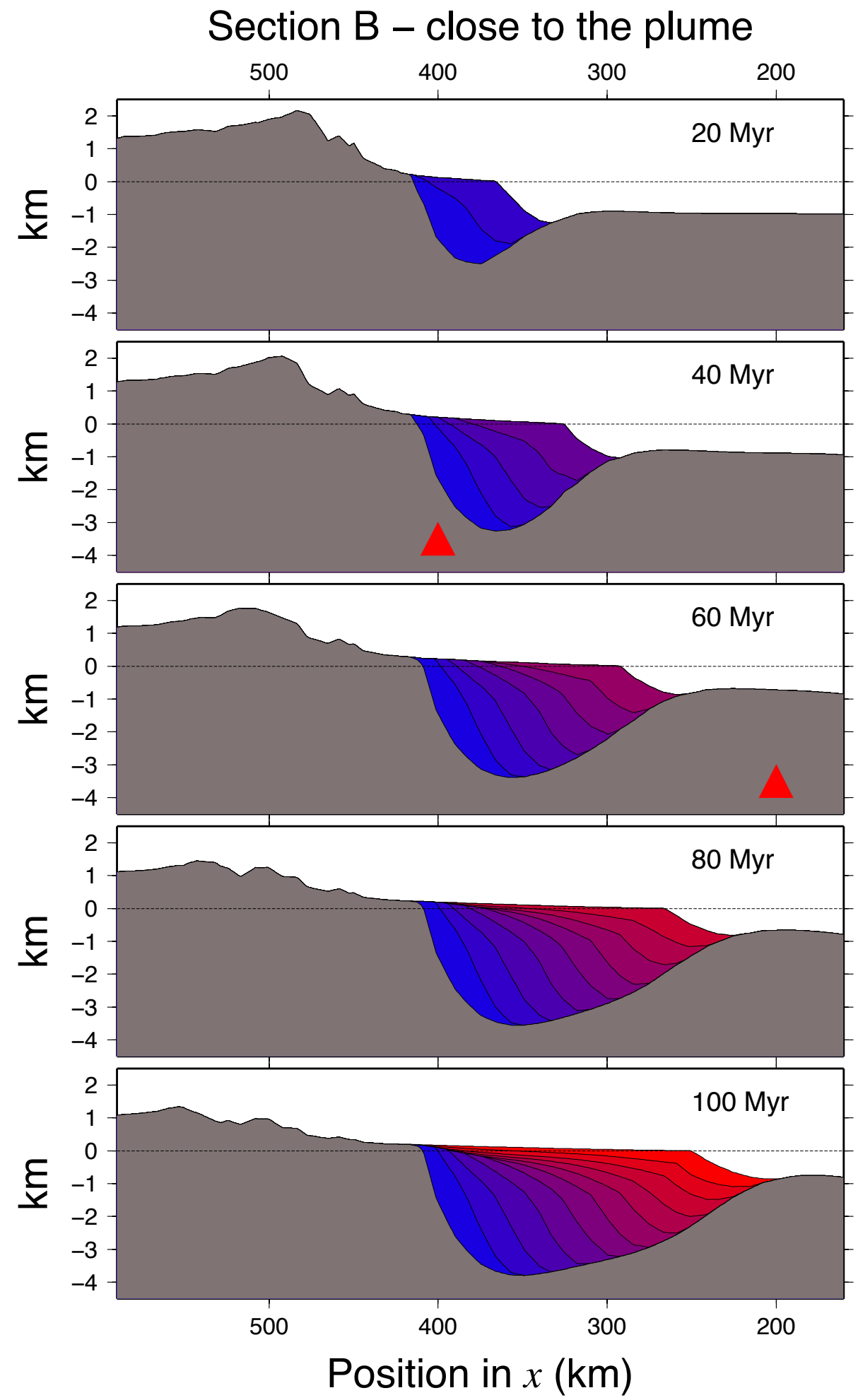

Figure 7.19: Stratigraphic evolution of the margin close to the thermal anomaly - Section B. The red triangles represent the position of the thermal anomaly. The stratigraphic interval is $10 \mathrm{Myr}$. 
A (Figure 7.19, $20 \mathrm{Myr}$ ). But at $40 \mathrm{Myr}$, the presence of the thermal anomaly under the margin results in regional uplift due to thermal heating of the lithosphere. This uplift induces partial erosion of the sedimentary layers, producing a pattern of stratigraphic offlap (Figure 7.19, 40-60 Myr). After the passage of the thermal anomaly, the margin undergoes subsidence due to the sedimentary loading and the thermal cooling of the lithosphere. This additional subsidence results in a progressive overstepping of younger strata, producing a clear stratigraphic onlap (Figure 7.19, 80-100 Myr).

The stratigraphic features discussed in the previous lines is better visualized in Figure 7.20, where both sections are presented at 100 Myr. Another aspect about the evolution of the margin is that, at the end of the simulation, the portion of the margin close to the thermal anomaly (Section B) presents a thinner and slightly wider sedimentary package than the portions far from the thermal anomaly (Section A).

Figure 7.21 shows the chronostratigraphy of the marginal basin through Sections A and B. We observe the formation of a hiatus (indicated as TUH - Thermal uplift hiatus in Figure 7.21) related to the uplift of the margin due to the passage of the thermal anomaly. This hiatus does not appear in Section A. The continuous line in Figure 7.21 represents the position of the thermal anomaly through time. Observe that the passage of the thermal uplift results initially in an erosional hiatus on the previously deposited strata, followed by a nondepositional hiatus. The combination of erosional and nondepositional hiatus produces the TUH.

If the relative velocity $v_{\text {rel }}$ increases from $1 \mathrm{~cm} / \mathrm{yr}$ to $2 \mathrm{~cm} / \mathrm{yr}$, the resulting chronostratigraphy of Section B (Figure 7.22) presents a TUH with nearly the same spatial extent of the previous case, but the hiatus crosses a shorter time interval. This occurs because the amplitude of the thermal uplift for $v_{r e l}=2 \mathrm{~cm} / \mathrm{yr}$ is lower than for the case with $v_{r e l}=1$ $\mathrm{cm} / \mathrm{yr}$ (see Figure 7.13) and the erosional hiatus is less expressive than in the previous model. Furthermore, the thermal subsidence after the passage of the thermal anomaly for the model with $v_{r e l}=2 \mathrm{~cm} / \mathrm{yr}$ is faster than in the previous model (Figure 7.14), and the nondepositional hiatus in the TUH is shorter in time.

The spatial and temporal extension of the TUH depends not only on the thermal model, but also on the flexural rigidity of the lithosphere and the dynamics of the surface processes. As an example, if the model with $v_{r e l}=1 \mathrm{~cm} / \mathrm{yr}$ is rerun with a higher effective 


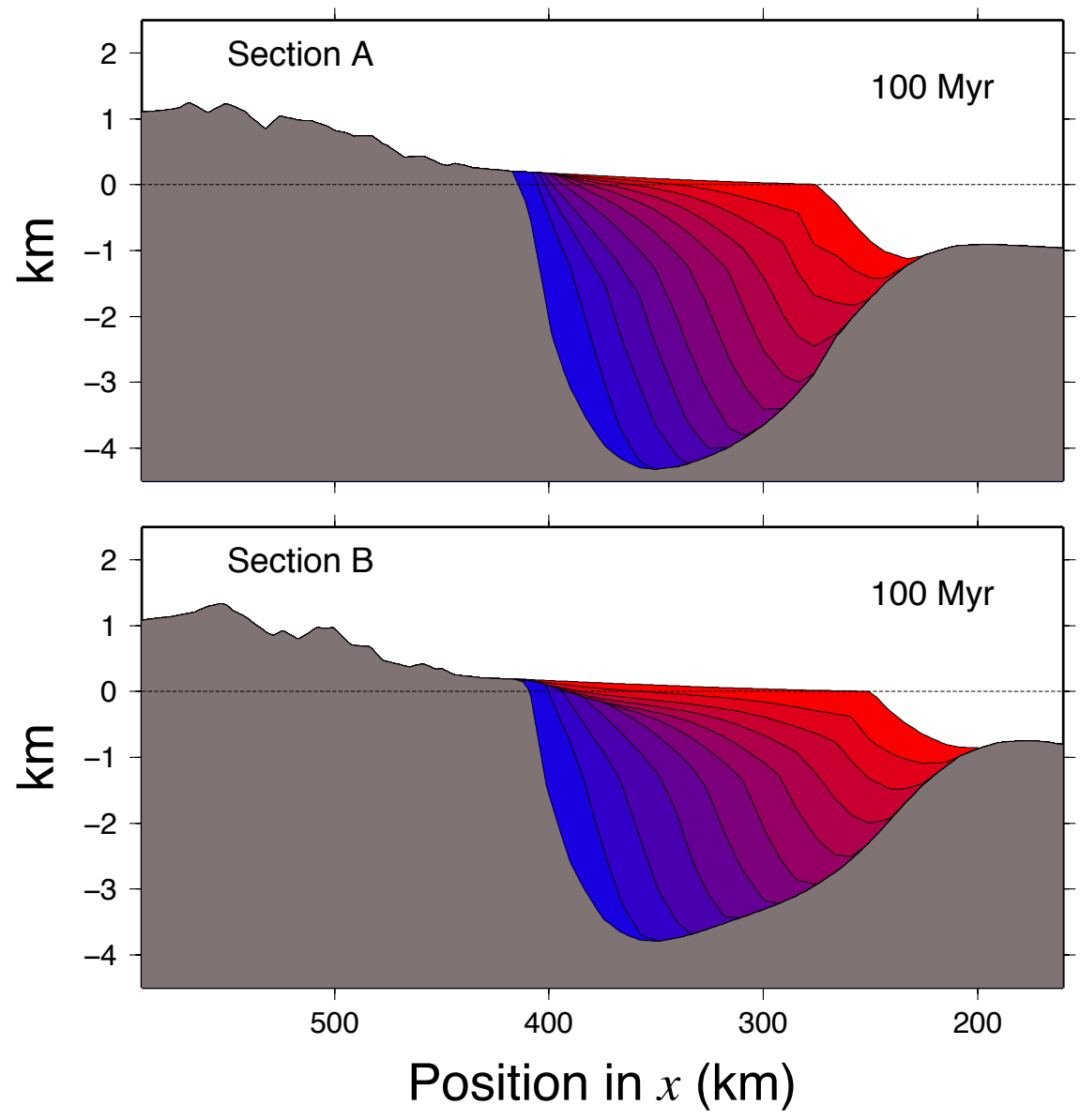

Figure 7.20: Comparison of the stratigraphy between Sections A and B, at $100 \mathrm{Myr}$. The stratigraphic interval is $10 \mathrm{Myr}$.

elastic thickness (from $T_{e}=5$ to $20 \mathrm{~km}$ ) the resulting margin presents thinner sedimentary layers and wider shelf than in the model with $T_{e}=5 \mathrm{~km}$. In this case, the passage of the thermal anomaly under the lithosphere results in a broader uplift of the sedimentary strata due to the higher rigidity, resulting in a more expressive influence of the TUH in the chronostratigraphy of the basin, both in space and time (Figure 7.23).

As a second example, we considered the model $v_{r e l}=1 \mathrm{~cm} / \mathrm{yr}$ with a higher flexural rigidity in the continent $\left(T_{e}=20 \mathrm{~km}\right)$ than in the ocean $\left(T_{e}=5 \mathrm{~km}\right)$. In this situation the spatial and temporal extent of the TUH is significantly affected (Figure 7.24). While in the original model the TUH comprises approximately $30 \mathrm{~km}$ along the section and $\sim 50$ Myr (Figure 7.21), in the model with higher rigidity in the continent the TUH reaches up to $60 \mathrm{~km}$ along the section and $\sim 70 \mathrm{Myr}$ through time (Figure 7.24). One interesting 

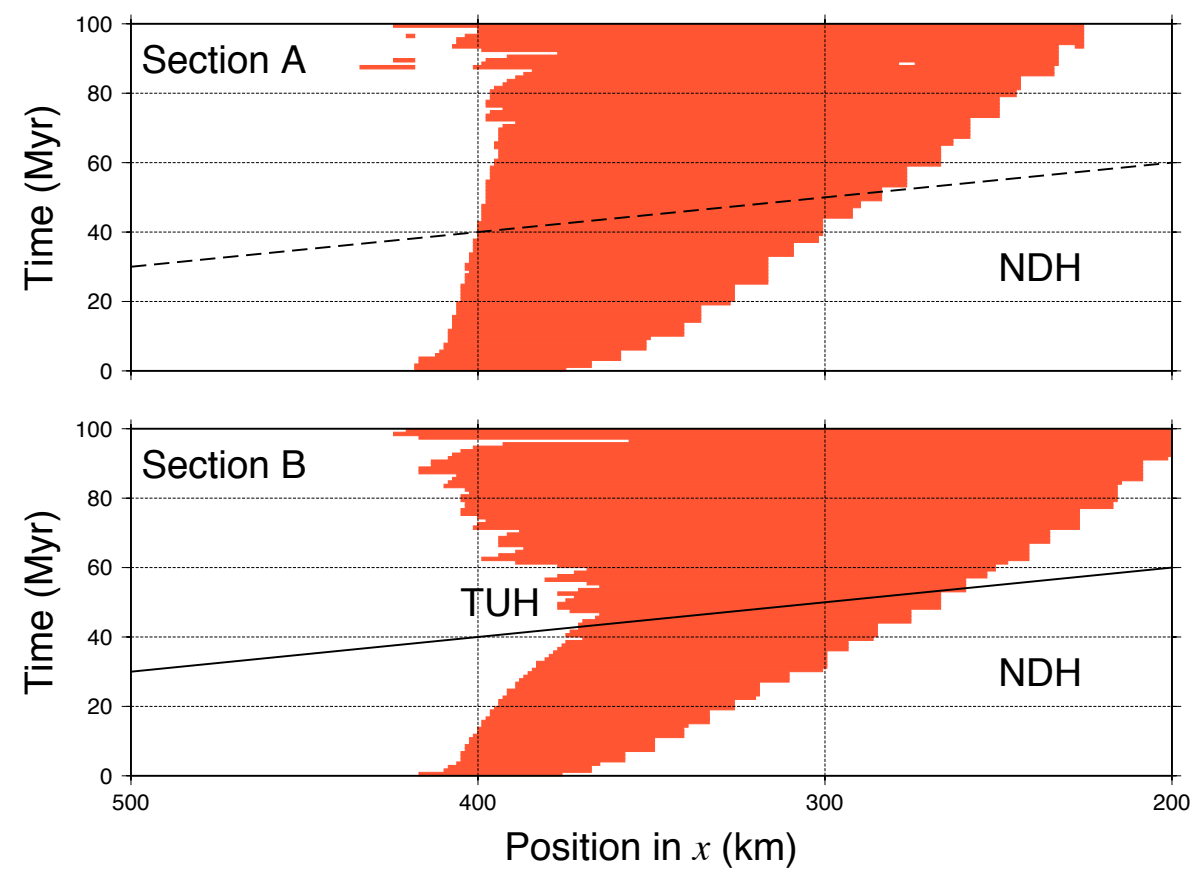

Figure 7.21: Chronostratigraphy of the marginal basin through Sections A and B. NDH Nondepositional hiatus. TUH - Hiatus related to the thermal uplift. The continuous line indicates the position of the thermal anomaly through time and the dashed line indicates the projection of the thermal anomaly on Section A. $T_{e}=5 \mathrm{~km}$ and $v_{r e l}=1 \mathrm{~cm} / \mathrm{yr}$.

aspect about this last model is that the increase of the rigidity in the continent drastically influenced the depositional evolution of the margin.

\subsubsection{Application: The influence of the Trindade Plume on the evolution of the Campos and Espírito Santo Basins}

The Trindade Island and the Martin Vaz archipelago are located more than $1000 \mathrm{~km}$ east of the Southeastern Brazilian coast and represent the eastern portion of the VitóriaTrindade Chain (Figure 7.25). The evolution of this ridge has been associated with the relative movement of the South American Plate and the Trindade Plume, resulting in the formation of a E-W volcanic track (e.g. O'Connor and Duncan, 1990).

Close to the margin, the Vitória-Trindade Chain is between the Campos and Espírito Santo Basins, and coincides with the north limit of the Vitória High and the south limit of the Espírito Santo Basin (Ferrari and Riccomini, 1999). 

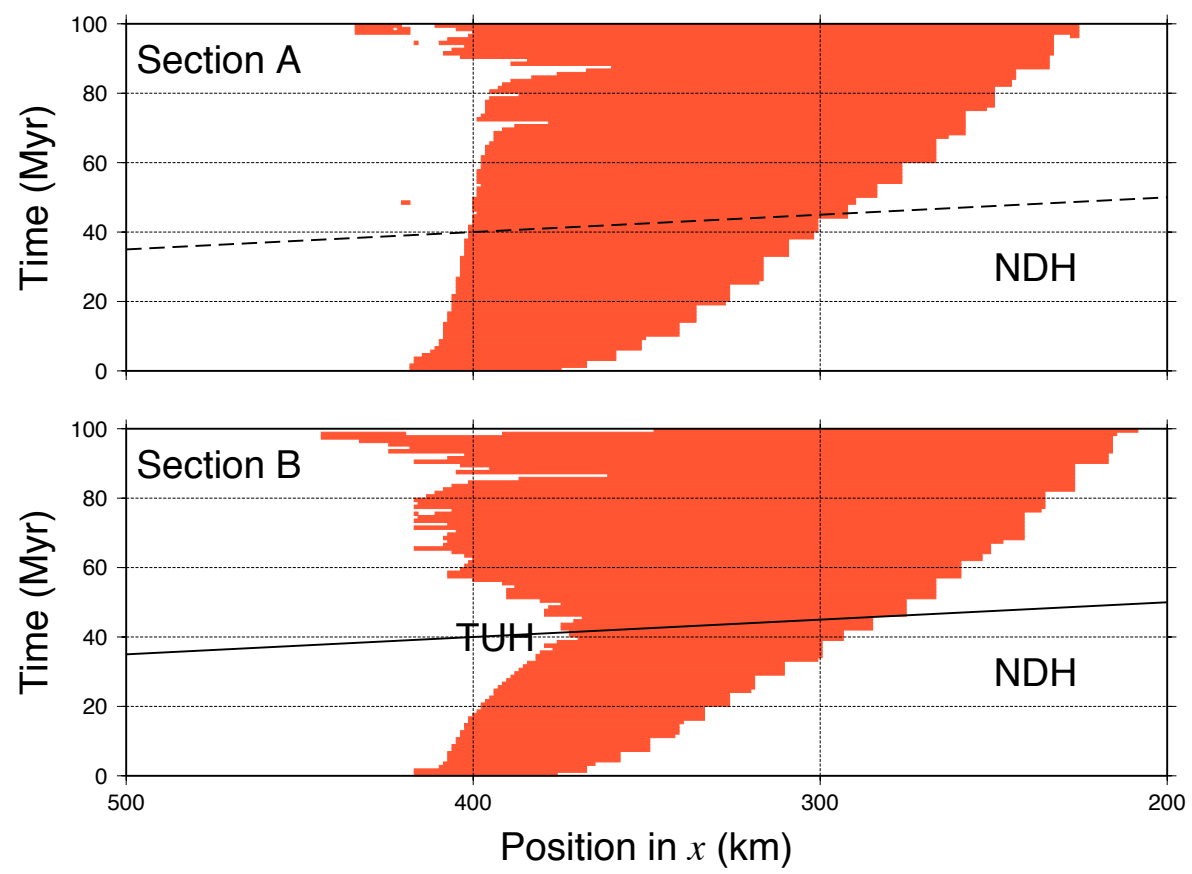

Figure 7.22: Chronostratigraphy of the marginal basin through Sections A and B as in Figure 7.21 , but with $v_{r e l}=2 \mathrm{~cm} / \mathrm{yr}$.

Assuming that the Vitória-Trindade Chain (Figure 7.25) was formed as a result of the migration of the South American plate over the Trindade Plume and taking into account the Abrolhos volcanism (47.5 Ma) as the moment of the impingement of the plume under the continental margin, Ferrari and Riccomini (1999) estimated the relative velocity between the lithosphere and the plume as $v_{r e l}=2.31 \mathrm{~cm} / \mathrm{yr}$. As predicted by the present numerical model, this relative velocity must reflect a perceptive transient uplift of the lithosphere due to its thermal expansion.

Analyzing the residual topography, Ito and van Keken (2007) observed that the swell associated with the Trindade Plume has a width of $\sim 1330 \mathrm{~km}$. Therefore, the passage of the Trindade plume probably uplifted both Campos and Espírito Santo Basins.

The chronostratigraphy of the Campos basin is marked by an expressive hiatus crossing the Paleocene and Eocene (Figure 7.26). The preserved Paleocene sedimentation occurs only in deep water, characterized mainly by mudstones. During the Eocene, an extensive erosion eliminated almost all the Paleocene sedimentation, mainly in the proximal and central regions of the basin (Dias et al., 1990). The proximal siliciclastic sedimentation 

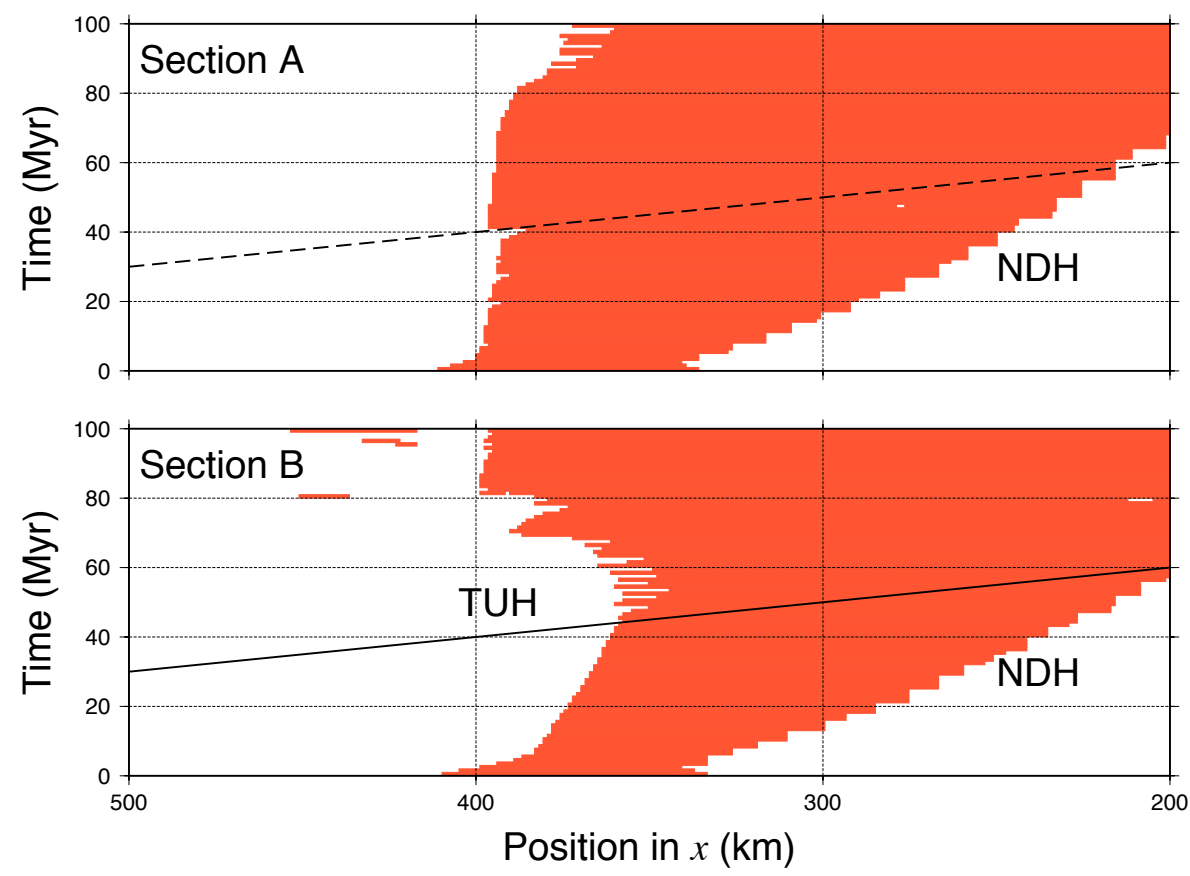

Figure 7.23: Chronostratigraphy of the marginal basin through Sections A and B as in Figure 7.21 , but with $T_{e}=20 \mathrm{~km}$.

in the Early Eocene occurred along depressions produced by halokinesis and tectonism related to reactivation of faults (Winter et al., 2007).

During the same period, the Santos Basin, located southwestward of the Campos basin and far from the influence of the Trindade Plume, presents restricted unconformities of few million years, some of them probably related to sea level variations (Moreira et al., 2007), and the siliciclastic sedimentation is observed throughout the Cenozoic (Figure 7.26).

Therefore, the protracted hiatus observed in the Campos Basin cannot be explained through an ubiquitous event along the Brazilian margin, but a local (or regional) process must be associated with the Paleocene-Eocene hiatus.

Thomaz Filho et al. (2005) associated the Eocene and Paleocene unconformities in the Campos Basin with the thermal uplift related to the Cabo Frio Magmatic Lineament. Through backstripping studies, they also observed an uplift event in the Campos Basin during the Paleocene/Eocene of $\sim 700 \mathrm{~m}$ (Figure 7.27).

On the other hand, Riccomini et al. (2005) concluded that the Cabo Frio Magmatic Lineament cannot be explained through the passage of a mantle plume beneath the 

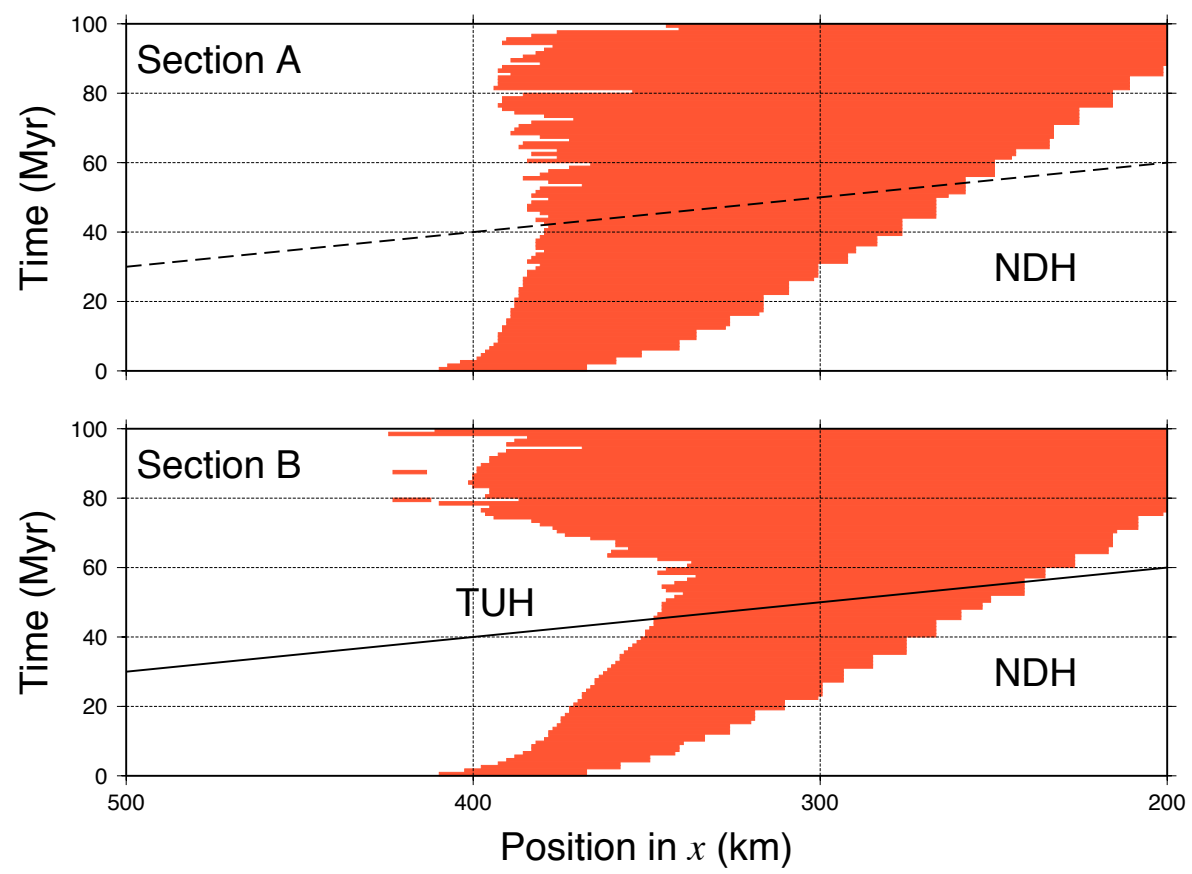

Figure 7.24: Chronostratigraphy of the marginal basin through Sections A and B as in Figure 7.21 , but with $T_{e}=20 \mathrm{~km}$ for the continent $(x>400 \mathrm{~km})$.

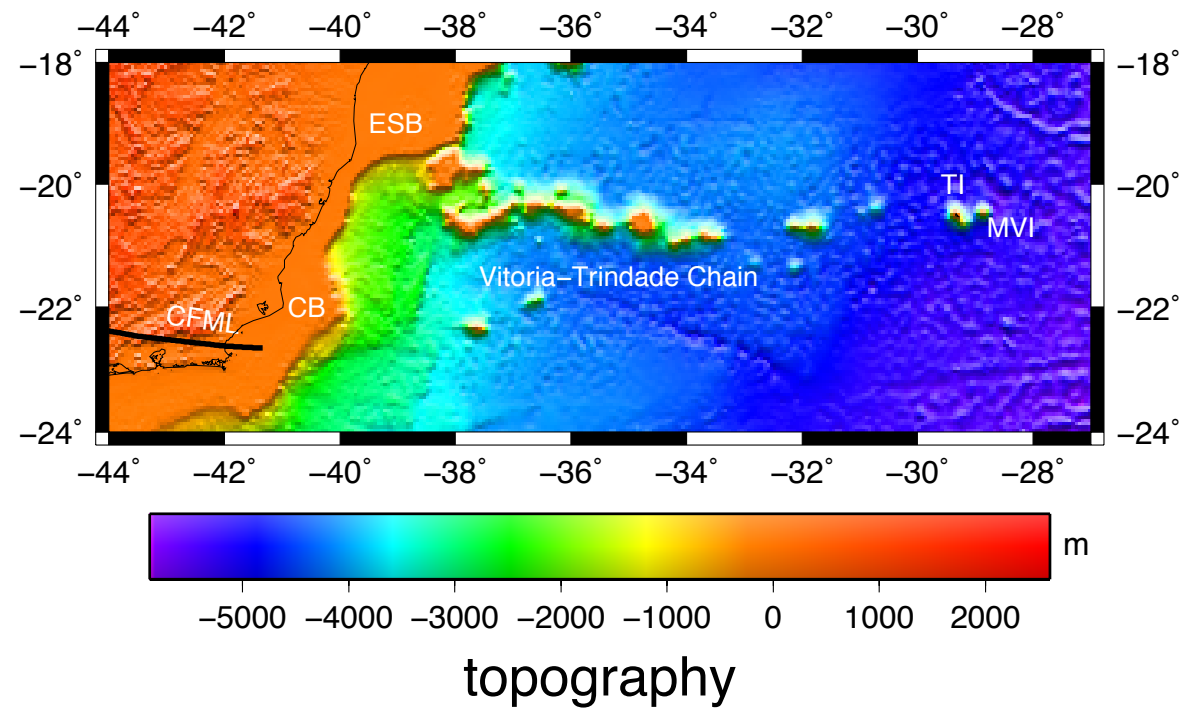

Figure 7.25: The Vitória -Trindade Chain. TI - Trindade Island; MVI - Martin Vaz Islands; ESB: Espírito Santo Basin; CB - Campos Basin; CFML - Cabo Frio Magmatic Lineament. 


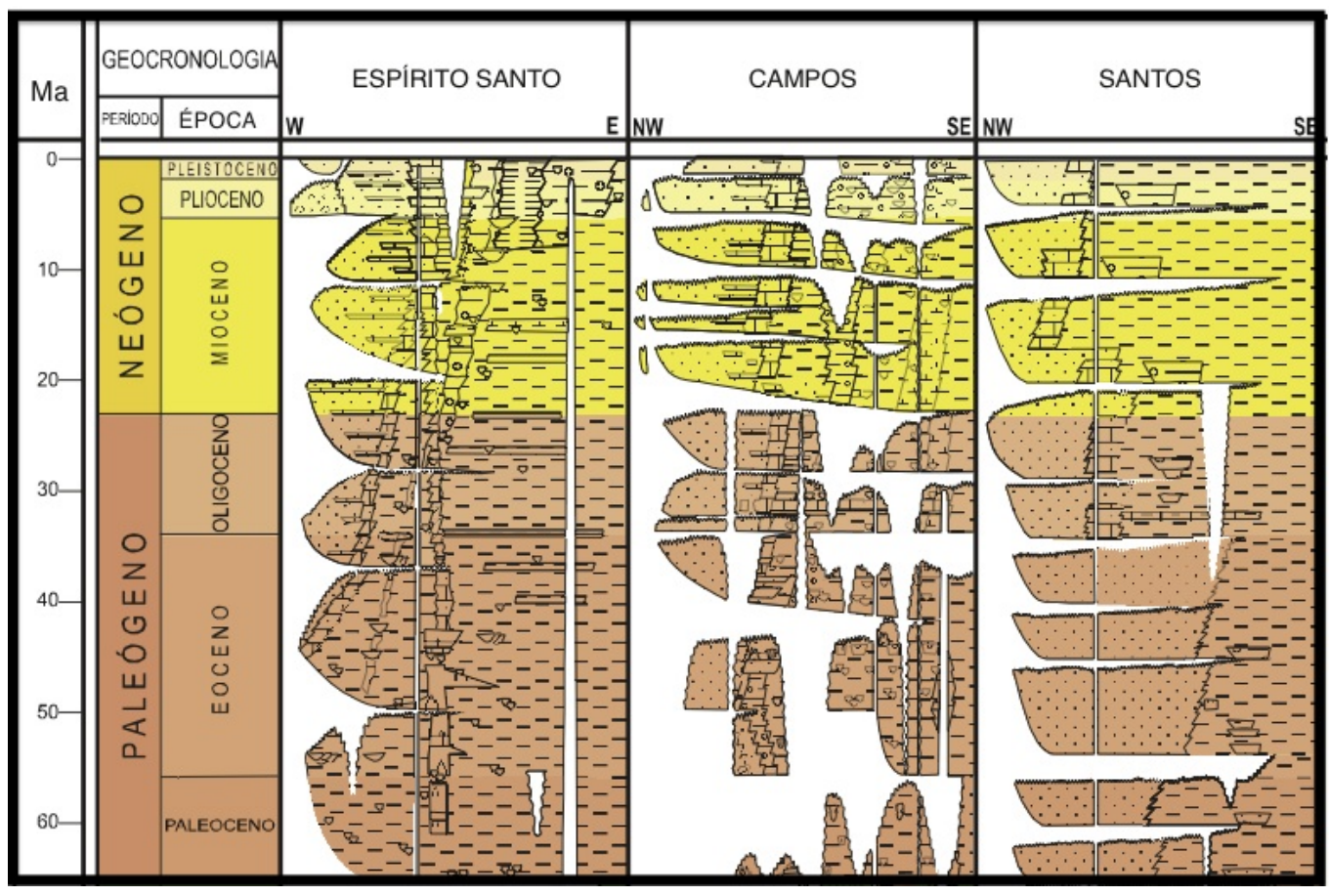

Figure 7.26: Stratigraphic charts for Santos, Campos and Espírito Santo Basins during the Cenozoic. Modified from Milani et al. (2007).

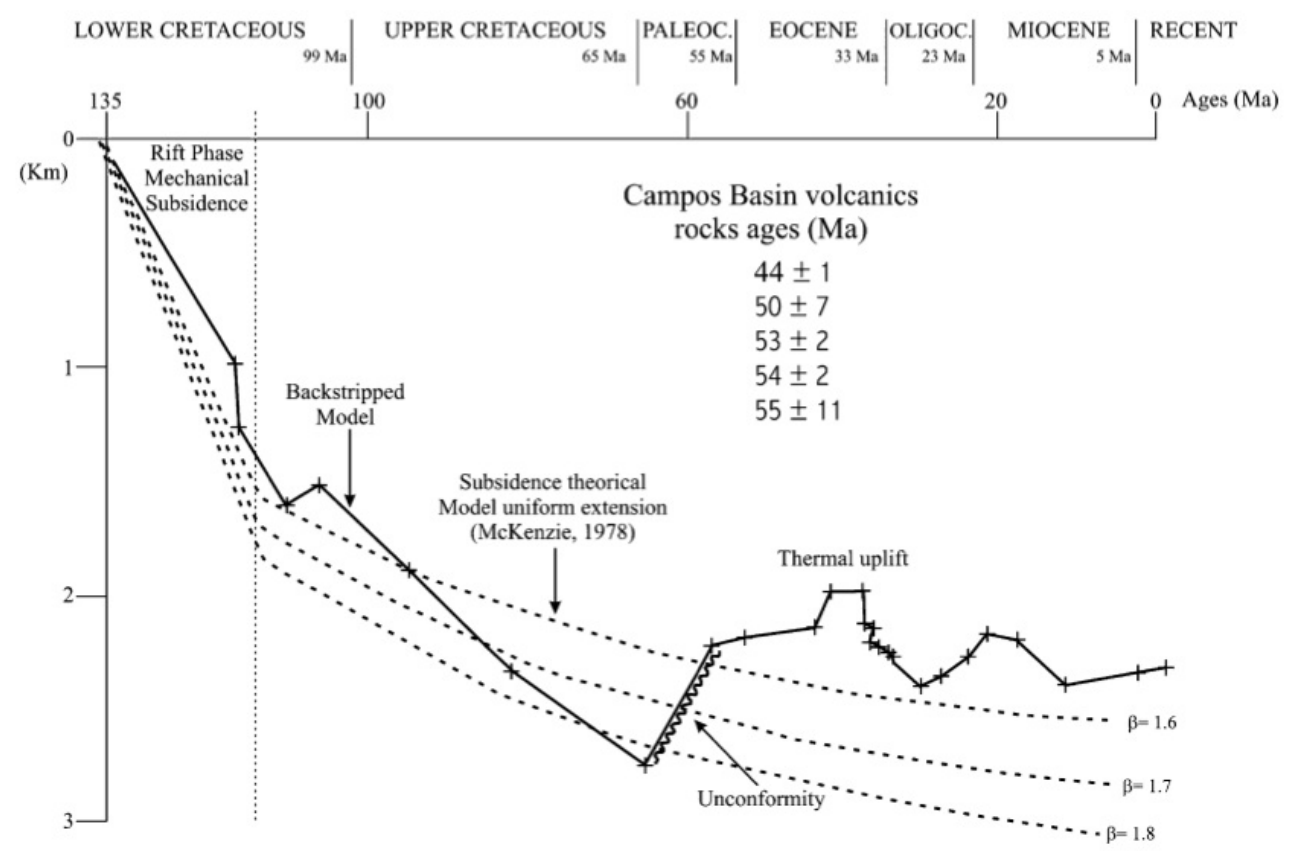

Figure 7.27: Backstripped model for the Campos Basin compared with curves of subsidence predicted by the model of McKenzie (1978). Modified from Thomaz Filho et al. (2005). 
lithosphere because the age of magmatism along the lineament does not decrease eastward, as would be expected in the plume model. They propose that the lineament correspond to a fracture zone, and the magmatic activity were emplaced along the lineament through structural discontinuities and the source of heating for the magmatism was a long-lived process of mantle upwelling lasting for $c a$. 210 Myr. In this case, the long-lived source of heat cannot be associated with the transient uplift of Campos Basin, unless the influence of this heat source significantly oscillated through time.

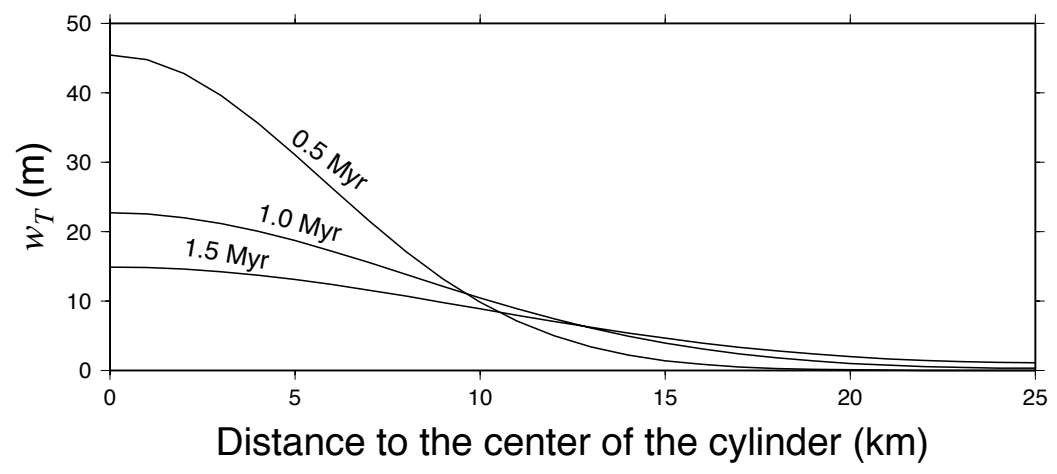

Figure 7.28: Uplift through time related to the emplacement of a vertical cylinder of $\sim 2 \mathrm{~km}$ wide with $T=1300^{\circ} \mathrm{C}$ crossing the entire lithosphere. Local isostasy is assumed.

Oreiro et al. (2008) related the Cabo Frio Magmatic Lineament to partial melting of the lithosphere by pressure release during reactivation of the fracture zone. To assess if pressure release and the rapid injection of hot material through the lithosphere is capable to induce a transient uplift as observed in the margin, we simulated the thermal diffusion and the associated thermal uplift due to the instantaneous emplacement of a vertical cylinder of $\sim 2 \mathrm{~km}$ wide with $T=1300^{\circ} \mathrm{C}$ crossing the entire lithosphere. The results show that the thermal uplift rapidly vanishes after the emplacement of the hot material (Figure 7.28). Furthermore, the extent of the thermal anomaly through time is restricted to a few kilometers around the cylinder and the flexural compensation of this narrow feature strongly smooth out the topographic expression of the thermal anomaly, even for low flexural rigidity. Therefore, regional thermal uplift due to the injection of hot mantle through fractures in the lithosphere is unlikely.

These aspects favor the Trindade Plume as the source for the transient uplift observed 
in the Campos Basin. It is possible that the impingement of the Trindade Plume uplifted the margin during the Eocene, contributing to part of the erosion of the Eocene and Paleocene sediments in the Campos Basin. Certainly other processes, like halokinesis and reactivation of faults (Winter et al., 2007), affected the evolution of the basin and hinder the correct identification of the TUH. Probably, the thermal uplift due to the passage of the Trindade Plume only contributed with part of the Eocene and Paleocene hiatus in the Campos Basin.

Unlike the Campos Basin, the Espírito Santo Basin does not present expressive hiatus during the Paleocene and Eocene, and the unconformities are restricted to the proximal region (Figure 7.26). A possible explanation for this is that during this period, the predominant sedimentation in the Espírito Santo Basin is characterized by shale, indicating a deep depositional environment. In spite of this, França et al. (2007) observed that the stratigraphic sequence encompassing the Paleocene and the Early-Eocene present an offlap pattern in the proximal region, indicating uplift of the margin (Figure 7.26). This sequence was followed by the sedimentation during the Middle Eocene that resulted in stratigraphic onlap on the older strata (França et al., 2007). This proximal hiatus can be related to the passage of the Trindade Plume and the thermal heating of the lithosphere.

Another aspect to be considered is that the center of the plume does not need to coincide with the Vitória-Trindade Chain. Ferrari and Riccomini (1999) proposed that the lineament of the chain is associated with a fracture zone that acted as a conduit for the magmatism associated with the Trindade Plume. If the center of the Trindade Plume is not under the Vitória-Trindade Chain, but is positioned southward of the chain, the Campos Basin was more influenced by the thermal uplift than the Espírito Santo Basin. However, the verification of these conjectures need more information about the mantle structure, e.g. from seismic velocity maps in the mantle with better resolution through the improvement of the coverage of the seismic networks including oceanic stations. Furthermore, geochemical data can give important contributions to understand the nature and the origin of the Trindade Plume that formed the Vitória-Trindade Chain (Marques et al., 1999).

It is important to emphasize that, in our model, the thermal anomaly at the base of the lithosphere does not need to be associated with a deep-mantle plume, but could be produced by anomalous warm asthenosphere. 


\subsubsection{Conclusions}

Through numerical models that couple thermal effects in the lithosphere, flexural isostasy and surface processes of erosion and deposition, the present work shows that the evolution of passive margins is significantly affected by the transient effect of a thermal anomaly at the base of the lithosphere.

The heating of the lithosphere and the associated thermal expansion may result in a lithospheric uplift of hundreds of meters that produces expressive unconformities in the marginal basin.

It is shown that the higher the relative velocity between the lithosphere and the thermal anomaly, the lower the amplitude of the thermal uplift. On the other hand, an increase of the relative velocity amplifies the rate of uplift or subsidence.

Besides the dynamics of the surface processes and relative velocity of the lithosphere, the effective elastic thickness of the lithosphere is an important parameter controlling the shape of the hiatus related to the thermal uplift.

This study proposes that the passage of the Trindade Plume beneath the Southeastern Brazilian margin resulted in thermal heating of the lithosphere and consequent uplift of the margin, creating unconformities in the Campos and Espírito Santo Basins during the Paleocene and Eocene. 


\section{Chapter 8}

\section{Final remarks}

No substantial part of the universe is so simple that it can be grasped and controlled without abstraction. Abstraction consists in replacing the part of the universe under consideration by a model of similar but simpler structure. (Rosenblueth and Wiener, 1945)

The numerical model presented here proved to be an useful tool to study the evolution of divergent margins since the beginning of rifting. Through this model it was possible to evaluate the relative importance of the different surface and tectonic processes on the evolution of rifted margins.

The incorporation of lithospheric stretching and rifting in the numerical model was an important aspect to obtain new insights into the evolution of escarpments in divergent margins. It was shown in Section 7.1 that the amount of extension during rifting can displace the position of the escarpment from the rift flank toward an inland position, many kilometers landward, depending on the flexural rigidity of the upper crust. This model can be further tested by studying in greater details the distribution of extension in passive margins and confronting the model with thermochronological data.

The results from the numerical models presented in Section 7.2 showed how the passage of a thermal anomaly under the lithosphere generates a transient lithospheric uplift of hundreds of meters related to thermal expansion. It is also shown how this transient uplift can affect the evolution of sedimentary basins in passive margins, resulting in offlapping followed by onlapping strata. The hiatus in the sedimentary basin related to the thermal uplift depends not only on the dynamics of the surface processes and the thermal anomaly, 
but also on the effective elastic thickness of the lithosphere, both in the ocean and in the adjacent continent.

It is important to highlight that the kinematic model for lithospheric stretching used in the present work is a simple description for the rifting process and does not take into account the dynamic effects related to strain-dependent rheologies. This simple model can be modified in the future, considering dynamical models for stretching (e.g. Buck et al., 2003; Huismans and Beaumont, 2003).

Additionally, the coupling of the processes in this work can be improved. In the present numerical model, the kinematic model for faulting and stretching of the lithosphere affects the other processes but is not affected by them (Figure 6.1). Indeed, the modification of the thermal state of the lithosphere influences its rheological behavior and consequently the rifting style (Buck, 1993). Likewise, erosion and deposition also affect the thermal state of the lithosphere and consequently its rigidity (Lavier and Steckler, 1997). Moreover, flexural isostasy modifies the stress state of the lithosphere and can influence the formation of faults in the crust.

Certainly, there are uncountable conditions to be tested in new models, coupling all the processes cited above, aiming to better describe and understand the interactions of the surface and tectonic processes. On the other hand, the development of new numerical models must be guided by the idea that models are "representations of reality", useful for leading to further research. Therefore, the sensitivity analysis for the different parameters that compose the numerical model is an important step to identify the processes that are really important for the problem and clarify "which aspects of the system are most in need of further study, and where more empirical data are most needed" (Oreskes et al., 1994). 


\section{References}

Ahnert, F. (1976). Brief description of a comprehensive three-dimensional process-response model of landform development. Zeitschrift für Geomorphologie Supplementband 25, 2949.

Allen, P. and J. Allen (2005). Basin analysis: principles and applications (2nd ed.). Blackwell Scientific Publications, Oxford.

Assine, M., F. Corrêa, and H.K.Chang (2008). Migração de depocentros na Bacia de Santos: importância na exploração de hidrocarbonetos. Revista Brasileira de Geociências 38, $111-127$.

Assumpção, M., D. James, and A. Snoke (2002). Crustal thicknesses in SE Brazilian Shield by receiver function analysis: Implications for isostatic compensation. Journal of Geophysical Research 10\%, 10.1029/2001JB000422.

Bar-Yam, Y. (1997). Dynamics of complex systems. Reading, MA: Addison-Wesley.

Barrell, J. (1914). The strength of the Earth's crust. Part I: Geologic tests of the limits of strength. Journal of Geology 22, 28-48.

Beaumont, C. (1978). The evolution of sedimentary basins on a viscoelastic lithosphere: theory and examples. Geophysical Journal of the Royal Astronomical Society 55, 471497.

Beaumont, C., P. Fullsack, and J. Hamilton (1992). Erosional control of active compressional orogens. In K. R. McClay (Ed.), Thrust Tectonics, pp. 1-18. Chapman and Hall. 
Beaumont, C., H. Kooi, and S. Willett (2000). Coupled tectonic-surface process models with applications to rifted margins and collisional orogens. In M. Summerfield (Ed.), Geomorphology and Global Tectonics, pp. 29-55. Wiley, Chichester.

Bishop, P. (2007). Long-term landscape evolution: linking tectonics and surface processes. Earth Surface Processes and Landforms 32, 329-365.

Bishop, P. and G. Goldrick (2000). Geomorphological evolution of the East Australian continental margin. In M. A. Summerfield (Ed.), Geomorphology and Global Tectonics, pp. 225-254. Wiley, Chichester.

Braun, J. (2003). Pecube: A new finite-element code to solve the 3D heat transport equation including the effects of a time-varying, finite amplitude surface topography. Computers and Geosciences 29(6), 787-794.

Braun, J. (2006). Recent advances and current problems in modelling surface processes and their interaction with crustal deformation. Geological Society Special Publication 253, $307-325$.

Braun, J. and C. Beaumont (1989). A physical explanation of the relationship between flank uplifts and the breakup unconformity at rifted continental margins. Geology 17, $760-764$.

Braun, J. and M. Sambridge (1997). Modelling landscape evolution on geological time scales: a new method based on irregular spatial discretization. Basin Research 9, 27-52.

Braun, J. and P. A. van der Beek (2004). Evolution of passive margin escarpments: what can we learn from low-temperature thermochronology? Journal of Geophysical Research 109, F04009.1-F04009.14.

Braun, J., D. Zwartz, and J. Tomkin (1999). A new surface-processes model combining glacial and fluvial erosion. Annals of Glaciology 28, 282-290.

Brown, C. and R. Phillips (2000). Crust-mantle decoupling by flexure of continental lithosphere. Journal of Geophysical Research B: Solid Earth 105, 13221-13237. 
Buck, W. (1993). Effect of lithospheric thickness on the formation of high- and low- angle normal faults. Geology 21, 933-936.

Buck, W. (2004). Consequences of asthenospheric variability on continental rifting. In G. Karner, B. Taylor, N. Driscoll, and D. Kohlstedt (Eds.), Rheology and Deformation of the Lithosphere at Continental Margins. Columbia University Press, New York, USA.

Buck, W., L. Lavier, and A. Babeyko (2003). A numerical model of lithoepheric extension producing fault-bounded basins and ranges. International Geology Review 45, 712-723.

Buck, W., L. Lavier, and A. Poliakov (1999). How to make a rift wide. Philosophical Transactions of the Royal Society 357, 671-693.

Burke, K. and Y. Gunnell (2008). The African Erosion Surface: A Continental-Scale Synthesis of Geomorphology, Tectonics, and Environmental Change over the Past 180 Million Years. Memoir of the Geological Society of America 201, 1-66.

Burov, E. and M. Diament (1995). The effective elastic thickness $\left(T_{e}\right)$ of continental lithosphere: what does it really mean? Journal of Geophysical Research 100, 39053927.

Carslaw, H. and J. Jaeger (1959). Conduction of Heat in Solids (2nd ed.). Oxford: Oxford University Press.

Clitheroe, G., O. Gudmundsson, and B. Kennett (2000). The crustal thickness of Australia. Journal of Geophysical Research 105, 13697-13713.

Coulthard, T. (2001). Landscape evolution models: a software review. Hydrological Processes $15,165-173$.

Delaunay, B. (1934). Sur la sphère vide. Izvestia Akademii Nauk SSSR, Otdelenie Matematicheskikh i Estestvennykh Nauk 7, 793-800.

Densmore, A., M. Ellis, and R. Anderson (1998). Landsliding and the evolution of normalfault-bounded mountains. Journal of Geophysical Research 103, 15203-15219.

Dias, J., J. Scarton, F. Esteves, M. Carminatti, and L. Guardado (1990). Aspectos da evolução tectono-sedimentar e a ocorrência de hidrocarbonetos na Bacia de Campos. In 
G. de Raja Gabaglia and E. Milani (Eds.), Origem e Evolução de Bacias Sedimentares, pp. 333-360. Petrobrás.

Dietrich, W., D. Bellugi, L. Sklar, J. Heimsath, and J. Roering (2003). Geomorphic transport laws for predicting landscape form and dynamics. In P. Wilcock and R. Iverson (Eds.), Prediction in Geomorphology. Geophysical Monograph, Volume 135, pp. doi 10.1029/135GM09. American Geophysical Union, Washington, DC.

Driscoll, N. and G. Karner (1998). Lower crustal extension across the Northern Carnarvon basin, Australia: Evidence for an eastward dipping detachment. Journal of Geophysical Research 103, 4975-4991.

Driscoll, N. and G. Karner (1999). Three-dimensional quantitative modeling of clinoform development. Marine Geology 154, 383-398.

Dumitru, T., K. Hill, D. Duddy, I. Foster, A. Gleadow, P. Green, B. Kohn, G. Laslett, and A. O'Sullivan (1991). Fission track thermochronology: Application to continental rifting of south-eastern Australia. Australian Petroleum Exploration Association Journal 31, $131-142$.

Ebinger, C., G. Karner, and J. Weissel (1991). Mechanical strength of extended continental lithosphere: constraints from the Western rift system, Africa. Tectonics 10, 1239-1256.

England, P. (1983). Constraints on extension of continental lithosphere. Journal of Geophysical Research 88, 1145-1152.

Ferrari, A. and C. Riccomini (1999). Campo de esforços Plio-Pleistocênico na ilha da Trindade (oceano Atlântico Sul, Brasil) e sua relação com a tectônica regional. Revista Brasileira de Geociências 29, 195-202.

Fletcher, R., N. Kusznir, and M. Cheadle (2009). Melt initiation and mantle exhumation at the Iberian rifted margin: Comparison of pure-shear and upwelling-divergent flow models of continental breakup . Comptes Rendus - Geoscience 341(5), 394-405.

Fortune, S. (1992). Voronoi diagrams and Delaunay triangulations. In D. Du and F. Hwang (Eds.), Computing in Euclidean Geometry, pp. 193-233. World Scientific Publishing Co. 
França, R., A. del Rey, C. Tagliari, J. Brandão, and P. Fontanelli (2007). Bacia de Espírito Santo. Boletim de Geociências da Petrobras 15, 501-509.

Gallagher, K. and R. Brown (1999). Denudation and uplift at passive margins: The record on the Atlantic Margin of southern Africa. Philosophical Transactions of the Royal Society A: Mathematical, Physical and Engineering Sciences 357, 835-859.

Garcia-Castellanos, D. (2002). Interplay between lithospheric flexure and river transport in foreland basins. Basin Research 14, 89-104.

Gilchrist, A. R., H. Kooi, and C. Beaumont (1994). Post-Gondwana geomorphic evolution of southwestern Africa: implications for the controls on landscape development from observations and numerical experiments. Journal of Geophysical Research 99, 12,21112,228 .

Gilchrist, A. R. and M. A. Summerfield (1990). Differential denudation and flexural isostasy in formation of rifted-margin upwarps. Nature 346, 739-742.

Goldenfeld, N. and L. Kadanoff (1999). Simple lessons from complexity. Science 284, $87-89$.

Gunnell, Y. and D. Harbor (2010). Butte detachment: How pre-rift geological structure and drainage integration drive escarpment evolution at rifted continental margins. Earth Surface Processes and Landforms 35, 1373-1385.

Herzberg, C. and M. O'Hara (2002). Plume-associated ultramafic magmas of Phanerozoic age. Journal of Petrology 43, 1857-1883.

Hetenyi, M. (1967). Beams on elastic foundation. Ann Arbor, Michigan: The University of Michigan Press.

Hiruma, S., C. Riccomini, M. Modenesi-Gauttieri, P. Hackspacher, J. Neto, and A. FrancoMagalhães (2010). Denudation history of the Bocaina Plateau, Serra do Mar, southeastern Brazil: Relationships to Gondwana breakup and passive margin development. Gondwana Research 18, 674-687. 
Hughes, T. and A. Brooks (1979). A multi-dimensional upwind scheme with no cross wind diffusion. In T. Hughes (Ed.), Finite Elements for Convection Dominated Flows, Volume 34. ASME.

Hughes, T. and A. Brooks (1982). A theoretical framework for Petrov-Galerkin methods with discontinuous weighting function. In R. Gallagher, D. Norrie, J. Oden, and O. Zienkiewicz (Eds.), Finite Elements in Fluids, Volume 4, pp. 47-65. Wiley, Chichester.

Huismans, R. and C. Beaumont (2003). Symmetric and asymmetric lithospheric extension: Relative effects of frictional-plastic and viscous strain softening. Journal of Geophysical Research 108, ETG 13-1 - ETG 13-22.

Ito, G. and P. Clift (1998). Subsidence and growth of Pacific Cretaceous plateaus. Earth and Planetary Science Letters 161, 85-100.

Ito, G. and P. van Keken (2007). Hot Spots and Melting Anomalies. In G. Schubert (Ed.), Treatise on Geophysics, Volume 7. Mantle Dynamics, pp. 371-435. Elsevier B.V.

Japsen, P., J. Bonow, P. Green, J. Chalmers, and K. Lidmar-Begström (2006). Elevated, passive continental margins: Long-term highs or Neogene uplifts? New evidence from West Greenland. Earth and Planetary Science Letters 248, 330-339.

Jarvis, G. and D. McKenzie (1980). The development of sedimentary basins with finite extension rates. Earth and Planetary Science Letters 48, 42-52.

Jaupart, C., S. Labrosse, and J.-C. Mareschal (2007). Temperatures, Heat and Energy in the Mantle of the Earth. In G. Schubert (Ed.), Treatise on Geophysics, Volume 7. Mantle Dynamics. Elsevier B.V.

Johnson, D. and C. Beaumont (1995). Preliminary results from a planform kinematic model of orogen evolution, surface processes and the development of clastic foreland basin stratigraphy. In S. Dorobek and G. Ross (Eds.), Stratigraphic Evolution of Foreland Basins, Volume 52, pp. 3-24. Spec. Publ. Soc. Econ. Paleont. Miner.

Jordan, T. and P. Flemings (1991). Large-scale stratigraphic architecture, eustatic variation, and unsteady tectonism: a theoretical evaluation. Journal of Geophysical Research 96, 6681-6699. 
Karner, G. (2000). Rifts of the Campos and Santos Basins, southeastern Brazil: distribution and timing. In M. R. Mello and B. J. Katz (Eds.), Petroleum systems of South Atlantic margins, pp. 301-315. AAPG Memoir 73.

Karner, G. and A. Watts (1983). Gravity anomalies and flexure of the lithosphere at mountain ranges. Journal of Geophysical Research 88, 10449-10477.

Kaufman, P., J. Grotzinger, and D. McCormick (1991). Depth-dependent diffusion algorithm for simulation of sedimentation in shallow marine depositional systems. In E. Franseen, W. Watney, C. Kendall, and W. Ross (Eds.), Sedimentary Modeling: Computer Simulations and Methods for Improved Parameter Definition, Volume 233, pp. 489-508. Kansas Geol. Surv. Bull.

Kaufmann, G. and J. Braun (2001). Modelling karst denudation on a synthetic landscape. Terra Nova 13, 313-320.

Kirkby, M. (1986). A two-dimensional simulation model for slope and stream evolution. In A. Abrahams (Ed.), Hillslope Processes, pp. 203-222. Boston, MA: Allen and Unwin.

Kocurek, G. and K. Havholm (1993). Eolian sequence stratigraphy - a conceptual framework. Siliciclastic sequence stratigraphy: recent developments and applications 58, 393-409.

Kooi, H. and C. Beaumont (1994). Escarpment evolution on high-elevation rifted margins: insights derived from a surface processes model that combines diffusion, advection, and reaction. Journal of Geophysical Research 99, 12,191-12,209.

Kusznir, N., R. Hunsdale, and A. Roberts (2004). Timing of depth-dependent lithosphere stretching on the S. Lofoten rifted margin offshore mid-Norway: pre-breakup or postbreakup? Basin Research 16, 279-296.

Kusznir, N. and G. Karner (2007). Continental lithospheric thinning and breakup in response to upwelling divergent mantle flow: application to the Woodlark, Newfoundland and Iberia margins. In G. Karner, G. Manatschal, and L. Pinheiro (Eds.), Imaging, Mapping and Modelling Continental Lithosphere Extension and Breakup, pp. 389-419. Geological Society, London. 
Kusznir, N., G. Marsden, and S. Egan (1991). A flexural-cantilever simple-shear/pureshear model of continental lithosphere extension: Application to the Jeanne d'Arc Basin, Grand Banks and Viking Graben, North Sea. In A. Roberts, G. Yielding, and B. Freeman (Eds.), Geological Society, London, Special Publications, 56: The Geometry of Normal Faults, Volume 56, pp. 41-60. Geological Society, London.

Kusznir, N. and P. Ziegler (1992). The mechanics of continental extension and sedimentary basin formation - a simple-shear pure-shear flexural cantilever model. Tectonophysics 215, 117-131.

Lambeck, K. and R. Stephenson (1986). The post-Palaeozoic uplift history of south-eastern Australia. Australian Journal of Earth Sciences 33, 253-270.

Lasserre, J. (1983). An analytical expression and an algorithm for the volume of a convex polyhedron in $R^{n}$. J. Optim. Theory Applications 39, 363-377.

Lavier, L. and M. Steckler (1997). The effect of sedimentary cover on the flexural strength of continental lithosphere. Nature 389, 476-479.

Lister, G. and M. Etheridge (1989). Detachment models for uplift and volcanism in the Eastern Highlands, and their application to the origin of passive margin mountains. In R. Johnson (Ed.), Intraplate Volcanism in Eastern Australia and New Zealand. Cambridge University Press.

Lister, G., M. Etheridge, and P. Symonds (1986). Detachment faulting and the evolution of passive continental margins. Geology 14, 246-250.

Lyon-Caen, H. and P. Molnar (1983). Constraints on the structure of the himalaya from an analysis of gravity anomalies and a flexural model of the lithosphere. Journal of Geophysical Research 88, 8171-8191.

Marques, L., M. Ulbrich, E. Ruberti, and C. Tassinari (1999). Petrology, geochemistry and Sr-Nd isotopes of the Trindade and Martin Vaz volcanic rocks (Southern Atlantic Ocean). Journal of Volcanology and Geothermal Research 93, 191-216.

Martin, Y. (2000). Modelling hillslope evolution: Linear and nonlinear transport relations. Geomorphology 34, 1-21. 
Matmon, A., P. Bierman, and Y. Enzel (2002). Pattern and tempo of great escarpment erosion. Geology 30, 1135-1138.

McKenzie, D. (1978). Some remarks on the development of sedimentary basins. Earth and Planetary Science Letters 40(1), 25-32.

Merrits, D. and M. Ellis (1994). Introduction to special section on tectonics and topography. Journal of Geophysical Research 99, 12135-12141.

Milani, E., H. Rangel, G. Bueno, J. Stica, W. Winter, J. Caixeta, and O. Pessoa Neto (2007). Bacias Sedimentares Brasileiras - Cartas Estratigráficas: Introdução. Boletim de Geociências da Petrobras 15, 183-205.

Mohriak, W., M. Nemčok, and G. Enciso (2008). South Atlantic divergent margin evolution: Rift-border uplift and salt tectonics in the basins of SE Brazil. Geological Society Special Publication 294, 365-398.

Molnar, P. and P. England (1990). Late Cenozoic uplift of mountain ranges and global climate change: chicken or egg? Nature 346, 29-34.

Moore, M., A. Gleadow, and J. Lovering (1986). Thermal evolution of rifted continental margins: new evidence from fission tracks in basement apatites from southeastern Australia. Earth and Planetary Science Letters 78, 255-270.

Moreira, J., C. Madeira, J. Gil, and M. Machado (2007). Bacia de Santos. Boletim de Geociências da Petrobras 15, 531-549.

Morgan, J. (1987). Melt migration beneath mid-ocean spreading centers. Geophysical Research Letters 14, 1238-1241.

Nadin, P. and N. Kusznir (1995). Palaeocene uplift and Eocene subsidence in the northern North Atlantic from 2D forward and reverse stratigraphic modelling. Journal of the Geological Society, London 152, 833-848.

O'Connor, J. and R. Duncan (1990). Evolution of the Walvis Ridge - Rio Grande Rise hot spot system: implications for African and South American plate motions over plumes. Journal of Geophysical Research 95, 17475-17502. 
Ollier, C. and C. Pain (1994). Landscape evolution and tectonics in southeastern Australia. AGSO Journal of Australian Geology $\& 3$ Geophysics 15, 335-345.

Oreiro, S., J. Cupertino, P. Szatmari, and A. Thomaz Filho (2008). Influence of presalt alignments in post-Aptian magmatism in the Cabo Frio High and its surroundings, Santos and Campos basins, SE Brazil: An example of non-plume-related magmatism. Journal of South American Earth Sciences 25, 116-131.

Oreskes, N., K. Shrader-Frechette, and K. Belitz (1994). Verification, Validation, and Confirmation of Numerical Models in the Earth Sciences. Science 263, 641-646.

O'Sullivan, P., D. Foster, B. Kohn, and A. Gleadow (1996). Multiple post-orogenic denudation events: An example from the eastern Lachlan fold belt, Australia. Geology 24, $563-566$.

Paola, C. (2000). Quantitative models of sedimentary basin filling. Sedimentology 47, $121-178$.

Parsons, B. and J. Sclater (1977). An analysis of the variation of ocean floor bathymetry and heat flow with age. Journal of Geophysical Research 82(5), 803-827.

Partridge, T. and R. Maud (1987). Geomorphic evolution of southern Africa since the Mesozoic. South African Journal of Geology 90, 179-208.

Pazzaglia, F. and T. Gardner (1994). Late Cenozoic flexural deformation of the middle US Atlantic passive margin. Journal of Geophysical Research 99, 12143-12157.

Persano, C., F. Stuart, P. Bishop, and D. Barford (2002). Apatite (U-Th)/He age constraints on the development of the Great Escarpment on the southeastern Australian passive margin. Earth and Planetary Science Letters 200, 79-90.

Pirmez, C., L. Pratson, and M. Steckler (1998). Clinoform development by advectiondiffusion of suspended sediment: Modeling and comparison to natural systems. Journal of Geophysical Research 103, 24141-24157.

Pitman, W. (1978). Relationship between eustacy and stratigraphic sequences of passive margins. The Geological Society of America Bulletin 89, 1389-1403. 
Press, W., S. Teukolky, W. Vetterling, and B. Flannery (2002). Numerical Recipes in C: The Art of Scientific Computing (second ed.). Cambridge University Press, Cambridge, England.

Reid, I. and H. Jackson (1981). Oceanic spreading rate and crustal thickness. Marine Geophysical Research 5(2), 165-172.

Reiners, P. and M. Brandon (2006). Using Thermochronology to Understand Orogenic Erosion. Annual Review of Earth and Planetary Sciences 34, 419-466.

Ribe, N. and U. Christensen (1994). Three-dimensional modelling of plume-lithosphere interaction. Journal of Geophysical Research 99, 669-682.

Ricard, Y. (2007). Physics of mantle convection. In G. Schubert (Ed.), Treatise on Geophysics, Volume 7. Mantle Dynamics. Elsevier B.V.

Riccomini, C., L. Sant'Anna, and A. Ferrari (2004). Evolução geológica do Rift Continental do Sudeste do Brasil. In V. Mantesso Neto, A. Bartorelli, C. Carneiro, and B. Neves (Eds.), Geologia do Continente Sul-Americano: Evolução da Obra de Fernando Flávio Marques de Almeida, pp. 383-405. Beca, São Paulo.

Riccomini, C., V. Velázquez, and C. Gomes (2005). Tectonic controls of the Mesozoic and Cenozoic alkaline magmatism in central-southeastern Brazilian Platform. In C. Gomes and P. Comin-Chiaramonti (Eds.), Mesozoic to Cenozoic alkaline magmatism in the Brazilian Platform, pp. 31-55. EDUSP-FAPESP, São Paulo.

Rivenæs, J. (1992). Application of a dual-lithology, depth-dependent diffusion equation in stratigraphic simulation. Basin Research 4, 133-146.

Rivenæs, J. (1997). Impact of sediment transport efficiency on large-scale sequence architecture: results from stratigraphic computer simulation. Basin Research 9, 91-105.

Roberts, A., E. Lundin, and N. Kusznir (1997). Subsidence of the Vøring Basin and the influence of the Atlantic continental margin. Journal of the Geological Society, London 154, 551-557. 
Rosenblueth, A. and N. Wiener (1945). The Role of Models in Science. Philosophy of Science 12, 316-321.

Royden, L. and C. Keen (1980). Rifting processes and thermal evolution of the continental margin of eastern Canada determined from subsidence curves. Earth and Planetary Science Letters 51, 343-361.

Sacek, V., J. Braun, and P. van der Beek (2011). The influence of rifting on escarpment migration. Journal of Geophysical Research. submitted.

Sacek, V. and N. Ussami (2009). Reappraisal of the effective elastic thickness for the subAndes using 3-D finite element flexural modelling, gravity and geological constraints. Geophysical Journal International 179, 778-786.

Salveson, J. O. (1978). Variations in the geology of rift basins: A tectonic model. In N. Los Alamos (Ed.), Conf. Proc. Los Alamos Natl. Lab., pp. p. 82-86.

Shaw, R. (1990). Development of the Tasman Sea and easternmost Australian continental margin - a review. Bulletin - Bureau of Mineral Resources, Geology 85 Geophysics, Australia 232, 53-66.

Sleep, N. (1987). Lithospheric heating by mantle plumes. Geophysical Journal of the Royal Astronomical Society 91, 1-11.

Sloan, S. (1987). A fast algorithm for constructing Delaunay triangulations in the plane. Advances in Engineering Software 9, 34-55.

Specht, B. (1988). Modified shape functions for the three node plate bending element passing the patch test. Int. J. Num. Meth. Eng. 26, 705-715.

Stewart, J. and A. Watts (1997). Gravity anomalies and spatial variations of flexural rigidity at mountain ranges. Journal of Geophysical Research 102(B3), 5327-5352.

Thomaz Filho, A., P. de Cesero, A. Mizusaki, and J. Leão (2005). Hot spot volcanic tracks and their implications for south American plate motion, Campos basin (Rio de Janeiro state), Brazil. Journal of South American Earth Sciences 18, 383-389. 
Timoshenko, S. and S. Woinowsky-Krieger (1959). Theory of Plates and Shells. McGrawHill.

Tucker, G. and R. Bras (2000). A stochastic approach to modeling the role of rainfall variability in drainage basin evolution. Water Resources Research 36, 1953-1964.

Tucker, G. and R. Slingerland (1994). Erosional dynamics, flexural isostasy, and longlived escarpments: a numerical modeling study. Journal of Geophysical Research 99, 12229-12243.

Tucker, G. and K. Whipple (2002). Topographic outcomes predicted by stream erosion models: Sensitivity analysis and intermodel comparison. Journal of Geophysical Research 10\%, 10.1029/2001JB000162.

Turcotte, D. and G. Schubert (1982). Geodynamics: Applications of Continuum Physics to Geological Problems. John Wiley, New York.

van Balen, R., P. van der Beek, and S. Cloetingh (1995). The effect of rift shoulder erosion on stratal patterns at passive margins: Implications for sequence stratigraphy. Earth and Planetary Science Letters 134, 527-544.

van der Beek, P. and J. Braun (1998). Numerical modelling of landscape evolution on geological time-scales: a parameter analysis and comparison with the south-eastern highlands of Australia. Basin Research 10, 49-68.

van der Beek, P. A. (1997). Flank uplift and topography at the central Baikal Rift (SE Siberia): A test of kinematic models for continental extension. Tectonics 16, 122-136.

van der Beek, P. A. and J. Braun (1999). Controls on post-mid-Cretaceous landscape evolution in the southeastern highlands of Australia: Insights from numerical surface process models. Journal of Geophysical Research B: Solid Earth 104, 4945-4966.

van der Beek, P. A., J. Braun, and K. Lambeck (1999). The post-Paleozoic uplift history of south-eastern Australia revisited: results from a process-based model of landscape evolution. Australian Journal of Earth Sciences 46, 157-172. 
van der Beek, P. A., A. Pulford, and J. Braun (2001). Cenozoic landscape development in the blue mountains (SE Australia): Lithological and tectonic controls on rifted margin morphology. Journal of Geology 109, 35-56.

van der Beek, P. A., M. A. Summerfield, J. Braun, R. W. Brown, and A. Fleming (2002). Modeling postbreakup landscape development and denudational history across the southeast African (Drakensberg Escarpment) margin. Journal of Geophysical Research B: Solid Earth 107, 11-18.

van Wees, J. and S. Cloetingh (1994). A Finite-Difference Technique to Incorporate Spatial Variations In Rigidity and Planar Faults Into 3-D Models For Lithospheric Flexure. Geophysical Journal International 117(1), 179-195.

Vening-Meinesz, F. (1950). Les Graben africains, resultat de compression ou de tension dans la croute terrestre? Inst. Roy. Colonial Belge, Bull. 21, 539-552.

Voronoi, M. (1908). Nouvelles applications des paramètres continus à la théorie de formes quadratiques. J. reine Angew. Math. 134, 198-287.

Walcott, R. (1970). Flexure of the lithosphere at Hawaii. Tectonophysics 9, 435-446.

Watts, A. (1982). Seamounts and flexure of the lithosphere. Nature 297, 182-183.

Watts, A. (2001). Isostasy and Flexure of the Lithosphere. Cambridge University Press, Cambridge, England.

Watts, A. (2007). An overview. In G. Schubert (Ed.), Treatise on Geophysics, Volume 6. Crust and Lithosphere Dynamics. Elsevier B.V.

Watts, A., G. Karner, and M. Steckler (1982). Lithospheric flexure and the evolution of sedimentary basins. Philosophical Transactions of the Royal Society 305A, 249-281.

Weissel, J. and G. Karner (1989). Flexural uplift of rifts flanks due to mechanical unloading of the lithosphere during extension. Journal of Geophysical Research 94, 13919-13950.

Wernicke, B. (1985). Uniform-sense normal simple shear of the continental lithosphere. Canadian Journal of Earth Sciences 22, 108-125. 
White, R., J. Bown, and J. Smallwood (1995). The temperature of the Iceland plume and origin of outward propagating V-shaped ridges. Journal of the Geological Society of London 152, 1039-1045.

Willgoose, G., R. Bras, and I. Rodriguez-Iturbe (1991). Results from a new model of river basin evolution. Earth Surface Processes \& Landforms 16, 237-254.

Winter, W., R. Jahnert, and A. França (2007). Bacia de Campos. Boletim de Geociências da Petrobras 15, 511-529.

Young, R. (1989). Crustal constraints on the evolution of the continental divide of eastern Australia. Geology 17, 528-530.

Zienkiewicz, O. and R. Taylor (2000a). The Finite Element Method (5th ed.), Volume 2: Solid Mechanics. Butterworth-Heinemann.

Zienkiewicz, O. and R. Taylor (2000b). The Finite Element Method (5th ed.), Volume 1: The Basis. Butterworth-Heinemann.

Zienkiewicz, O. and R. Taylor (2000c). The Finite Element Method (5th ed.), Volume 3: Fluid Dynamics. Butterworth-Heinemann. 
Appendix 



\section{Appendix A}

\section{Flexure of an elastic plate with an abrupt rigidity variation under a line load}

Consider the case of an infinite elastic plate composed of two portions of different flexural rigidities:

$$
\begin{aligned}
& \text { for } x \geq 0, D=D_{1} \\
& \text { for } x<0, D=D_{2}
\end{aligned}
$$

This plate is floating on an inviscid fluid of density $\rho$. At $x=0$ the plate is under the action of a line load $V_{0}$ (Figure A.1a).

(a)

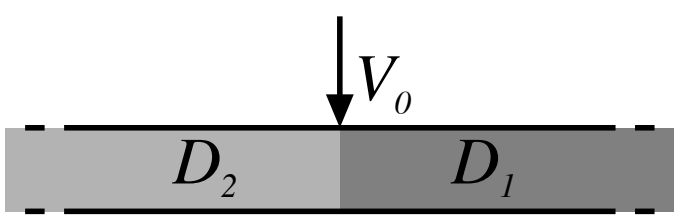

(b)

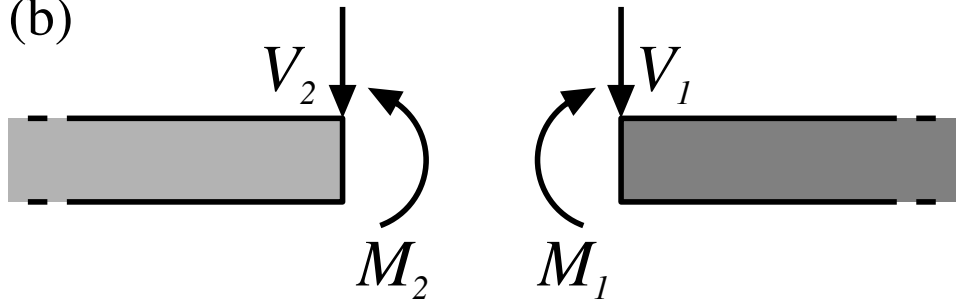

Figure A.1: (a) Scheme of the problem of an infinite elastic plate with two different rigidities $D_{1}$ and $D_{2}$ under a line load $V_{0}$. (b) Representation of the continuous plate by two semiinfinite plates. The moments $M_{1}$ and $M_{2}$ and the line loads $V_{1}$ and $V_{2}$ represent the coupling of the two halves. 
To solve this problem analytically, a good strategy is to divide the plate in two halves and treat each half as a semi-infinite plate (Figure A.1b), broken at $x=0$. To represent the coupling of the halves and the continuity between them as in the original plate, it is imposed bending moments $M_{1}$ and $M_{2}$ and line loads $V_{1}$ and $V_{2}$ on the edges of the plates.

The equation that describes the flexure of this plate can be obtained from Equation 2.1 and eliminating the derivative with respect to $y$ :

$$
\frac{d^{2}}{d x^{2}}\left(D(x) \frac{d^{2} w}{d x^{2}}\right)-q=0
$$

Since the applied load is zero except at $x=0$, the only vertical force comes from the buoyancy force $-\rho g w$ :

$$
\frac{d^{2}}{d x^{2}}\left(D(x) \frac{d^{2} w}{d x^{2}}\right)+\rho g w=0
$$

The general solution for Equation A.1 is

$$
w=e^{x / \alpha}\left(c_{1} \cos \frac{x}{\alpha}+c_{2} \sin \frac{x}{\alpha}\right)+e^{-x / \alpha}\left(c_{3} \cos \frac{x}{\alpha}+c_{4} \sin \frac{x}{\alpha}\right)
$$

where $c_{1}, c_{2}, c_{3}$ and $c_{4}$ are constants obtained from the boundary conditions and $\alpha$ is the flexural parameter $\left(\alpha=\left[\frac{4 D}{\rho g}\right]^{1 / 4}\right)$.

Far from the load vector the deflection $w \rightarrow 0$. Therefore, the equation A.2 becomes for the right plate

$$
w_{1}=e^{-x / \alpha_{1}}\left(c_{3} \cos \frac{x}{\alpha_{1}}+c_{4} \sin \frac{x}{\alpha_{1}}\right)
$$

and for the left plate

$$
w_{2}=e^{x / \alpha_{2}}\left(c_{1} \cos \frac{x}{\alpha_{2}}+c_{2} \sin \frac{x}{\alpha_{2}}\right)
$$

where $\alpha_{1}=\left[\frac{4 D_{1}}{\rho g}\right]^{1 / 4}$ and $\alpha_{2}=\left[\frac{4 D_{2}}{\rho g}\right]^{1 / 4}$.

For the right plate the bending moment at $x=0$ is $M_{1}$. The bending moment is the flexural rigidity of the plate divided by the radius of curvature of the plate $R_{\text {curv }}$ (Turcotte and Schubert, 1982). Approximating $1 / R_{\text {curv }} \approx-\frac{d^{2} w}{d x^{2}}$, we obtain:

$$
M_{1}=-\left.D_{1} \frac{d^{2} w_{1}}{d x^{2}}\right|_{x=0}=\frac{2 D_{1} c_{4}}{\alpha_{1}^{2}} \rightarrow c_{4}=\frac{M_{1} \alpha_{1}^{2}}{2 D_{1}}
$$

The $c_{3}$ constant can be obtained from the following relation (Turcotte and Schubert, 1982):

$$
\frac{d M}{d x}=V .
$$


Therefore, for the right plate we have

$$
\begin{gathered}
\left.\frac{d M}{d x}\right|_{x=0}=V_{1} \rightarrow-\left.D_{1} \frac{d^{3} w_{1}}{d x^{3}}\right|_{x=0}=V_{1} \rightarrow \frac{2}{\alpha_{1}^{3}}\left(c_{4}+c_{3}\right)=-\frac{V_{1}}{D_{1}} \rightarrow \\
\rightarrow c_{3}=-\frac{V_{1} \alpha_{1}^{3}}{2 D_{1}}-c_{4} \rightarrow \\
\rightarrow c_{3}=\left(-M_{1}-V_{1} \alpha_{1}\right) \frac{\alpha_{1}^{2}}{2 D_{1}}
\end{gathered}
$$

A similar procedure can be done for the left plate to obtain $c_{1}$ and $c_{2}$ :

$$
\begin{gathered}
c_{1}=\left(-M_{2}-V_{2} \alpha_{2}\right) \frac{\alpha_{2}^{2}}{2 D_{2}} \\
c_{2}=-\frac{M_{2} \alpha_{2}^{2}}{2 D_{2}}
\end{gathered}
$$

Replacing A.7 and A.8 into A.4 and A.6 and A.5 into A.3

$$
\begin{array}{cc}
w_{1}=\frac{\alpha_{1}^{2} e^{-x / \alpha_{1}}}{2 D_{1}}\left\{M_{1} \sin \frac{x}{\alpha_{1}}-\left[M_{1}+V_{1} \alpha_{1}\right] \cos \frac{x}{\alpha_{1}}\right\} & \text { for } x \geq 0 \\
w_{2}=\frac{\alpha_{2}^{2} e^{x / \alpha_{2}}}{2 D_{2}}\left\{-M_{2} \sin \frac{x}{\alpha_{2}}-\left[M_{2}+V_{2} \alpha_{2}\right] \cos \frac{x}{\alpha_{2}}\right\} & \text { for } x<0
\end{array}
$$

The sum of $V_{1}$ and $V_{2}$ must be equal to the original applied load $V_{0}$ and the moment $M$ must be continuous at $x=0$, leading to $M_{1}=M_{2}$. Defining $M_{1}=M_{2} \equiv M_{0}$ and $V_{1}=V_{0}-V_{2}$, the expressions for $w_{1}$ and $w_{2}$ become

$$
\begin{array}{cc}
w_{1}=\frac{\alpha_{1}^{2} e^{-x / \alpha_{1}}}{2 D_{1}}\left\{M_{0} \sin \frac{x}{\alpha_{1}}-\left[M_{0}+\left(V_{0}-V_{2}\right) \alpha_{1}\right] \cos \frac{x}{\alpha_{1}}\right\} \quad \text { for } x \geq 0 \\
w_{2}=\frac{\alpha_{2}^{2} e^{x / \alpha_{2}}}{2 D_{2}}\left\{-M_{0} \sin \frac{x}{\alpha_{2}}-\left[M_{0}+V_{2} \alpha_{2}\right] \cos \frac{x}{\alpha_{2}}\right\} & \text { for } x<0
\end{array}
$$

To determine $M_{0}$ and $V_{2}$, we impose continuity of $w$ and $\frac{d w}{d x}$ between the two plates

$$
\begin{aligned}
\left.w_{2}\right|_{x \rightarrow 0^{-}} & =\left.w_{1}\right|_{x=0} \\
\left.\frac{d w_{2}}{d x}\right|_{x \rightarrow 0^{-}} & =\left.\frac{d w_{1}}{d x}\right|_{x=0}
\end{aligned}
$$

and the solution of the linear system A.9 for $M_{0}$ and $V_{2}$ leads up to

$$
\begin{gathered}
M_{0}=\frac{-\left(\alpha_{1}^{2} \alpha_{2}^{3}+\alpha_{1}^{3} \alpha_{2}^{2}\right) D_{1} D_{2} V_{0}}{\left[\alpha_{1}^{4} D_{2}^{2}+2\left(\alpha_{1} \alpha_{2}^{3}+\alpha_{1}^{2} \alpha_{2}^{2}+\alpha_{1}^{3} \alpha_{2}\right) D_{1} D_{2}+\alpha_{2}^{4} D_{1}^{2}\right]} \\
V_{2}=V_{0} \frac{\alpha_{1}^{4} D_{2}^{2}+\left(\alpha_{1}^{2} \alpha_{2}^{2}+2 \alpha_{1}^{3} \alpha_{2}\right) D_{1} D_{2}}{\left[\alpha_{1}^{4} D_{2}^{2}+2\left(\alpha_{1} \alpha_{2}^{3}+\alpha_{1}^{2} \alpha_{2}^{2}+\alpha_{1}^{3} \alpha_{2}\right) D_{1} D_{2}+\alpha_{2}^{4} D_{1}^{2}\right]}
\end{gathered}
$$




\section{Appendix B}

\section{Analytical proof of the "water load delay"}

\section{approximation}

\section{B.1 Exact solution for null rigidity}

To demonstrate that the algorithm for the isostatic compensation presented in equation 6.7 converges to the exact solution, assume for simplicity that the rigidity of the plate is zero implying that the first term in equation 6.7 is null. Consider a crust of thickness $H_{c}$ under a layer of water $h_{w}$ in isostatic equilibrium (Figure B.1i).
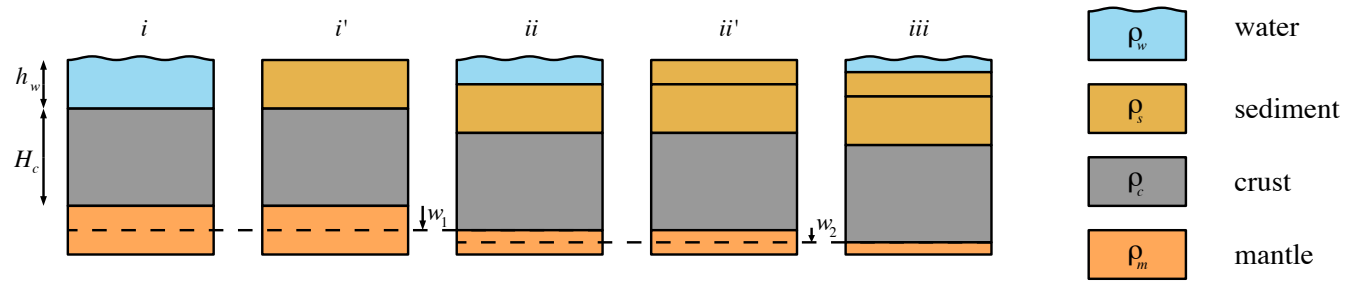

Figure B.1: Successive loading of the crust by sedimentation. The figures $i$, ii and iii are in isostatic equilibrium and $i^{\prime}$ and $i i^{\prime}$ are out of isostatic equilibrium.

If the water layer $h_{w}$ is replaced by sediment (Figure B.1 $i^{\prime}$ ) the new configuration, after isostatic equilibrium, results in subsidence of the crust and filling of the top with water (Figure B.1ii).

Comparing the isostatic state $i$ and $i i$, it is possible to calculate the subsidence $w_{1}$ due to the sedimentary load of thickness $h_{w}$ (here all the terms were divided by $g$ to simplify 
the equation):

$$
\begin{aligned}
h_{w} \rho_{w}+H_{c} \rho_{c}+w_{1} \rho_{m} & =w_{1} \rho_{w}+h_{w} \rho_{s}+H_{c} \rho_{c} \\
h_{w} \rho_{w}+w_{1} \rho_{m} & =w_{1} \rho_{w}+h_{w} \rho_{s} \\
w_{1}\left(\rho_{m}-\rho_{w}\right) & =h_{w}\left(\rho_{s}-\rho_{w}\right)
\end{aligned}
$$

In equation B.2, the first term is the isostatic term, where $\rho_{m}-\rho_{w}=\Delta \rho$, and the second term is the effective load, represented by the sediment that replaced the water.

Isolating $w_{1}$ :

$$
w_{1}=h_{w} \frac{\rho_{s}-\rho_{w}}{\rho_{m}-\rho_{w}}=h_{w} r .
$$

If the new water layer $w_{1}$ is replaced by sediment (Figure B. $1 i i^{\prime}$ ) the new configuration, after isostatic equilibrium, results in subsidence of the crust and filling of the top with water (Figure B.1iii).

$$
\begin{gathered}
w_{1} \rho_{w}+h_{w} \rho_{s}+H_{c} \rho_{c}+w_{2} \rho_{m}=w_{2} \rho_{w}+w_{1} \rho_{s}+h_{w} \rho_{s}+H_{c} \rho_{c} \\
w_{1} \rho_{w}+w_{2} \rho_{m}=w_{2} \rho_{w}+w_{1} \rho_{s} \\
w_{2}=w_{1} \frac{\rho_{s}-\rho_{w}}{\rho_{m}-\rho_{w}}=w_{1} r=h_{w} r^{2}
\end{gathered}
$$

Therefore, the $n$th replacement of the water layer by sediment results in a subsidence

$$
w_{n}=h_{w} r^{n}
$$

and the total subsidence $w_{\text {total }}$ is

$$
w_{\text {total }}=\sum_{n=1}^{\infty} w_{n}=\sum_{n=1}^{\infty} h_{w} r^{n} .
$$

For $|r|<1, \sum_{n=1}^{\infty} r^{n}=r /(1-r)$. Therefore:

$$
w_{\text {total }}=h_{w} \frac{r}{1-r}=h_{w} \frac{\frac{\rho_{s}-\rho_{w}}{\rho_{m}-\rho_{w}}}{1-\frac{\rho_{s}-\rho_{w}}{\rho_{m}-\rho_{w}}}=h_{w} \frac{\rho_{s}-\rho_{w}}{\rho_{m}-\rho_{s}}
$$

The total subsidence $w_{\text {total }}$ represents the maximum subsidence produced when the basin is completely filled with sediments. 


\section{B.2 "Water load delay" approximation for null rigidity}

In the algorithm used in the present work, the water load due to the isostatic effect is taken into account in the next time step. Therefore the equation B.1 becomes:

$$
\begin{gathered}
h_{w} \rho_{w}+w_{1}^{\prime} \rho_{m}=h_{w} \rho_{s} \\
w_{1}^{\prime}=h_{w} \frac{\rho_{s}-\rho_{w}}{\rho_{m}}
\end{gathered}
$$

Observe that the subsidence $w_{1}^{\prime}<w_{1}$, because $w_{1}^{\prime}$ does not take into account the water load associated with the isostatic compensation.

In the next step, the crust is loaded with the sedimentary load of thickness $w_{1}^{\prime}$. Additionally, the load of the water layer of the previous step is included. Therefore, the equation B.4 becomes:

$$
w_{1}^{\prime} \rho_{w}+w_{2}^{\prime} \rho_{m}=\underbrace{w_{1}^{\prime} \rho_{w}}_{\text {previous step }}+w_{1}^{\prime} \rho_{s}
$$

And the subsidence in the second step $w_{2}^{\prime}$ is

$$
w_{2}^{\prime}=w_{1}^{\prime} \frac{\rho_{s}}{\rho_{m}}=w_{1}^{\prime} r^{\prime}
$$

Likewise the subsidence $w_{3}^{\prime}$ in the third step is

$$
w_{3}^{\prime}=w_{2}^{\prime} \frac{\rho_{s}}{\rho_{m}}=w_{2}^{\prime} r^{\prime}=w_{1}^{\prime} r^{\prime 2}
$$

and, therefore, the subsidence of the following steps can be represented as

$$
w_{n}^{\prime}=w_{1}^{\prime} r^{\prime n-1}
$$

The total subsidence $w_{\text {total }}^{\prime}$ is

$$
w_{\text {total }}^{\prime}=w_{1}^{\prime} \sum_{n=1}^{\infty} r^{\prime n-1}=w_{1}^{\prime} \frac{1}{1-r^{\prime}}
$$

therefore

$$
w_{\text {total }}^{\prime}=w_{1}^{\prime} \frac{1}{1-r^{\prime}}=w_{1}^{\prime} \frac{\rho_{m}}{\rho_{m}-\rho_{s}}=h_{w} \frac{\rho_{s}-\rho_{w}}{\rho_{m}} \frac{\rho_{m}}{\rho_{m}-\rho_{s}}=h_{w} \frac{\rho_{s}-\rho_{w}}{\rho_{m}-\rho_{s}}
$$

that is exactly the same subsidence $w_{\text {total }}$ in equation B.7. This shows that the approximation of considering the water load associated with the subsidence from the previous time step also converges to the exact solution. 


\section{B.3 Exact solution for nonzero rigidity}

The "water load delay" approximation is also valid when the rigidity of the plate is not null. To show this, consider an elastic plate with rigidity $D$. Assume that the plate is under the action of a periodic load

$$
\left(\rho_{s}-\rho_{w}\right) g h_{q 1}
$$

where

$$
h_{q 1}=h_{l} \cos (\phi x)
$$

and assume that the isostatic compensation occurs under the water, implying that $\Delta \rho=$ $\rho_{m}-\rho_{w}$. In this situation the equation 6.5 becomes:

$$
D \frac{\partial^{4} w}{\partial x^{4}}+\left(\rho_{m}-\rho_{w}\right) g w=\left(\rho_{s}-\rho_{w}\right) g h_{q 1} .
$$

The general solution for equation B.9 is:

$$
w_{1}=A \cos (\phi x)
$$

Replacing B.10 in B.9:

$$
\begin{gathered}
D A \phi^{4}+\left(\rho_{m}-\rho_{w}\right) g A=\left(\rho_{s}-\rho_{w}\right) h_{l} g \\
A=h_{l} \frac{\left(\rho_{s}-\rho_{w}\right) g}{D \phi^{4}+\left(\rho_{m}-\rho_{w}\right) g}
\end{gathered}
$$

and

$$
w_{1}=h_{q 1} \frac{\left(\rho_{s}-\rho_{w}\right) g}{D \phi^{4}+\left(\rho_{m}-\rho_{w}\right) g}
$$

Assuming that the load for the next step is $\left(\rho_{s}-\rho_{w}\right) g h_{q 2}=\left(\rho_{s}-\rho_{w}\right) g w_{1}$, then

$$
w_{2}=h_{q 2} \frac{\left(\rho_{s}-\rho_{w}\right) g}{D \phi^{4}+\left(\rho_{m}-\rho_{w}\right) g}=h_{q 1}\left[\frac{\left(\rho_{s}-\rho_{w}\right) g}{D \phi^{4}+\left(\rho_{m}-\rho_{w}\right) g}\right]^{2}
$$

and the deflections $w_{n}$ of the following steps are

$$
w_{n}=h_{q 1}\left[\frac{\left(\rho_{s}-\rho_{w}\right) g}{D \phi^{4}+\left(\rho_{m}-\rho_{w}\right) g}\right]^{n}=h_{q 1} r_{D}^{n} .
$$

The total subsidence $w_{\text {total }}$ is

$$
w_{\text {total }}=\sum_{n=1}^{\infty} w_{n}=h_{q 1} \sum_{n=1}^{\infty} r_{D}^{n}
$$

and as $\left|r_{D}\right|<1$

$$
w_{\text {total }}=h_{q 1} \frac{r_{D}}{1-r_{D}}=h_{q 1} \frac{\left(\rho_{s}-\rho_{w}\right) g}{D \phi^{4}+\left(\rho_{m}-\rho_{s}\right) g}
$$




\section{B.4 "Water load delay" approximation for nonzero rigidity}

In the approximation for the isostatic compensation in the numerical model described in section 6.4, the isostatic term is dependent only on $\rho_{m}$. Therefore, equation B.9 becomes

$$
D \frac{\partial^{4} w_{1}^{\prime}}{\partial x^{4}}+\rho_{m} g w_{1}^{\prime}=\left(\rho_{s}-\rho_{w}\right) g h_{q 1}
$$

resulting in

$$
w_{1}^{\prime}=h_{q 1} \frac{\left(\rho_{s}-\rho_{w}\right) g}{D \phi^{4}+\rho_{m} g}
$$

Assume that the load in the next step is $\left(\rho_{s}-\rho_{w}\right) g h_{q 2}^{\prime}=\left(\rho_{s}-\rho_{w}\right) g w_{1}^{\prime}$. Taking into account also the load of the water from the previous step $\rho_{w} g w_{1}^{\prime}$, the total load in the second step is:

$$
\left(\rho_{s}-\rho_{w}\right) g w_{1}^{\prime}+\rho_{w} g w_{1}^{\prime}=\rho_{s} g w_{1}^{\prime}
$$

Therefore, the equation for $w_{2}^{\prime}$ is

$$
D \frac{\partial^{4} w_{2}^{\prime}}{\partial x^{4}}+\rho_{m} g w_{2}^{\prime}=\rho_{s} g h_{q 2}
$$

resulting in

$$
w_{2}^{\prime}=h_{q 2} \frac{\rho_{s} g}{D \phi^{4}+\rho_{m} g}=w_{1}^{\prime} \frac{\rho_{s} g}{D \phi^{4}+\rho_{m} g}=w_{1}^{\prime} r_{D}^{\prime}
$$

It is possible to observe that the deflection $w_{n}^{\prime}$ of the step $n$ is of the following form

$$
w_{n}^{\prime}=w_{1}^{\prime} r_{D}^{\prime n-1}
$$

and the total deflection $w_{\text {total }}^{\prime}$ is

$$
w_{\text {total }}^{\prime}=w_{1}^{\prime} \sum_{n=1}^{\infty} r_{D}^{\prime n-1}=w_{1}^{\prime} \frac{1}{1-r_{D}^{\prime}} .
$$

Therefore

$$
w_{\text {total }}^{\prime}=w_{1}^{\prime} \frac{1}{1-r_{D}^{\prime}}=w_{1}^{\prime} \frac{D \phi^{4}+\rho_{m} g}{D \phi^{4}+\left(\rho_{m}-\rho_{s}\right) g} .
$$

From B.13:

$$
w_{\text {total }}^{\prime}=h_{q 1} \frac{\left(\rho_{s}-\rho_{w}\right) g}{D \phi^{4}+\rho_{m} g} \frac{D \phi^{4}+\rho_{m} g}{D \phi^{4}+\left(\rho_{m}-\rho_{s}\right) g}=h_{q 1} \frac{\left(\rho_{s}-\rho_{w}\right) g}{D \phi^{4}+\left(\rho_{m}-\rho_{s}\right) g} .
$$

Comparing equations B.11 and B.14 it is possible to see that the total deflection are the same $\left(w_{\text {total }}=w_{\text {total }}^{\prime}\right)$ in both cases. This shows that the algorithm presented in section 6.4 converges to the exact solution even when $D>0$. 


\section{B.5 Conclusions}

As shown in the examples of the previous sections, the "water load delay" approximation converges to the exact solution, independent of the flexural rigidity of the plate.

In this approximation, the isostatic equilibrium is not instantaneously achieved during the loading, but is gradually reached in the following time steps. Actually, almost all the isostatic equilibrium is achieved in first few time steps after loading.

For example, for $D=0$, the exact subsidence $w_{1}$ due to the load of a sedimentary layer of thickness $h_{w}$ is (see equation B.3)

$$
w_{1}=h_{w} \frac{\rho_{s}-\rho_{w}}{\rho_{m}-\rho_{w}}
$$

In the first step in the "water load delay" approximation, the subsidence $w_{1}^{\prime}$ is (see equationB.13)

$$
w_{1}^{\prime}=h_{w} \frac{\rho_{s}-\rho_{w}}{\rho_{m}}
$$

which represents almost $69 \%$ of the exact subsidence, for $\rho_{m}=3300 \mathrm{~kg} / \mathrm{m}^{3}$ and $\rho_{w}=1030$ $\mathrm{kg} / \mathrm{m}^{3}$. Without additional sedimentary loading, the subsidence continues in the second time step due to the layer o water $w_{1}^{\prime}$, resulting in

$$
w_{2}^{\prime}=w_{1}^{\prime} \frac{\rho_{w}}{\rho_{m}}
$$

The summation $w_{1}^{\prime}+w_{2}^{\prime}$ represents $90 \%$ of the exact subsidence.

The subsidence continues in the following steps, approaching the exact solution:

$$
w_{n}^{\prime}=w_{1}^{\prime}\left[\frac{\rho_{w}}{\rho_{m}}\right]^{n-1} .
$$

In the third step, the total subsidence is $97 \%$ of the exact subsidence, and in the fourth step, the total subsidence is $99 \%$.

As the time step is small in the numerical model $\left(10^{2}-10^{3}\right.$ years $)$ relative to the characteristic time of the different geological processes involved, the "water load delay" approximation works almost like the exact solution considering the load of water instantaneously. 